UNIVERSIDADE DE SÃO PAULO

ESCOLA DE ENFERMAGEM

LUCIANA BOCHEMBUZIO

\title{
AVALIAÇÃO DO INSTRUMENTO \\ NURSING ACTIVITIES SCORE (NAS) \\ EM NEONATOLOGIA
}




\section{LUCIANA BOCHEMBUZIO}

\section{AVALIAÇÃO DO INSTRUMENTO NURSING ACTIVITIES SCORE (NAS) EM NEONATOLOGIA}

Tese apresentada à Escola de Enfermagem da Universidade de São Paulo para obtenção do Título de Doutor em Enfermagem.

Área de Concentração:

Administração dos Serviços de Enfermagem

Orientadora:

Prof. 므. Dr. Raquel Rapone Gaidzinski

São Paulo

2007 


\section{Catalogação na Publicação (CIP) \\ Biblioteca "Wanda de Aguiar Horta" \\ Escola de Enfermagem da Universidade de São Paulo}

Bochembuzio, Luciana.

Avaliação do instrumento Nursing Activities Score (NAS) em neonatologia. / Luciana Bochembuzio. - São Paulo, 2007.

$160 \mathrm{p}$.

Tese (Doutorado) - Escola de Enfermagem da Universidade de São Paulo.

Orientadora: Prof ${ }^{a} \operatorname{Dr}^{a}$ Raquel Rapone Gaidzinski.

1. Recém-nascido 2. Enfermagem neonatal 3. Assistência de enfermagem (duração) 4. Profissionais de enfermagem (dimensionamento) 5. Trabalho (quantificação). I. Título. 
"Não importa onde você parou... em que momento da vida você cansou... o que importa é que sempre é possível e necessário recomeçar" 
“Não pense na história que você não pode viver. Viva esta e você vai acabar descobrindo que existem coisas muito boas nela também".

S. mãe de T.

“Você ter um filho prematuro é como ganhar uma peça errada de um quebra cabeça. Não tem jeito, você precisa encaixá-la de qualquer maneira".

A. pai de V.

“Meu filho, o que importa é que ela está viva. Nós vamos dar um jeito dela ser feliz também". avô de G.

"Quando você crescer a gente vai chutar caramujos juntos...". (coletado por Juliana Delamônica)

"Você quer tocar, quer pegar no colo, quer dizer que ela é importante, não importa que esteja internada". D. mãe de S. e V.

"Eu tinha que trazer sonhos para vocês" R. mãe de R. 


\section{DEDICATÓRIA}

\section{Ao Carlos Alberto,}

parceiro de todos os momentos. Meu farol incansável, guardião dos meus maiores desejos e aspirações que por muitas vezes iluminou o meu caminho e as minhas decisões

Às pessoas mais necessárias, meus pais, Maria e Luiz, que enxergam a vida com os olhos cheios de amor. Vocês tornam suas as minhas escolhas.

Aos meus irmãos Mário, Márcia, Louise e a família linda que cada um soube formar. Vocês são capazes de compreender minhas ausências muito mais do que eu posso imaginar. 


\section{Para os recém-nascidos que sempre me ensinam sobre a vida e a superação}

\section{AGRADECIMENTOS}

- À Deus que sempre está presente em minha vida em todos os momentos, guiando meu caminho...

- À Profa ${ }^{a} r^{a}$ Raquel Rapone Gaidzinski, pela sensibilidade que continuou demonstrando também nessa orientação. Obrigada pelo respeito e pela sua maneira de me acompanhar.

- À Prof ${ }^{a} D r^{a}$ Fernanda Togeiro Fugulin e Prof ${ }^{a} D r^{a}$ Katia Grilo Padilha pelas sugestões no Exame de Qualificação.

- À Eliete Genovez Spir, chefe da Unidade Neonatal e Telma Moreira Souza, chefe da UTI Neonatal que prontamente disponibilizaram as unidades e as equipes para a realização do estudo.

- À equipe de enfermagem da Unidade Neonatal e UTI Neonatal que dedicaram seu tempo para participar desse estudo, fornecendo informações essenciais. Agradeço pelo auxílio e por participarem de forma solícita e desprendida.

- Às enfermeiras da Unidade Neonatal pelo auxílio, compreensão e apoio de todas vocês.

- À enfermeira e amiga Lilian Mara Rondello pela paciência e disposição em me ajudar. Nossas longas conversas sobre o trabalho e sobre a vida são sempre muito especiais.

- Ao Raul Gaidzinski pelo primor no trabalho estatístico. Agradeço sobretudo o tempo dedicado ao meu auxílio nas dificuldades encontradas ao final do estudo.

- À todas as pessoas que convivem comigo e que de alguma forma contribuíram para a realização deste trabalho. 


\section{SUMÁRIO}

Lista de Figuras

Lista de Tabelas

Resumo

Abstract

Resumem

1. INTRODUÇÃO. 21

1.1. Instrumentos de Medida de Gravidade e Carga de Trabalho em UTI Pediátrica e Neonatal: Revisão de Literatura......................................................................... 27

1.2. Escores desenvolvidos para Unidade Pediátrica.............................................. 30

1.2.1. Pediatric Therapeutic Intervention Scoring System (TISS) ....................... 30

1.2.2. Physiological Stability Index (PSI).................................................. 31

1.2.3. Pediatric Risk of Mortality Score (PRISM) ............................ 33

1.2.4. Pediatric Risk of Mortality Score III (PRISM III) ........................ 34

1.2.5. The Pediatric Risk of Hospital Admission Score II (PRISAII) ............... 37

1.3. Escores desenvolvidos para Unidade Neonatal................................................... 39

1.3.1. Neonatal Therapeutic Intervention Scoring System (NTISS)................ 39

1.3.2. Physiological Stability Index Modify (PSI) ............................. 41

1.3.3. Clinical Risk Index for Babies (CRIB) e o Clinical Risk Index for Babies II

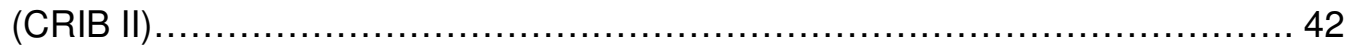

1.3.4. Score for Neonatal Acute Psysiology (SNAP)........................... 45

1.3.5. The Mortality Index for Neonatal Transportation Score (MINT) ............. 48

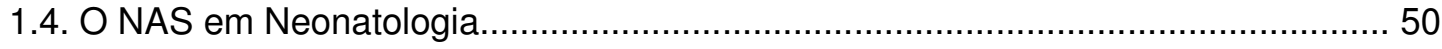

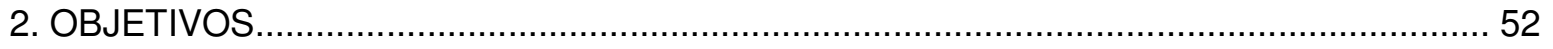

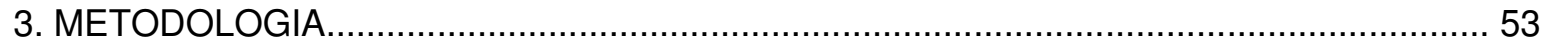

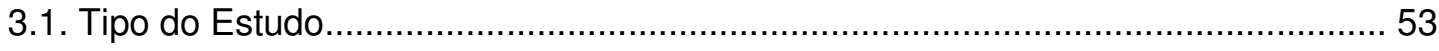

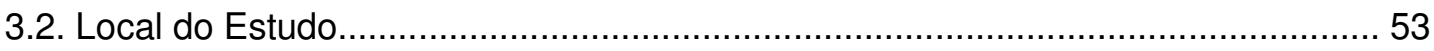

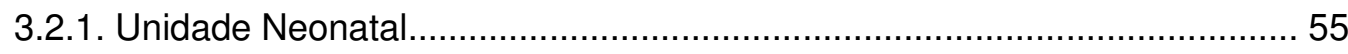

3.2.2. Unidade de Terapia Intensiva Neonatal................................................ 58 
3.2.3. Unidade Neonatal e Unidade de Terapia Intensiva Neonatal: dinâmica de trabalho 60

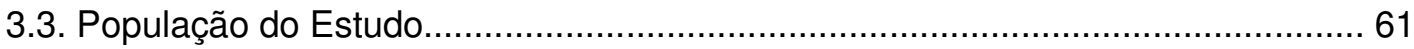

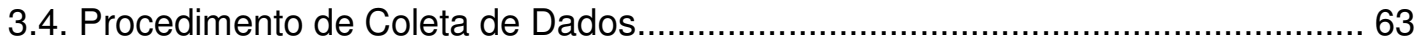

3.4.1. Ficha de identificação demográfica e clínica dos recém-nascidos.............. 63

3.4.2. Instrumento de medida de carga de trabalho (NAS) .............................. 63

3.4.2.1 Tutorial para categorização de cuidados assistenciais.................. 65

3.4.3. Índice de medida de gravidade....................................................... 71

3.4.4. Medida da carga diária de cuidado por recém-nascido na Unidade Neonatal e Unidade de Terapia Intensiva Neonatal................................................... 72

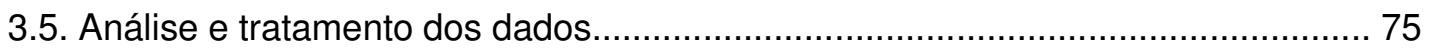

3.5.1. Avaliação dos quantitativos diários da equipe de enfermagem................. 76

3.5.2. Avaliação geral da aplicação do instrumento......................................... 77

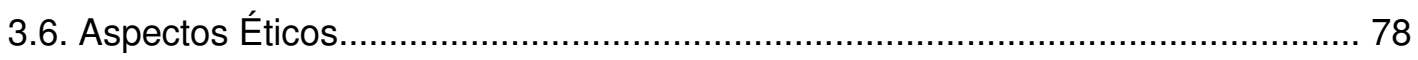

4. APRESENTAÇÃO E DISCUSSÃO DOS RESULTADOS ............................................. 79

4.1. Caracterização da amostra dos recém-nascidos quanto aos dados demográficos e

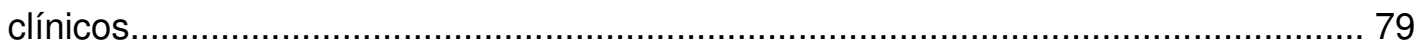

4.2. Avaliação da carga de trabalho da equipe de enfermagem................................ 83

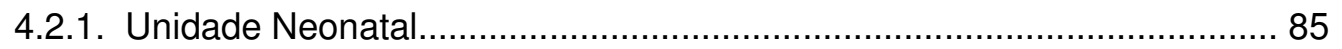

4.2.2. Unidade de Terapia Intensiva Neonatal................................................ 95

4.2.3. Pontuação do NAS em relação ao tempo de assistência de

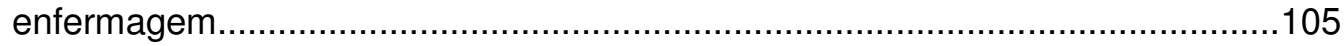

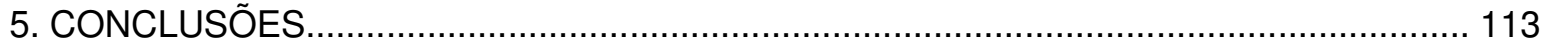

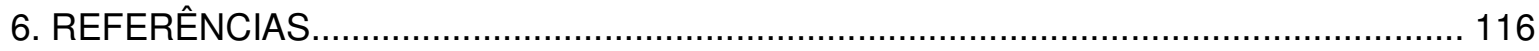

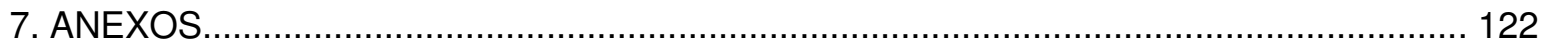




\section{LISTA DE FIGURAS}

FIGURA 1 - TISS - Pediatric Therapeutic Intervention Scoring System, adaptação pediátrica, indicado por Keene \& Cullen (1983). São Paulo, 2006.

FIGURA 2 - PSI - Psysiological Stability Index, desenvolvido por Pollack et al (1984). São Paulo, 2006.

FIGURA 3 - PRISM - Pediatric Risk of Mortality, adaptado por Pollack et al (1988). São Paulo, 2006. 34

FIGURA 4 - PRISM III - Pediatric Risk of Mortality III adaptado por Pollack et al (1994). São Paulo, 2006. 36

FIGURA 5 - PRISA II - Pediatric Risk of Hospital Admission Score II, desenvolvido por Chamberlain et al (2005). São Paulo, 2006. 38

FIGURA 6 - NTISS - Neonatal Therapeutic Intervention Scoring System, adaptado por Gray (1990). São Paulo, 2006. 40

FIGURA 7 - PSI Modify - Psysiological Stability Index, adaptado por Georgieff (1989). São Paulo, 2006. 42

FIGURA 8 - CRIB - Clinical Risk Index for Babies, desenvolvido por International Neonatal Network (1993). São Paulo, 2006. 
FIGURA 9 - CRIB II - Clinical Risk Index for Babies II, elaborado por Parry et al (2003). São Paulo, 2006. 45

FIGURA 10 - SNAP - Score for Neonatal Acute Psysiology, adaptado por Richardson et al (1993). São Paulo, 2006. 47

FIGURA 11 - MINT - Mortality Index for Neonatal Transportation Score desenvolvido por Broughton et al (2004). São Paulo, 2006 49

FIGURA 12 - Distribuição da equipe de enfermagem na Unidade Neonatal, no ano de 2006. HU-USP, São Paulo, 2006. 57

FIGURA 13 - Distribuição das ausências previstas e não previstas na Unidade Neonatal para a equipe de enfermagem, no ano 2006. HU-USP. São Paulo, 2006 57

FIGURA 14 - Distribuição da equipe de enfermagem na UTIN, no ano 2006. HUUSP, São Paulo, 2006 59

FIGURA 15 - Distribuição das ausências previstas e não previstas na UTIN para a equipe de enfermagem, no ano 2006. HU-USP. São Paulo, 2006 . 60

FIGURA 16 - Quantidade média de recém-nascidos internados na Unidade Neonatal e UTIN, conforme o dia da semana, de 06 de novembro de 2006 a 06 de dezembro de 2006. HU-USP. São Paulo, 2006. 83

FIGURA 17 - Quantidade diária de recém-nascidos internados na Unidade Neonatal e UTI Neonatal, período de 06 de novembro de 2006 a 06 de dezembro de 2006. HU-USP. São Paulo, 2006 84 
FIGURA 18 - Análise estatística da distribuição dos recém-nascidos internados, do quadro de profissionais disponível em serviço, da pontuação NAS e do quadro da equipe de enfermagem, segundo NAS. Unidade Neonatal, período de 06 de novembro de 2006 a 06 de dezembro de 2006. HU-USP. São Paulo, 2006 86

FIGURA 19 - Comparação entre a equipe de enfermagem requerida pelo NAS e a equipe de enfermagem disponível. Unidade Neonatal, período de 06 de novembro de 2006 a 06 de dezembro de 2006. HU-USP. São Paulo, 2006. 87

FIGURA 20 - Correlação entre as quantidades diárias e de RN e de profissionais de enfermagem na Unidade Neonatal, período de 06 de novembro de 2006 a 06 de dezembro de 2006. HU-USP. São Paulo, 2006. 88

FIGURA 21 - Carga média diária de cuidado (em horas) por recém-nascido, segundo: profissionais de enfermagem disponíveis em serviço, pontuação NAS, Resolução COFEN no 293/04 e HU-USP 5 anos. Unidade Neonatal. HU-USP. São Paulo, 2006 90

FIGURA 22 - Demonstrativo do quantitativo de profissionais de enfermagem, segundo as horas médias de cuidado: disponíveis em serviço, pontuação NAS, Resolução COFEN no 293/04 e HU-USP 5 anos, Unidade Neonatal. HU-USP. São Paulo, 2006. 92

FIGURA 23 - Quantitativo médio da equipe de enfermagem, segundo a carga de trabalho obtida: cálculo do quadro disponível na Unidade Neonatal, pontuação 
NAS, Resolução COFEN n 293/04 e HU-USP 5 anos, Unidade Neonatal. HUUSP. São Paulo, 2006. 94

FIGURA 24 - Variações diárias do quantitativo de profissionais na Unidade Neonatal segundo: o número de pacientes, o quadro disponível, a pontuação NAS, Resolução COFEN no 293/04 e HU-USP 5 anos, Unidade Neonatal. HU-USP. São Paulo, 2006. 95

FIGURA 25 - Análise estatística da distribuição dos recém-nascidos internados, do quadro de profissionais disponível em serviço, da pontuação NAS e do quadro da equipe de enfermagem, segundo NAS. UTIN, período de 06 de novembro de 2006 a 06 de dezembro de 2006. HU-USP. São Paulo, 2006 96

FIGURA 26 - Comparação entre a equipe de enfermagem requerida pelo NAS e a equipe de enfermagem disponível, período de 06 de novembro de 2006 a 06 de dezembro de 2006. HU-USP. São Paulo, 2006. 98

FIGURA 27 - Correlação entre as quantidades diárias e de RN e de profissionais de enfermagem disponíveis na UTIN, período de 06 de novembro de 2006 a 06 de dezembro de 2006. HU-USP. São Paulo, 2006 99

FIGURA 28 - Tempo médio diário (em horas) por recém-nascido, segundo: profissionais de enfermagem disponíveis em serviço; pontuação NAS, Resolução COFEN no 293/04 e Portaria MS no 3432/98, UTIN. HU-USP. São Paulo, 2006 100

FIGURA 29 - Demonstrativo do quantitativo de profissionais de enfermagem, segundo: profissionais de enfermagem disponíveis em serviço, pontuação NAS, Resolução COFEN no 293/04 e Portaria MS no 3432/98, UTIN. HU-USP. São Paulo, 2006 103 
FIGURA 30 - Quantitativo médio da equipe de enfermagem, segundo a carga de trabalho disponível na UTI Neonatal; pontuação NAS, Resolução COFEN no293/04 e Portaria MS no 3432/98, UTIN. HU-USP. São Paulo, 2006. 104

FIGURA 31 - Variações diárias do quantitativo de profissionais na UTI Neonatal segundo: o número de pacientes; o quadro disponível, a pontuação NAS, Resolução COFEN no 293/04 e Portaria MS no 3432/98, UTIN. HU-USP. São Paulo, 2006. 105

FIGURA 32 - Distribuição da freqüência e a média de pontuação de cada item e sub-item do NAS para RNs internados na Unidade Neonatal, período de 06 de novembro de 2006 a 06 de dezembro de 2006. HU-USP. São Paulo, 2006. 107

FIGURA 33 - Distribuição da freqüência e a média de pontuação de cada item e sub-item do NAS para RNs internados na UTIN, período de 06 de novembro de 2006 a 06 de dezembro de 2006. HU-USP. São Paulo, 2006 . 110

FIGURA 34 - Comparação entre cada item e sub-item do NAS de maior pontuação para RNs internados na Unidade Neonatal e UTIN, período de 06 de novembro de 2006 a 06 de dezembro de 2006. HU-USP. São Paulo, 2006. 


\section{LISTA DE TABELAS}

TABELA 1 - Distribuição absoluta e percentual de RN internados na Unidade Neonatal, segundo dados demográficos e clínicos, no período 06 de novembro de 2006 a 06 de dezembro de 2006. HU-USP. São Paulo, 2006............................. 80

TABELA 2 - Distribuição absoluta e percentual de RN internados na UTIN, segundo dados demográficos e clínicos, no período 06 de novembro de 2006 a 06 de dezembro de 2006. HU-USP. São Paulo, 2006........................................... 82 
Bochembuzio L. Avaliação do instrumento Nursing Activities Score (NAS) em Neonatologia. São Paulo. [Tese]. São Paulo: Escola de Enfermagem, Universidade de São Paulo; 2007.

\section{RESUMO}

Estudo de abordagem metodológica para avaliação de um instrumento de medida de carga de trabalho foi realizado na Unidade Neonatal e na UTIN (Unidade de Terapia Intensiva Neonatal) do Hospital Universitário da USP (HUUSP), no período de 06 de novembro de 2006 a 06 de dezembro de 2006 . Teve como objetivo avaliar o resultado da aplicação do NAS, como instrumento de medida da carga de trabalho de enfermagem em neonatologia. Reviu-se a literatura sobre os instrumentos de medida de gravidade e carga de trabalho em UTI Pediátrica e Neonatal para que se iniciasse o processo de diferenciação dos processos assistenciais básicos nas unidades infantis. A amostra foi composta por $48 \mathrm{RN}$ avaliados na Unidade Neonatal e 11 na UTIN e que permaneceram internados por um período mínimo de 24 horas. O NAS foi aplicado 301 vezes na Unidade Neonatal e 106 vezes na UTIN. Foi elaborado um tutorial para a melhor interpretação das atividades do NAS que facilitou a compreensão do instrumento, na área neonatal. Comparando as amostras segundo variáveis demográficas e clínicas, entre as unidades estudadas, observou-se que as únicas estatisticamente significativas foram peso ao nascer e tempo de permanência na unidade. A pontuação do NAS médio para a Unidade Neonatal foi de 66,9 pontos. Em média, $67 \%$ do tempo de um profissional de enfermagem é dedicado ao cuidado dos RN enquanto permanecem na Unidade. Ainda em relação ao tempo de cuidado, considerando que cada ponto NAS equivale a $14,4 \mathrm{~min}$, foi identificada no estudo uma média de $16 \mathrm{~h} 04$ min de assistência por RN/24h. O valor médio para a equipe de enfermagem calculada pela pontuação do NAS obtido da amostra do estudo foi de 26,7 profissionais. Em média, a equipe disponível em serviço foi de 20,7 profissionais. O número médio de profissionais requerido, segundo o NAS foi $29 \%$ mais elevado do que no quadro de profissionais de enfermagem disponível para a Unidade Neonatal. Isso indica que nessa unidade deve haver sobrecarga de trabalho. A pontuação do NAS médio para a UTIN foi de 91,1 pontos. Em média, $90 \%$ do tempo de um profissional de enfermagem é dedicado ao cuidado dos RN enquanto permanecem na UTIN. Quanto ao tempo de cuidado, foi identificada uma média de $21 \mathrm{~h} 54$ min de assistência por RN/24h. O valor médio para a equipe de enfermagem calculada pela pontuação do NAS obtido da amostra do estudo foi de 12,8 profissionais. Em média, a equipe disponível em serviço foi de 12 profissionais. Essa diferença é menor que 1,7\% e faz com que os valores sejam significativamente semelhantes e indiquem que não havia sobrecarga de serviço na UTIN. Os resultados da aplicação do NAS permitem identificar o perfil de cuidados de enfermagem na assistência semi-intensiva e intensiva aos recém nascidos. 
Descritores: Recém-nascido, Enfermagem neonatal, Assistência de enfermagem (duração), Profissionais de enfermagem (dimensionamento), Trabalho (quantificação). 
Bochembuzio L. Evaluation of index Nursing Activities Score (NAS) in neonatology area. São Paulo. [thesis]. São Paulo: Escola de Enfermagem, Universidade de São Paulo; 2007.

\section{ABSTRACT}

Study of methodological approach of an instrument of workload measuring evaluation was done in the Neonatal Unit and the NICU (Neonatal Unit of Intensive Care) of the University Hospital of USP (HU-USP), in the period of 06 of November of 2006 to 06 of December of 2006. It had as objective to evaluate the application of the NAS (Nursing Activity Score) result as an instrument to measure the nursing workload in neonatology area. It was reviewed the available literature related to the gravity and to the workload measuring instruments in the Pediatric Intensive Care Unit and NICU, so then it was initiated the basic process differentiation of the assistant processes in the infantile units. The sample was composed by 48 neonates and evaluated in the Neonate Unit and 11 in NICU's that had remained interned for a minimum period of 24-hour. The NAS instrument was applied 301 times in the Neonate Unit and 106 times in the NICU. A tutorial route was elaborated for better NAS activities interpretation and that has facilitated the instrument understanding, in the neonate area. Comparing the samples in according to demographic and clinical variables among the studied units, it was observed that only the statistical significant ones had been the weight at birth and length of stay in the unit. The punctuation of the medium NAS for the Neonatal Unit was of 66,9 points. On average, $67 \%$ of the time of a nursing professional is dedicated to the newborn (NB) care while they remain in the Unit. Even though in relation to the care time, considering that each NAS point is equivalent to $14,4 \mathrm{~min}$, it was identified in the study the a average of $16 \mathrm{~h} 04 \mathrm{~min}$ of assistance for NB/24h. The average value for the team of nursing calculated for the NAS punctuation gotten from the study sample of 26,7 professionals. On average, the available team in service was of 20,7 professionals. The average number of professionals required, in according to NAS was raised $29 \%$ more than what was available in the professionals total of available nursing in the Neonatal Unit. This indicates that in this unit it must have overload work. The punctuation of the average NAS for the NICU was 91,1 points. On average, $90 \%$ of a nursing professional time is dedicated to the NB care while they remain in the NICU. Related to the time of care, it was identified that the assistance average time as $21 \mathrm{~h} 54$ min by NB/24h. The average value for nursing team calculated by the NAS punctuation gotten from the study sample was of 12,8 professionals. On average, the available team in service was of 12 professionals. This difference is less than $1.7 \%$ and makes the values significantly similar and indicates that did not have overload of service in the NICU. The results of the application of the NAS allow identifying the care profile of nursing in the semi-intensive and intensive assistance to the newborn.

Key words: Newborn, Neonatal Nursing, Nursing care (duration), Professionals of nursing (dimensioning), Work (quantification). 
Bochembuzio L. Evaluación do instrumento Nursing Activities Score (NAS) em Neonatología. São Paulo. [tesis]. São Paulo: Escola de Enfermagem, Universidade de São Paulo; 2007.

\section{RESUMEN}

Estudio de abordaje metodológica para la evaluación de un instrumento de medida de la cantidad de trabajo realizado en la Unidad Neonatal y en la UTIN (Unidad de Terapia Intensiva Neonatal) del Hospital Universitario de la USP (HUUSP), en el período de 06 de noviembre de 2006 hasta el 06 de diciembre de 2006. El estudio tuvo como objetivo evaluar el resultado del uso del NAS (Nursing Activities Score) como instrumento de la medida de la carga del trabajo de los enfermeros en el área de neonatología. Fue revisada la literatura sobre los instrumentos de la medida de la gravedad y de la carga del trabajo en la UTI Pediátrica y Neonatal, para que se iniciase el proceso de diferenciación de los procesos asistenciales básicos en las unidades infantiles. La muestra fue compuesta por 48 recién nacidos y evaluados en la Unidad Neonatal y de 11 en el UTIN, que habían seguido internados por un período mínimo 24 horas. El instrumento NAS fue aplicado 301 veces en la Unidad Neonatal y 106 veces en el UTIN. Fue elaborado un guía de tutoría para la mejor interpretación de las actividades del NAS y que facilitó la comprensión del instrumento en el área neonatal. Comparando las muestras según las variables demográficas y clínicas entre las unidades estudiadas, fue observado que las únicas con significativo estadísticos habían sido a la peso al nacer y tiempo de permanencia en la Unidad. La puntuación del NAS medio en la Unidad Neonatal fue el 66.9 puntos. En el promedio, $67 \%$ del tiempo de un profesional del oficio de enfermería es dedicado al cuidado del RN (Recién-Nacido), mientras permanecen en la Unidad. Todavía en relación al tiempo de cuidado, considerando que cada punto del NAS es equivalente a 14.4 minutos, fue identificado en el estudio, un promedio de $16 \mathrm{~h} 04$ min. de asistencia por RN/24h. El valor medio para el equipo del oficio de enfermería calculada por la puntuación del NAS conseguido de la muestra del estudio, fue de 26.7 profesionales. En promedio, el equipo disponible en servicio fue de 20.7 profesionales. El número medio de los profesionales requeridos, según el NAS fue el $29 \%$ más elevado de lo que se encuentro en el cuadro de profesionales del oficio de enfermera disponible para la Unidad Neonatal. Esto indica que en esta unidad debe haber sobrecarga de trabajo. La puntuación del NAS medio para la UTIN fue de 91.1 puntos. En promedio, los $90 \%$ del tiempo de un profesional del oficio de enfermera se dedican al cuidado del $\mathrm{RN}$ mientras que permanecen en el UTIN. Cuánto al tiempo del cuidado, fue identificado el promedio de $21 \mathrm{~h} 54 \mathrm{~min}$. de trabajo de asistencia por RN/24. El valor medio para el equipo del oficio de enfermera calculada por la puntuación del NAS, conseguida de la muestra del estudio, fue de 12.8 profesionales. En promedio, el equipo de enfermería disponible en servicio fue de 12 profesionales. Esta diferencia es menor que $1.7 \%$ y hace con que los valores sean perceptiblemente similares y que indican que no había sobrecarga del servicio en el UTIN. Los resultados del uso del NAS permiten identificar el perfil de cuidados de enfermería en la asistencia semi-intensiva a los recién-nacidos. 
Descriptores: Recién-nacidos, Enfermería Neonatal, Asistencia de enfermería, (duración), Profesionales del oficio de enfermera (dimensión), Trabajo (cuantificación). 


\section{INTRODUÇÃO}

A sociedade vive grandes mudanças. O desenvolvimento científico, tecnológico, cultural e as transformações demográficas vêm criando novas formas de relação das pessoas umas com as outras e com o ambiente. Os indivíduos vão adquirindo novos níveis de consciência, passando a exigir novas posturas nos contratos sociais, discutindo o tamanho e o papel do Estado e clamando pela apuração de escândalos e denúncias de corrupção. Os países defendem a abertura dos mercados ao mesmo tempo em que, paradoxalmente, protegem os seus próprios. O homem constrói clones, defende a valorização e 0 desenvolvimento da ética e tem medo da falta de água e de energia elétrica. $E$ tudo isso ao mesmo tempo.

O avanço tecnológico e as mudanças no mundo moderno impõem transformações no sistema de gerenciamento e produção de bens de serviços que ultrapassam limites geográficos, políticos, ideológicos, econômicos, sociais e culturais. As inovações fazem parte de um grande processo de aprendizagem.

Essas mudanças também ocorrem nas instituições de saúde, alcançando grandes proporções, pela crescente pressão da demanda e pela universalização do acesso à saúde (Pena, 2003). Reafirma-se, assim, a necessidade da incorporação e estabelecimento de mudanças organizacionais no setor hospitalar. Nesse contexto, a adoção de novas técnicas de gestão apresenta-se como necessária ao estímulo à mudança e aos ajustes fundamentais para garantir maior desenvolvimento organizacional. Para isso, deve haver uma modernização gerencial através da reestruturação interna dos hospitais, no sentido de otimizar seus processos e gerenciar seus custos.

Com essa perspectiva, iniciou-se na década de 1920 o conceito de avaliação da qualidade na saúde, quando se estabeleceu o programa de padronização hospitalar. Esse programa definiu um conjunto de normas que garantia a qualidade da assistência aos pacientes. Esses padrões referiam-se às condições necessárias à realização de procedimentos médicos e ao processo de 
trabalho, não levando em consideração outras exigências e ou serviços como dimensionamento da equipe de enfermagem ou a necessidade da assistência 24 horas (Schiesari, 1999).

A padronização dos processos de avaliação vem ao longo dos anos evoluindo e aprimorando a identificação de critérios, indicadores e normas cada vez mais significativas para os vários serviços hospitalares (Queijo, Padilha, 2004).

A cultura da qualidade divulgou a uniformização dos processos de trabalho, a qualidade da assistência e a necessidade de profissionais de enfermagem nas instituições, fatores importantes para o gerenciamento, porque exige que os hospitais encontrem mecanismos para garantir a qualidade assistencial e institucional. Ressalta-se, nesse contexto, a contenção dos custos, na medida em que procura racionalizar os recursos existentes.

As organizações de saúde estão sendo obrigadas a modernizar sua forma de gerir as pessoas e o trabalho. Segundo Perroca (2000), fica inviabilizada qualquer forma tradicional de gerenciamento fundamentada no controle e na supervisão das ações de enfermagem, uma vez que focalizam as formas de execução do trabalho e não a qualidade dos resultados obtidos.

Gerência é a arte de pensar, de decidir e de agir; é a arte de fazer acontecer, de obter resultados. Resultados que podem ser definidos, previstos, analisados e avaliados, mas que têm de ser alcançados através das pessoas e numa interação humana constante. A arte de pensar e julgar que caracteriza a gerência exige maior amplitude e lateralidade de pensamento. Por isso se recomenda aos dirigentes mais conhecimentos ou mesmo uma formação avançada para estimular a sua mente e curiosidade, na busca de novos horizontes e perspectivas sobre a realidade em que estão inseridos (Motta, 2000).

O futuro será das organizações que possuírem algum tipo de certificação e que, de certa forma, quebrará o paradigma da fragmentação da saúde proporcionando serviços que realmente atendam as necessidades da população com segurança (Feldman, Gatto, Cunha, 2005). 
Nesse contexto, o emprego de indicadores que avaliem objetivamente a condição clínica do paciente, bem como a necessidade de cuidado, tornou-se instrumento indispensável quando se busca melhorar a relação custo-benefício na assistência à saúde. No caso da enfermagem, indicadores de cuidados são cada vez mais necessários para a real quantificação do pessoal nas diferentes unidades hospitalares (Queijo, Padilha, 2004).

Para Gaidzinski (1998), o dimensionamento do pessoal de enfermagem é um instrumento gerencial para a busca da qualidade da assistência, na medida em que procura adequar o quadro de pessoal disponível às necessidades da clientela e da instituição. A avaliação da qualidade assistencial tem sido cada vez mais utilizada na área da enfermagem, especialmente depois que se comprovou que as propriedades do dimensionamento de recursos humanos são parâmetros válidos e reprodutíveis.

A abordagem do dimensionamento de pessoal é referência para descrever a avaliação da carga de trabalho em enfermagem. Diversos instrumentos têm sido propostos e utilizados com a finalidade de avaliar a carga de trabalho (Bochembuzio, Gaidzinski, 2005; Perroca, 2000; Queijo, Padilha, 2004). São instrumentos que consideram a complexidade do cuidado sobre o processo de trabalho, em uma determinada população.

A estrutura do dimensionamento de pessoal também é uma referência para representar o conceito do Sistema de Classificação de Pacientes (SCP) em enfermagem. O SCP é um indicador de necessidade assistencial e de preocupação com a qualidade.

O objetivo primordial de um SCP consiste em combinar necessidades do paciente na assistência de enfermagem, para assim, realizar a estimativa da carga de trabalho do pessoal de enfermagem em cada unidade. Esses dados possibilitam projeções mais racionais e efetivas do quadro de pessoal de enfermagem necessárias para 0 atendimento das necessidades individualizadas dos pacientes (Perroca, 2000). 
A Resolução COFEN oㅡ 293/04 (2004) fixa e estabelece parâmetros para o dimensionamento do quadro de profissionais de enfermagem nas unidades assistenciais das instituições de saúde, fundamentando-se no SCP de Fugulin et al (1994). No art. 4ํㅡㄹ desse documento, o COFEN no 293/04 (2004) considera como horas de enfermagem, por leitos, nas 24 horas, o grau de dependência do paciente em relação aos cuidados de enfermagem:

- 3,8 horas de enfermagem, por cliente, na assistência mínima ou autocuidado;

- 5,6 horas de enfermagem, por cliente, na assistência intermediária;

- 9,4 horas de enfermagem, por cliente, na assistência semiintensiva;

- 17,9 horas de enfermagem, por cliente, na assistência intensiva.

A avaliação da carga de trabalho de enfermagem é tema de fundamental interesse, visto que uma equipe superdimensionada implica alto custo. Por outro lado, sabe-se que uma equipe reduzida tende a determinar a queda da qualidade da assistência, prolongando o tempo de internação e gerando um maior custo no tratamento dos pacientes (Livianu et al, 1994; Queijo, Padilha, 2004).

$\mathrm{Na}$ literatura nacional e internacional, o interesse pela produção de instrumentos voltados à medida de carga de trabalho de enfermagem não é recente (Nunes, 2000, Terzi, 1997, Tranquitelli, 2005). Muitos desses índices foram desenvolvidos dentro de um panorama abrangente que inclui as diferentes unidades hospitalares, entre elas, a UTI, sem se voltar especificamente para ela. Por ser a UTI uma unidade que reúne pacientes com características diferenciadas, a necessidade de indicadores que retratem de modo fidedigno sua realidade, tem sido buscados (Queijo, Padilha, 2004).

Nessa direção, iniciativas de diferentes países levaram à proposição de instrumentos de medida de trabalho de enfermagem para UTI de adulto, como Omega, proposto pela Commission D'Evaluation de la Societé de Reanimation da Langue Française em 1986, na França; o PRN (Project of Research of Nursing), 
determinado por Health Administration Department of Montreal, em 1980, no Canadá, e posteriormente reformulado em 1987; o TOSS (Time Oriented Score System), descrito em 1991, como resultado de um estudo do Italian Multicenter Group of ICU Research, na Itália; e o sistema TISS (Therapeutic Intervention Scoring System) (Miranda et al, 1996), que inclui a versão mais atual denominada NAS (Nursing Activities Score) (Miranda et al, 2003). Destaca-se que esse instrumento foi desenvolvido e tem sido utilizado para avaliar a carga de trabalho de enfermagem em UTI adulto (Conishi, 2005; Dias, 2006; Gonçalves, 2006; Queijo, Padilha, 2004; Tranquitelli, 2005). .

O NAS foi um método desenhado essencialmente para a aplicação nas unidades de cuidados intensivos adultos. Ele incorpora a diferenciação dos níveis de complexidade dos doentes críticos e atrela a concepção da gestão de pessoas com a performance determinada pela medida da carga de trabalho.

Surgiu do processo de modificação do TISS-28. Tornou-se um índice representativo de $81 \%$ das atividades realizadas pela enfermagem, ou seja, ele significa $81 \%$ do tempo da enfermagem. É um escore mais abrangente no sentido de medir, de forma representativa a carga de trabalho de enfermagem na UTI. Com a vantagem de quantificar os cuidados de enfermagem e o grau de complexidade envolvido. $O$ instrumento contém um maior número de atividades desenvolvidas pela equipe de enfermagem no decorrer do turno de trabalho (Conishi, 2005; Dias, 2006; Queijo, Padilha, 2004).

O escore total obtido com a pontuação do NAS representa a porcentagem de tempo gasto pela equipe de enfermagem, na assistência direta ao paciente, variando de $0 \%$ a $100 \%$ ou mais. Com todos esses atributos, o NAS pode ser considerado um instrumento capaz não só de estimar o quantitativo de pessoal, como também, de auxiliar no cálculo orçamentário do serviço de enfermagem (Queijo, Padilha, 2004).

O NAS foi traduzido para o português e validado por Queijo (Queijo, Padilha, 2004). 
As unidades infantis também investiram na oportunidade de estudar a gravidade dos pacientes e carga de trabalho de enfermagem especificamente na UTI Pediátrica e Neonatal. Assim, para as unidades pediátricas foram adaptados 0 TISS Pediátrico (Pediatric Therapeutic Intervention Scoring System), em 1983; o PSI (Physiological Stability Index), em 1984; o PRISM (Pediatric Risk of Mortality Score), em 1988; o PRISM III (Pediatric Risk of Mortality Score III), em 1988; 0 PRISA II (Pediatric Risk of Hospital Admission Score II), em 2005. Para as Unidades Neonatais foram transformados o NTISS (Neonatal Therapeutic Intervention Scoring System), em 1992; o PSI adaptado (Physiological Stability Index), em 1989; CRIB (Clinical Risk Index for Babies), em 1993 e o CRIB II em 2003; o SNAP (Score for Neonatal Acute Psysiology), em 1993; o MINT (Mortality Index for Neonatal Transportation Score), em 2004. Todos estes instrumentos seguiram a proposta do TISS para seu desenvolvimento e adaptação.

Estudos brasileiros como o de Santos (2006) e Dini (2007) avaliaram a carga de trabalho da equipe de enfermagem em Unidades Pediátricas. Santos (2006) validou o conteúdo de um instrumento de identificação de carga de trabalho em Pediatria a partir da Classificação das Intervenções de Enfermagem (NIC) (McCloskey, Bulechek, 2004). A autora se propõe, em uma próxima pesquisa, correlacionar as intervenções e atividades do NIC com o tempo dedicado na prática assistencial.

Dini (2007) construiu um instrumento para classificação de pacientes pediátricos e validou sua confiabilidade. Nesse estudo a classificação de pacientes em 5 categorias de cuidado cria subsídios para a aferição da variação do tempo médio de enfermagem nas diferentes categorias de cuidado, porém a autora recomenda que sejam realizados estudos para quantificar o tempo de cuidado de enfermagem em pediatria.

\subsection{Instrumentos de Medida de Gravidade e Carga de Trabalho em UTI Pediátrica e Neonatal: Revisão de Literatura}


As Unidades de Terapia Intensiva Pediátrica (UTIP) são locais de grande sofisticação e transferência de conhecimentos. É uma das principais unidades consumidoras do orçamento hospitalar. No contexto do cuidado da UTIP se incorpora a tecnologia para tratar pacientes com diferentes prognósticos e níveis de gravidade. Nem sempre esses recursos utilizados têm a padronização das práticas ou a melhor relação custo-benefício (Martha et al, 2005).

Índices para prognóstico de gravidade da doença de pacientes pediátricos têm sido aperfeiçoados para garantir a sobrevida dos pacientes com qualidade. Além disso, podem ser utilizados para comparação entre estudos clínicos e planejamento de recursos tecnológicos em diferentes serviços.

Para a Unidade de Terapia Intensiva Neonatal (UTIN) a utilização de novas tecnologias tem contribuído para o aumento da sobrevida dos recém-nascidos $(R N)$, especialmente os que possuem os menores valores de idade gestacional e peso de nascimento. Os avanços tecnológicos e os cuidados concentrados são fatores que pretendem, de forma sustentável, garantir sua participação na assistência.

A evolução nos cuidados neonatais teve influência da reposição do surfactante, da nutrição parenteral total, da monitorização dos sinais vitais, da ventilação com alta freqüência, do uso de óxido nítrico e da terapia com laser para a retinopatia da prematuridade (Mendes, 2005). As UTIN têm oferecido bons resultados para os $\mathrm{RN}$ de alto risco, incluindo os prematuros e aqueles com graves condições médicas ou cirúrgicas.

Os cuidados neonatais apresentam características específicas inerentes a estrutura, processo e resultado que exigem, para avaliação das variações das práticas assistenciais, instrumentos padronizados que contemplem os diversos processos envolvidos na assistência aos RN de risco (Mendes et al, 2006).

Por outro lado, a utilização de várias e complexas tecnologias nos cuidados intensivos pediátricos e neonatais envolve risco de morbidade. Deve-se considerar também a existência de muitas práticas e resultados clínicos entre as diferentes unidades. O desenvolvimento de instrumentos e/ou métodos que possam fornecer 
substratos para identificar e medir preditores de risco de gravidade e de mortalidade tornou-se cada vez mais premente.

$\mathrm{Na}$ UTIP e UTIN têm sido desenvolvidos escores mais completos de avaliação do risco de mortalidade, agregando parâmetros fisiológicos que refletem o estado clínico inicial das crianças maiores e dos neonatos (Brito et al, 2003). Os índices de gravidade da doença são ferramentas que auxiliam, indiretamente, na medida da carga de trabalho de enfermagem. A avaliação da gravidade da doença tem sido amplamente utilizada em UTIP (Keene, Cullen, 1983; Pollack et al, 1984; Georgieff et al, 1989; Chamberlainet al, 2005; Pollack et al, 1988; Pollack et al, 1996; Knaus et al, 1981; Kruse et al 1988; Knaus et al, 1991; Richardson et al, 2001); e em UTIN (Gray et al, 1992; International Neonatal Network, 1993; Nascimento, Ramos, 2004; Matsuoka et al, 1998; Richardson et al, 1993; Brougton et al 2004; Richardson et al, 2001; Mendes, 2005; Mendes et al, 2006; Britoet al, 2003) com objetivos diversos.

A gravidade da doença e a carga de trabalho de enfermagem para pacientes pediátricos e neonatos têm sido determinadas de acordo com a qualidade da assistência, o sistema de classificação de pacientes, o controle clínico da intensidade da doença, a utilização e o gerenciamento dos recursos das UTI. No contexto das UTI, estes conceitos, às vezes, ficam difíceis de definir e, através dos modelos preditores de mortalidade, se descreve uma situação mais racional e objetiva (Pollack et al, 1996).

Estes preditores foram uma estratégia de validação dos instrumentos para avaliar a eficácia da terapia e prognóstico, o cuidado requerido e a precisão de resultados. De todos os escores desenvolvidos, uns são mais simples, com poucas variáveis e de aplicação rápida; outros são mais complexos, com um maior número de variáveis e de aplicação mais trabalhosa.

As pesquisas que tratam da gravidade da doença e carga de trabalho em UTIN apontam dificuldades na utilização dos instrumentos de medida, devido aos processos fisiopatológicos do $\mathrm{RN}$ que diferem substancialmente do adulto e crianças maiores. O padrão dos cuidados e o tempo de permanência dos RN 
também são diferentes de outras populações. Para os RN, mortalidade e período de internação não dependem apenas do curso da doença, mas também da maturidade fisiológica (Bochembuzio, Gaidzinski, 2005). Alguns autores afirmam que a utilização de escores pediátricos em UTIN limita sua avaliação (Richardson et al, 1993).

A abordagem formal mais conhecida para o cuidado do $\mathrm{RN}$ foi desenvolvida pela psicóloga norte-americana Heidelise Als, na década de 1980, denominada Programa de Avaliação e Cuidado Desenvolvimental Individualizado ao Neonato (NIDCAP - Neonatal Individualized Developmental Care and Assessment Program). Dentre os componentes do padrão do cuidado, incluem-se: o manejo do ambiente (diminuição do ruído e da luminosidade); o posicionamento do bebê em flexão (simulando a posição intra-uterina); o agrupamento dos cuidados (evitando o excesso de manipulação); a sucção não nutritiva; o manejo da dor; o cuidado canguru; o incentivo ao aleitamento materno; as atividades de promoção de autoregulação dos estados de consciência; e a participação dos pais no cuidado, na perspectiva do cuidado centrado na família (Als, 1986).

\subsection{Escores desenvolvidos para Unidade Pediátrica 1.2.1. Pediatric Therapeutic Intervention Scoring System (TISS)}

Para a pediatria, Keene \& Cullen (1983), adaptaram o método que inicialmente tinha sido proposto por Cullen et al (1974), para a UTI adulto. O TISS Pediátrico é um índice que monitora e quantifica as modalidades das intervenções terapêuticas. O objetivo do escore é avaliar a gravidade da doença, a instabilidade clínica do doente e o custo. 
O instrumento foi avaliado por um painel de especialistas que discutiu cada item e definiu a escala final do TISS pediátrico. Originalmente, eram 76 itens, após discussão e análise, ficaram 63 itens. Foi atribuído pesos de 1 a 4, onde 04 era 0 mais grave, para 4 itens baseados em grau de complexidade e terapêutica (respiratório, cardiovascular, terapêutica medicamentosa, monitorização, entre outros). O escore foi computado para cada paciente no ato da sua admissão ou nas primeiras 24 horas do dia de sua admissão. As avaliações seguintes eram feitas por neonatologistas durante seu atendimento, onde completavam um instrumento baseado nos 5 pontos da escala Likert.

A pontuação indica que há uma classificação de gravidade, porém não correlaciona com o tempo. $O$ instrumento apresentou outras deficiências: 0 profissional que aplicava o escore era um médico, assim, a carga de trabalho e as atividades da equipe de enfermagem estavam sendo avaliadas por um profissional que não o enfermeiro; não contemplava o conjunto das atividades administrativas desenvolvidas pela enfermagem $e$ as atividades de suporte à família. Esse indicador, assim como o TISS, tem uma relação importante com o diagnóstico, a terapêutica e os procedimentos que envolvem o paciente crítico.

A seguir, a Figura 1 mostra o sistema de escore para intervenção terapêutica (TISS) com adaptação pediátrica (adaptado de Keene \& Cullen, 1983). 


\begin{tabular}{|c|c|c|c|}
\hline Variável & Pontos & Variável & Pontos \\
\hline $\begin{array}{l}4 \text { pontos } \\
\text { Insuficiência cardiaca } \pm \text { entre } 48 \text { horas } \\
\text { Ventilação controlada ( } \pm \text { PEEP) } \\
\text { Ventilação controlada com paralisia muscular } \\
\text { Variáveis com tamponamento de balão } \\
\text { Infusão arterial contínua } \\
\text { Cateter em artéria pulmonar } \\
\text { Marcapasso atrial } \pm \text { ventricular } \\
\text { Hemodiálise (paciente instável) } \\
\text { Diálise peritoneal } \\
\text { Indução de hipotermia } \\
\text { † da pressão por transfusão sangüinea } \\
\text { Monitorização da PIC (qualquer método) } \\
\text { Transfusão de plaquetas } \\
\text { Balão intra-aórtico } \\
\text { Procedimento cirúrgico de emergência (passadas } 24 \mathrm{~h} \text { ) } \\
\text { Lavagem do sangramento do trato gastrintestinal } \\
\text { Endoscopia ou broncoscopia de emergência } \\
\text { zinfusão de droga vasoativa contínua } \\
\\
3 \text { pontos } \\
\text { Nutrição parenteral central } \\
\text { Localização de marcapasso } \\
\text { Tubo(s) torácico(s) } \\
\text { Ventilação assistida (VMI) } \\
\text { CPAP } \\
\text { Infusão de potássio concentrada (> } 60 \mathrm{mEg} / \mathrm{L} \text { ) } \\
\text { Intubação oro ou nasotraqueal } \\
\text { Aspiração de coágulo intratraqueal } \\
\text { Sangramento, ou > } 20 \text { mL/Kg de hemoderivados/24h } \\
\text { Push' de medicações IV } \\
1 \text { infusão contínua de droga vasoativa } \\
\text { Infusão contínua de droga vasoativa } \\
\text { Infusão contínua de antiarítmicos } \\
\text { Cardioversão para arritmias } \\
\text { Hipotermia } \\
\text { Cateter arterial } \\
\text { Digitalização aguda (entre } 48 \mathrm{~h} \text { ) } \\
\text { Determinação do débito cardiaco } \\
\text { Diurese ativa devido a hiper-hidratação ou edema cerebral } \\
\text { Terapia ativa para alcalose metabólica } \\
\text { Terapia ativa para acidose metabólica } \\
\text { Emergência tora, para e pericardiocentese } \\
\text { Anticoagulação (primeiras } 48 \mathrm{~h} \text { ) } \\
\text { >2 antibióticos IV } \\
\text { Flebotomia para hiperexpansão com volume } \\
\text { Terapia para convulsõs ou encefalopatia (entre } 48 \mathrm{~h} \text { do início) }\end{array}$ & & 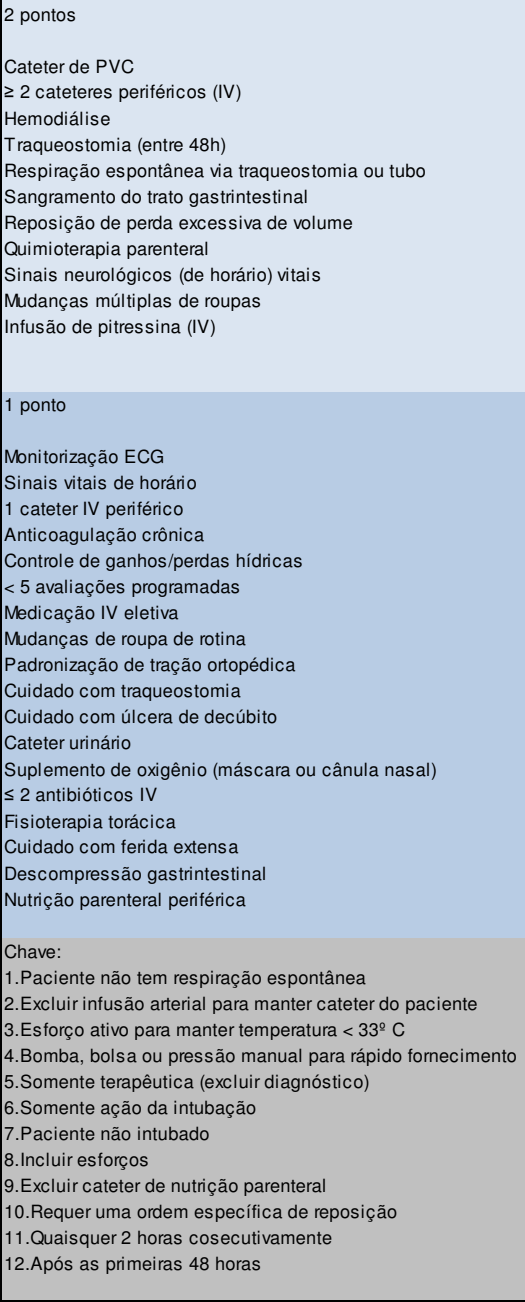 & \\
\hline
\end{tabular}

Figura 1: TISS - Pediatric Therapeutic Intervention Scoring System - adaptação pediátrica por Keene \& Cullen (1983).

\subsubsection{Physiological Stability Index (PSI)}

Pollack et al (1984), avaliaram a gravidade da doença através do índice denominado PSI. Ele quantifica a instabilidade clínica com base em 34 variáveis e 76 co-variáveis distribuídas em 7 sistemas: cardiovascular, respiratório, neurológico, hematológico, renal, gastrintestinal e metabólico. As variáveis foram selecionadas em um consenso de médicos intensivistas pediátricos. 
Para cada variável era apontado um valor entre 1,3 ou 5 que refletia 0 estado clínico da criança, sendo que o valor 1 representava o estado preocupante, mas não necessitava de uma alteração de conduta; o valor 3 representava, também, o estado preocupante, porém era necessária uma mudança na terapia; e no valor 5 o paciente apresentava risco iminente de vida.

A coleta de dados foi realizada no período de dezembro de 1980 a julho de 1981, com 423 crianças com idades entre 1 mês a 254 meses.

Esse escore tem como fator limitante um número muito grande de variáveis e co-variáveis para um mesmo sistema, dificultando sua aplicação em todas as UTIP (Pollack et al, 1984).

A Figura 2 apresenta o PSI, desenvolvido por Pollack et al (1984).

\begin{tabular}{|c|c|c|c|c|c|c|c|}
\hline System & $1+$ & $3+$ & $5+$ & System & $1+$ & $3+$ & $5+$ \\
\hline Cardiovascular & & & & Hematologic & & & \\
\hline Infants & & & & All ages & $18.0-22.0$ & $3.0-5.0$ & $<3.0$ \\
\hline \multirow[t]{2}{*}{ Blood pressure, systolic (torr) } & $55-65$ & $40-54$ & $<40$ & Hemoglobin $(\mathrm{g} / \mathrm{dL}$ ) & $5.0-7.0$ & $22.1-25.0$ & $>25.0$ \\
\hline & $130-160$ & $>160$ & & & & & \\
\hline \multirow[t]{2}{*}{ Heart rate (beat/min) } & $75-90$ & $50-74$ & $>220$ & WBC (cell/mm3) & $3-5.000$ & $<3.000$ & \\
\hline & $160-180$ & $181-220$ & $<50$ & & $20-40.000$ & $>40.000$ & \\
\hline Children & & & & Platelets & $20-50.000$ & $<20.000$ & \\
\hline Blood pressure, systolic (torr) & $65-75$ & $50-64$ & $<50$ & & $>1$ milion & & \\
\hline \multirow[t]{3}{*}{ Heart rate (beat $/ \mathrm{min})$} & $150-200$ & $>200$ & & PT/PTT & $>1.5$ Xcontrol & & \\
\hline & $60-80$ & $40-59$ & $>200$ & $\mathrm{FSP}(\mu \mathrm{g} / \mathrm{mL})$ & $>40$ & & \\
\hline & $150-170$ & $171-200$ & $<40$ & Renal & & & \\
\hline All ages & & & & All ages & & & \\
\hline Blood pressure, diastolic (torr) & $90-110$ & $>100$ & & BUN (mg/dL) & $40-100$ & $>100$ & \\
\hline Cardiac index $[1 /(\min . m 2)]$ & $2.0-3.0$ & $1.0-1.9$ & $<1.0$ & Creatinine $(\mathrm{mg} / \mathrm{dL})$ & $2.0-10.0$ & $>10.0$ & \\
\hline \multirow{2}{*}{ avDO_ $($ vol \%) } & $<3.0$ & $>6.5$ & & Urine output (cc. & $0.5-1.0$ & $<0.5$ & \\
\hline & $5.5-6.5$ & & & \multirow{5}{*}{$\begin{array}{l}\text { Gastrointestinal } \\
\text { All ages } \\
\text { AST/ALT (IU/I) } \\
\text { Amylase (U/l) } \\
\text { Total bilirubin } \\
\text { Albumin (g/dL) }\end{array}$} & & & \\
\hline CVP (torr) & $<0 .>15$ & & & & & & \\
\hline PCWP/LA (torr) & $<5.15-25$ & $>25$ & & & $>100$ & & \\
\hline & & & & & $>500$ & & \\
\hline $\begin{array}{l}\text { Respiratory } \\
\text { Infants }\end{array}$ & $50-60$ & $61-90$ & $>90$ & & $\begin{array}{c}>3.5 \\
1.2-2.0\end{array}$ & $<1.2$ & \\
\hline Respiratory rate (breath/min) & & & & Metabolic & & & \\
\hline Children & $30-50$ & $51-70$ & $>70$ & $\begin{array}{l}\text { All ages } \\
\text { Sodium (mEq/L) }\end{array}$ & $115-125.150-160$ & $<115 .>160$ & \\
\hline \multirow[t]{2}{*}{ Respiratory rate (breath/min) } & & & & \multirow[t]{2}{*}{ Potassium } & $3.0-3.5$ & $2.5-2.9$ & $<2.5$ \\
\hline & & & & & $6.5-7.5$ & $7.6-8.0$ & $>8.0$ \\
\hline All ages & $50-60$ & $40-49$ & $<40$ & \multirow[t]{3}{*}{ Calcium (mg/dL) } & $7.0-8.0$ & $5.0-6.9$ & $<5.0$ \\
\hline $\mathrm{PaO}$ (torr) & $200-300$ & $<200$ & & & $12.0-15.0$ & $>15.0$ & \\
\hline $\mathrm{PaO}^{-} / \mathrm{FiO}$ & $<30.45-50$ & $51-65$ & $<65$ & & $40-60$ & 20-39 & $<20$ \\
\hline \multicolumn{4}{|l|}{$\mathrm{PaCO}^{-0}$ (torr) } & \multirow[t]{2}{*}{ Glucose (mg/dL) } & $250-400$ & $>400$ & \\
\hline Neurologic & & & & & $320-350$ & $>350$ & \\
\hline All ages & & & & Osmolarity & $7.20-7.30$ & $7.10-7.19$ & $<7.10$ \\
\hline Glascow coma score & $8 /$ nov & $5 / \mathrm{jul}$ & $<5$ & $\mathrm{pH}(\mathrm{U})$ & $7.55-7.65$ & $<7.65$ & \\
\hline Intracranial pressure (torr) & $15-20$ & $21-40$ & $>40$ & & $<16 .>32$ & & \\
\hline Seizures & focal & grand $\mathrm{mal} / \mathrm{status}$ & & $\mathrm{HCO}_{-}(\mathrm{U})$ & & & \\
\hline Pupils & equal-sluggish & $\begin{array}{l}\text { unequal-dilated } \\
\text { sluggish }\end{array}$ & fixed/dilated & & & & \\
\hline
\end{tabular}

Figura 2: PSI - Psysiological Stability Index - desenvolvido por Pollack et al (1984). 


\subsubsection{Pediatric Risk of Mortality Score (PRISM)}

O PRISM foi um escore que surgiu a partir da revisão do PSI. Ele é a segunda geração dos preditores de mortalidade para pacientes pediátricos (Pollack, Pattel, Ruttimann, 1996). Esse instrumento surgiu como uma tentativa de reduzir o número de variáveis fisiológicas necessárias para avaliar a gravidade da doença e obter números importantes e consideráveis em relação ao risco de morte no paciente crítico (Pollack et al, 1988).

Pollack et al (1988), adaptaram o método para viabilizar seu uso em todas as UTIP. Ele foi o instrumento mais amplamente conhecido e utilizado nas UTIP, sendo aplicado em estudos clínicos como o escore prognóstico padrão para gravidade da doença em pacientes pediátricos (Martha et al, 2005).

Para se transformar no PRISM, os autores submeteram o PSI a um painel de intensivistas pediátricos que avaliou a instabilidade fisiológica das 34 variáveis e dos 7 sistemas fisiológicos. O número de variáveis foi reduzido de 34 para $14 \mathrm{e}$ o de co-variáveis de 75 para 23. A eliminação das variáveis não resultou em alteração do escore em relação ao PSI e pode ser aplicado em todas as UTIP.

Para cada variável era apontado um valor 1,3 ou 5 que refletia o estado clínico da criança, sendo que 1 era preocupante, mas não necessitava de uma alteração de conduta; o 3 já era uma situação onde a criança precisava de uma mudança na terapia e no 5 o paciente estava em risco iminente de vida.

A desvantagem do uso do PRISM é que a avaliação só é obtida após a evidência clínica da doença. Ele não sofre influência do diagnóstico médico, nem da condição cirúrgica do paciente e não retrata os cuidados de enfermagem e o tempo despendido na assistência.

A seguir, veremos na Figura 3 o PRISM, adaptado por Pollack et al (1988). 


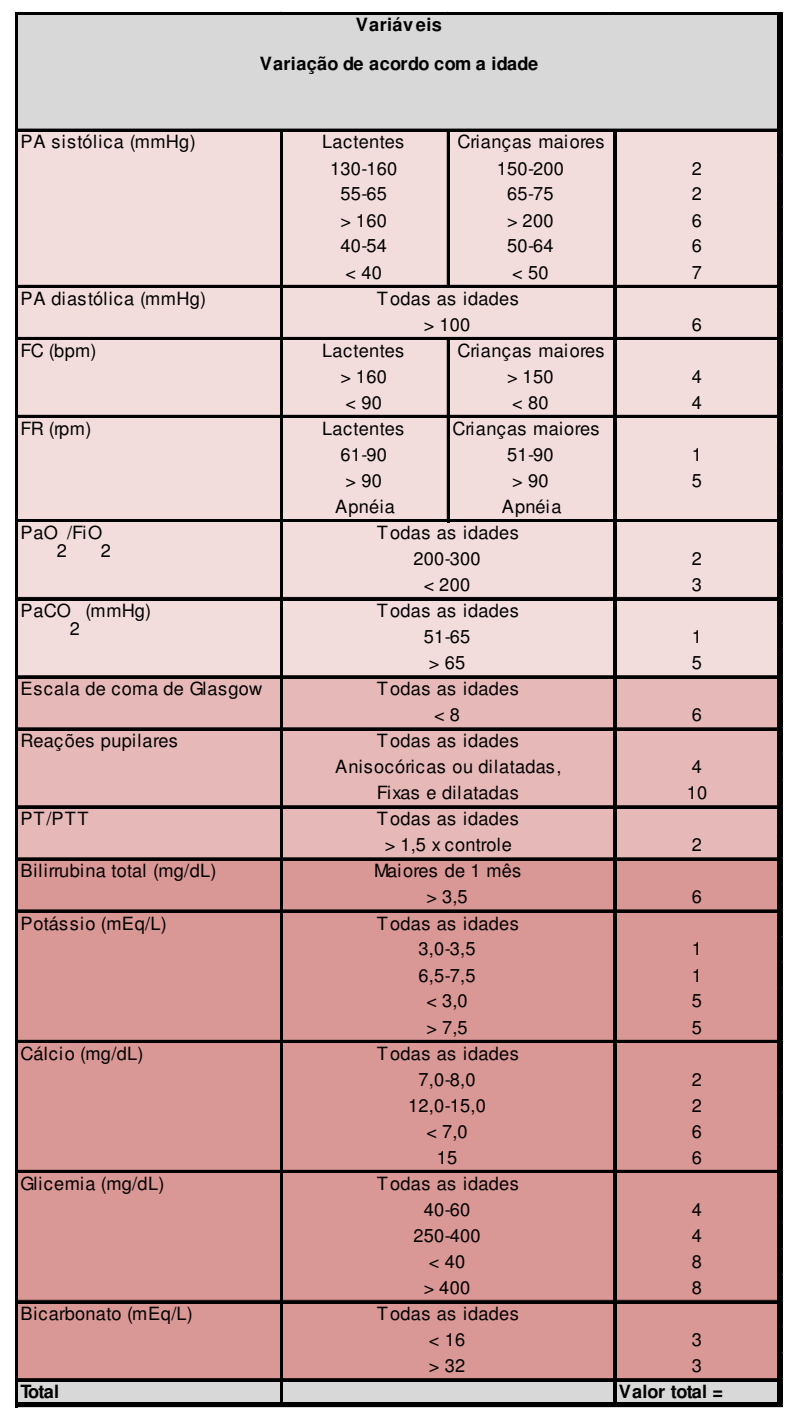

Figura 3: PRISM - Pediatric Risk of Mortality - adaptado por Pollack et al (1988).

\subsubsection{Pediatric Risk of Mortality Score III (PRISM III)}

O PRISM III foi desenvolvido e validado como um escore de terceira geração dos preditores de mortalidade para pacientes pediátricos (Pollack, Pattel Ruttimannn, 1996). Foi baseado numa amostra de 11.165 crianças (543 mortes) admitidas em 32 UTIP no ano de 1993 e 1994.

Foram excluídos do estudo admissões de outros hospitais, pacientes que permaneceram um tempo menor que 2 horas internados nas UTI, pacientes 
transferidos de uma UTI para outra e crianças submetidas à ressuscitação cardiopulmonar que não conseguiram estabilizar os parâmetros vitais por um período de até 2 horas. Os dados foram coletados nas primeiras 24 horas de permanência nas UTIP.

Da mesma forma que o PRISM, para cada variável era apontado um valor 1, 3 ou 5 que refletia o estado clínico da criança.

O PRISM III foi elaborado por Pollack et al (1994) a partir do PRISM, e foi disponibilizado a partir de 1996. O número de variáveis ficou em 17, subdivididas em 26 co-variáveis. É um modelo mais preciso para a avaliação individual do risco de mortalidade pediátrica por ter uma maior capacidade preditiva (Gray et al, 1992; Pollack, Pattel, Ruttimann, 1996).

Assim como o PRISM, o uso desse indicador só é obtido após a evidência clínica da doença. Ele não sofre influência do diagnóstico médico, nem da condição cirúrgica do paciente e não retrata os cuidados de enfermagem e o tempo despendido na assistência.

Outro fator que limita seu uso, mesmo em países desenvolvidos, é o fato de ser cobrada uma importância em dinheiro para sua utilização rotineira (Gray et al, 1992).

Na Figura 4 temos o PRISM III elaborado por Pollack et al (1994). 
Luciana Bochembuzio

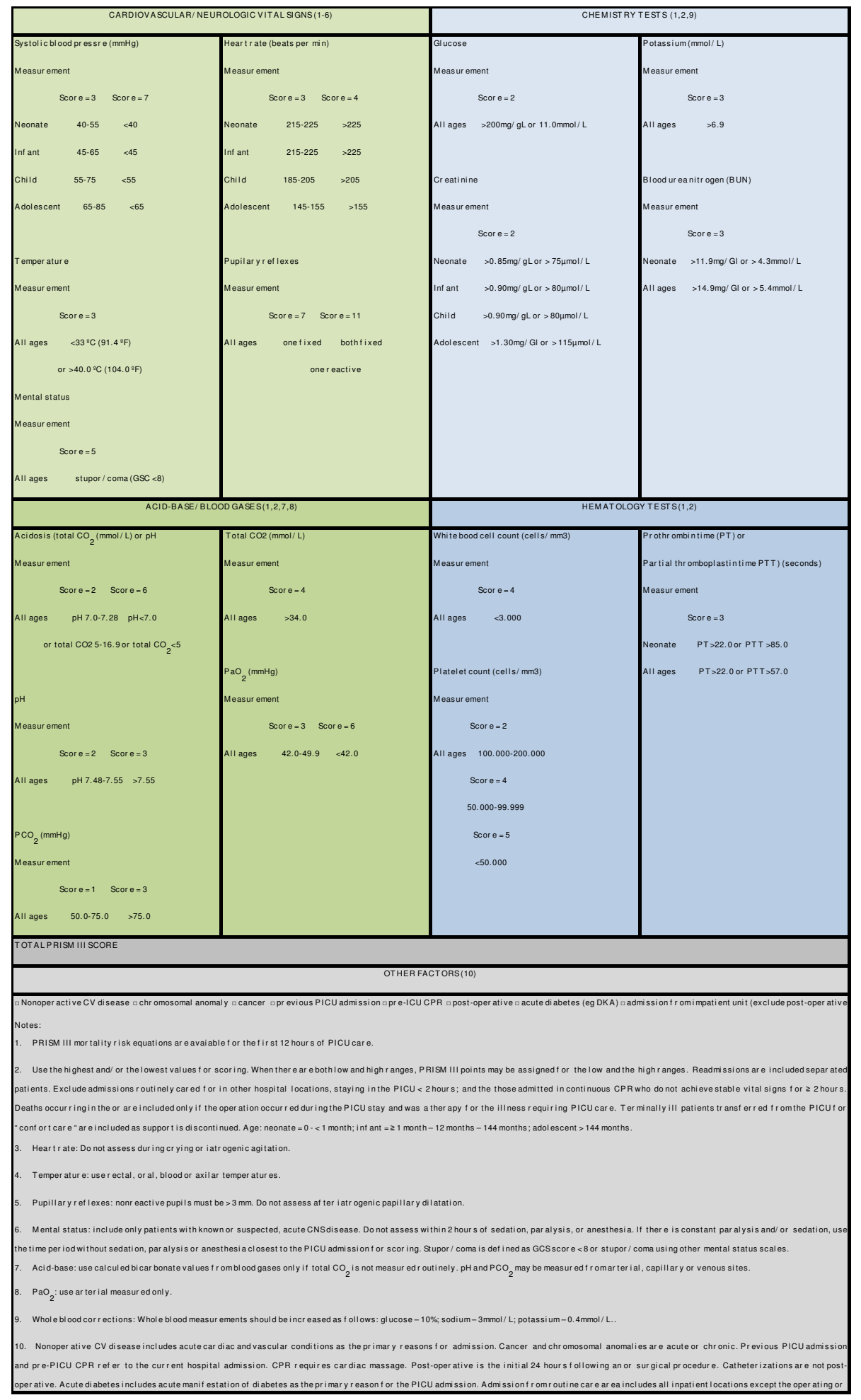

Figura 4: PRISM III - Pediatric Risk of Mortality III - adaptado por Pollack et al (1994). 


\subsubsection{The Pediatric Risk of Hospital Admission Score II (PRISAII)}

PRISA II foi um escore planejado e validado por Chamberlain et al (2005) para a aplicação em pacientes de emergência pediátrica. A proposta do PRISA II foi desenvolver um método de gravidade da doença para pacientes na admissão na emergência pediátrica. Os autores identificaram características de qualidade do cuidado, tempo de permanência e medidas de eficiência do uso adequado do leito (Chamberlain et al, 2005).

Para a validação do escore 16 emergências pediátricas foram estudadas num total de 11664 pacientes, com idades entre 5,8-6,8 anos. A aplicação do escore era feita nas primeiras 24 horas de admissão.

O PRISA II utilizou 17 variáveis: idade, parâmetros clínicos da criança como tipos de doença, medidas de temperatura, pressão arterial, medidas laboratoriais.

O máximo valor para o PRISA II são 96 pontos. A fórmula para o cálculo do PRISA II é obtida através da fórmula:

$$
P=\frac{1}{\left(1+e^{-R}\right)}
$$

onde $\mathrm{R}=-4.0250+0.2888^{\star}$ (PRISA II score) $-0.00279^{\star}(\text { PRISA II score) })^{2}$.

O desenvolvimento de medidas de gravidade para aplicação em emergências pediátricas tem sido muito difícil porque a maioria das unidades não tem o escore implantado. No entanto, é um método de gravidade de doença que utiliza recursos clínicos, que avalia a performance institucional e a qualidade da assistência (Chamberlain et al, 2005). 


\section{A Figura 5 representa o PRISA II, desenvolvido por Chamberlain et al} (2005).

\begin{tabular}{|c|c|c|c|}
\hline Parameter & Score & Parameter & Score \\
\hline $\begin{array}{l}\text { Age }<90 \mathrm{~d} \\
\text { Minor injury * } \\
\text { Abdominal pain in an adolescent } \dagger \\
\text { Imunodeficiency } ¥ \\
\text { Indwelling medical device } \S \\
\text { Controller asthma medications } \\
\text { Referral status } \\
\text { Low temperature } \\
\text { Neonates: }<35.5 \\
\text { Infants: }<35.5 \\
\text { Children: } 35.0 \\
\text { Adolescents: } 35.0 \\
\text { Decreased mental status \# } \\
\text { Low systolic BP }\end{array}$ & $\begin{array}{c}4 \\
-2 \\
11 \\
7 \\
4 \\
6 \\
5 \\
4\end{array}$ & $\begin{array}{l}\text { Neonates: }<70 \\
\text { Infants: }<70 \\
\text { Children: }<83 \\
\text { Adolescents: }<100 \\
\text { High diastolic BP } \\
\text { Neonates: }<>59 \\
\text { Infants: }>59 \\
\text { Children: }>70 \\
\text { Adolescents: }>90 \\
\text { Low serum bicarbonate }(<20) \\
\text { High potassium }(>4.9) \\
\text { High BUN }(>18) \\
\text { High WBC }(>20000) \\
\text { Oxygen } \text { ** } \\
\text { Low bicarbonate and high potassium }\end{array}$ & $\begin{array}{c}9 \\
10 \\
6 \\
10 \\
9 \\
-7\end{array}$ \\
\hline
\end{tabular}

The probability of mandatory admission, $P=1 /\left(1+e^{-R}\right)$, where

$R=-4.0250+0.2888$ * (PRISA II score) -0.00279 * $(\text { PRISA II score })^{2}$

* Strain, sprain, abrasion, laceracion and fracture without associated cranial, thoracic or abdominal injury.

$\dagger$ chief complaint of abdominal pain in a pacient from that age group.

$\ddagger \mathrm{HIV}<$ oncologic disease, sickle cell hemoglobinopathy and transplanted organ.

$\S$ tracheostomy, long term venous catheter, dialylis catheter or shunt, ventricular drainage catheter, feeding tube, home apnea monitor and home oxygen.

!! any asthma medication other than bronchodilatators.

I referral from a phisysician"s office or another ED.

\# Irritable, lethargic, obthuned or comatose.

** Oxygen administered other than during inhaled brochodilatador treatments.

Figura 5: PRISA II - Pediatric Risk of Hospital Admission Score II - desenvolvido por Chamberlain et al (2005). 


\subsection{Escores desenvolvidos para Unidade Neonatal \\ 1.3.1. Neonatal Therapeutic Intervention Scoring System (NTISS)}

Gray et al (1992), criaram o NTISS a partir da modificação do TISS. Esses autores validaram o instrumento com um grupo de pacientes de UTIN . O estudo foi realizado com $1643 \mathrm{RN}$ admitidos em três UTIN, no período de novembro de 1989 a setembro de 1990 (Gray et al, 1992).

O NTISS avalia a gravidade do paciente em função do número de intervenções terapêuticas durante as primeiras 24 horas da admissão do RN na UTIN, em que são considerados 62 itens como possíveis intervenções.

A validação ocorreu em dois estágios. Primeiro, construíram uma lista com procedimentos específicos de UTIN e acrescentadas ao TISS original. Em seguida, enviaram todo o material para ser examinado por um grupo de especialistas composto por 5 médicos neonatologistas, 1 médico pediatra intensivista e 1 enfermeira neonatal. O painel de especialistas discutiu cada item e definiu a escala final do NTISS. Originalmente, eram 76 itens, após discussão e análise, 42 itens foram extintos e 28 foram acrescentados, ficando um total de 62 itens. Foram atribuídos pesos de 1 a 4 , com 4 muito grave, para 8 dimensões baseadas em grau de complexidade e terapêutica (respiratório, cardiovascular, terapêutica medicamentosa, monitoração, entre outros). O escore era computado para cada paciente no ato da sua admissão ou nas primeiras 24 horas do dia de sua admissão. As avaliações seguintes eram feitas por neonatologistas durante seu atendimento, onde completavam um instrumento baseado nos 5 pontos da escala Likert.

De acordo com os autores, Gray et al (1992), esse instrumento apresentou algumas falhas: os autores avaliaram apenas 55 neonatos e não presenciaram nenhuma morte, o que pode prejudicar a relação entre gravidade da doença e mortalidade neonatal.

Outra observação é que o profissional que aplicava o escore era um médico, de modo que a carga de trabalho e as atividades da equipe de 
enfermagem estavam sendo avaliadas por outro profissional que não 0 enfermeiro; assim como o TISS original, ele não abordava as atividades administrativas e de suporte à família.

Apesar disto, existem autores, (Mendes et al, 2006), que afirmam que o NTISS é um método que pode avaliar a gravidade da doença e fazer grandes associações com taxas de mortalidades dentro do hospital. Acreditam ainda que esse instrumento ofereça a oportunidade de se rever os processos assistenciais nas UTIN e otimizar a alocação de recursos no tratamento de RN de risco.

A Figura 6 representa os itens do NTISS, adaptado de Gray (1992).

\begin{tabular}{|c|c|c|c|}
\hline Item & Subscore & Item & Subscore \\
\hline Respiratory & & Metabolic/nutrition & \\
\hline Supplemental oxygen & $1 \mathrm{a}$ & Gavage feeding & 1 \\
\hline Surfactant administration & 1 & Intravenous fat emulsion & 1 \\
\hline Tracheostomy care & $1 \mathrm{~b}$ & Intravenous amino acid solution & 1 \\
\hline Tracheostomy placement & $1 \mathrm{~b}$ & Phototherapy & 1 \\
\hline Continuous positive airway pressure & $2 a$ & Insulin administration & 2 \\
\hline administration & & Potassium infusion & 3 \\
\hline Endotracheal intubation & 2 & Transfusion & \\
\hline Mechanical ventilation & 3a & Intravenous gamma globulin & 1 \\
\hline Mechanical ventilation with muscle relation & $4 a$ & Red blood cell transfusion $(\leq 15 \mathrm{~mL} / \mathrm{Kg}$ ) & \\
\hline High-frequency ventilation & $4 a$ & Partial volume exchange transfusion & $2 \mathrm{i}$ \\
\hline Extracorporeal membrane oxygenation & $4 a$ & Red blood cell transfusion (>15 mL/Kg) & 2 \\
\hline Cardiovascular & & Platelet transfusion & $3 \mathrm{i}$ \\
\hline Indomethacin administration & 1 & White blood cell transfusion & 3 \\
\hline Volume expansion $(\leq 15 \mathrm{~mL} / \mathrm{Kg})$ & $1 \mathrm{c}$ & Double volume exchange transfusion & 3 \\
\hline Vasopressor administration (1 agent) & $2 d$ & Procedural & \\
\hline Volume expansion (> 15 mL/Kg) & $3 c$ & Transport of pacient & 3 \\
\hline Vasopressor administration (1 agent) & $3 d$ & Single chest tube in place & 2 \\
\hline Pacemaker on standby & $3 e$ & Minor operation & $2 \mathrm{j}$ \\
\hline Pacemaker used & $4 \mathrm{e}$ & Multiple chest tubes in place & $2 \mathrm{k}$ \\
\hline Cardiopulmonary resuscitation & 4 & Thoracentesis & $3 \mathrm{j}$ \\
\hline Drug therapy & & Major operation & 3 \\
\hline Antibiotic administration ( $\leq 2$ agents) & 1f & Pericardiocentesis & 4 \\
\hline Diuretics administration (enteral) & $1 \mathrm{~g}$ & Pericardial tube in place & $4 \mathrm{k}$ \\
\hline Steroid administration (postnatal) & 1 & Dialysis & 41 \\
\hline Anticonvulsant administration & 1 & Vascular access & \\
\hline Aminophylline administration & 1 & Peripheral intravenous line & 41 \\
\hline Other unscheduled medication & 1 & Arterial line & 1 \\
\hline Antibiotic administration ( $>2$ agents) & $2 f$ & Central venous line & 2 \\
\hline Diuretic administration (parenteral) & $2 \mathrm{~g}$ & & \\
\hline Treatment of metabolic acidosis & 3 & & \\
\hline Potassium binding resin administration & 3 & & \\
\hline Monitoring & & & \\
\hline Frequent vital signs & 1 & & \\
\hline Cardiorespiratory monitoring & 1 & & \\
\hline Phlebotomy (5-10 blood draws) & $1 \mathrm{~h}$ & & \\
\hline Thermoregulated environment & 1 & & \\
\hline Noninvasive oxygen monitoring & 1 & & \\
\hline Arterial pressure monitoring & 1 & & \\
\hline Central venous pressure monitoring & 1 & & \\
\hline Urinary catheter & 1 & & \\
\hline Quantitative intake and output & 1 & & \\
\hline Extensive phlebotomy ( $>10$ blood draws) & $2 \mathrm{~h}$ & & \\
\hline
\end{tabular}

Figura 6: NTISS - Neonatal Therapeutic Intervention Scoring System - adaptado por Gray (1992). 


\subsubsection{Physiological Stability Index Modify (PSI)}

Para UTIN, Georgieff et al (1989), propuseram o PSI adaptado. Esses autores foram os primeiros a explorar a possibilidade de adaptar um escore para populações como a de RN. Esse escore correlaciona aspectos do TISS com a modificação do PSI. Eles consideram as peculiaridades dos RN para prognosticar o risco de mortalidade para neonatos.

O instrumento quantifica a instabilidade clínica com base em 23 variáveis relacionadas a sinais vitais e medidas de laboratório, distribuídas em 7 sistemas: cardiovascular, respiratório, neurológico, hematológico, renal, gastrintestinal e metabólico.

Para cada variável era apontado um dos números: 1,3 , ou 5 , o qual refletia o estado clínico do neonato, sendo que 1 era preocupante, mas não necessitava de uma alteração de conduta; no 3 era necessário uma mudança na terapia e no 5 o paciente apresentava risco iminente de vida. Foram considerados os valores mais elevados para os registros das variáveis, dentro das 24 horas, para avaliar $\mathrm{RN}$ com risco de morbidade significativo e que necessitavam de cuidados de UTIN.

Entretanto, esses autores examinaram apenas $55 \mathrm{RN}$ no período de janeiro e fevereiro de 1987, não observaram as mortes neonatais e sua relação com a gravidade da doença.

A Figura 7 mostra o PSI modificado para RN, adaptado por Georgieff (1989). 


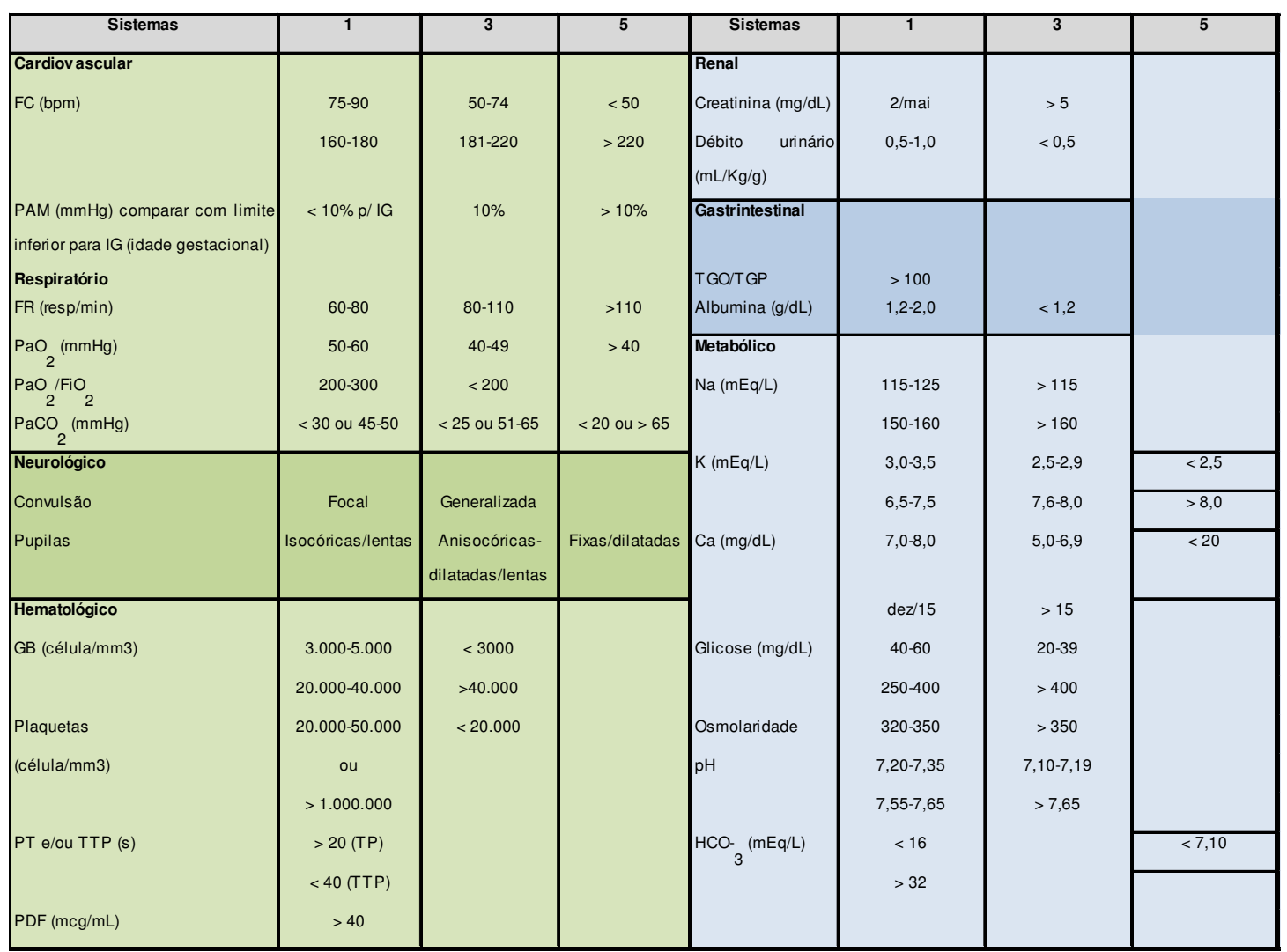

Figura 7: PSI - Psysiological Stability Index Modify - adaptado por Georgieff (1989).

\subsubsection{Clinical Risk Index for Babies (CRIB) e o Clinical Risk Index for Babies II (CRIB II)}

O CRIB foi um escore desenvolvido pelo International Neonatal Network (1993), no Reino Unido, e baseia-se no registro de dados pesquisados nas primeiras 12 horas após o nascimento. É considerado um escore preditor de óbitos em UTIN. Foi utilizado para avaliar a qualidade da assistência intensiva, comparando-se a taxa de mortalidade de hospitais do Reino Unido (International Neonatal Network, 1993; Matsuoka et al, 1998; Nascimento, Ramos, 2004;).

Esse instrumento avalia seis fatores nas primeiras 12 horas de vida, mas deve ser utilizado somente para $\mathrm{RN}$ com menos de 31 semanas de idade gestacional e/ou com peso ao nascer inferior a 1500g (Brito et al, 2003; 
International Neonatal Network, 1993; Knaus et al, 1991; Matsuoka et al, 1998; Nascimento, Ramos, 2004; Parry et al, 2003).

É composto pelas seguintes variáveis: peso ao nascer, idade gestacional, a presença de malformações congênitas (excluindo malformações inevitavelmente letais - anencefalia, trissomia do cromossomo 18 e agenesia renal) e três indicadores do estado fisiológico: o valor mais elevado de excesso de bases (BE) acidótico, obtida pela gasometria arterial; máxima e mínima fração inspirada de oxigênio utilizadas $\left(\mathrm{FiO}_{2}\right)$, apropriadas para manter a saturação de oxigênio da hemoglobina entre $90 \%$ e $96 \%$, estimada por oxímetro de pulso, para, assim, manter boa oxigenação com risco reduzido de toxicidade pelo oxigênio (Brito et al, 2003; International Neonatal Network, 1993; Knaus et al, 1991; Matsuoka et al, 1998; Nascimento, Ramos, 2004; Parry et al, 2003; Zardo, Procianoy, 2003).

Cada item tem um valor numérico, pré-determinado, que pode variar de 0 a 7 e após obter os valores somados desses itens (escore), os RN devem ser distribuídos em 4 grupos: G1 escore de 0 a 5; G2 de 6 a 10; G3 de 11 a 15 e G4 $\geq$ 16. Os $\mathrm{RN}$ que obtiverem escores altos são considerados de mau prognóstico em relação à sobrevida.

O CRIB é um escore prático porque analisa os dados que constam na rotina do atendimento neonatal, e é objetivo, ao mensurar alterações fisiológicas agudas nas primeiras horas após o nascimento. Constata precocemente que os grupos de RN com escores altos apresentam maior risco para o óbito, apesar das intervenções preconizadas dentro das UTIN (Costa et al, 1998).

Quanto à aplicabilidade, o CRIB é um instrumento fácil e rápido de ser realizado, porque o número de variáveis a serem observadas é menor. A desvantagem é que ele só pode ser aplicado em RN com peso inferior a $1500 \mathrm{~g} \mathrm{e}$ IG menor que 31 semanas (Zardo, Procianoy, 2003).

Posteriormente, em 2003, Parry et al (2003), aperfeiçoaram a estrutura desse instrumento, criando o CRIB II. Foi uma atualização do CRIB. Eles examinaram os itens do CRIB e atualizaram 5 dos itens existentes: sexo, peso ao nascer, idade gestacional, temperatura na admissão e excesso de bases. 
Foram estudadas em 54 UTIN, 3027 crianças nascidas com menos de 32 semanas de gestação, e um peso médio ao nascer equivalente a $1355 \mathrm{~g}$, no período de março de 1998 a abril de 1999.

A Figura 8 mostra a construção do CRIB.

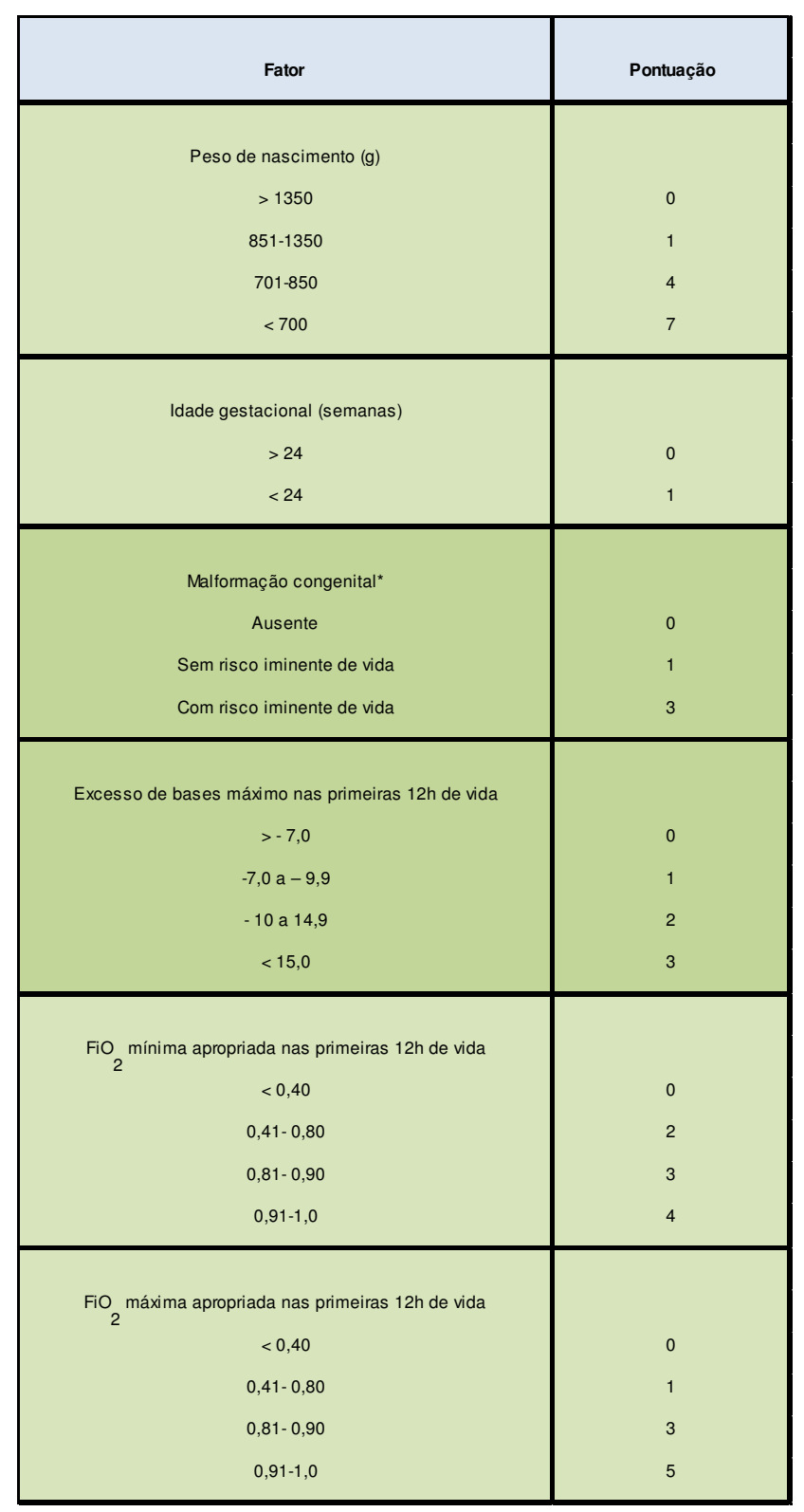

* excluindo malformações inevitavelmente letais

Figura 8: CRIB - Clinical Risk Index for Babies - desenvolvido por International Neonatal Network (1993). 
A Figura 9, reproduz a construção do CRIB II, elaborada por Parry et al (2003).

Figura 9: CRIB II - Clinical Risk Index for BabiesIl - elaborada por Parry et al (2003).

\subsubsection{Score for Neonatal Acute Psysiology (SNAP)}

O SNAP foi desenvolvido por Richardson et al (1993) para avaliar a gravidade clínica dos RN internados em UTIN. Foi validado prospectivamente em todos os RN admitidos em três UTI no período de novembro de 1989 a outubro de 1990. Foram admitidos 1768 pacientes, 114 morreram e 1643 RN foram estudados.

Baseado em 34 medidas fisiológicas múltiplas realizadas necessariamente nas primeiras 24 horas de internação na UTIN, considerando os momentos mais críticos dessas 24 horas, ou seja, a pior avaliação do período deve ser pontuada e 
o valor final é dado pela somatória de pontos nas primeiras 24 horas após a admissão do RN na UTIN (Silveira, Schlabendorff, Procianoy, 2001).

Foi um método que surgiu como um desdobramento do Acute Physiology and Chronic Health Evaluation (APACHE) (Knaus, et al, 1981; Kruse et al, 1988) e do PSI. Os autores utilizaram uma escala de 0 a 5 , com 0 sendo o normal. $O$ APACHE é um preditor de mortalidade para paciente adulto internado em UTI. Ele usa parâmetros como idade do doente, diagnóstico, indicadores clínicos e laboratoriais e disfunções orgânicas para obter um escore de gravidade ou o risco de mortalidade (Knaus et al, 1981, 1991; Kruse et al, 1988). Em 1988 surgiu a segunda versão do APACHE, o APACHE II (Kruse et al, 1988) e em 1991 a última atualização, o APACHE III (Knaus et al, 1991).

Para o SNAP foram selecionados e modificados itens do PSI com o acréscimo de outras variáveis consideradas relevantes para neonatos. A seleção dos itens e a atribuição dos pesos foram dadas por um grupo de especialistas composto por 5 neonatologistas, 1 pediatra intensivista e uma enfermeira neonatal. A partir do PSI, 13 itens foram excluídos, 5 itens foram adicionados, e 2 itens foram substituídos, e a variação clínica foi adaptada em 71 categorias das 76 remanescentes.

Os autores consideraram que o SNAP é um escore de estimativa clínica de risco de mortalidade intra-hospitalar. Correlacionam diversas medidas de recursos clínicos, incluindo terapêutica intensiva, carga de trabalho de enfermagem, tempo de permanência do paciente e análise de custos da UTIN (Richardson et al, 1993).

O SNAP foi baseado em parâmetros clínicos, destes: medidas de pressão arterial, freqüência cardíaca e respiratória, temperatura, $\mathrm{PO}_{2}, \mathrm{PCO}_{2}, \mathrm{FiO}_{2}$, medidas de oxigenação sangüínea, medidas laboratoriais de sódio, potássio, uréia, creatinina, bilirrubina direta e indireta, convulsões, apnéia, sangue nas fezes, entre outras.

Existem algumas limitações do uso deste método que não invalidam o estudo, mas os próprios autores sugerem que sejam destacadas. O SNAP foi aplicado em apenas três hospitais. Richardson et al (1993) acreditam que isso 
balize o estudo, principalmente quando comparado aos escores adulto e pediátrico que tiveram uma aplicação mais ampla. Uma segunda consideração é um pequeno número de casos de $\mathrm{RN}$ com menos de $750 \mathrm{~g}$ de peso ao nascer. $\mathrm{O}$ longo tempo de permanência dos prematuros nas UTI pode fazer com que o escore da admissão seja diferente, dependendo das seqüelas e das complicações. Outro fator pode ser o fato de que os itens do SNAP são relativamente longos e complexos.

A Figura 10 representa o SNAP, adaptado por Richardson et al (1993).

\begin{tabular}{|c|c|c|c|c|c|c|c|}
\hline Parameter & 1-Point Range & 3-Point Range & 5-Point Range & Parameter & 1-Point Range & 3-Point Range & 5-Point Range \\
\hline Blood pressure (mean), mmHG & & & & Blood pressure (mean), $\mathrm{mmHG}$ & & & \\
\hline High & $66-80$ & $81-100$ & $>100$ & Direct bilirubin, $\mathrm{mg} / \mathrm{dL}$ & $\geq 2.0$ & .. & ... \\
\hline Low & $30-35$ & $20-29$ & $<20$ & Sodium, mEq / L & & & \\
\hline Heart rate & & & & High & $150-160$ & $161-180$ & $>180$ \\
\hline High & $180-200$ & $201-250$ & $>250$ & Low & $120-130$ & $<120$ & ... \\
\hline Low & $80-90$ & $40-79$ & $<40$ & Potassium, mEq / L & & & \\
\hline Respiratory rate & $60-100$ & $>100$ & $\ldots$ & High & $6.6-7.5$ & $7.6-9.0$ & $>9.0$ \\
\hline Temperature, ${ }^{\circ} \mathrm{F}$ & $95-96$ & $92-94.9$ & $<92$ & Low & $2.0-2.9$ & $<2.0$ & $\ldots$ \\
\hline $\mathrm{PO}, \mathrm{mmHg}$ & $50-65$ & $30-50$ & $<30$ & Calcium (ionized)2, $\mathrm{mg} / \mathrm{dL}$ & & & \\
\hline $\mathrm{PO}_{-}^{-}$/ $\mathrm{FiO}$ ratio* & $2.5-3.5$ & $0.3-2.49$ & $<0.3$ & High & $\geq 1.4$ & $\ldots$ & $\ldots$ \\
\hline $\mathrm{PCO}, \mathrm{mm} \mathrm{Hg}$ & $50-65$ & $66-90$ & $>90$ & Low & $0.8-1.0$ & $<0.8$ & $\ldots$ \\
\hline Oxygenation index & $0.07-0.20$ & $0.21-0.40$ & $>0.40$ & Calcium (total)2, $\mathrm{mg} / \mathrm{dL}$ & & & \\
\hline Hematocrit, \% & & & & High & $\geq 12$ & & $\cdots$ \\
\hline High & $66-70$ & $>70$ & $\ldots$ & Low & $5.0-6.9$ & $<5.0$ & $\ldots$ \\
\hline Low & $30-35$ & $20-29$ & $<20$ & Glucose (or reagent strip), $\mathrm{mg} / \mathrm{dL}$ & & & \\
\hline White blood cell count $(x 100)$ & $2.0-5.0$ & $<2.0$ & $\ldots$ & High & $150-250$ & $>250$ & $\ldots$ \\
\hline Imature total ratio & $>0.21$ & $\ldots$ & $\ldots$ & Low & $30-40$ & $<30$ & $\cdots$ \\
\hline Absolut neutrophil count & $500-999$ & $<500$ & $\ldots$ & Serum bicarbonate, $\mathrm{mEq} / \mathrm{L}$ & & & \\
\hline Platelet count (x100) & $30-100$ & $0-29$ & $\ldots$ & High & $\geq 33$ & . & .. \\
\hline Blood urea nitrogen, $\mathrm{mg} / \mathrm{dL}$ & $40-80$ & $>80$ & $\ldots$ & Low & nov/15 & $\leq 10$ & $\ldots$ \\
\hline Creatinina, $\mathrm{mg} / \mathrm{dL}$ & $1.2-2.4$ & $2.5-4.0$ & $>4.0$ & Serum $\mathrm{pH}$ & $7.20-7.30$ & $7.10-7.19$ & $<7.10$ \\
\hline 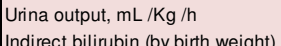 & $0.5-0.9$ & $0.1-0.49$ & $<0.1$ & Seizure & $\begin{array}{l}\text { single } \\
\text { responsive to }\end{array}$ & $\begin{array}{l}\text { multiple } \\
\text { unresponsive to }\end{array}$ & $\begin{array}{c}\ldots \\
\text { complete apnea }\end{array}$ \\
\hline$>2 \mathrm{Kg}: \mathrm{mg} / \mathrm{dL} 1$ & $15-20$ & $>20$ & $\ldots$ & Stool guaiac & positive & $\ldots$ & ... \\
\hline$\leq 2 \mathrm{Kg}: \mathrm{mg} / \mathrm{dL} / \mathrm{Kg} 1$ & 5/out & $>10$ & & & & & \\
\hline
\end{tabular}

${ }^{*} \mathrm{FiO} 2$, fration of inspired oxygen as a percent.

1,2 Mutually exclusive items.

Figura 10: SNAP - Score for Neonatal Acute Psysiology - adaptado por Richardson et al (1993).

Em 2001 Richardson et al (2001) validaram a segunda geração do SNAP, o SNAP II, o SNAP-PE e o SNAP-PE II, para que fossem escores mais simples, mais seguros e empiricamente importantes para refletirem os riscos de mortalidade do paciente grave. Reduziu-se o número de itens e eliminaram-se os mais complexos e difíceis do instrumento inicial. O SNAP II foi reduzido para apenas seis itens e no SNAP-PE II, os itens perinatais como Apgar e classificação do $\mathrm{RN}$ como pequeno para a idade gestacional (PIG), tiveram seus escores com 
pontuações mais elevadas do que os itens que descrevem as condições fisiológicas.

\subsubsection{The Mortality Index for Neonatal Transportation Score (MINT)}

Este escore foi desenvolvido por Broughton et al (2004). Os autores pretenderam demonstrar que o MINT é um preditor de morte que, quando utilizado em prematuros de muito baixo peso é mais eficaz do que com os prematuros por idade gestacional ou baixo peso.

Os dados foram coletados no período de fevereiro de 1992 a julho de 2001. Os prematuros do estudo deveriam ter menos de 72 horas de vida no momento do primeiro contato com o serviço de transporte de referência para neonatos (Newborn and Pediatric Emergency Transport Service - NETS). Durante o contato telefônico é informado a data de nascimento e o tempo de vida, o diagnóstico médico, a história clínica, a idade gestacional, o peso de nascimento, o sexo, o apgar do $1^{\circ}$ e do $5^{\circ}$ minuto de vida e relembrado o horário da admissão.

O MINT foi baseado em 7 variáveis clínicas: $\mathrm{pH}$, idade (em horas de vida) até $72 \mathrm{~h}$ de vida, apgar do $1^{\circ}$ ao $5^{\circ}$ minuto de vida, peso ao nascer, $\mathrm{PaCO}_{2}$, anormalidades congênitas e se o RN estava ou não intubado no momento do contato.

Foram estudados 2504 prematuros (1585 do sexo masculino); a idade gestacional média foi de 36 semanas (a variação foi de 24-43 semanas de gestação); o peso de nascimento foi de 2782g (520-6140g); a média de idade no tempo do primeiro contato com o serviço de transporte de referência foi de 4,5 horas $(0.67-9 h)$. 
A equação usada para gerar a probabilidade de morte para o modelo é:

logit $=-25.53-2.50 \exp -02 . a g e+0.29$. Apgar no $1^{\circ}$ minuto $+2.07 \exp -04$. birth weight $-0.88 \mathrm{exp}-03 . \mathrm{PaO}_{2}+3.74 . \mathrm{pH}-1.75$. congenital abnormality 1.23 . intubation status.

A probabilidade de morte (y) é dada pela seguinte equação:

$$
y=\frac{\exp (\operatorname{logit})}{[1+\exp (\operatorname{logit})]}
$$

O MINT é um método que não foi planejado para avaliar carga de trabalho de enfermagem e classificação de pacientes. Ele poderia ser utilizado como um índice de triagem de emergências médicas que avaliam as condições clínicas do RN.

A Figura 11 mostra o MINT, desenvolvido por Broughton et al (2004).

\begin{tabular}{|c|c|c|c|}
\hline Parameter & Points & Parameter & Points \\
\hline $\mathrm{pH}$ & & Birth w eight & \\
\hline$<6.9$ & 10 & $<750 \mathrm{~g}$ & 5 \\
\hline $6.91-7.1$ & 4 & $751-1000 \mathrm{~g}$ & 2 \\
\hline$>7.1$ & 0 & $1001-1500 \mathrm{~g}$ & 1 \\
\hline Age & & $>1500 \mathrm{~g}$ & 0 \\
\hline $0-1 h$ & 4 & $\mathrm{PaO}_{2}$ & \\
\hline$>1 \mathrm{~h}$ & 0 & $\leq 3 \mathrm{kPa}$ & 2 \\
\hline Apgar score at $1 \mathrm{~min}$ & & $>3 \mathrm{kPa}$ & 0 \\
\hline 0 & 8 & Congenital abnormality & \\
\hline 1 & 5 & Yes & 5 \\
\hline 2 & 2 & No & 0 \\
\hline 3 & 2 & Intubated at time of call & \\
\hline \multirow[t]{2}{*}{$>3$} & 0 & Yes & 6 \\
\hline & & No & 0 \\
\hline Maximum & 40 & & \\
\hline
\end{tabular}

Figura 11: MINT- Mortality Index for Neonatal Transportation Score - desenvolvido por Broughton et al (2004) 


\subsection{O NAS em Neonatologia}

Para a área neonatal foi proposto um SCP que considerava as necessidades de cuidado dos RN (Bochembuzio, 2002). Entretanto, a aplicação e as características deste instrumento de classificação foram limitadas, tendo em vista que não associavam tempo à complexidade assistencial, ou seja, não estimavam o tempo dedicado pela equipe de enfermagem na realização de suas atividades, em uma jornada de trabalho, quando se determinavam as necessidades de cuidado dos RN.

Esses índices não consideram o diferencial proporcionado pela mobilidade que o NAS garante, enquanto instrumento de planejamento e gestão estratégica hospitalar: a relação entre os cuidados de enfermagem e o tempo utilizado para prestar assistência.

Em que pese à importância desses estudos, por ser a Pediatria e em especial, a Unidade Neonatal uma área que reúne pacientes com características diferenciadas, julga-se apropriada a utilização de indicadores que representem a assistência prestada. É fundamental a adoção de um modelo de cuidado integral e humanizado, que considere a família uma aliada na participação do cuidado ao $\mathrm{RN}$, associado às práticas e procedimentos de enfermagem no processo de saúde-doença. A enfermagem, ao adotar como meta a qualidade assistencial, precisa desenvolver modelos de assistência tendo como suporte um conhecimento técnico e científico específico para atuar no processo de diagnóstico e tratamento, atendendo a necessidade de restaurar as condições de vitalidade do RN.

Assim, o planejamento da assistência de enfermagem para o neonato doente constitui um processo muito complexo que necessita de uma avaliação rigorosa e progressiva para determinar sua efetividade. Esta avaliação é específica devido à freqüente introdução de novas modalidades de tratamento, falta de comunicação verbal com o paciente, estreita margem entre as respostas favoráveis e as adversas da terapia, falta de reações devido ao desenvolvimento 
imaturo e a extrema vulnerabilidade, particularmente nas crianças mais prematuras ou doentes (Bochembuzio, 2002).

A partir dessas considerações, analisou-se a proposta do NAS com indicadores semelhantes aos do SCP. Nos valores do NAS estão subentendidos a associação do tempo com a complexidade assistencial, identificando a medida da carga de trabalho de enfermagem, por paciente, nas 24 horas.

Neste estudo, as perspectivas se organizam em torno da aplicabilidade e implementação do NAS em RN. A medida da carga de trabalho e o dimensionamento de pessoal são recursos que irão consolidar uma série de avanços tecnológicos e organizacionais que serão necessários para viabilizar a implantação. A presente pesquisa será desenvolvida sob a égide desse modelo proposto por Miranda et al (2003).

Atenta às modificações que vêm ocorrendo nesse cenário e buscando na reflexão um aprendizado que beneficie o desenvolvimento do país, a Escola de Enfermagem da Universidade de São Paulo - EEUSP/SP- desenvolve pesquisas a este respeito. O Grupo de Pesquisa intitulado: Gerenciamento de Recursos Humanos: conceitos, instrumentos e indicadores do processo de dimensionamento de pessoal de saúde; está cadastrado junto ao CNPq (Conselho Nacional de Desenvolvimento Científico e Tecnológico), e dispõe de uma equipe composta por professores, alunos de graduação, de mestrado, e doutorado, além de enfermeiros de diversas instituições hospitalares do município de São Paulo.

No contexto da globalização da economia, o grupo tem trabalhado com o objetivo de compreender, discutir e gerar conhecimentos sobre os fenômenos que acontecem nos hospitais no âmbito do dimensionamento do pessoal de enfermagem e do gerenciamento de recursos humanos em enfermagem e em saúde. Organizado em vários subprojetos, o grupo analisa aspectos legais, mercadológicos, tecnológicos e organizacionais da grande mudança que tem se passado nos hospitais. É dentro de um destes subprojetos que esta tese foi desenvolvida. 


\section{OBJETIVOS}

\section{Geral}

- Avaliar o resultado da aplicação do NAS, como variável no cálculo da medida da carga de trabalho de enfermagem em neonatologia.

\section{Específicos}

- Comparar o quantitativo diário da equipe de enfermagem requerida pela pontuação NAS com o quantitativo diário da equipe disponível nas unidades estudadas;

- Comparar o quantitativo médio da equipe de enfermagem requerida pela pontuação NAS com os quantitativos médios da equipe de enfermagem obtidos de outras fontes da literatura para os mesmos tipos de unidades estudadas.

- Avaliar a freqüência das atividades do instrumento NAS, quando aplicado em neonatologia. 


\section{METODOLOGIA}

\subsection{Tipo do Estudo}

Este estudo é uma pesquisa metodológica, que de acordo com Polit e Hugler (1995) trata-se de um método de obtenção, organização e análise de dados que elabora, valida e avalia os instrumentos e técnicas de pesquisas.

\subsection{Local do Estudo}

O estudo foi realizado na Unidade Neonatal e Unidade de Terapia Intensiva Neonatal (UTIN) do Hospital Universitário da Universidade de São Paulo (HUUSP).

O HU-USP é parte integrante do Sistema Integrado de Saúde da Universidade de São Paulo (SISUSP) e tem como objetivo estimular e promover o ensino, a pesquisa e a extensão dos serviços de saúde à comunidade (Universidade de São Paulo, 2002). Dispõe de 247 leitos, distribuídos nas especialidades clínica médica geral, cirurgia geral, ginecologia/obstetrícia e pediatria.

O hospital é campo de estágio dos alunos da Faculdade de Medicina, Escola de Enfermagem, Faculdade de Ciências Farmacêuticas, Faculdade de Odontologia, Faculdade de Saúde Pública e Instituto de Psicologia. A população atendida compreende a comunidade USP, que é constituída pelos servidores, discentes da Universidade, incluindo seus dependentes, e pela comunidade residente na região do Butantã, pertencentes ao subdistrito do Butantã, servindo de referência às Unidades Básicas de Saúde (UBS) da região. Os recursos financeiros são provenientes de orçamento da Universidade de São Paulo e dos serviços prestados ao Sistema Único de Saúde.

Os órgãos da Administração Superior do HU-USP são: o Conselho Deliberativo (CD); e a Superintendência. O CD é constituído pelos diretores da 
Faculdade de Medicina, Escola de Enfermagem, Faculdade de Ciências Farmacêuticas, Faculdade de Odontologia, Faculdade de Saúde Pública e Instituto de Psicologia, pelo Superintendente do HU-USP, pela representação discente e por um representante da comunidade. Uma das principais funções do CD é definir as diretrizes básicas da assistência médico-hospitalar, de pesquisa, de cooperação didática e de prestação de serviços médico-hospitalares à comunidade. A Superintendência é o órgão de direção executiva que coordena, supervisiona e controla todas as atividades do HU-USP. Diretamente ligados à Superintendência ficam o Departamento Médico (DM) e o Departamento de Enfermagem (DE), ambos com a finalidade de coordenar, supervisionar e controlar as atividades desenvolvidas nas áreas: médica e de enfermagem a eles, respectivamente, subordinadas (Gualda, 2001).

Os recursos humanos são contratados por meio de concurso público com base na Consolidação das Leis Trabalhistas (CLT).

A estrutura organizacional do Departamento de Enfermagem é composta por quatro divisões (clínica, cirúrgica, materno-infantil e pacientes externos). Em cada divisão existe um enfermeiro, diretor de divisão; seções subordinadas às divisões, com enfermeiros, chefes de seção; enfermeiros assistenciais em todas as seções e pessoal de nível médio, assistencial, técnicos e auxiliares de enfermagem. O Departamento de Enfermagem possui um Serviço de Apoio Educacional que coordena os programas de treinamento e desenvolvimento e as atividades de ensino de graduação e especialização desenvolvidas na área de enfermagem.

O Departamento de Enfermagem do HU-USP, desde sua implantação em 1981, preocupou-se em definir um método de trabalho que retratasse a qualidade do processo de cuidado. Para garantir esse objetivo adotou modelos da Teoria de Enfermagem de Horta (1979) e empregou conceitos da Teoria do Autocuidado de Orem (1991).

Para operacionalizar esta proposta teórica aplica o processo de enfermagem que consiste em: histórico (entrevista e exame físico), diagnóstico, sob referencial da North American Nursing Diagnosis Association International 
(NANDA-I) (2002), prescrição e evolução de enfermagem. Nos Anexos 1, 2, 3 e 4 estão os impressos que são utilizados nas unidades do estudo para a documentação desse processo.

A equipe de enfermagem do HU-USP trabalha com a dinâmica do Primary Nursing de Manthey (1980). Ele prevê a existência de uma equipe de enfermagem responsável pelas intervenções de enfermagem, bem como pela avaliação dos resultados da assistência prestada a determinados pacientes durante toda a internação até a alta. Nessa dinâmica de trabalho, o enfermeiro é a referência do paciente, faz as comunicações interdisciplinares, centraliza e dirige as ações de enfermagem, bem como verifica se os cuidados prescritos estão sendo realizados de forma satisfatória.

\subsubsection{Unidade Neonatal}

A Unidade Neonatal dedica-se ao atendimento de RN que apresentam instabilidade sob ponto de vista clínico e de enfermagem. Seus objetivos são: prestar assistência de enfermagem de forma individualizada; proporcionar condições favoráveis para que os pais possam estabelecer vínculo adequado com seu filho; favorecer e promover o aprendizado dos pais em relação aos cuidados com o seu filho; promover, apoiar e incentivar a prática do aleitamento materno; estimular e proporcionar a permanência da mãe nas 24 horas; proporcionar a prática da posição canguru; oferecer condições para o desenvolvimento do ensino e da pesquisa em unidade neonatal.

Tem uma planta física com cerca de $200 \mathrm{~m}^{2}$, com 24 leitos para RN que necessitam de internação até o $2^{\circ}$ dia de vida. Para o atendimento de crianças nascidas na instituição são destinados 19 leitos; essas crianças podem ser procedentes do Centro Obstétrico, das unidades de Alojamento Conjunto, da UTIN. Os outros 5 leitos são reservados para RN externos, isto é: procedentes do Pronto Socorro Infantil, ou Ambulatório, ou UTIN de outras instituições.

A taxa de ocupação da Unidade Neonatal gira em torno de 50,7\% (Rogenski, 2006), com média de permanência próxima a 5 dias de internação, 
exceto nos casos de prematuridade, onde esse período ultrapassa 30 dias. Considerando a taxa de mortalidade infantil no ano de 2006, não foi observada presença de óbitos neonatais. O índice de infecção hospitalar para o ano de 2006 foi de 16,61\% (Universidade de São Paulo, 2002).

As causas mais freqüentes de internação são: desconforto respiratório precoce; distúrbios metabólicos, principalmente hipoglicemia e hiperbilirrubinemia; infecções congênitas; problemas relacionados com a prematuridade e febre.

Em relação à complexidade assistencial os RN são classificados de acordo com a classificação proposta por Fugulin et al (1994), em cuidado semi-intensivo: RN sujeitos à instabilidade de funções vitais, sem risco iminente de vida, porém com risco de agravamento súbito do seu estado clínico, que requeiram assistência de enfermagem e médica permanente e especializada (Fugulin, Gaidzinski, Kurcgant, 2005).

Para a garantia da qualidade da assistência o quadro de pessoal de enfermagem é distribuído, diariamente, por turnos, de acordo com o dimensionamento de pessoal.

\begin{tabular}{|l|c|c|c|c|c|c|}
\hline \multicolumn{1}{|c|}{ FUNÇÃO } & \multicolumn{5}{c|}{ DISTRIBUIC̃ÃO POR TURNO } \\
\cline { 5 - 8 } & QUADRO & HA & M & T & NP & NI \\
\hline CHEFE DE SEÇÃO & 1 & 1 & 0 & 0 & 0 & 0 \\
\hline ENFERMEIRO & 9 & 0 & 4 & 3 & 1 & 1 \\
\hline $\begin{array}{l}\text { TÉCNICO DE } \\
\text { MATERIAL }\end{array}$ & 1 & 1 & 0 & 0 & 0 & 0 \\
\hline $\begin{array}{l}\text { TÉCNICO DE } \\
\text { BANCO DE LEITE }\end{array}$ & 2 & 2 & 0 & 0 & 0 & 0 \\
\hline $\begin{array}{l}\text { TÉCNICO/AUXILIAR } \\
\text { DE ENFERMAGEM }\end{array}$ & 25 & 0 & 8 & 7 & 5 & 5 \\
\hline $\begin{array}{l}\text { TÉCNICO } \\
\text { ADMINISTRATIVO }\end{array}$ & 1 & 1 & 0 & 0 & 0 & 0 \\
\hline TOTAL & 39 & 5 & 12 & 10 & 6 & 6 \\
\hline
\end{tabular}

$\mathrm{HA}=$ horário administrativo; $\mathrm{M}=$ manhã; $\mathrm{T}=$ tarde; $\mathrm{NP}=$ noturno par; $\mathrm{NI}=$ noturno ímpar 
Fonte: Manual de Gerenciamento da Unidade Neonatal do HU-USP (2006).

Figura 12: Distribuição da equipe de enfermagem na Unidade Neonatal, no ano de 2006, HU-USP. São Paulo, 2006.

A carga horária semanal de toda a equipe de enfermagem é de 36 horas, com jornada de 6 horas no diurno e $12 \times 36$ no noturno.

A taxa de ausências previstas (folgas e férias) e não previstas (faltas e licenças) para o ano de 2006 encontra-se demonstrada na figura abaixo.

\begin{tabular}{|c|c|c|c|}
\hline \multirow{6}{*}{ 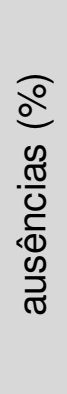 } & \multirow{3}{*}{ enfermeiros } & previstas & 39,74 \\
\hline & & não previstas & 0,2 \\
\hline & & total & 40,02 \\
\hline & \multirow{3}{*}{$\begin{array}{l}\text { técnicos de } \\
\text { enfermagem }\end{array}$} & previstas & 34,18 \\
\hline & & não previstas & 6,71 \\
\hline & & total & 43,18 \\
\hline
\end{tabular}

Fonte: Manual de Gerenciamento da Unidade Neonatal do HU-USP (2006).

Figura 13: Distribuição das ausências previstas e não previstas na Unidade Neonatal para a equipe de enfermagem do HU-USP, no ano de 2006, São Paulo, 2006.

\subsubsection{Unidade de Terapia Intensiva Neonatal}

A UTIN destina-se ao atendimento de RN hemodinamicamente instáveis. Tem como objetivo prestar assistência humanizada, de maneira rápida, segura e eficaz, restabelecer a saúde, minimizar os traumas e as seqüelas provocadas pelo tratamento intensivo e proporcionar condições para o desenvolvimento do ensino e da pesquisa em terapia intensiva neonatal.

A UTIN está localizada no $3^{\circ}$ andar do HU-USP, em uma planta física destinada à Unidade de Terapia Intensiva Pediátrica e Neonatal. A UTIN possui uma área com cerca de $50 \mathrm{~m}^{2}$. 
A UTIN dispõe de 6 leitos que atendem RN de até 28 dias de vida. Os leitos estão distribuídos lado a lado, com fácil acesso, visibilidade e possibilidade de diferentes fluxos internos. Existe um leito reservado para o RN que tem indicação de quarto privativo. Caso não haja vaga na UTIN, o RN com menor complexidade assistencial é transferido à Unidade Neonatal e passa a ser acompanhado pela equipe médica e de enfermagem da Unidade. Todo o ambiente da UTIN recebe luz natural, exceto o quarto privativo que tem um sistema climatizado de fluxo de ar.

Os RN podem ser provenientes do: Pronto Socorro Infantil, da Unidade Neonatal, do Alojamento Conjunto, do Centro Obstétrico, ou de outras instituições por intermédio da central de vagas da cidade de São Paulo.

A taxa de ocupação da UTIN gira em torno de 56,6\% (Rogenski, 2006), com média de permanência de 6 dias de internação, exceto nos casos de prematuridade, onde esse período ultrapassa 30 dias. Para o ano de 2006 a taxa de infecção hospitalar foi de 51,18\%. A taxa de mortalidade é de 9,16\% (Universidade de São Paulo, 2002).

As causas mais freqüentes de internação são: RN internados por peso menor que 1000 g, e/ou idade gestacional inferior a 30 semanas; asfixia perinatal; insuficiência respiratória e cardíaca; arritmias cardíacas; depressão respiratória ao nascimento devido ao uso de drogas maternas; anomalias e infecções congênitas; infecções perinatais graves; problemas neurológicos; síndrome convulsiva; distúrbios hidroeletrolíticos e metabólicos; pós-operatório imediato. A Unidade recebe $\mathrm{RN}$ que necessitam de procedimentos específicos como: surfactante; exsangüíneotransfusão; cateterismo umbilical; diálise peritoneal; ventilação mecânica invasiva e não invasiva.

Em relação à complexidade assistencial, os RN são classificados de acordo com o modelo proposto por Fugulin et al (1994), que define a UTIN como de cuidados intensivos como proposta de categoria: cuidados a $\mathrm{RN}$ graves, com risco iminente de vida, sujeitos à instabilidade de sinais vitais, que requeiram assistência de enfermagem e médica permanente e especializada (Fugulin, Gaidzinski, Kurcgant, 2005). 
Para a garantia da qualidade da assistência o quadro de pessoal de enfermagem é distribuído diariamente, por turnos, de acordo com o dimensionamento de pessoal.

\begin{tabular}{|l|c|c|c|c|c|c|}
\hline \multicolumn{2}{|l|}{ FUNÇÃO } & \multicolumn{5}{|c|}{ DISTRIBUIÇÕO POR TURNO } \\
\cline { 3 - 7 } & QUADRO & HA & M & T & NP & NI \\
\hline CHEFE DE SEÇÃO & 1 & 1 & 0 & 0 & 0 & 0 \\
\hline ENFERMEIRO & 14 & 0 & 5 & 4 & 3 & 2 \\
\hline $\begin{array}{l}\text { TÉCNICO DE } \\
\text { MATERIAL }\end{array}$ & 1 & 1 & 0 & 0 & 0 & 0 \\
\hline $\begin{array}{l}\text { TÉCNICO/AUXILIA } \\
\text { R DE } \\
\text { ENFERMAGEM }\end{array}$ & 25 & 0 & 7 & 8 & 7 & 7 \\
\hline $\begin{array}{l}\text { TÉCNICO } \\
\text { ADMINISTRATIVO }\end{array}$ & 1 & 1 & 0 & 0 & 0 & 0 \\
\hline TOTAL & 41 & 3 & 12 & 12 & 10 & 10 \\
\hline
\end{tabular}

$\mathrm{HA}=$ horário administrativo; $\mathrm{M}=$ manhã; $\mathrm{T}=$ tarde; $\mathrm{NP}=$ noturno par; $\mathrm{NI}=$ noturno ímpar Fonte: Manual de Gerenciamento da UTIN do HU-USP (2006).

Figura 14: Distribuição da equipe de enfermagem na UTIN, no ano de 2006. HU-USP, São Paulo, 2006.

A carga horária semanal de toda a equipe de enfermagem é de 36 horas, com jornada de 6 horas nos turnos do dia e 12x36 horas nos turnos da noite.

A taxa de ausências previstas (folgas e férias) e não previstas (faltas e licenças) para o ano de 2006 encontra-se demonstrada na figura abaixo.

\begin{tabular}{|c|c|c|c|}
\hline \multirow{6}{*}{ 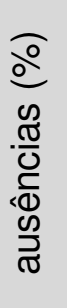 } & \multirow{3}{*}{ enfermeiros } & previstas & 36,45 \\
\hline & & não previstas & 1,8 \\
\hline & & total & 38,90 \\
\hline & \multirow{3}{*}{$\begin{array}{l}\text { técnicos de } \\
\text { enfermagem }\end{array}$} & previstas & 28,59 \\
\hline & & não previstas & 11,79 \\
\hline & & total & 43,76 \\
\hline
\end{tabular}

Fonte: Manual de Gerenciamento da UTIN do HU-USP (2006).

Figura 15: Distribuição das ausências previstas e não previstas na UTIN para a equipe de enfermagem do HU-USP, no ano de 2006, São Paulo, 2006. 


\subsubsection{Unidade Neonatal e Unidade de Terapia Intensiva Neonatal: dinâmica de trabalho}

O dimensionamento do pessoal de enfermagem para a assistência ao RN está baseado na divisão dos profissionais por turno de trabalho, elaborada de acordo com a distribuição das atividades, a dinâmica de cada plantão, a complexidade dos pacientes assistidos e o número de leitos existentes. A equipe de enfermagem é única e fixa na Unidade Neonatal e na UTIN. No dia-a-dia a conformação das equipes é dinâmica, podendo, a critério do julgamento dos enfermeiros, serem deslocados profissionais, técnicos e/ou enfermeiros, entre as unidades, conforme carga de trabalho que se apresente. Especificamente na UTIN, mensalmente, a equipe de enfermagem se divide nos cuidados da UTIN e da UTIP. Entretanto, quando necessário, os profissionais são deslocados para as outras unidades.

Os pais ou algum membro da família são incentivados a participar dos cuidados prestados a seu filho, no início, acompanhados pelos profissionais da equipe de enfermagem, passando gradualmente a realizar os cuidados de higiene, conforto e alimentação. Eles são estimulados a permanecer como acompanhantes da criança, em poltronas ao lado do leito do seu filho. Para os acompanhantes são oferecidas refeições com horários pré-estabelecidos.

Semanalmente, no grupo de pais, os acompanhantes são convidados a participar de uma reunião com a presença de profissionais da equipe de saúde que coordenam o grupo. A finalidade destes encontros é oferecer aos pais um espaço para esclarecer dúvidas, promover o contato entre si e a equipe e estimular a troca de opiniões. É permitido que os pais ofereçam apoio espiritual conforme suas crenças e valores.

Existe horário de visitas no período da tarde, mas, procura-se atender as necessidades de horários mais flexíveis apresentadas pelos pais e demais familiares, caso necessitem, no período da manhã e à noite, inclusive. 0 atendimento, tanto pessoal quanto telefônico aos pais e às famílias para informações mais detalhadas e específicas, é realizado pelos enfermeiros. 
O Banco de Leite Humano (BLH) da instituição dá suporte às mães de RN prematuros, que muitas vezes, não amamentam seus filhos, como decorrência da imaturidade dos mesmos.

A existência de tais características tornam as Unidades do HU-USP, locais adequados à presente investigação, tendo em vista a excelência na prestação de serviços de enfermagem.

\subsection{População do Estudo}

Este estudo abrange a população de RN internados na Unidade Neonatal e UTIN do HU-USP, independente do diagnóstico e do tempo de permanência, submetidos a tratamento clínico ou cirúrgico e que permaneceram internados por um período mínimo de 24 horas.

Como o processo de chegada dos $\mathrm{RN}$ nessas unidades acontece de forma aleatória, as amostras dos $\mathrm{RN}$ tiradas de qualquer período das seqüências podem ser consideradas amostras randômicas da população.

O tamanho das amostras foi baseado nos seguintes critérios:

- a população foi considerada normalmente distribuída;

- o intervalo de confiança aceitável de $95 \%(Z c=1,96)$;

- o erro percentual (e\%), admitido entre as médias das amostras e a média da população, deve ser igual ou menor que $5 \%$;

- as taxas de ocupação percentual das unidades (To\%) foram tomadas das médias históricas, isto é: 50,7\% para a Unidade Neonatal e 56,6\% para a UTIN;

- a Unidade Neonatal dispõe de $L=24$ leitos; e a UTIN dispõe de $L=6$ leitos;

- o coeficiente de variação $(\boldsymbol{C v})$ foi calculado com os dados históricos das unidades através da seguinte equação:

$$
C v=\frac{1}{3}\left(\frac{1}{T o}-1\right)
$$

- o tamanho das amostras foi calculado através da seguinte equação: 


$$
n=\left(\frac{Z c \cdot C v}{e}\right)^{2}
$$

- o período de amostragem foi calculado através da seguinte equação:

$$
T=\frac{n}{T o . L}
$$

Introduzindo os dados nas equações descritas e efetuando os cálculos necessários, chegou-se aos seguintes resultados:

Para a Unidade Neonatal a amostra correspondeu a 162 RN durante um período de 14 dias.

Para a UTIN a amostra correspondeu a $101 \mathrm{RN}$ durante um período de 30 dias.

Portanto, o maior período de coleta de dados deve ser de 30 dias na UTIN. Para facilitar a obtenção dos dados, escolheu-se um período único de 30 dias de coleta de dados em ambas as unidades.

\subsection{Procedimento de Coleta de Dados}

A coleta de dados foi realizada pela pesquisadora através das informações obtidas dos enfermeiros, técnicos e auxiliares de enfermagem que estavam prestando cuidados no momento da coleta. Eventualmente, houve a necessidade de obter dados do prontuário para complementar as informações dos profissionais da equipe de enfermagem.

O período da coleta foi de 06 de novembro a 06 de dezembro de 2006, com início às 8 horas na Unidade Neonatal e em seguida na UTIN, respectivamente, segundo o mesmo procedimento metodológico, por meio de um instrumento padronizado, conforme descrição a seguir:

- Ficha de identificação demográfica e clínica dos RN

- Instrumento de medida de carga de trabalho (NAS) 


\subsubsection{Ficha de identificação demográfica e clínica dos recém-nascidos}

No Anexo 5 encontra-se a ficha de levantamento de dados utilizada para o registro dos dados demográficos e clínicos, do primeiro ao último dia de internação do $\mathrm{RN}$ na unidade, estando assim constituída: número de registro hospitalar; idade, sexo; data de internação e saída da Unidade, motivo da internação, procedência (Unidade Neonatal, UTIN, Alojamento Conjunto, Pronto Socorro Infantil, Ambulatório, outro hospital), peso, altura, horas/dias de internação.

\subsubsection{Instrumento de medida de carga de trabalho (NAS)}

O índice NAS, (Anexo 6), foi utilizado para avaliar a carga de trabalho de enfermagem. Foi traduzido e validado para a realidade brasileira, demonstrando índices satisfatórios de confiabilidade, permitindo sugerir sua utilização. O NAS é um indicador confiável, válido e estável para mensurar carga de trabalho de enfermagem em UTI de pacientes adultos (Queijo, Padilha, 2004). No entanto, na visão de alguns autores, o NAS não caracteriza exclusividade para esse tipo de paciente e para esse campo de estudo (Miranda et al, 2003).

O instrumento NAS foi aplicado em cada um dos RN, por meio da avaliação da assistência requerida pelos pacientes, de acordo com os indicadores do instrumento e quando necessário completado com as informações relatadas pela equipe de enfermagem.

O instrumento NAS utilizado neste estudo, tal como proposto por Miranda et al (2003), está constituído por 23 itens referentes às intervenções terapêuticas e aos cuidados de enfermagem: 1. Monitorização e controles; 2 . Investigações laboratoriais; 3. Medicação, exceto drogas vasoativas; 4. Procedimentos de higiene; 5. Cuidados com drenos; 6. Mobilização e posicionamento; 7. Suporte e cuidados aos pacientes e familiares; 8. Tarefas administrativas e gerenciais; 9. Suporte ventilatório; 8. Tarefas administrativas e gerenciais; 9. Suporte respiratório; 10. Cuidado com vias aéreas artificiais; 11. Tratamento para melhora da função pulmonar; 12. Medicação vasoativa; 13. Reposição intravenosa de 
grandes perdas; 14. Monitorização de átrio esquerdo; 15. Reanimação cardiorrespiratória; 16. Técnicas de hemofiltração; 17. Medida quantitativa do débito urinário; 18. Suporte neurológico; 19. Tratamento da acidose/alcalose metabólica; 20. Hiperalimentação intravenosa; 21. Alimentação enteral; 22. Intervenções específicas na unidade; 23. Intervenções específicas fora da unidade.

Os itens 1, 4, 6, 7 e 8 são compostos de subitens, diferenciados de acordo com o tempo gradativo despendido nas atividades propostas, que por sua vez, são mutuamente excludentes.

O cálculo total do NAS para cada paciente representa a somatória dos valores atribuídos a cada um dos 23 itens. O escore total do NAS expressa em porcentagem o tempo gasto pela equipe de enfermagem na assistência ao $\mathrm{RN}$, nas 24 horas, sendo seu valor máximo de 176,8\% (Miranda et al, 2003).

De acordo com a definição 100 pontos NAS equivalem a 100\% do tempo de um profissional de enfermagem nas $24 \mathrm{~h}$, não sendo normalmente incluídos nos métodos tradicionais de medida de produção, por exemplo, taxa de ocupação de unidade ou instrumentos de classificação que desconsideram informações sobre permanências menores que $24 \mathrm{~h}$. Cada ponto NAS equivale há 14,4 minutos, ou 0,24 horas.

Para nortear a aplicação do NAS aos RN do estudo, fez-se necessário definir alguns critérios. Um tutorial serviu de apoio na aplicação do instrumento, permitindo uma orientação mais detalhada sobre os diversos aspectos que podem ou não ser incluídos em cada item, e da necessidade de adaptar alguns itens para a aplicação, mantendo a relação lógica com a estrutura do instrumento. A seguir estão descritas as definições do tutorial (Bochembuzio, 2002; Padilha et al, 2005):

\subsubsection{TUTORIAL PARA CATEGORIZAÇÃO DE CUIDADOS ASSISTENCIAIS}

\section{ATIVIDADES BÁSICAS}




\section{MONITORIZAÇÃO E CONTROLES}

1a. Sinais vitais horários, cálculo e registro regular do balanço hídrico ( 4,5 pontos): Aplicam-se ao $\mathrm{RN}$ que se monitoram os sinais vitais horários e/ou cálculo e registro regular do balanço hídrico. Será pontuado o RN estável sob ponto de vista respiratório e hemodinâmico.

1b. Presença à beira do leito e observação ou atividade contínua por 2 horas ou mais em algum plantão, (para que um profissional possa sair do lado do RN outro deverá ficar em seu lugar), por razões de segurança, gravidade ou terapia, tais como: ventilação mecânica não invasiva, desmame, agitação, confusão mental, posição prona, procedimentos de doação de órgãos, preparo e administração de fluidos ou medicação, auxílio em procedimentos específicos (passagem de cateter central de inserção periférica, medida de pressão arterial nos 4 membros, avaliação da dor no RN, medidas relacionadas à prevenção de quedas, fugas, controle de temperatura de 2/2 horas ou 4/4 horas, monitorização cardíaca, peso em incubadora, peso em incubadora em gôndola, desmame de $\mathrm{O}_{2}$, medida de irradiância da fototerapia, queda de saturação, acesso venoso difícil, cuidados com sondas gástricas, incoordenação de sucção, auxílio na amamentação, RN com sucção débil em seio materno, sendo necessário: complemento em copo ou mamadeira, ordenha mamária, posição canguru, informações sobre o banco de leite (12,1 pontos);

1c. Presença à beira do leito e observação ou atividade contínua por 4 horas ou mais (para que um profissional possa sair do lado do $\mathrm{RN}$ outro deverá ficar em seu lugar), por razões de segurança, gravidade ou terapia, tais como os exemplos acima (19,6 pontos);

2.INVESTIGAÇÕES LABORATORIAIS: bioquímicas e microbiológicas (4,3 pontos):

Pontua-se o RN submetido à coleta de material biológico para investigação laboratorial (coleta de fezes e urina por saco coletor, coleta de secreções), realização de dosagem de glicemia capilar, verificação e controle de glicosúria e cetonúria, coleta do teste do pezinho, à beira do leito; 
3. MEDICAÇÃO, exceto drogas vasoativas (5,6 pontos):

Pontua-se o RN submetido a preparo e administração de qualquer medicação, vacinas, vitamina $\mathrm{K}$, psicotrópicos, exceto drogas vasoativas, independente da quantidade, freqüência ou via de administração. Para $R N$ existe o ajuste das dosagens prescritas.

\section{PROCEDIMENTOS DE HIGIENE}

4a. Realização de procedimentos de higiene tais como: curativos de lesões de pele, incisão cirúrgica; curativos de cateteres centrais (flebotomias, cateter umbilical) e periféricos (PICC, acesso venoso periférico); cuidados com o ostoma; troca de roupa de cama (incubadora, berço aquecido, berço comum, biliberço); troca de fralda; troca de vestimentas; banho de imersão; higiene corporal do paciente em situações especiais (incontinência, diarréia, evacuações líquidas, vômito, sangramentos, queimaduras, múltiplas lesões, eviscerações ou lesão de grande extensão, curativos cirúrgicos complexos com irrigação, peso inferior a $800 \mathrm{~g}$ ); procedimentos especiais (ex. isolamento - $\mathrm{RN}$ com necessidade de restrição de ambiente - sala de precauções de contato/gotículas/aerossóis); cuidados com equimoses e hiperemias perineais, etc, que contínuos ou somados durarem menos que 2 horas ( 4,1 pontos);

4b. Realização de procedimentos de higiene freqüente, 3 a 4 vezes, que, contínuos ou somados, durarem mais do que 2 horas, em algum plantão (16,5 pontos);

4c. Realização de procedimentos de higiene freqüente, mais de 4 vezes, que, contínuos ou somados, durarem mais do que 4 horas, em algum plantão (20,0 pontos);

5. CUIDADOS COM DRENOS. Todos, exceto sonda gástrica. (1,8 pontos): Consideram-se cuidados todos os drenos (dreno de tórax) e sondas, exceto sonda gástrica; 
6. MOBILIZAÇÃO E POSICIONAMENTO incluindo procedimentos tais como: mudança de decúbito, mobilização do paciente, transferência de leito (berço/ incubadora), transporte (p.ex. paciente imóvel, tração, posição prona), mobilização para acalmar o RN, manter o RN no colo, posicionamento para melhorar o padrão respiratório, utilização de mecanismos para posicionamento (ninho, rampa e suspensório, contenções devido à restrição de movimentos como fratura de clavícula):

6a. Aplica-se para o RN submetido a procedimento(s) realizado(s) 3 a 6 vezes por 1 profissional de enfermagem (5,5 pontos);

6b. Aplica-se para o RN submetido a procedimento(s) realizado(s) mais do que 6 vezes ou com 2 profissionais de enfermagem em qualquer freqüência (12,4 pontos);

6c. Aplica-se para o RN submetido a procedimento(s) realizado(s) com 3 ou mais profissionais de enfermagem em qualquer freqüência (17,0 pontos);

\section{SUPORTE E CUIDADOS AOS FAMILIARES E PACIENTES incluindo} procedimentos tais como telefonemas, entrevistas, aconselhamento. Freqüentemente, o suporte e cuidado, sejam aos familiares ou aos pacientes permitem a equipe continuar com outras atividades de enfermagem (ex: comunicação com o paciente e à família durante procedimentos de higiene, comunicação com os familiares enquanto presente à beira do leito observando o paciente, apresentação da unidade e dos equipamentos à mãe, ao pai do $\mathrm{RN}$ e demais familiares, apresentação do RN à mãe, ao pai e demais familiares):

7a. Aplica-se para suporte e cuidados aos familiares e RN que requerem dedicação exclusiva (não simultânea com outro tipo de assistência), por até 1 hora contínua ou fracionada, pessoalmente e/ou por telefone para explicar condições clínicas, lidar com a dor e angústia, lidar com circunstâncias familiares difíceis, tais como: ansiedade pelo medo de perder o RN internado; óbito materno. (4,0 pontos);

7b. Aplica-se para suporte e cuidados aos familiares e RN que requerem dedicação exclusiva (não simultânea com outro tipo de assistência), por 3 horas 
ou mais, contínuas ou fracionadas, pessoalmente e/ou por telefone para auxiliar em situações como morte, circunstâncias trabalhosas, problemas de linguagem, familiares hostis (32,0 pontos);

\section{TAREFAS ADMINISTRATIVAS E GERENCIAIS}

8a. Aplica-se a todo RN submetido à realização de tarefas de rotina tais como: processamento de dados clínicos, solicitação de exames, troca de informações profissionais (por ex. passagem de plantão, visitas clínicas), aplicação e documentação do processo de enfermagem, preparo e acompanhamento profissional de enfermagem ou estudante para realização de atividade específica com o $\mathrm{RN}$, que tenham durado até 1 hora, contínuas ou fracionadas (4,2 pontos);

8b. Aplica-se a todo $\mathrm{RN}$ submetido à realização de tarefas administrativas e gerenciais que requerem dedicação integral por cerca de 2 horas em algum plantão tais como: atividades de pesquisa, aplicação de protocolos, procedimentos de admissão e alta; procedimentos de preparo, acompanhamento e transferência do RN para outra unidade ou outra instituição, elaboração de relatórios para notificação sobre ocorrências e encaminhamentos a outros profissionais ou instituições, elaboração e implementação de protocolos de pesquisa a serem desenvolvidos junto ao $\mathrm{RN}$, participação do enfermeiro em reunião clínica com a família do $\mathrm{RN}$ (23,2 pontos);

8c. Aplica-se a todo $\mathrm{RN}$ submetido à realização de tarefas administrativas e gerenciais que requerem dedicação integral por cerca de 4 horas ou mais de tempo em algum plantão tais como: morte e procedimentos de doação de órgãos, coordenação com outras disciplinas (30,0 pontos).

\section{SUPORTE VENTILATÓRIO}

9. Suporte respiratório. Presença de qualquer forma de ventilação mecânica; ventilação assistida: com ou sem pressão expiratória final positiva; com ou sem relaxantes musculares; respiração espontânea: com ou sem pressão expiratória final positiva (e.g. CPAP ou BIPAP, halo, nebulização contínua, nebulização às 
dietas, cateter nasal); com ou sem tubo endotraqueal; oxigênio suplementar por qualquer método (1,4 pontos);

10. Realização de cuidado com vias aéreas artificiais (higiene nasal, remoção de crostas labiais). Tubo endotraqueal ou cânula de traqueostomia (posicionamento, troca de curativo/fixação) uma vez ou mais nas 24 horas (1,8 pontos);

11. Realização de tratamento para melhora da função pulmonar e/ou fisioterapia respiratória e/ou terapia inalatória e/ou aspiração endotraqueal uma vez ou mais nas 24 horas, tais como: obstrução nasal, aspirações nas vias aéreas superiores e tubo endotraqueal. (4,4 pontos);

\section{SUPORTE CARDIOVASCULAR}

12. Aplica-se ao $\mathrm{RN}$ que recebe medicação vasoativa instalada, independente do tipo e dose (1,2 pontos);

13. Aplica-se ao $\mathrm{RN}$ que recebe reposição intravenosa de grandes perdas de fluidos. Administração de fluídos, mas independente do tipo de fluido administrado: soroterapia, sangue e hemoderivados (2,5 pontos);

14. Monitorização do átrio esquerdo. Cateter da artéria pulmonar com ou sem medida de débito cardíaco (1,7 pontos);

- Não se aplica. Não é prática usar cateter de artéria pulmonar em RN.

15. Aplica-se ao RN que é submetido à reanimação cardiorrespiratória com exceção de soco precordial. (7,1 pontos);

\section{SUPORTE RENAL}

16. Realização de técnicas de hemofiltração. Técnicas dialíticas (qualquer terapia de substituição renal) com qualquer duração. (7,7 pontos);

17. Realização de medida quantitativa do débito urinário, com qualquer duração e freqüência, sejam por sonda vesical de demora; peso de fraldas; saco coletor; e/ou qualquer outro tipo de controle de diurese. (7,0 pontos);

\section{SUPORTE NEUROLÓGICO}


18. Presença, em qualquer duração, de cateter de pressão intracraniana/ medida de pressão intracraniana/ cuidados com derivação ventricular externa ou periférica, reação a estímulos (1,6 pontos);

\section{SUPORTE METABÓLICO}

19. Realização de tratamento da acidose/alcalose metabólica complicada. (1,3 pontos);

20. Administração de hiperalimentação intravenosa, com qualquer duração: uso de NPP. (2,8 pontos);

21. Administração de alimentação enteral, com qualquer duração. Através de tubo gástrico ou via gastrintestinal, por exemplo: jejunostomia. (1,3 pontos);

\section{INTERVENÇÕES ESPECÍFICAS}

22. Realização de intervenções específicas na unidade, em qualquer freqüência. Intubação endotraqueal, cardioversão, endoscopias, cirurgia de emergência, lavagem gástrica, exsangúíneotransfusão. Intervenções de rotina sem conseqüências diretas para as condições clínicas do paciente, tais como: Raio X, ecografia, eletrocardiograma, curativos ou inserção de cateteres venosos ou arteriais não estão incluídos (2,8 pontos);

23. Realização de intervenções específicas fora da unidade nas últimas 24 horas. Procedimentos diagnósticos ou cirúrgicos (preparo); acompanhamento e transferência do RN para outra unidade, ou outra instituição; realização de exames e procedimentos em outra unidade, ou em outro hospital acompanhados por um profissional de enfermagem, Por exemplo: fundo de olho; avaliação neurológica; exames diagnósticos. (1,9 pontos); 


\subsection{3. Índice de medida de gravidade}

Para caracterizar a população do estudo quanto à gravidade, todas as crianças com idade gestacional menor que 31 semanas e peso de nascimento menor que $1500 \mathrm{~g}$, tiveram uma classificação baseada no índice CRIB (Figura 8), referente aos dados das primeiras 12 horas de internação, inclusive os $\mathrm{RN}$ que já se encontravam internados no primeiro dia do estudo. Apenas 4 crianças atenderam a esses critérios padronizados pelo índice CRIB.

O objetivo da aplicação deste escore é apresentar o resultado aplicado em todos os RN internados, como preditor de óbito neonatal em UTI. Para esse estudo grande parte da amostra não atendeu aos critérios exigidos pelo índice.

Por outro lado, os RN submetidos à aplicação do CRIB foram os que tiveram maior tempo de permanência no hospital provavelmente devido às condições de nascimento, ao ganho de peso e ao tipo de procedimento realizado na reanimação e durante toda a internação. Não houve nenhum caso de óbito neonatal, na amostra estudada.

\subsubsection{Medida da carga diária de cuidado por recém-nascido na Unidade Neonatal e Unidade de Terapia Intensiva Neonatal}

Inicialmente, é necessário, para facilitar a leitura e compreensão deste trabalho estabelecer uma terminologia uniformizada para diferenciar o trabalho requerido pelos pacientes e o trabalho disponibilizado pelos profissionais de enfermagem. Assim sendo, chamar-se-á "carga de trabalho requerido" a quantidade de trabalho necessária para prestar assistência aos pacientes; por outro lado chamaremos de "tempo de trabalho disponível" a quantidade de trabalho disponível na unidade para prestar a assistência ao paciente. Embora conceitualmente diferentes, eles são medidos pela mesma relação de grandezas: horas/dia/RN. 
Para comparar o tempo de assistência disponível para o cuidado na Unidade Neonatal e UTIN com a carga de trabalho requerida pela pontuação NAS e com outros dados similares da literatura foi necessário proceder-se da seguinte forma:

3.4.4.1 Tempo médio de assistência disponível em serviço nas unidades, calculado a partir do valor da moda do quantitativo da equipe de profissionais de enfermagem que estavam trabalhando na unidade, durante o período da amostra, ou seja:

$$
\boldsymbol{h}_{k}=\frac{\boldsymbol{q}_{k} \cdot \boldsymbol{t}}{\bar{n}}
$$

onde:

$\boldsymbol{h}_{\boldsymbol{k}}=$ tempo médio de trabalho (em horas) de cuidado, por RN, segundo a categoria profissional $\boldsymbol{k}$;

$\boldsymbol{q}_{\boldsymbol{k}}=$ valor da moda da quantidade diária de profissionais da categoria profissional $\boldsymbol{k}$;

$\boldsymbol{t}=$ jornada de trabalho dos profissionais;

$\bar{n}=$ quantidade média de RN.

3.4.4.2. Tempo médio de assistência requerido pelos $R N$, segundo a pontuação média do NAS (cada ponto NAS requer 14,4 minutos de assistência ou 0,24 horas), tomou-se o valor da pontuação média NAS e multiplicou-se por 14,4, ou seja:

$$
\begin{aligned}
& \text { - Unidade Neonatal }=\overline{\text { NAS }} \times 14,4 \mathrm{~min} \\
& \text { - UTIN }=\overline{\text { NAS }} \times 14,4 \mathrm{~min}
\end{aligned}
$$


3.4.4.3. Tempo médio de assistência, segundo Resolução COFEN no 293/04 (2004): 9,4 horas/dia/paciente, valor recomendado para a assistência semiintensiva em Unidade Neonatal e de 17,9 horas/dia/RN valor recomendado para a assistência intensiva.

3.4.4.4. Tempo médio de trabalho disponibilizado segundo a série histórica estudada por Rogenski (2006), onde foi encontrado um valor médio do tempo de cuidado dentro de um período amostral de cinco anos, correspondendo aos anos de 2000 a 2005, para Unidade Neonatal do HU-USP de 11,4 horas/dia/RN. A UTIN não foi estudada pela autora.

Rogenski (2006) realizou uma pesquisa com o objetivo de identificar e analisar o tempo médio de trabalho de assistência de enfermagem no HU-USP, no período de 2001 a 2005. A autora determinou as variáveis intervenientes para 0 cálculo do tempo médio de trabalho de assistência de enfermagem, permitindo visualizar a distribuição dos leitos, a quantidade média diária de RN assistidos e a quantidade média de pessoal existente nas unidades de internação.

3.4.4.5. Tempo médio de assistência estabelecido para UTI tipo III pela Portaria do Ministério da Saúde oㅜ 3432/98 (Brasil, 1998): 19,2 horas/dia/paciente.

O Ministério da Saúde, através de sua Portaria no 3432/98 (1998) estabeleceu critérios de classificação para as unidades de tratamento intensivo (UTI), de acordo com a tecnologia incorporada, especialização de recursos humanos e área física disponível. Considera que para ser classificada como tipo II a UTI deve contar com uma equipe de enfermagem composta por:

- 1 enfermeiro coordenador, exclusivo da unidade, responsável pela área da enfermagem;

- 1 enfermeiro, exclusivo da unidade, para cada 10 leitos ou fração, por turno de trabalho; 

- 1 técnico ou auxiliar de enfermagem para cada 2 leitos ou fração, por turno de trabalho.

As Unidades de Terapia Intensiva especializadas, para serem classificadas como tipo III devem, além da equipe básica exigida para as UTI do tipo II, contar com:
- 1 enfermeiro exclusivo da unidade para cada 5 leitos, por turno de trabalho.

As relações de proporção enfermagem/leito, indicadas pelo Ministério da Saúde no 3432/98 (1998), podem ser transformadas em horas de assistência de enfermagem, conforme demonstrado, obtendo-se:

\section{Para UTI tipo II:}

- 1 enfermeiro $\times 24$ horas/dia $\div 10$ leitos = 2,4 horas/leito/dia;

- 1 técnico ou auxiliar de enfermagem $\times 24$ horas/dia $\div 2$ leitos $=12$ horas/leito/dia;

Total de horas de assistência de enfermagem = 14,4 horas/leito/dia, sendo $16,7 \%$ atribuídas ao enfermeiro e $83,3 \%$ aos técnicos ou auxiliares de enfermagem.

\section{Para UTI tipo III:}
- 1 enfermeiro $\times 24$ horas/dia $\div 10$ leitos = 2,4 horas/leito/dia;
- 1 enfermeiro $\times 24$ horas/dia $\div 5$ leitos $=4,8$ horas/leito/dia;
- 1 técnico ou auxiliar de enfermagem $\times 24$ horas/dia $\div 2$ leitos = 12 horas/leito/dia;

Total de horas de assistência de enfermagem $=19,2$ horas/leito/dia, das quais $37,5 \%$ são atribuídas aos enfermeiros e $62,5 \%$ aos técnicos ou auxiliares de enfermagem. 


\subsection{Análise e tratamento dos dados}

Após a coleta das amostras, os dados foram ordenados e armazenados em planilhas eletrônicas desenvolvidas no programa Microsoft ${ }^{\circledR}$ Excel 2003, de maneira que as pontuações da avaliação diária das atividades NAS de cada um dos RN amostrados foram lançadas numa única coluna da planilha, e as pontuações de cada atividade NAS de todos os RN amostrados podem ser vistas numa linha da mesma planilha (Anexo 7 e 8).

\subsubsection{Avaliação dos quantitativos diários da equipe de enfermagem}

Inicialmente foi obtida a soma dos pontos NAS de cada um dos RN amostrados. Em seguida foi calculado o total diário dos pontos NAS dos RN internados em cada um dos dias do período amostral. A partir desses dados, calculou-se o quantitativo diário $\boldsymbol{Q}$ da equipe de profissionais de enfermagem requerido para o cuidado dos $\boldsymbol{i} \mathrm{RN}$ internados na unidade através da seguinte expressão:

$$
Q=\frac{24}{6} \cdot \frac{\sum_{I=1}^{n} N A S_{i}}{100}
$$

Por outro lado, os dados obtidos pela amostragem do quantitativo de profissionais de enfermagem disponibilizada para o serviço nos mesmos dias do período amostral foram organizados em uma tabela (Figura 18).

A análise estatística descritiva dos quantitativos diários de profissionais de enfermagem obtidos a partir da soma dos pontos NAS de cada um dos RN e a partir da amostra da equipe de profissionais de enfermagem em serviço permitiu:

- obter os valores da média e mediana desses dados,

- obter o grau de dispersão desses dados em torno de suas médias; 
- ter uma idéia preliminar sobre o grau de simetria da distribuição de freqüência desses dados quando se faz a comparação dos valores de suas respectivas média e mediana;

- obter o intervalo de confiança no qual o valor da média tem $95 \%$ de probabilidade de ocorrer;

- obter o valor da moda para os dados em que sua dispersão tem origem nas variações da equipe de profissionais (como no caso dos profissionais em serviço), em determinados dias, em decorrência de problemas administrativos como faltas ou folgas não cobertas.

Para auxiliar a análise dos dados dessas unidades foi calculado o Coeficiente $\boldsymbol{r}$ de Pearson, por meio do qual se pode estabelecer o grau de correlação entre os dados referentes à quantidade de pacientes (RN) nelas internados com os dados referentes ao quantitativo de profissionais de enfermagem disponíveis em serviço.

O valor da carga média diária de serviço por RN em cada unidade estudada foi calculado, ou obtido das seguintes fontes:

- valor da moda da equipe disponível em serviço na Unidade Neonatal e UTIN;

- valor médio diário da equipe requerido pela pontuação NAS amostradas na Unidade Neonatal e UTIN;

- Resolução COFEN nº 293/04 (2004) que recomenda cuidados semiintensivos para $\mathrm{RN}$ internados em Unidade Neonatal e cuidados intensivos para pacientes internados em UTIN;

- obtida do valor da média histórica (5 anos) da Unidade Neonatal encontrado por Rogenski (2006);

- valor recomendado pela Portaria do Ministério da Saúde n³432/98 (1998).

Os valores diários do quantitativo de profissionais de enfermagem requeridos para o cuidado de enfermagem, calculados mediante a utilização dos valores médios obtidos, conforme explicado anteriormente, foram comparados estatisticamente através do teste $t$ de Student e do teste LSD (Menor Diferença 
Significativa) para verificar se suas diferenças foram significativas ou não ao nível de confiança de $95 \%$.

\subsubsection{Avaliação geral da aplicação do instrumento}

A avaliação do instrumento NAS foi verificada pela análise de cada uma das atividades NAS da amostra. Para efetuar-se esta análise foram calculadas as seguintes estatísticas: a soma dos pontos NAS; a distribuição percentual dos pontos em relação ao total de pontos NAS da amostra; quantidade de dias em que ocorreu a atividade; quantidade de RN amostrados por atividade NAS; percentual da quantidade de RN amostrados por atividade; média diária dos pontos NAS; dispersão da média diária.

Uma simplificação do instrumento pode ser sugerida pela análise da ocorrência de cada uma das atividades. As atividades que não ocorreram no período poderiam ser suprimidas do instrumento, concorrendo para a simplificação do mesmo.

A comparação dos instrumentos já simplificados permite caracterizar a Unidade Neonatal e UTIN através de suas atividades próprias.

\subsection{Aspectos Éticos}

O projeto de pesquisa foi aprovado pela Câmara de Pesquisa e Comitê de Ética em Pesquisa do Hospital Universitário da Universidade de São Paulo (Anexo 9). 


\section{APRESENTAÇÃO E DISCUSSÃO DOS RESULTADOS}

\subsection{Caracterização da amostra dos recém-nascidos quanto aos dados demográficos e clínicos.}

Do total de $59 \mathrm{RN}$ que integraram a amostra do estudo, 48 foram admitidos na Unidade Neonatal e 11 na UTIN. A distribuição segundo as diferentes variáveis encontram-se descritas a seguir e apresentadas nas Tabela 1 e 2.

Os dados da Tabela 1 mostram que a quantidade dos RN do sexo masculino $(47,9 \%)$ e do sexo feminino $(52,1 \%)$ foi praticamente semelhante. Quanto à idade gestacional (IG), predominou os $\mathrm{RN}$ nascidos com mais de 38 semanas $(81,2 \%)$, seguidos daqueles com IG entre 33 semanas e 37 semanas $(16,7 \%)$. Apenas $2,1 \%$ dos $\mathrm{RN}$ tinham IG inferior a 32 semanas.

Com relação às horas de vida no momento da primeira coleta de dados, $68,7 \%$ dos RN foram avaliados quando tinham entre $24 \mathrm{~h}$ e $48 \mathrm{~h}$ de vida, $4,2 \%$ quando tinham entre $49 \mathrm{~h}$ e $72 \mathrm{~h}$ de vida e $27,1 \%$ com mais de $72 \mathrm{~h}$ de vida. Quanto ao tipo de parto, $66,7 \%$ dos $\mathrm{RN}$ nasceram de parto normal, $31,2 \%$ de parto cesárea e 2,1\% de parto fórcipe.

Observou-se que grande parte dos pacientes foi procedente do Alojamento Conjunto (43,8\%) e Centro Obstétrico (31,2\%). Em 18,7\% das admissões, os RN vieram do Pronto Socorro Infantil, em 4,2\% da UTIN e em 2,1\% do Ambulatório. No período do estudo a Unidade Neonatal não recebeu $\mathrm{RN}$ de outros hospitais.

Em relação ao peso de nascimento, $58,4 \%$ dos casos estiveram entre $2500 \mathrm{~g}$ e $3499 \mathrm{~g}, 22,9 \%$ superior a $3500 \mathrm{~g}$ e $18,7 \%$ entre $1500 \mathrm{~g}$ e $2499 \mathrm{~g}$. Grande parte dos RN permaneceu menos de sete dias internados $(83,3 \%)$.

Verificou-se que vários foram os motivos para as internações. Houve predomínio das alterações infecciosas $(27,1 \%)$, seguidas das alterações pulmonares associadas à outras doenças (18,7\%), alterações pulmonares e cardiológicas com 12,5\% cada uma, icterícia e outras doenças (10,4\%), alterações metabólicas $(6,3 \%)$ e alterações neurológicas com 2,1\%. 


\begin{tabular}{|c|c|c|}
\hline \multirow{2}{*}{ Variáveis } & \multicolumn{2}{|c|}{ Geral (n 48) } \\
\hline & $\mathbf{n}$ & $\%$ \\
\hline \multicolumn{3}{|l|}{ Sexo } \\
\hline Masculino & 23 & 47,9 \\
\hline Feminino & 25 & 52,1 \\
\hline \multicolumn{3}{|l|}{ Idade Gestacional } \\
\hline$<32$ sem & 1 & 2,1 \\
\hline 33 sem - 37 sem & 8 & 16,7 \\
\hline > $38 \mathrm{sem}$ & 39 & 81,2 \\
\hline \multicolumn{3}{|l|}{ Horas de Vida } \\
\hline $24 h-48 h$ & 33 & 68,7 \\
\hline $49 h-72 h$ & 2 & 4,2 \\
\hline$>72 \mathrm{~h}$ & 13 & 27,1 \\
\hline \multicolumn{3}{|l|}{ Tipo de parto } \\
\hline normal & 32 & 66,7 \\
\hline cesárea & 15 & 31,2 \\
\hline fórcipe & 1 & 2,1 \\
\hline \multicolumn{3}{|l|}{ Procedência } \\
\hline centro obstétrico & 15 & 31,2 \\
\hline alojamento conjunto & 21 & 43,8 \\
\hline unidade neonatal & 0 & 0 \\
\hline pronto socorro infantil & 9 & 18,7 \\
\hline UTI neonatal & 2 & 4,2 \\
\hline ambulatório & 1 & 2,1 \\
\hline outro hospital & 0 & 0 \\
\hline \multicolumn{3}{|l|}{ Peso ao Nascer } \\
\hline $500 g-999 g$ & 0 & 0 \\
\hline $1000 g-1499 g$ & 0 & 0 \\
\hline $1500 g-2499 g$ & 9 & 18,7 \\
\hline $2500 g-3499 g$ & 28 & 58,4 \\
\hline$>3500 \mathrm{~g}$ & 11 & 22,9 \\
\hline \multicolumn{3}{|l|}{ Tempo de Permanência } \\
\hline$<7$ dias & 40 & 83,3 \\
\hline $8-15$ dias & 8 & 16,7 \\
\hline $16-20$ dias & 0 & 0 \\
\hline 21 - 30 dias & 0 & 0 \\
\hline$>30$ dias & 0 & 0 \\
\hline \multicolumn{3}{|l|}{ Motivo da internação } \\
\hline alterações pulmonares & 6 & 12,5 \\
\hline alterações pulmonares e outras* & 9 & 18,7 \\
\hline alterações infecçiosas & 13 & 27,1 \\
\hline icterícia & 5 & 10,4 \\
\hline alterações cardiológicas & 6 & 12,5 \\
\hline alterações neurológicas & 1 & 2,1 \\
\hline alterações metabólicas & 3 & 6,3 \\
\hline outros $* *$ & 5 & 10,4 \\
\hline $\begin{array}{l}\text { Nota: }{ }^{*} \text { outras associadas às descritas } \\
{ }^{* *} \text { outros: causas maternas, tocotrauma }\end{array}$ & & \\
\hline
\end{tabular}

Tabela 1 - Distribuição absoluta e percentual de RN internados na Unidade Neonatal, segundo dados demográficos e clínicos, no período de 06 de novembro de 2006 a 06 de dezembro de 2006. HU-USP. São Paulo, 2006. 
A Tabela 2 mostra que a admissão de $R N$ do sexo masculino $(63,6 \%)$ foi predominante em relação à do sexo feminino (36,4\%). Quanto à idade gestacional (IG), houve um equilíbrio entre os valores: $36,4 \%$ para os $\mathrm{RN}$ nascidos com mais de 38 semanas e para os com IG inferior a 32 semanas. 27,2\% para aqueles com IG entre 33 semanas e 37 semanas.

Com relação às horas de vida no momento da coleta de dados, 72,8\% dos $\mathrm{RN}$ foram avaliados quando tinham entre $24 \mathrm{~h}$ e $48 \mathrm{~h}$ de vida, e 27,2\% com mais de $72 \mathrm{~h}$ de vida. Nenhum dos RN foi admitido entre $49 \mathrm{~h}$ e $72 \mathrm{~h}$ de vida. Verificou-se que $54,6 \%$ dos RN nasceram de parto cesárea, 27,2\% de parto normal, e 18,2\% de parto fórcipe.

Observou-se que grande parte dos pacientes foi procedente do Centro Obstétrico (63,6\%), em 18,2\% da Unidade Neonatal e 18,2\% de outro hospital. A UTIN não recebeu RN do Alojamento Conjunto, do Pronto Socorro Infantil e do Ambulatório, no período do estudo.

Em relação ao peso de nascimento, 45,5\% dos casos tiveram peso entre $1500 \mathrm{~g}$ e $2499 \mathrm{~g}, 27,2 \%$ entre $2500 \mathrm{~g}$ e 3499g, e 9,1\% estiveram distribuídos nas crianças com peso inferior a $1499 \mathrm{~g}$ e superior a $3500 \mathrm{~g}$. Grande parte dos RN permaneceu mais de 30 dias internados (54,5\%). Prevaleceram alterações pulmonares associadas a outras doenças em $90,9 \%$ dos casos. 


\begin{tabular}{|c|c|c|}
\hline \multirow[b]{2}{*}{ Variáveis } & \multicolumn{2}{|c|}{ Geral (n 11) } \\
\hline & $\mathbf{n}$ & $\%$ \\
\hline \multicolumn{3}{|l|}{ Sexo } \\
\hline Masculino & 7 & 63,6 \\
\hline Feminino & 4 & 36,4 \\
\hline \multicolumn{3}{|l|}{ Idade Gestacional } \\
\hline$<32$ sem & 4 & 36,4 \\
\hline 33 sem - 37 sem & 3 & 27,2 \\
\hline$>38$ sem & 4 & 36,4 \\
\hline \multicolumn{3}{|l|}{ Horas de Vida } \\
\hline $24 h-48 h$ & 8 & 72,8 \\
\hline $49 h-72 h$ & 0 & 0 \\
\hline$>72 \mathrm{~h}$ & 3 & 27,2 \\
\hline \multicolumn{3}{|l|}{ Tipo de parto } \\
\hline normal & 3 & 27,2 \\
\hline cesárea & 6 & 54,6 \\
\hline fórcipe & 2 & 18,2 \\
\hline \multicolumn{3}{|l|}{ Procedência } \\
\hline centro obstétrico & 7 & 63,6 \\
\hline alojamento conjunto & 0 & 0 \\
\hline unidade neonatal & 2 & 18,2 \\
\hline pronto socorro infantil & 0 & 0 \\
\hline UTI neonatal & 0 & 0 \\
\hline ambulatório & 0 & 0 \\
\hline outro hospital & 2 & 18,2 \\
\hline \multicolumn{3}{|l|}{ Peso ao Nascer } \\
\hline $500 g-999 g$ & 1 & 9,1 \\
\hline $1000 g-1499 g$ & 1 & 9,1 \\
\hline $1500 g-2499 g$ & 5 & 45,5 \\
\hline $2500 g-3499 g$ & 3 & 27,2 \\
\hline$>3500 \mathrm{~g}$ & 1 & 9,1 \\
\hline \multicolumn{3}{|l|}{ Tempo de Permanência } \\
\hline$<7$ dias & 2 & 18,2 \\
\hline $8-15$ dias & 2 & 18,2 \\
\hline 16 - 20 dias & 0 & 0 \\
\hline 21 - 30 dias & 1 & 9,1 \\
\hline$>30$ dias & 6 & 54,5 \\
\hline \multicolumn{3}{|l|}{ Motivo da internação } \\
\hline alterações pulmonares & 1 & 9,1 \\
\hline alterações pulmonares e outras* & 10 & 90,9 \\
\hline alterações infecçiosas & 0 & 0 \\
\hline icterícia & 0 & 0 \\
\hline alterações cardiológicas & 0 & 0 \\
\hline alterações neurológicas & 0 & 0 \\
\hline alterações metabólicas & 0 & 0 \\
\hline outros** & 0 & 0 \\
\hline $\begin{array}{l}\text { Nota: *outras associadas às descritas } \\
{ }^{*} \text { outros: causas maternas, tocotrauma }\end{array}$ & & \\
\hline
\end{tabular}

Tabela 2 - Distribuição absoluta e percentual de RN internados na UTIN, segundo dados demográficos e clínicos, no período de 06 de novembro de 2006 a 06 de dezembro de 2006 . HUUSP, São Paulo, 2006. 


\subsection{Avaliação da carga de trabalho da equipe de enfermagem, medida através do NAS}

O instrumento NAS (Anexo 6) foi aplicado 301 vezes na Unidade Neonatal e 106 vezes, na UTIN, durante 30 dias. O valor médio diário de $\mathrm{RN}$ internados na Unidade Neonatal foi de $10(95 \%$ IC = 8,74 a 11,26) e na UTIN foi de 3,5 (95\% IC $=3,22$ a 3,78), (Figuras 16 e 17).

\begin{tabular}{|c|c|c|}
\hline \multirow{2}{*}{ DIA SEMANA } & \multicolumn{2}{|c|}{ RECÉM NASCIDOS } \\
\cline { 2 - 3 } & UNIDADE & UTI \\
NEONATAL & NEONATAL \\
\hline dom & 8,7 & 3,7 \\
\hline seg & 10,0 & 3,8 \\
\hline ter & 11,0 & 3,4 \\
\hline qua & 10,4 & 3,4 \\
\hline qui & 10,5 & 3,8 \\
\hline sex & 10,0 & 3,3 \\
\hline sab & 9,0 & 3,5 \\
\hline \hline média & 9,9 & 3,5 \\
\hline desv.padrão & 0,83 & 0,21 \\
\hline C.V.\% & 8,4 & 5,8 \\
\hline
\end{tabular}

Figura 16 - Quantidade média de RN internados na Unidade Neonatal e UTIN, conforme o dia da semana, período de 06 de novembro de 2006 a 06 de dezembro de 2006, HU-USP. São Paulo, 2006. 


\begin{tabular}{|r|c|c|c|}
\hline & \multirow{2}{*}{ DIA DA } & \multicolumn{2}{|c|}{ RECÉM-NASCIDOS } \\
\cline { 3 - 4 } DATA & UNIDADE & UTI \\
\hline $6 / 11 / 2006$ & segANA & NEONATAL & NEONATAL \\
\hline $7 / 11 / 2006$ & ter & 6 & 4 \\
\hline $8 / 11 / 2006$ & qua & 5 & 4 \\
\hline 9/11/2006 & qui & 8 & 5 \\
\hline $10 / 11 / 2006$ & sex & 9 & 4 \\
\hline $11 / 11 / 2006$ & sáb & 8 & 4 \\
\hline $13 / 11 / 2006$ & seg & 9 & 3 \\
\hline $14 / 11 / 2006$ & ter & 13 & 3 \\
\hline $15 / 11 / 2006$ & qua & 10 & 2 \\
\hline $16 / 11 / 2006$ & qui & 10 & 3 \\
\hline $17 / 11 / 2006$ & sex & 6 & 3 \\
\hline $18 / 11 / 2006$ & sáb & 6 & 4 \\
\hline $19 / 11 / 2006$ & dom & 5 & 4 \\
\hline $20 / 11 / 2006$ & seg & 10 & 5 \\
\hline $21 / 11 / 2006$ & ter & 10 & 4 \\
\hline $22 / 11 / 2006$ & qua & 9 & 4 \\
\hline $23 / 11 / 2006$ & qui & 10 & 4 \\
\hline $24 / 11 / 2006$ & sex & 9 & 4 \\
\hline $25 / 11 / 2006$ & sáb & 7 & 3 \\
\hline $26 / 11 / 2006$ & dom & 8 & 3 \\
\hline $27 / 11 / 2006$ & seg & 11 & 3 \\
\hline $28 / 11 / 2006$ & ter & 14 & 3 \\
\hline $29 / 11 / 2006$ & qua & 14 & 3 \\
\hline $30 / 11 / 2006$ & qui & 14 & 3 \\
\hline $1 / 12 / 2006$ & sex & 16 & 2 \\
\hline $2 / 12 / 2006$ & sáb & 15 & 3 \\
\hline $3 / 12 / 2006$ & dom & 13 & 4 \\
\hline $4 / 12 / 2006$ & seg & 14 & 4 \\
\hline $5 / 12 / 2006$ & ter & 15 & 3 \\
\hline $6 / 12 / 2006$ & qua & 14 & 3 \\
\hline \hline NÚMERO DE DIAS & 30 & 30 \\
\hline SOMA & & 301 & 106,0 \\
\hline MEDIA & 10,0 & 3,5 \\
\hline DEDIANA & 10 & 3,5 \\
\hline JTERV. CONFIANÇA DE 95 & 1,26 & 0,28 \\
\hline
\end{tabular}

Figura 17 - Quantidade diária de RN internados na Unidade Neonatal e UTIN, período de 06 de novembro de 2006 a 06 de dezembro de 2006, HU-USP. São Paulo, 2006.

Para facilitar a compreensão dos resultados da pesquisa, optou-se por analisar, separadamente, os dados da Unidade Neonatal e da UTIN. 


\subsubsection{Unidade Neonatal}

A Figura 18 apresenta os dados, obtidos no período amostral (06 de novembro de 2006 a 06 de dezembro de 2006), referentes: à distribuição diária dos $\mathrm{RN}$, ao quantitativo diário de profissionais de enfermagem disponíveis na Unidade; e ao quantitativo diário de profissionais de enfermagem requeridos pela pontuação NAS. 
Constata-se que no período do estudo o valor da moda foi de 5 enfermeiros e de 16 técnicos/auxiliares de enfermagem, perfazendo o total de 21 profissionais de enfermagem, nas 24 horas, para assistirem em média $10(95 \% I C=8,74$ a $11,26)$ RN (Figura 18).

A média de pontuação NAS total dos RN durante o período estudado foi de 668,6 (95\% IC = 587,2 a 750) pontos NAS e a média da pontuação NAS diária por $\mathrm{RN}$ foi de 66,9 (95\% IC = 65,6 a 68,2) pontos NAS (Figura 18).

A partir da pontuação NAS total e da expressão (5) obteve-se o valor da equipe de enfermagem requerida para o cuidado diário dos $\mathrm{RN}$. O valor médio da equipe de enfermagem calculada pela pontuação do NAS obtida da amostra em estudo foi de 26,7 (95\% IC = 23,4 a 30,0) profissionais.

As variações diárias das equipes de enfermagem e dos $\mathrm{RN}$ internados na Unidade Neonatal é melhor visualizada no gráfico da Figura 19.

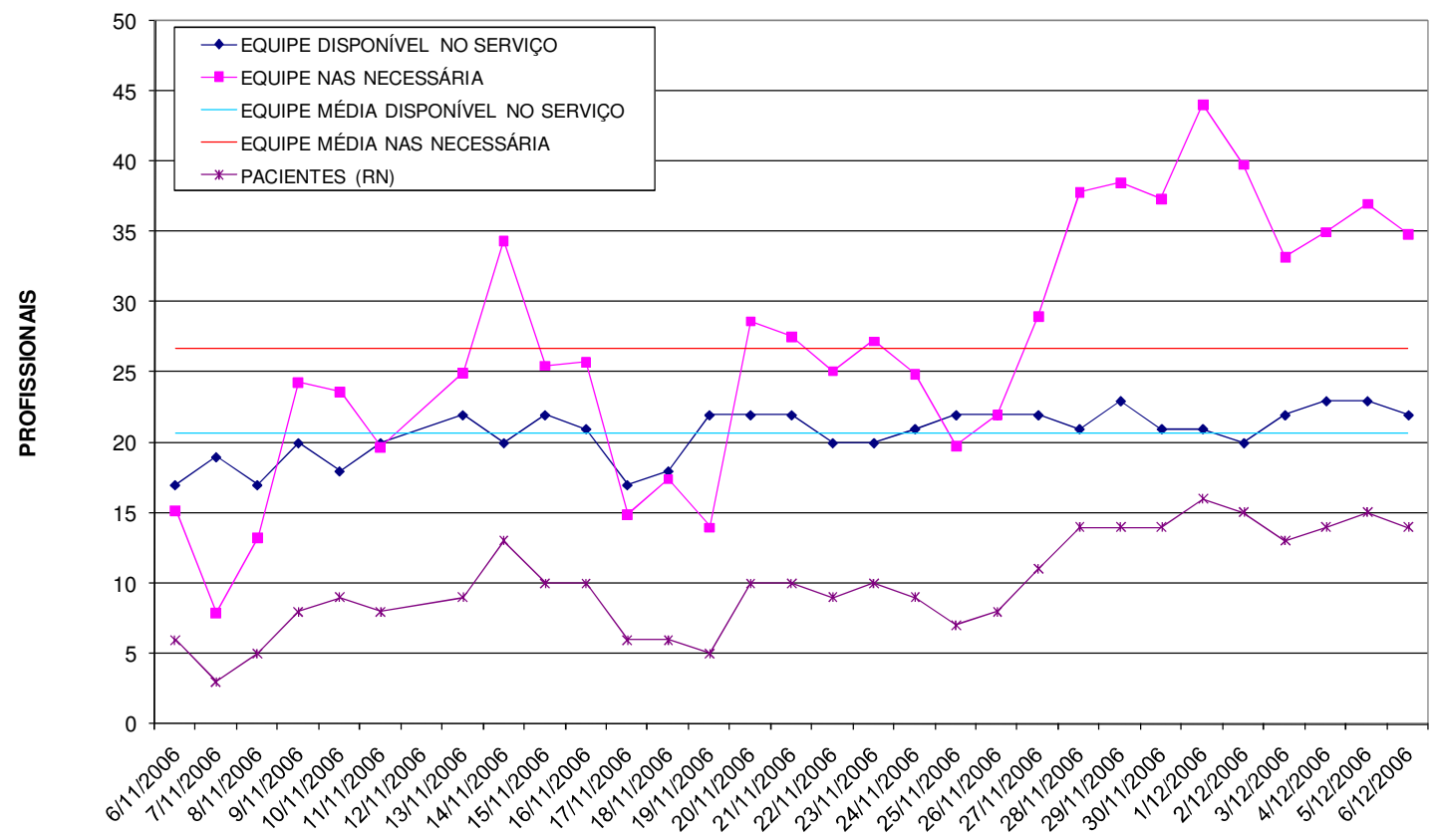

Figura 19 - Comparação entre a equipe de enfermagem requerida pelo NAS e a equipe de enfermagem disponível, período de 06 de novembro de 2006 a 06 de dezembro de 2006, Unidade Neonatal, HU-USP. São Paulo, 2006. 
Observa-se pelo gráfico que o valor da equipe de enfermagem calculada por meio da pontuação NAS ajusta-se melhor as variações de RN internados do que o valor da equipe de enfermagem disponível em serviço, o que indica que o valor da equipe obtida pela pontuação NAS é mais sensível à variação da quantidade diária de $\mathrm{RN}$, pois a resultante sempre acompanha a variação diária dos pacientes da unidade, o mesmo não acontece em relação à equipe de enfermagem disponível na unidade. Essas afirmações são corroboradas pela análise de correlação entre quantidade de $\mathrm{RN}$ internados na unidade com a equipe de enfermagem em serviço e com a equipe de enfermagem requerida pelo NAS. Chegou-se a tal conclusão através do calculo do coeficiente $r$ de Pearson que fornece o grau de correlação dos dados.

Os resultados dessas análises estão sumarizados na Figura 20, onde se observa que houve correlação positiva moderada entre a quantidade de RN internados e o número de profissionais de enfermagem em serviço na unidade, indicando que, em média, o aumento do número de RN suscitou um aumento de profissionais da equipe de enfermagem disponível na Unidade. Já a correlação dos RN internados com a equipe de enfermagem requerida pela pontuação NAS foi fortemente positiva. Essa constatação possibilita a afirmação de que a carga de trabalho calculada pela pontuação NAS é uma função direta da quantidade de RN internados.

\begin{tabular}{|c|c|}
\hline CORRELAÇÃO ENTRE & Coeficiente $\boldsymbol{r}$ de Pearson \\
\hline ENFERMEIRAS EM SERVIÇO XRN & 0,162 \\
\hline AUX.TÉCNICOS EM SERVIÇO X RN & 0,578 \\
\hline \hline EQUIPE EM SERVIÇO X RN & $\mathbf{0 , 5 5 1}$ \\
\hline EQUIPE NAS X RN & $\mathbf{0 , 9 8 9}$ \\
\hline
\end{tabular}

Figura 20 - Correlação entre as quantidades diárias e de RN e de profissionais de enfermagem na Unidade Neonatal, período de 06 de novembro de 2006 a 06 de dezembro de 2006, Unidade Neonatal, HU-USP. São Paulo, 2006.

Destaca-se, ainda, na Figura 20 que durante o período do estudo o número médio de profissionais requerido, segundo o NAS foi $29 \%$ mais elevado do que no 
quadro de profissionais de enfermagem disponível. Esta diferença representa 3,33 vezes o desvio padrão da média da equipe disponível em serviço. O que pode indicar que nessa unidade deve haver sobrecarga de trabalho.

Na Figura 21 apresentam-se os valores médios relativos à carga/tempo de cuidado, por categoria profissional, nas $24 \mathrm{~h}$ por $\mathrm{RN}$, considerando-se:

- tempo (horas) médio diário por RN disponível na Unidade Neonatal calculadas a partir da expressão (4). Substituindo-se as variáveis da expressão pelos valores numéricos encontrados no estudo, tem-se:

$$
\boldsymbol{h}_{\text {enf }}=\frac{\mathbf{5} \times \mathbf{6}}{\mathbf{1 0}}=\mathbf{3 , 0} \text { horas } / \mathrm{dia} / \mathrm{RN}
$$

Seguindo-se o mesmo procedimento calcularam-se as horas médias de cuidado por técnico/auxiliar de enfermagem, isto é:

$$
\boldsymbol{h}_{\text {tec }}=\frac{16 \times 6}{10}=9,6 \mathrm{horas} / \mathrm{dia} / \mathrm{RN}
$$

Somando-se o tempo médio diário por RN dos enfermeiros com o tempo médio diário por $\mathrm{RN}$ dos técnicos/auxiliares de enfermagem obteve-se o valor de 12,6 horas/dia/RN para a equipe de enfermagem;

- tempo (horas) médio diário por $\mathrm{RN}$ requerido pela pontuação média do NAS (cada ponto NAS equivale a 14,4 minutos de cuidado), tomando-se a pontuação média NAS, na Unidade Neonatal 66,9 pontos, transformadas em horas têm-se: $66,9 \times 14,4=16,1$ horas/dia/RN (Figura 18);

- tempo (horas) médio diário por paciente segundo a Resolução COFEN no 293/04 (2004) que recomenda 9,4 horas/dia/paciente que necessita da assistência semi-intensiva;

- tempo (horas) médio diário por paciente segundo a série histórica estudada por Rogenski (2006), cujo estudo encontrou um valor médio diário de tempo (horas) de cuidado por RN, com uma amostragem de um período de cinco anos correspondendo aos anos de 2000 a 2005, para Unidade Neonatal do HUUSP de 11,4 horas/dia/RN. 
- tempo (horas) médio dos tempos médios diários por RN calculada com os valores dos dados de todas as fontes consideradas foi de 12,4 horas/dia/RN.

A Figura 21 mostra, também, para cada uma das fontes de dados a participação percentual das categorias que compõem a equipe de profissional de enfermagem na realização do trabalho de cuidado dos RN na Unidade Neonatal. Observa-se que a participação da categoria profissional enfermeiro recomendada pela Resolução COFEN no 293/04 (2004) é, expressivamente maior (37\%) do que a amostra histórica da Unidade Neonatal.

\begin{tabular}{|c|c|c|c|c|c|c|}
\hline \multirow{2}{*}{ FONTES } & \multicolumn{2}{|c|}{ ENFERMEIRAS } & \multicolumn{2}{c|}{ TÉC/AUXILIARES } & \multicolumn{2}{c|}{ EQUIPE } \\
\cline { 2 - 7 } & TEMPO & $\%$ PARTIC. & TEMPO & $\%$ PARTIC. & TEMPO & $\%$ PARTIC. \\
\hline EQUIPE EM SERVIÇO & 3,0 & 23,8 & 9,6 & 76,2 & 12,6 & 100,0 \\
\hline PONTOS NAS & 3,8 & 23,8 & 12,2 & 76,2 & 16,1 & 100,0 \\
\hline RESOLUÇÄO COFEN & 3,9 & 42,0 & 5,5 & 58,0 & 9,4 & 100,0 \\
\hline HUUSP 5 ANOS & 3,0 & 26,3 & 8,4 & 73,7 & 11,4 & 100,0 \\
\hline \hline MÉDIA & 3,4 & 27,8 & 8,9 & 72,2 & 12,4 & 100,0 \\
\hline
\end{tabular}

Figura 21 - Tempo médio diário de cuidado (em horas) por recém-nascido, segundo: profissionais de enfermagem disponíveis em serviço, pontuação NAS, Resolução COFEN no 293/04 e HU-USP 5 anos, Unidade Neonatal, HU-USP. São Paulo, 2006.

Comparando-se os valores do tempo médio diário de cuidado por $\mathrm{RN}$, constata-se que o valor da carga média de assistência utilizando-se o instrumento NAS foi, expressivamente, mais elevado $(71,2 \%)$ do que o valor preconizado pela Resolução COFEN no 293/04 (2004) para assistência semi-intensiva, cujos respectivos valores foram: 16,1 horas/dia/RN e 9,4 horas/dia/RN. Já a comparação com o valor do tempo médio de assistência disponível na Unidade Neonatal, embora seja, também, mais elevado, a diferença cai para 27,8\%, indicando que 0 instrumento NAS possibilita medir com maior sensibilidade as atividades desenvolvidas pela equipe de enfermagem no cuidado desses $\mathrm{RN}$, uma vez que contempla em sua estrutura, além das atividades de cuidado, a mensuração do tempo despendido no planejamento, orientação e coordenação do cuidado aos RN e familiares. Pode-se constatar, também, que o valor do tempo 
médio diário por $\mathrm{RN}$, obtida da equipe em serviço está bem próxima $(10,5 \%)$ do valor médio diário por paciente obtida no estudo de Rogenski (2006), cujos respectivos valores foram 12,6 horas/dia/RN e 11,4 horas/dia/RN.

A Figura 22 apresenta os valores da variação diária da equipe de enfermagem obtidas a partir da carga média diária por $\mathrm{RN}$ das seguintes fontes:

- equipe em serviço disponível na Unidade Neonatal;

- pontuação NAS dos RN da Unidade Neonatal;

- amostra HU-USP no período de 2000 a 2005 da Unidade Neonatal;

- Resolução COFEN no 293/04 (2004) para Unidade Neonatal.

- médias obtidas dos valores médios das fontes acima.

As médias da equipe de enfermagem para o período amostrado foram as seguintes:

- em serviço: 21,1 (95\% IC = 18,46 a 23,74) profissionais;

- pontuação NAS: 27,1 (95\% IC = 23,71 a 30,49) profissionais;

- HU-USP 5 anos: 19,1 (95\% IC = 16,71 a 21,49) profissionais;

- Resolução COFEN no 293/04 (2004): 15,7 (95\% IC = 13,73 a 17,67) profissionais;

- valor médio: 20,7 (95\% IC = 18,11 a 23,29) profissionais. 
Figura 22 - Demonstrativo do quantitativo de profissionais de enfermagem, segundo as horas médias de cuidado: disponíveis em serviço, pontuação NAS, Resolução COFEN no 293/04 e HUUSP 5 anos, Unidade Neonatal, HU-USP. São Paulo, 2006. 
Pela comparação dos intervalos de confiança dos valores médios da equipe de enfermagem, bem como pelos resultados da aplicação dos testes $t$ de Student e LSD (Menor Diferença Significativa) aos dados da Figura 22 pode-se afirmar que:

O valor médio da equipe obtido pela pontuação NAS apresenta uma diferença significativa com relação a todos os outros valores médios da equipe de enfermagem calculados com dados de outras fontes.

O valor médio da equipe em serviço não apresenta diferença significativa com a média da equipe obtida pela amostra do HU-USP no período de 2000 a 2005.

O valor médio da equipe obtido pela resolução COFEN n 293/04 (2004) não apresentou diferença significativa com 0 valor médio da equipe de enfermagem obtida pela amostra HU-USP no período de 2000 a 2005.

A Figura 23 compara através de um gráfico de colunas os valores médios do quantitativo da equipe de enfermagem, conforme a carga média diária por RN das fontes mencionadas, com exceção da variação devido ao valor médio das médias. 


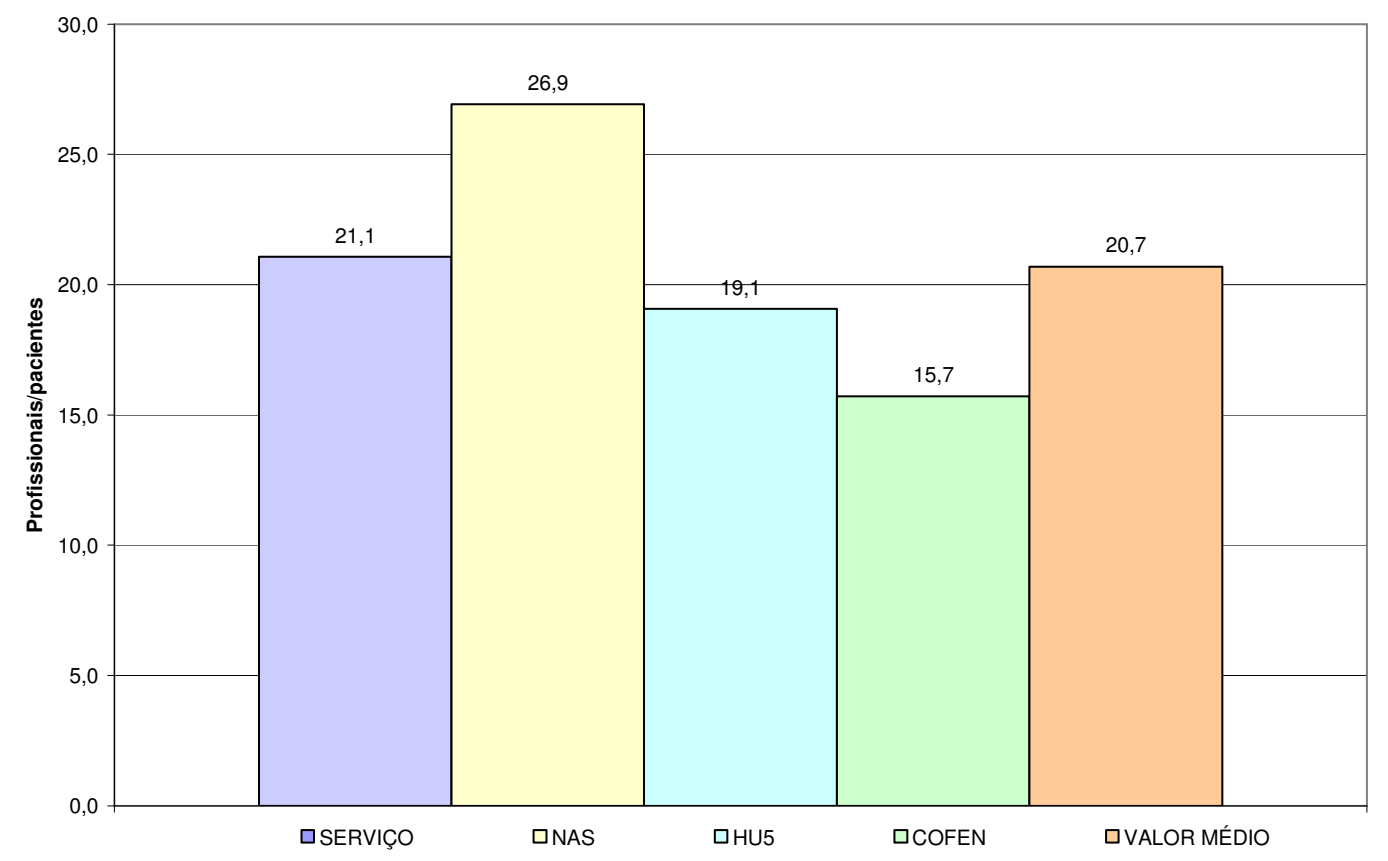

Figura 23 - Quantitativo médio da equipe de enfermagem, segundo a carga de trabalho obtida: cálculo do quadro disponível na Unidade Neonatal, pontuação NAS, Resolução COFEN no 293/04 e HU-USP 5 anos, Unidade Neonatal, HU-USP. São Paulo, 2006.

As variações diárias da equipe de enfermagem projetadas, segundo os valores de horas de cuidado citados são visualizadas na figura 24. 


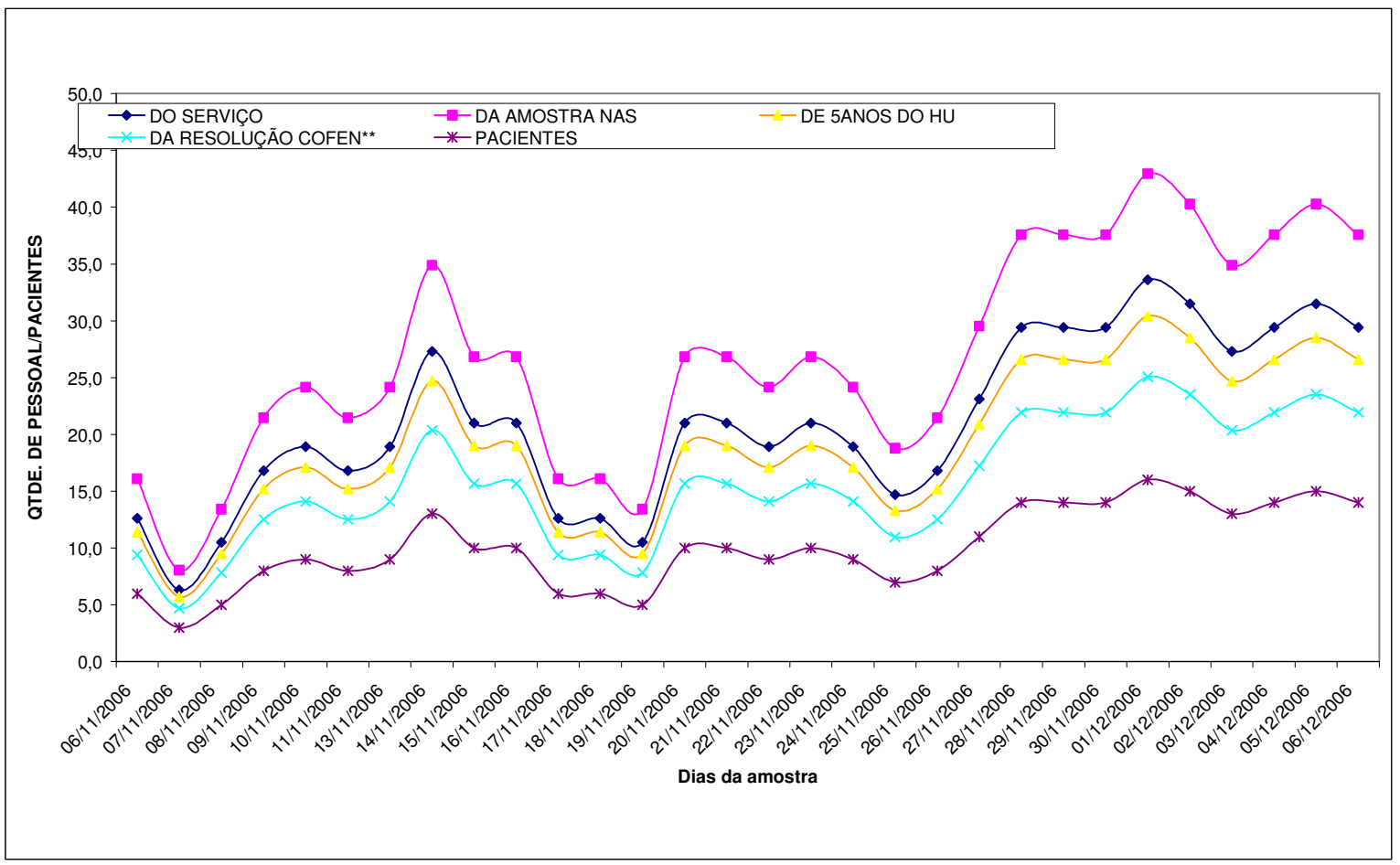

Figura 24 - Variações diárias do quantitativo de profissionais na Unidade Neonatal segundo: o número de pacientes, o quadro disponível, a pontuação NAS, Resolução COFEN no 293/04 e HUUSP 5 anos, Unidade Neonatal, HU-USP. São Paulo, 2006.

\subsubsection{Unidade de Terapia Intensiva Neonatal}

A Figura 25 apresenta os dados, obtidos no período amostral (06 de novembro de 2006 a 06 de dezembro de 2006), referentes à distribuição diária dos $\mathrm{RN}$, ao quantitativo diário de profissionais de enfermagem disponíveis na Unidade e ao quantitativo diário de profissionais de enfermagem requeridos pela pontuação NAS. 


\begin{tabular}{|c|c|c|c|c|c|c|c|c|c|c|c|c|c|c|c|c|c|c|c|c|c|}
\hline \multirow{2}{*}{\begin{tabular}{|r|} 
DATA \\
\end{tabular}} & \multirow{2}{*}{$\begin{array}{c}\text { DIA DA } \\
\text { SEMANA }\end{array}$} & \multirow[b]{2}{*}{$\mathrm{RN}$} & \multirow[b]{2}{*}{ LEITOS } & \multicolumn{5}{|c|}{ ENFERMEIRAS } & \multicolumn{5}{|c|}{ TÉC/AUXILIARES } & \multicolumn{5}{|c|}{ EQUIPE DE ENFERMAGEM } & \multirow{2}{*}{$\begin{array}{c}\text { NAS } \\
\text { DIÁRIO }\end{array}$} & \multirow{2}{*}{\begin{tabular}{|c|} 
NAS \\
MÉDIO
\end{tabular}} & \multirow{2}{*}{$\begin{array}{c}\text { EQUIPE } \\
\text { NAS }\end{array}$} \\
\hline & & & & $\bar{M}$ & $T$ & $\mathrm{~N} 1$ & N2 & NO DIA & $M$ & $T$ & $\mathrm{~N} 1$ & N2 & NO DIA & $M$ & $\mathrm{~T}$ & $\mathrm{~N} 1$ & N2 & NO DIA & & & \\
\hline $6 / 11 / 2006$ & 2 & 4 & 5 & 2 & 1 & 1 & 1 & 5 & 2 & 2 & 1 & 1 & 6 & 4 & 3 & 2 & 2 & 11 & 345,2 & 86,3 & 13,8 \\
\hline $7 / 11 / 2006$ & 3 & 4 & 5 & 1 & 1 & 1 & 1 & 4 & 2 & 2 & 1 & 1 & 6 & 3 & 3 & 2 & 2 & 10 & 345,7 & 86,4 & 13,8 \\
\hline $8 / 11 / 2006$ & 4 & 5 & 5 & 2 & 1 & 1 & 1 & 5 & 2 & 2 & 2 & 2 & 8 & 4 & 3 & 3 & 3 & 13 & 451,9 & 90,4 & 18,1 \\
\hline 9/11/2006 & 5 & 5 & 5 & 1 & 1 & 1 & $\overline{1}$ & 4 & 2 & 3 & 2 & 2 & 9 & 3 & 4 & $\overline{3}$ & 3 & 13 & 418,4 & 83,7 & 16,7 \\
\hline $10 / 11 / 2006$ & 6 & 4 & 5 & 1 & 1 & 1 & 1 & 4 & 2 & 2 & 2 & 2 & 8 & 3 & 3 & 3 & 3 & 12 & 333,3 & 83,3 & 13,3 \\
\hline $11 / 11 / 2006$ & 7 & 4 & 5 & 2 & 1 & 1 & 1 & 5 & 3 & 3 & 2 & 2 & 10 & 5 & 4 & 3 & 3 & 15 & 333,3 & 83,9 & 13,3 \\
\hline $13 / 11 / 2006$ & 2 & 3 & 5 & 2 & 1 & 1 & 1 & 5 & 3 & 2 & 2 & 2 & 9 & 5 & 3 & 3 & 3 & 14 & 257,9 & 86,0 & 10,3 \\
\hline $14 / 11 / 2006$ & 3 & 3 & 5 & 2 & 1 & 1 & 1 & 5 & 2 & 2 & 2 & 2 & 8 & 4 & 3 & 3 & 3 & 13 & 296,2 & 98,7 & 11,8 \\
\hline $15 / 11 / 2006$ & 4 & 2 & 5 & 1 & 1 & 1 & 1 & 4 & 2 & 2 & 2 & 2 & 8 & 3 & 3 & 3 & 3 & 12 & 191,6 & 95,8 & 7,7 \\
\hline $16 / 11 / 2006$ & 5 & 3 & 5 & 1 & 1 & 1 & 1 & 4 & 2 & 2 & 2 & 2 & 8 & 3 & 3 & 3 & 3 & 12 & 289,9 & 96,6 & 11,6 \\
\hline $17 / 11 / 2006$ & 6 & 3 & 5 & 1 & 1 & 1 & 1 & 4 & 2 & 2 & 2 & 2 & 8 & 3 & 3 & 3 & 3 & 12 & 285,5 & 95,2 & 11,4 \\
\hline $18 / 11 / 2006$ & 7 & 4 & 5 & 1 & 1 & 1 & 1 & 4 & 2 & 2 & 2 & 2 & 8 & 3 & 3 & 3 & 3 & 12 & 373,3 & 93,3 & 14,9 \\
\hline $19 / 11 / 2006$ & 1 & 4 & 5 & 1 & 1 & 1 & 1 & 4 & 1 & 1 & 1 & 1 & 4 & 2 & 2 & 2 & 2 & 8 & 371,4 & 92,9 & 14,9 \\
\hline $20 / 11 / 2006$ & 2 & 5 & 5 & 1 & 1 & 1 & 1 & 4 & 1 & 1 & 1 & 1 & 4 & 2 & 2 & 2 & 2 & 8 & 483,2 & 96,6 & 19,3 \\
\hline $21 / 11 / 2006$ & 3 & 4 & 5 & 1 & 1 & 1 & 1 & 4 & 2 & 1 & 1 & 1 & 5 & 3 & 2 & 2 & 2 & 9 & 366,1 & 91,5 & 14,6 \\
\hline $22 / 11 / 2006$ & 4 & 4 & 5 & 1 & 1 & 1 & 1 & 4 & 2 & 2 & 2 & 2 & 8 & 3 & 3 & 3 & 3 & 12 & 366,5 & 91,6 & 14,7 \\
\hline $23 / 11 / 2006$ & 5 & 4 & 5 & 1 & 1 & 1 & 1 & 4 & 2 & 3 & 2 & 2 & 9 & 3 & 4 & 3 & 3 & 13 & 367,8 & 92,0 & 14,7 \\
\hline $24 / 11 / 2006$ & 6 & 4 & 5 & 1 & 1 & 1 & 1 & 4 & 2 & 2 & 2 & 2 & 8 & 3 & 3 & 3 & 3 & 12 & 355,5 & 89,1 & 14,2 \\
\hline $25 / 11 / 2006$ & 7 & 3 & 5 & 1 & 1 & 1 & 1 & 4 & 2 & 1 & 2 & 2 & 7 & 3 & 2 & 3 & 3 & 11 & 274,5 & 91,5 & 11,0 \\
\hline $26 / 11 / 2006$ & 1 & 3 & 5 & 2 & 2 & 1 & 1 & 6 & 1 & 1 & 2 & 2 & 6 & 3 & 3 & 3 & 3 & 12 & 274,7 & 91,6 & 11,0 \\
\hline $27 / 11 / 2006$ & 2 & 3 & 5 & 1 & 1 & 1 & 1 & 4 & 2 & 2 & 2 & 2 & 8 & 3 & 3 & 3 & 3 & 12 & 279,0 & 93,0 & 11,2 \\
\hline $28 / 11 / 2006$ & 3 & 3 & 5 & 1 & 1 & 1 & 1 & 4 & 2 & 2 & 2 & 2 & 8 & 3 & 3 & 3 & 3 & 12 & 283,1 & 94,4 & $\overline{11,3}$ \\
\hline $29 / 11 / 2006$ & 4 & 3 & 5 & 1 & 1 & 1 & 1 & 4 & 2 & 2 & 2 & 2 & 8 & 3 & 3 & 3 & 3 & 12 & 280,7 & 93,6 & 11,2 \\
\hline $30 / 11 / 2006$ & 5 & 3 & 5 & 2 & 2 & 1 & 1 & 6 & 2 & 2 & 3 & 3 & 10 & 4 & 4 & 4 & 4 & 16 & 272,6 & 90,9 & 10,9 \\
\hline $1 / 12 / 2006$ & 6 & 2 & 5 & 2 & 1 & 1 & 1 & 5 & 2 & 2 & 2 & 2 & 8 & 4 & 3 & 3 & 3 & 13 & 178,8 & 89,4 & 7,2 \\
\hline 2/12/2006 & 7 & 3 & 5 & 1 & 1 & 1 & 1 & 4 & 2 & 2 & 2 & 2 & 8 & 3 & 3 & 3 & 3 & 12 & 259,8 & 86,6 & 10,4 \\
\hline $3 / 12 / 2006$ & 1 & 4 & 5 & 1 & 1 & 1 & 1 & 4 & 2 & 2 & 2 & 2 & 8 & 3 & 3 & 3 & 3 & 12 & 357,9 & 89,5 & 14,3 \\
\hline $4 / 12 / 2006$ & 2 & 4 & 5 & 1 & 1 & 1 & 1 & 4 & 2 & 3 & 2 & 2 & 9 & 3 & 4 & 3 & 3 & 13 & 368,5 & 92,1 & 14,7 \\
\hline $5 / 12 / 2006$ & 3 & 3 & 5 & 2 & 1 & 1 & 1 & 5 & 2 & 2 & 2 & 2 & 8 & 4 & 3 & 3 & 3 & 13 & 281,8 & 93,9 & 11,3 \\
\hline $6 / 12 / 2006$ & 4 & 3 & 5 & 1 & 1 & 1 & 1 & 4 & 2 & 2 & 2 & 2 & 8 & 3 & 3 & 3 & 3 & 12 & 279,4 & 93,1 & $\overline{11,2}$ \\
\hline \multicolumn{2}{|l|}{ NUMERO DE DIAS } & 30 & 30 & 30 & 30 & $\overline{30}$ & $\overline{30}$ & 30 & 30 & 30 & 30 & 30 & 30 & 30 & 30 & $\overline{30}$ & 30 & 30 & 30 & 30 & 30 \\
\hline \multicolumn{2}{|l|}{\begin{tabular}{|l} 
MEDIA \\
MFDIANA
\end{tabular}} & 3,5 & 5 & 1,3 & 1,1 & 1,0 & 1,0 & 4,4 & 2,0 & 2,0 & 1,9 & 1,9 & 7,7 & 3,3 & 3,0 & 2,9 & 2,9 & 12,0 & 320,8 & 91,1 & 12,8 \\
\hline MEDIANA & & 3,5 & 5 & 1 & 1 & 1 & 1 & 4 & 2 & 2 & 2 & 2 & 8 & 3 & 3 & 3 & 3 & 12 & 314,8 & 91,6 & 12,6 \\
\hline \multicolumn{2}{|l|}{ MODA } & 3 & 5 & 1 & 1 & 1 & 1 & 4 & 2 & 2 & 2 & 2 & 8 & 3 & 3 & 3 & 3 & 12 & & & \\
\hline \multicolumn{2}{|l|}{ DESVIO PADRAO } & 0,8 & 0,0 & 0,5 & 0,3 & 0,0 & 0,0 & 0,6 & \begin{tabular}{|l|}
0,4 \\
\end{tabular} & 0,6 & 0,4 & $\mid 0,4$ & 1,5 & 0,7 & 0,6 & 0,4 & 0,4 & 1,7 & 67,7 & 4,0 & 2,7 \\
\hline \multirow{2}{*}{\multicolumn{4}{|c|}{\begin{tabular}{|l|} 
DIST. $\%$ DO PESSOAL NO DIA \\
\end{tabular}}} & 35,9 & 23,8 & 0,0 & 0,0 & 14,1 & 21,0 & 28,3 & 23,3 & 23,3 & 19,2 & 21,2 & 18,3 & 15,1 & 15,1 & 14,1 & 21,1 & 4,4 & 21,1 \\
\hline & & & & 29,8 & 24,4 & 22,9 & 22,9 & 100,0 & 25,7 & 25,7 & 24,3 & 24,3 & 100,0 & 27,1 & 25,2 & 23,8 & 23,8 & 100,0 & & & \\
\hline \multicolumn{4}{|c|}{ DIST. \% DAS CATEGORIAS PROFISSIONAIS } & 10,8 & 8,9 & 8,3 & 8,3 & 36,3 & 16,3 & 16,3 & 15,5 & 15,5 & 63,7 & 27,1 & 25,2 & 23,8 & 23,8 & 100,0 & & & \\
\hline \multicolumn{4}{|c|}{ INTERVALO DE CONFIANÇA DE 95\% } & & & & & & & & & & & & & & & 0,6 & 24,2 & 1,4 & $\overline{1,0}$ \\
\hline
\end{tabular}

Figura 25 - Análise estatística da distribuição dos recém-nascidos internados, do quadro de profissionais disponível em serviço, da pontuação NAS e do quadro da equipe de enfermagem, segundo NAS. UTI Neonatal, período de 06 de novembro de 2006 a 06 de dezembro de 2006 , HU-USP.

São Paulo, 2006. 
Constata-se na Figura 25 que, no período amostral, o valor da moda dos profissionais em serviço na Unidade foi de 4 enfermeiros e de 8 técnicos/auxiliares de enfermagem, perfazendo o total de 12 profissionais de enfermagem, disponíveis para cobrirem os 4 turnos de trabalho de 6 horas do dia, e prestarem assistência em média a 3,5 (95\% IC = 3,22 a 3,78) RN.

A média da pontuação NAS total dos RN durante o período estudado foi de $320,8(95 \%$ IC = 296,6 a 345,0) pontos e a média diária da pontuação por RN foi de $91,1(95 \%$ IC = 89,7 a 92,5) pontos (Figura 25).

O valor médio do quadro de profissionais de enfermagem disponível na UTIN foi de 12,0 (95\% IC = 11,4 a 12,6) profissionais.

A partir da pontuação NAS total e da expressão (5) obteve-se o valor médio da equipe de enfermagem requerida para o cuidado, cujo valor médio foi de 12,8 $(95 \%$ IC $=12,2$ a 13,4$)$ profissionais.

A diferença entre o valor médio da equipe de enfermagem disponível e o valor médio da equipe de enfermagem requerida para o cuidado é menor que $1,7 \%$ o que os torna significativamente semelhantes e indicam que não havia sobrecarga de serviço na UTIN, baseados nesses valores.

As variações diárias da equipe de enfermagem disponível, da equipe de enfermagem requerida, bem como a variação diária de $\mathrm{RN}$ internados são mostradas no gráfico da Figura 26. 


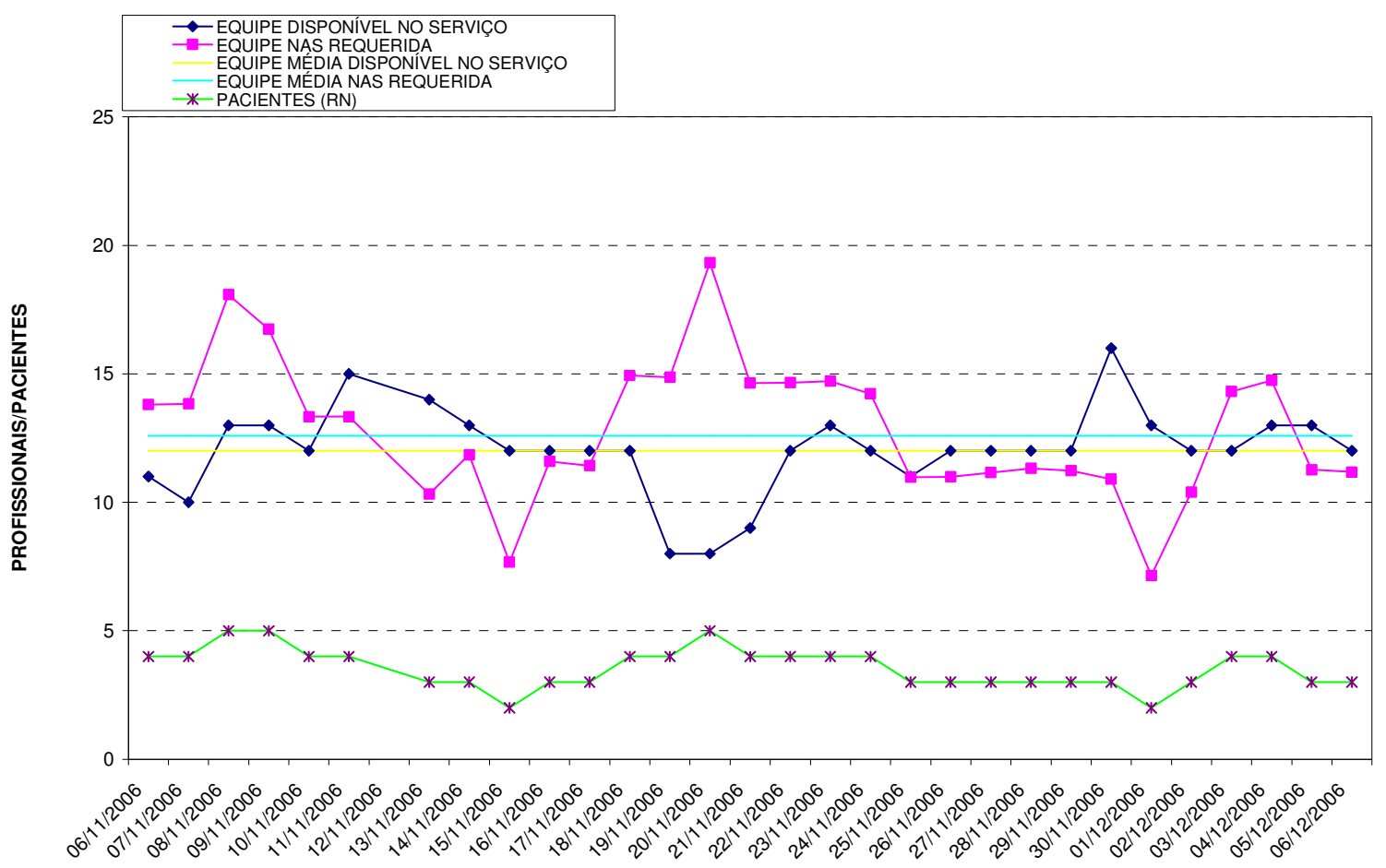

Figura 26 - Comparação entre a equipe de enfermagem requerida pelo NAS e a equipe de enfermagem disponível, período de 06 de novembro de 2006 a 06 de dezembro de 2006, UTIN, HU-USP. São Paulo, 2006.

Observa-se nessa representação que o valor da equipe de enfermagem calculado por meio da pontuação NAS ajusta-se melhor às variações de RN internados do que o valor da equipe de enfermagem disponível em serviço, o que indica que o valor da equipe obtida pela pontuação NAS é mais sensível às variações da quantidade de $\mathrm{RN}$, pois a resultante sempre acompanha a variação diária dos pacientes da Unidade.

Essas afirmações são corroboradas pela análise de correlação realizada entre as quantidades diárias de RN internados, as quantidades diárias de profissionais da equipe de enfermagem em serviço e as quantidades de profissionais da equipe de enfermagem requerida pela pontuação NAS.

Os resultados dessa análise, sumarizados na Figura 27 foram obtidos pelo cálculo do coeficiente de $\boldsymbol{r}$ de Pearson que fornece o grau de correlação dos dados.

O valor do coeficiente $\boldsymbol{r}$ de Pearson da correlação entre as quantidades diárias de profissionais de enfermagem da equipe ou individualizadas por 
categoria profissional e a quantidade de $\mathrm{RN}$, indicam que houve correlação fracamente negativa, significando que com o aumento do número de RN houve uma diminuição de profissionais da equipe de enfermagem disponível na Unidade.

Já o valor do coeficiente $\boldsymbol{r}$ de Pearson da correlação entre os $\mathrm{RN}$ internados com o quantitativo diário da equipe de enfermagem requerida pela pontuação NAS foi fortemente positivo. Da mesma forma que na Unidade Neonatal, aqui também se constata que a carga de trabalho requerida pela pontuação NAS é diretamente proporcional a quantidade de RN internados.

\begin{tabular}{|c|c|}
\hline CORRELAÇÃO ENTRE & Coeficiente $r$ de Pearson \\
\hline ENFERMEIRAS EM SERVIÇO X RN & $-0,207$ \\
\hline AUX/TÉCNICOS EM SERVIÇO XRN & $-0,232$ \\
\hline \hline EQUIPE EM SERVIÇOXRN & $-0,277$ \\
\hline EQUIPE NAS XRN & 0,976 \\
\hline
\end{tabular}

Figura 27 - Correlação entre as quantidades diárias e de RN e de profissionais de enfermagem disponíveis na UTI Neonatal, período de 06 de novembro de 2006 a 06 de dezembro de 2006, Unidade Neonatal, HU-USP. São Paulo, 2006.

$\mathrm{Na}$ Figura 28 apresentam-se os valores médios relativos ao tempo de cuidado, por categoria profissional, nas 24 horas, por RN, considerando-se:

- o tempo médio diário de trabalho disponível na UTIN - calculado a partir da expressão (4), na qual substituindo as variáveis pelos seus valores numéricos encontrados no estudo, tem-se:

$$
\boldsymbol{h}_{\text {enf }}=\frac{4 \times 6}{3,53}=6,8 \text { horas } / \mathrm{dia} / \mathrm{RN}
$$

Seguindo-se o mesmo procedimento calcularam-se as horas médias de cuidado por técnico/auxiliar de enfermagem, isto é:

$$
h_{\text {tec }}=\frac{8 \times 6}{3,53}=13,6 \text { horas } / \text { dia } / \mathrm{RN}
$$

Somando-se o tempo médio diário de cuidado por RN dos enfermeiros com o tempo médio diário de cuidado por $\mathrm{RN}$ dos técnicos/auxiliares de 
enfermagem obteve-se o valor de 20,4 horas/dia/RN para a equipe de enfermagem;

- tempo médio diário por RN requerido pela média do NAS (cada ponto NAS equivale a 14,4 minutos de cuidado, ou seja, 0,24 horas), tomando-se a pontuação média do NAS na UTIN 91,1 pontos, têm-se: $91,1 \times 0,24=21,9$ horas/dia/RN (Figura 28);

- tempo médio diário por paciente segundo a Resolução COFEN no․ 293/04 (2004) que recomenda 17,9 horas/dia/RN, na assistência intensiva;

- tempo médio diário por leito segundo a Portaria do Ministério da Saúde no 3432/98 (1998), para UTI tipo III é 19,2 horas/dia/RN.

- valor médio dos tempos médios diários por RN calculado com os valores dos dados de todas as fontes consideradas anteriormente é 19,8 horas/dia/RN.

\begin{tabular}{|c|c|c|c|c|c|c|}
\hline \multirow{2}{*}{ FONTES } & \multicolumn{2}{|c|}{ ENFERMEIRAS } & \multicolumn{2}{c|}{ TÉC/AUXILIARES } & \multicolumn{2}{c|}{ EQUIPE } \\
\cline { 2 - 7 } & TEMPO & $\%$ PARTIC. & TEMPO & $\%$ PARTIC. & TEMPO & $\%$ PARTIC. \\
\hline EQUIPE EM SERVIÇO & 3,0 & 23,8 & 9,6 & 76,2 & 12,6 & 100,0 \\
\hline PONTOS NAS & 3,8 & 23,8 & 12,2 & 76,2 & 16,1 & 100,0 \\
\hline RESOLUÇÃO COFEN & 3,9 & 42,0 & 5,5 & 58,0 & 9,4 & 100,0 \\
\hline HUUSP 5 ANOS & 3,0 & 26,3 & 8,4 & 73,7 & 11,4 & 100,0 \\
\hline \hline MÉDIA & 3,4 & 27,8 & 8,9 & 72,2 & 12,4 & 100,0 \\
\hline
\end{tabular}

Figura 28 - Tempo médio diário (em horas) por recém-nascido, segundo: profissionais de enfermagem disponíveis em serviço; pontuação NAS, Resolução COFEN no 293/04 e Portaria Ministério da Saúde no 3432/98, UTIN. HU-USP. São Paulo, 2006.

Comparando-se esses valores de tempo médio diário de cuidado por RN, constata-se que o valor do tempo médio de assistência utilizando-se o instrumento NAS foi mais elevado $(22,3 \%)$ do que o preconizado pela Resolução COFEN no 293/04 (2004) para assistência intensiva, cujos respectivos valores foram: 21,9 horas/dia/RN e 17,9 horas/dia/RN. Já a comparação com o valor do tempo médio de assistência disponível na UTIN, embora seja, também, mais elevado a diferença cai para $7,4 \%$, indicando que o instrumento NAS possibilita medir com maior sensibilidade as atividades desenvolvidas pela equipe de enfermagem no cuidado dos RN, uma vez que contempla em sua estrutura, além das atividades 
de cuidado, a mensuração do tempo despendido no planejamento, orientação e coordenação do cuidado aos RN e familiares. Constata-se, também, que o valor do tempo médio diário por RN obtida pela pontuação NAS é 6,3\% maior que o valor do tempo médio diário por RN requerida pela Portaria do Ministério da Saúde no 3432/98 (1998) por RN.

A Figura 29 apresenta os valores da variação diária da equipe de enfermagem obtidas a partir dos valores do tempo médio diário por $\mathrm{RN}$ das seguintes fontes:

- equipe em serviço, disponível na UTIN;

- pontuação NAS dos RN da UTIN;

- Resolução COFEN nº 293/04 (2004);

- Portaria do Ministério da Saúde nº 3432/98 (1998);

- média obtida dos valores médios das fontes citadas.

Os valores médios das equipes de enfermagem para o período amostrado foram os seguintes:

- equipe em serviço na UTIN: 12,0 (95\% IC = 11,06 a 12,94) profissionais;

- equipe requerida pela pontuação NAS: $12,9(95 \%$ IC = 11,89 a 13,91) profissionais;

- equipe requerida pela Resolução COFEN no 293/04 (2004): 10,5 $(95 \%$ IC = 9,67 a 11,33) profissionais;

- equipe requerida pela Portaria do Ministério da Saúde nº 3432/98 (1998): 11,3 (95\% IC = 10,41 a 12,19) profissionais;

- equipe média obtida dos valores médios citados: 11,8 (95\% IC = $10,87$ a 12,73$)$ profissionais.

Pela comparação dos valores limites do intervalo de confiança de cada uma das fontes entre si, e pelo resultado da aplicação dos testes $\boldsymbol{t}$ de Student e LSD (Menor Diferença Significativa) aos dados da Figura 29 pode-se afirmar que:

- o valor médio da equipe de enfermagem obtido pela pontuação NAS, embora maior que o valor médio da equipe de enfermagem disponível no serviço, não é significativo, isto é, ele pode ser devido ao acaso. 
- o valor médio da equipe de enfermagem obtido pela pontuação NAS apresenta diferença significativa com as equipes de enfermagem obtidas pelas fontes citadas (Portaria do Ministério da Saúde no 3432/98, 1998; Resolução COFEN no 293/04, 2004).

- o valor médio da equipe de enfermagem requerida pela Portaria do Ministério da Saúde oㅜ 3432/98 (1998), não apresenta diferença significativa com os valores médios das equipes de enfermagem disponíveis em serviço e requeridos pela Resolução COFEN no 293/04 (2004). 


\begin{tabular}{|c|c|c|c|c|c|c|c|c|c|}
\hline \multirow[b]{2}{*}{ DATA } & \multirow[b]{2}{*}{$\begin{array}{c}\text { DIA DA } \\
\text { SEMANA }\end{array}$} & \multirow[b]{2}{*}{$\mathrm{RN}$} & \multicolumn{7}{|c|}{ EQUIPE DE ENFERMAGEM } \\
\hline & & & \begin{tabular}{|c|} 
PELA \\
AMOSTRA
\end{tabular} & $\begin{array}{l}\text { PELO } \\
\text { NAS }\end{array}$ & $\begin{array}{c}\text { RESOLUÇÃO } \\
\text { COFEN }\end{array}$ & $\begin{array}{c}\text { PORTARIA } \\
\text { MS } 3432\end{array}$ & MÉDIA & D.PAD. & C.V.\% \\
\hline $6 / 11 / 2006$ & seg & 4 & \begin{tabular}{l|}
13,6 \\
\end{tabular} & 14,6 & 11,9 & 12,8 & 13,4 & 1,35 & 10,1 \\
\hline $7 / 11 / 2006$ & ter & 4 & 13,6 & 14,6 & 11,9 & 12,8 & 13,4 & 1,35 & 10,1 \\
\hline $8 / 11 / 2006$ & qua & 5 & 17,0 & 18,3 & 14,9 & 16,0 & 16,7 & 1,68 & 10,1 \\
\hline $9 / 11 / 2006$ & qui & 5 & \begin{tabular}{l|l}
17,0 &
\end{tabular} & 18,3 & 14,9 & 16,0 & 16,7 & 1,68 & 10,1 \\
\hline $10 / 11 / 2006$ & $\operatorname{sex}$ & 4 & 13,6 & 14,6 & 11,9 & 12,8 & 13,4 & 1,35 & 10,1 \\
\hline $11 / 11 / 2006$ & sáb & 4 & 13,6 & 14,6 & 11,9 & 12,8 & 13,4 & 1,35 & 10,1 \\
\hline $13 / 11 / 2006$ & seg & 3 & \begin{tabular}{l|l}
10,2 \\
\end{tabular} & 11,0 & 9,0 & 9,6 & 10,0 & 1,01 & 10,1 \\
\hline $14 / 11 / 2006$ & ter & 3 & 10,2 & 11,0 & 9,0 & 9,6 & 10,0 & 1,01 & 10,1 \\
\hline $15 / 11 / 2006$ & qua & 2 & 6,8 & 7,3 & 6,0 & 6,4 & 6,7 & 0,67 & 10,1 \\
\hline $16 / 11 / 2006$ & qui & 3 & \begin{tabular}{l|}
10,2 \\
\end{tabular} & 11,0 & 9,0 & 9,6 & 10,0 & 1,01 & 10,1 \\
\hline $17 / 11 / 2006$ & $\operatorname{sex}$ & 3 & \begin{tabular}{l|}
10,2 \\
\end{tabular} & 11,0 & 9,0 & 9,6 & 10,0 & 1,01 & 10,1 \\
\hline $18 / 11 / 2006$ & sáb & 4 & 13,6 & 14,6 & 11,9 & 12,8 & 13,4 & 1,35 & 10,1 \\
\hline $19 / 11 / 2006$ & dom & 4 & 13,6 & 14,6 & 11,9 & 12,8 & 13,4 & 1,35 & 10,1 \\
\hline $20 / 11 / 2006$ & seg & 5 & 17,0 & 18,3 & 14,9 & 16,0 & 16,7 & 1,68 & 10,1 \\
\hline $21 / 11 / 2006$ & ter & 4 & 13,6 & 14,6 & 11,9 & 12,8 & 13,4 & 1,35 & 10,1 \\
\hline $22 / 11 / 2006$ & qua & 4 & 13,6 & 14,6 & 11,9 & 12,8 & 13,4 & 1,35 & 10,1 \\
\hline $23 / 11 / 2006$ & qui & 4 & 13,6 & 14,6 & 11,9 & 12,8 & 13,4 & 1,35 & 10,1 \\
\hline $24 / 11 / 2006$ & $\operatorname{sex}$ & 4 & 13,6 & 14,6 & 11,9 & 12,8 & 13,4 & 1,35 & 10,1 \\
\hline $25 / 11 / 2006$ & sáb & 3 & \begin{tabular}{l|l}
10,2 \\
\end{tabular} & 11,0 & 9,0 & 9,6 & 10,0 & 1,01 & 10,1 \\
\hline $26 / 11 / 2006$ & dom & 3 & \begin{tabular}{l|}
10,2 \\
\end{tabular} & 11,0 & 9,0 & 9,6 & 10,0 & 1,01 & 10,1 \\
\hline $27 / 11 / 2006$ & seg & 3 & 10,2 & 11,0 & 9,0 & 9,6 & 10,0 & 1,01 & 10,1 \\
\hline $28 / 11 / 2006$ & ter & 3 & 10,2 & 11,0 & 9,0 & 9,6 & 10,0 & 1,01 & 10,1 \\
\hline $29 / 11 / 2006$ & qua & 3 & \begin{tabular}{l|l}
10,2 \\
\end{tabular} & 11,0 & 9,0 & 9,6 & 10,0 & 1,01 & 10,1 \\
\hline $30 / 11 / 2006$ & qui & 3 & \begin{tabular}{l|l}
10,2 \\
\end{tabular} & 11,0 & 9,0 & 9,6 & 10,0 & 1,01 & 10,1 \\
\hline $1 / 12 / 2006$ & $\operatorname{sex}$ & 2 & 6,8 & 7,3 & 6,0 & 6,4 & 6,7 & 0,67 & 10,1 \\
\hline $2 / 12 / 2006$ & sáb & 3 & \begin{tabular}{l|l}
10,2 \\
\end{tabular} & 11,0 & 9,0 & 9,6 & 10,0 & 1,01 & 10,1 \\
\hline $3 / 12 / 2006$ & dom & 4 & 13,6 & 14,6 & 11,9 & 12,8 & 13,4 & 1,35 & 10,1 \\
\hline $4 / 12 / 2006$ & seg & 4 & 13,6 & 14,6 & 11,9 & 12,8 & 13,4 & 1,35 & 10,1 \\
\hline $5 / 12 / 2006$ & ter & 3 & \begin{tabular}{l|l}
10,2 \\
\end{tabular} & 11,0 & 9,0 & 9,6 & 10,0 & 1,01 & 10,1 \\
\hline $6 / 12 / 2006$ & qua & 3 & 10,2 & 11,0 & 9,0 & 9,6 & 10,0 & 1,01 & 10,1 \\
\hline NÚMERO DE DI & IAS & 30 & 30 & 30 & 30 & 30 & 30 & 30 & $\overline{100,0}$ \\
\hline MEDIA & & 3,5 & \begin{tabular}{l|l}
12,0 \\
\end{tabular} & 12,9 & 10,5 & 11,3 & 11,8 & & \\
\hline MEDIANA & & 3,5 & 11,9 & 12,8 & 10,4 & 11,2 & 11,7 & & \\
\hline DESVIO PADR & & 0,8 & 2,6 & 2,8 & 2,3 & 2,5 & 2,6 & & \\
\hline C.V.\% & & 22,0 & 22,0 & 22,0 & 22,0 & 22,0 & 22,0 & & \\
\hline \begin{tabular}{|l} 
INTERV.CONF \\
\end{tabular} & IANÇA 95\% & 0,28 & 0,94 & 1,01 & 0,83 & 0,89 & 0,93 & & \\
\hline
\end{tabular}

Figura 29 - Demonstrativo do quantitativo de profissionais de enfermagem, segundo: profissionais de enfermagem disponíveis em serviço, pontuação NAS, Resolução COFEN no 293/04 e Portaria do Ministério da Saúde no 3432/98, UTIN, HU-USP. São Paulo, 2006. 
A Figura 30 representa os valores médios do quantitativo da equipe de enfermagem conforme o tempo médio diário por RN proveniente das fontes mencionadas anteriormente.

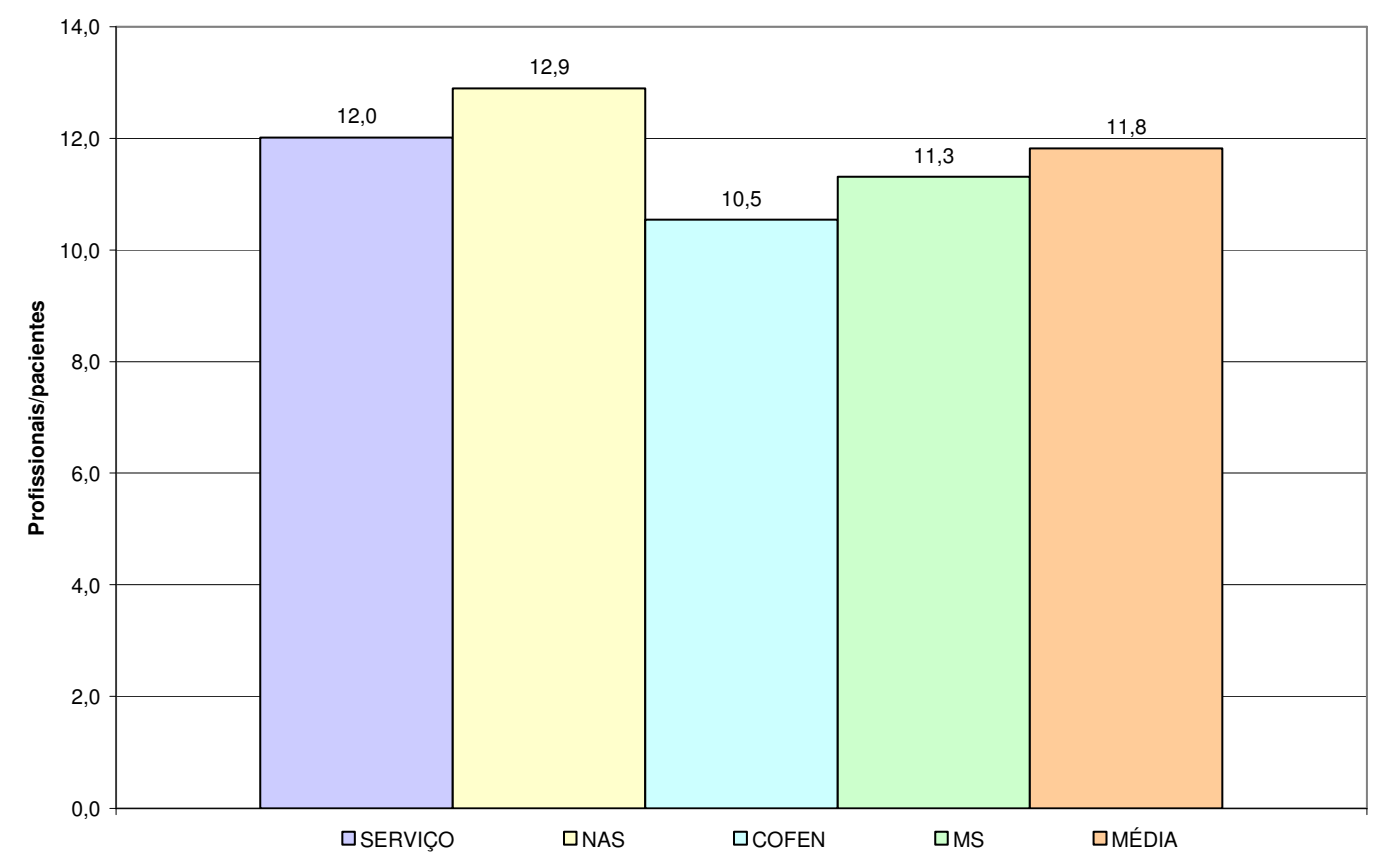

Figura 30 - Quantitativo médio da equipe de enfermagem, segundo o tempo de cuidado na UTIN; pontuação NAS, Resolução COFEN n 293/04 e Portaria do Ministério da Saúde no 3432/98, UTIN, HU-USP. São Paulo, 2006.

As variações diárias dos valores do quantitativo da equipe de enfermagem conforme o tempo médio diário por RN provenientes das fontes mencionadas anteriormente são visualizadas graficamente na Figura 31, o qual permite verificar que todas as variações acompanham a quantidade de RN internados possuindo, portanto a mesma variabilidade, o que facilita comparar seus valores. 


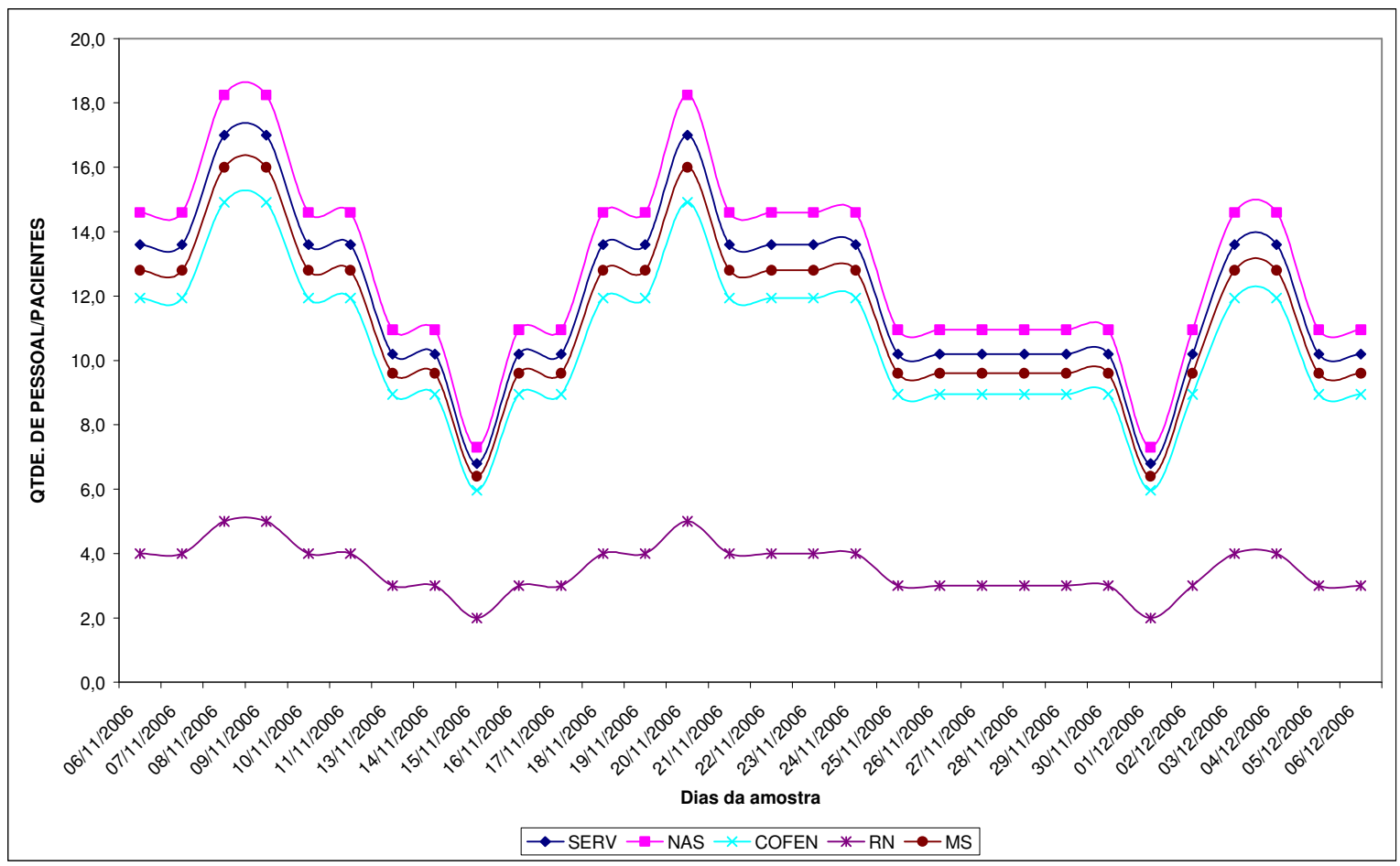

Figura 31 - Variações diárias do quantitativo de profissionais na UTIN segundo: o número de pacientes; o quadro disponível, a pontuação NAS, Resolução COFEN no 293/04 e Portaria do Ministério da Saúde no 3432/98, UTIN, HU-USP. São Paulo, 2006.

\subsubsection{Pontuação do NAS: freqüência dos indicadores do instrumento e a relação com o tempo despendido nas atividades de enfermagem}

Para prosseguir a análise é prudente salientar que carga de trabalho é o tempo, em horas, dedicado pela equipe de enfermagem, para realizar as atividades relacionadas ao RN. Como o NAS é um índice que mede carga de trabalho, se a pontuação for 100, devemos interpretar que o RN necessitou de $100 \%$ do tempo de um funcionário de enfermagem no seu cuidado nas 24 horas.

A Figura 32 indica o perfil de pontuação do NAS dos RN na Unidade Neonatal. Verificou-se nesse estudo que os indicadores (itens/subitens) mais freqüentemente pontuados foram:

1b - monitorização e controles: observação ou atividade contínua por 2 horas ou mais $(98,7 \%)$; 
3 - medicação, com pontuação igual a 42,0 pontos NAS $(74,8 \%)$;

$\mathbf{4} \mathbf{b}$ - procedimentos de higiene que durem mais de 2 horas $(99,3 \%)$;

6b - mobilização e posicionamento: realização do procedimento mais do que 3 vezes ou com 2 profissionais de enfermagem (100\%);

7a - suporte e cuidados aos familiares que requerem dedicação exclusiva por até 1 hora contínua ou fracionada (94,7\%);

$\mathbf{8 a}$ - tarefas administrativas: tarefas de rotina como processamento de dados clínicos (94\%);

22 - intervenções específicas na unidade: (100\%).

Essas atividades caracterizam o processo assistencial da Unidade Neonatal (alimentação oral em copinho, administração de dieta via gástrica a cada $2 \mathrm{~h}$, troca de fralda a cada $3 \mathrm{~h}$, contenção do choro do $\mathrm{RN}$, controle da assistência respiratória com episódios de apnéia, suporte à mãe, ao pai e demais familiares.

Os seguintes indicadores (itens/subitens) não foram pontuados:

5 - cuidados com drenos, 12 - medicação vasoativa, 14 monitorização do átrio esquerdo, 15 - reanimação cardiorrespiratória, 16 técnicas de hemofiltração/técnicas dialíticas, 18 - medida de pressão intracraniana e 19 - tratamento da acidose/alcalose metabólica complicada. 


\begin{tabular}{|c|c|c|c|c|c|c|c|c|c|c|}
\hline ATIVIDADES BÁSICAS NAS & PONTOS & $\begin{array}{c}\text { SOMA DOS } \\
\text { PONTOS NO } \\
\text { PERÍODO }\end{array}$ & \begin{tabular}{|c|} 
DISTRIBUIÇÃO \\
\%DOS \\
PONTOS NAS
\end{tabular} & $\begin{array}{c}\text { DIAS DE } \\
\text { OCORRÊNCIA } \\
\end{array}$ & $\begin{array}{l}\text { OCORRÊNCIAS } \\
\text { NO PERÍODO }\end{array}$ & \begin{tabular}{|c|} 
PERCENTUAL \\
DE \\
OCORRÊNCIA \\
\end{tabular} & \begin{tabular}{|c|} 
MÉDIA DOS \\
PONTOS NAS \\
POR DIA \\
\end{tabular} & \begin{tabular}{|c|} 
MÉDIA DOS \\
PONTOS NAS \\
POR RN \\
\end{tabular} & \begin{tabular}{|c|} 
D.PADRÃO \\
DOS PONTOS \\
NAS POR DIA \\
\end{tabular} & C.V.\% \\
\hline 1. Monitorização e controles & & & & & & & & & & \\
\hline $1 \mathrm{a}$. & 4,5 & 0,0 & 0,0 & 0 & 0 & 0,0 & 0,0 & 0,0 & 0,0 & 0,0 \\
\hline 1b. & 12,1 & 3593,7 & 17,9 & 30 & 297 & 98,7 & 119,8 & 11,9 & 43,4 & 36,2 \\
\hline 1c. & 19,6 & 78,4 & 0,4 & 4 & 4 & 1,3 & 2,6 & 0,3 & 0,0 & 0,0 \\
\hline 2. Investigações laboratoriais & 4,3 & 524,6 & 2,6 & 30 & 122 & 40,5 & 17,5 & 1,7 & 9,4 & 54,0 \\
\hline 3. Medicação & 5,6 & 1260,0 & 6,3 & 30 & 225 & 74,8 & 42,0 & 4,2 & 15,3 & 36,3 \\
\hline 4. Procedimentos de higiene & & 0,0 & & & & & & & & \\
\hline $4 a$. & 4,1 & 0,0 & 0,0 & 0 & 0 & 0,0 & 0,0 & 0,0 & 0,0 & 0,0 \\
\hline 4b. & 16,5 & 4933,5 & 24,6 & 30 & 299 & 99,3 & 164,5 & 16,4 & 58,2 & 35,4 \\
\hline $4 \mathrm{c}$. & 20,0 & 20,0 & 0,1 & 1 & 1 & 0,3 & 0,7 & 0,1 & 0,0 & 0,0 \\
\hline 5. Cuidados com drenos & 1,8 & 0,0 & 0,0 & 0 & 0 & 0,0 & 0,0 & 0,0 & 0,0 & 0,0 \\
\hline 6.Mobilização/posicionamento & & 0,0 & & & & & & & & \\
\hline $6 a$. & 5,5 & 0,0 & 0,0 & 0 & 0 & 0,0 & 0,0 & 0,0 & 0,0 & 0,0 \\
\hline $6 \mathrm{~b}$. & 12,4 & 3732,4 & 18,6 & 30 & 301 & 100,0 & 124,4 & 12,4 & 43,5 & 35,0 \\
\hline $6 c$. & 17,0 & 0,0 & 0,0 & 0 & 0 & 0,0 & 0,0 & 0,0 & 0,0 & 0,0 \\
\hline 7. Suporte e cuidados ... & & 0,0 & & & & & & & & \\
\hline $7 \mathrm{a}$. & 4,0 & 1140,0 & 5,7 & 30 & 285 & 94,7 & 38,0 & 3,8 & 15,2 & 40,1 \\
\hline $7 \mathrm{~b}$. & 32,0 & 512,0 & 2,6 & 11 & 16 & 5,3 & 17,1 & 1,7 & 17,6 & 102,9 \\
\hline 8. Tarefas administrativas & & 0,0 & & & & & & & & \\
\hline $8 a$. & 4,2 & 1188,6 & 5,9 & 30 & 283 & 94,0 & 39,6 & 3,9 & 13,1 & 33,0 \\
\hline $8 \mathrm{~b}$. & 23,2 & 417,6 & 2,1 & 16 & 18 & 6,0 & 13,9 & 1,4 & 5,7 & 40,9 \\
\hline 8c. & 30,0 & 0,0 & 0,0 & 0 & 0 & 0,0 & 0,0 & 0,0 & 0,0 & 0,0 \\
\hline Suporte ventilatório & & 0,0 & & & & & & & & \\
\hline 9. & 1,4 & 113,4 & 0,6 & 30 & 81 & 26,9 & 3,8 & 0,4 & 1,8 & 48,8 \\
\hline 10. & 1,8 & 97,2 & 0,5 & 18 & 54 & 17,9 & 3,2 & 0,3 & 2,6 & 81,2 \\
\hline 11. & 4,4 & 299,2 & 1,5 & 24 & 68 & 22,6 & 10,0 & 1,0 & 6,8 & 68,2 \\
\hline Suporte cardiovascular & & 0,0 & & & & & & & & \\
\hline 12. & 1,2 & 15,0 & 0,1 & 6 & 12,5 & 4,2 & 0,5 & 0,0 & 0,0 & 0,0 \\
\hline 13. & 2,5 & 70,0 & 0,3 & 17 & 28 & 9,3 & 2,3 & 0,2 & 1,1 & 48,3 \\
\hline 14. & 1,7 & 0,0 & 0,0 & 0 & 0 & 0,0 & 0,0 & 0,0 & 0,0 & 0,0 \\
\hline 15. & 7,1 & 0,0 & 0,0 & 0 & 0 & 0,0 & 0,0 & 0,0 & 0,0 & 0,0 \\
\hline Suporte renal & & 0,0 & & & & & & & & \\
\hline 16. & 7,7 & 0,0 & 0,0 & 0 & 0 & 0,0 & 0,0 & 0,0 & 0,0 & 0,0 \\
\hline 17. & 7 & 973,0 & 4,9 & 30 & 139 & 46,2 & 32,4 & 3,2 & 13,6 & 41,8 \\
\hline Suporte neurológico & & 0,0 & & & & & & & & \\
\hline 18. & 1,6 & 0,0 & 0,0 & 0 & 0 & 0,0 & 0,0 & 0,0 & 0,0 & 0,0 \\
\hline Suporte metabólico & & 0,0 & & & & & & & & \\
\hline 19. & 1,3 & 0,0 & 0,0 & 0 & 0 & 0,0 & 0,0 & 0,0 & 0,0 & 0,0 \\
\hline 20. & 2,8 & 50,4 & 0,3 & 12 & 18 & 6,0 & 1,7 & 0,2 & 0,9 & 53,6 \\
\hline 21. & 1,3 & 78,0 & 0,4 & 26 & 60 & 19,9 & 2,6 & 0,3 & 1,1 & 41,0 \\
\hline Intervenções específicas & & 0,0 & & & & & & & & \\
\hline 22. & 2,8 & 842,8 & 4,2 & 30 & 301 & 100,0 & 28,1 & 2,8 & 9,8 & 35,0 \\
\hline 23. & 1,9 & 117,8 & 0,6 & 26 & 62 & 20,6 & 3,9 & 0,4 & 2,4 & 62,4 \\
\hline \multicolumn{2}{|l|}{ SOMA } & 20057,6 & 100,0 & 30 & & & 668,6 & 66,6 & 3,5 & 0,53 \\
\hline \multicolumn{2}{|l|}{ TOTAL DE RECÉM NASCIDOS } & 301,0 & & 30 & & & 10,0 & & 3,5 & 35,0 \\
\hline
\end{tabular}

Figura 32: Distribuição da freqüência e a média de pontuação de cada item e subitem do NAS para RN internados na Unidade Neonatal, período de 06 de novembro de 2006 a 06 de dezembro de 2006, HU-USP. São Paulo, 2006. 
A Figura 33 mostra o perfil de pontuação do NAS dos RN na UTIN, em cada indicador (item e subitem). Os itens/subitens que ocorreram com maior freqüência foram:

1c - monitorização e controles: observação contínua por 4 horas ou mais $(100 \%)$;

3 - medicação (100\%);

4b - procedimentos de higiene: procedimento de 3 a 4 vezes que durem mais do que 2 horas (100\%);

6b - mobilização e posicionamento (procedimento realizado mais do que 6 vezes ou com 2 profissionais (100\%);

$7 a$ - suporte e cuidados aos familiares que requerem dedicação exclusiva por até 1 hora contínua ou fracionada $(98,1 \%)$;

8a - tarefas administrativas: processamento de dados clínicos (79\%);

9 - suporte respiratório: qualquer forma de ventilação mecânica; ventilação assistida com ou sem pressão expiratória final positiva, com ou sem relaxantes musculares, respiração espontânea com ou sem pressão expiratória final positiva (100\%);

10 - cuidados com vias áreas superiores $(96,1 \%)$;

11 - tratamentos para melhora da função pulmonar (100\%);

21 - alimentação enteral (88,6\%);

22 - intervenções específicas na unidade (100\%).

Essas atividades são executadas aos RN em estado grave, que exigem controles e cuidados intensivos devido: a instabilidade hemodinâmica e respiratória, a prematuridade, 0 extremo baixo peso ao nascer e 0 comprometimento dos diferentes órgãos sistêmicos. Além disso, devido às condições dos RN (o uso da intubação e da sedação dificultando a movimentação e o choro, por exemplo) eles são ainda mais vulneráveis e dependentes da equipe de enfermagem.

Quanto aos indicadores (itens/subitens) que não foram pontuados tem-se:

5 - cuidados com drenos, 14 - monitorização do átrio esquerdo, 16 técnicas de hemofiltração/técnicas dialíticas, 18 - medida de pressão intracraniana 
Luciana Bochembuzio

e o 19 - tratamento da acidose/alcalose metabólica complicada. Lembrando que o item 14 monitorização de artéria pulmonar não se aplica para RN. 


\begin{tabular}{|c|c|c|c|c|c|c|c|c|c|}
\hline ATIVIDADES BÁSICAS NAS & $\begin{array}{c}\text { PONTOS } \\
\text { NAS }\end{array}$ & $\begin{array}{c}\text { SOMA DOS } \\
\text { PONTOS NAS } \\
\text { NO PERÍODO }\end{array}$ & \begin{tabular}{|c|} 
DISTRIBUIÇÃO \\
\%DOS \\
PONTOS NAS \\
\end{tabular} & \begin{tabular}{|c|} 
DIAS EM QUE \\
OCORREU A \\
ATIVIDADE \\
\end{tabular} & $\begin{array}{c}\text { OCORRÊNCIA DA } \\
\text { ATIVIDADE NO } \\
\text { PERÍODO } \\
\end{array}$ & $\begin{array}{c}\text { PERCENTUUAL DA } \\
\text { OCORRÊNCIA NO } \\
\text { PERÍODO }\end{array}$ & $\begin{array}{c}\text { MÉDIA DIÁRIA } \\
\text { DOS PONTOS } \\
\text { NAS } \\
\end{array}$ & D.PADRÃO & C.V.\% \\
\hline \multicolumn{10}{|l|}{ 1. Monitorização e controles } \\
\hline $1 \mathrm{a}$. & 4,5 & 0,0 & 0,0 & 0 & 0 & 0,0 & 0,0 & 0,0 & 0,0 \\
\hline $1 \mathrm{~b}$. & 12,1 & 0,0 & 0,0 & 0 & 0 & 0,0 & 0,0 & 0,0 & 0,0 \\
\hline $1 \mathrm{c.}$ & 19,6 & 2058,0 & 21,6 & 30 & 105 & 100,0 & 68,6 & 15,2 & 22,2 \\
\hline 2. Investigações laboratoriais & 4,3 & 240,8 & 2,5 & 27 & 56 & 53,3 & 8,0 & 4,5 & 56,1 \\
\hline 3. Medicação & 5,6 & 588,0 & 6,2 & 30 & 105 & 100,0 & 19,6 & 4,4 & 22,2 \\
\hline \multicolumn{10}{|l|}{ 4. Procedimentos de higiene } \\
\hline $4 a$. & 4,1 & 0,0 & 0,0 & 0 & 0 & 0,0 & 0,0 & 0,0 & \\
\hline $4 \mathrm{~b}$. & 16,5 & 1732,5 & 18,2 & 30 & 105 & 100,0 & 57,8 & 12,8 & 22,2 \\
\hline $4 \mathrm{c}$. & 20,0 & 0,0 & 0,0 & 0 & 0 & 0,0 & 0,0 & 0,0 & 0,0 \\
\hline 5. Cuidados com drenos & 1,8 & 0,0 & 0,0 & 0 & 0 & 0,0 & 0,0 & 0,0 & 0,0 \\
\hline \multicolumn{10}{|l|}{ 6.Mobilização/posicionamento/ } \\
\hline $6 a$. & 5,5 & 0,0 & 0,0 & 0 & 0 & 0,0 & 0,0 & 0,0 & \\
\hline $6 \mathrm{~b}$. & 12,4 & 1302,0 & 13,6 & 30 & 105 & 100,0 & 43,4 & 9,6 & 22,2 \\
\hline $6 \mathrm{c.}$ & 17,0 & 0,0 & 0,0 & 0 & 0 & 0,0 & 0,0 & 0,0 & \\
\hline \multicolumn{10}{|l|}{\begin{tabular}{|l|}
7. Suporte e cuidados ... \\
\end{tabular}} \\
\hline $7 \mathrm{a}$. & 4,0 & 412,0 & 4,3 & 30 & 103 & 98,1 & 13,7 & 3,1 & 22,5 \\
\hline $7 \mathrm{~b}$. & 32,0 & 64,0 & 0,7 & 2 & 2 & 1,9 & 2,1 & 0,0 & 0,0 \\
\hline \multicolumn{10}{|l|}{ 8. Tarefas administrativas ... } \\
\hline $8 \mathrm{a}$. & 4,2 & 348,6 & \begin{tabular}{l|l}
3,7 \\
\end{tabular} & 30 & 83 & 79,0 & 11,6 & 3,9 & 33,8 \\
\hline $8 \mathrm{~b}$. & 23,2 & 510,4 & 5,3 & 21 & 22 & 21,0 & 17,0 & 4,2 & 24,7 \\
\hline $8 \mathrm{c}$. & 30,0 & 0,0 & 0,0 & 0 & 0 & 0,0 & 0,0 & 0,0 & 0,0 \\
\hline \multicolumn{10}{|l|}{ Suporte ventilatório } \\
\hline 9. & 1,4 & 147,0 & 1,5 & 30 & 105 & 100,0 & 4,9 & 1,1 & 22,2 \\
\hline 10. & 1,8 & 181,8 & \begin{tabular}{l|l|}
1,9 \\
\end{tabular} & 30 & 101 & 96,2 & 6,1 & 1,2 & 19,9 \\
\hline 11. & 4,4 & 462,0 & 4,8 & 30 & 105 & 100,0 & 15,4 & 3,4 & 22,2 \\
\hline \multicolumn{10}{|l|}{ Suporte cardiovascular } \\
\hline 12. & 1,2 & 1,2 & 0,0 & 1 & 1 & 1,0 & 0,0 & 0,0 & 0,0 \\
\hline 13. & 2,5 & 137,5 & 1,4 & 30 & 55 & 52,4 & 4,6 & 1,6 & 35,3 \\
\hline 14. & 1,7 & 0,0 & \begin{tabular}{l|l}
0,0 \\
\end{tabular} & 0 & 0 & 0,0 & 0,0 & 0,0 & 0,0 \\
\hline 15. & 7,1 & 7,1 & 0,1 & 1 & 1 & 1,0 & 0,2 & 0,0 & 0,0 \\
\hline \multicolumn{10}{|l|}{ Suporte renal } \\
\hline 16. & 7,7 & 0,0 & 0,0 & 0 & 0 & 0,0 & 0,0 & 0,0 & 0,0 \\
\hline 17. & 7 & 735,0 & 7,7 & 30 & 105 & 100,0 & 24,5 & 5,4 & 22,2 \\
\hline \multicolumn{10}{|l|}{ Suporte neurológico } \\
\hline 18. & 1,6 & 0,0 & 0,0 & 이 & 이 & 0,0 & 0,0 & 0,0 & 0,0 \\
\hline \multicolumn{10}{|l|}{ Suporte metabólico } \\
\hline 19. & 1,3 & 0,0 & 0,0 & 0 & 0 & 0,0 & 0,0 & 0,0 & 0,0 \\
\hline 20. & 2,8 & 128,8 & 1,3 & 25 & 46 & 43,8 & 4,3 & 1,2 & 28,0 \\
\hline 21. & 1,3 & 120,9 & 1,3 & 30 & 93 & 88,6 & 4,0 & 0,9 & 23,0 \\
\hline \multicolumn{10}{|l|}{ Intervenções específicas } \\
\hline 22. & 2,8 & 294,0 & 3,1 & 30 & 105 & 100,0 & 9,8 & 2,2 & 22,2 \\
\hline 23. & 1,9 & 70,3 & 0,7 & 25 & 37 & 35,2 & 2,3 & 1,2 & 52,7 \\
\hline \multicolumn{2}{|l|}{ SOMA } & 9541,9 & 100,0 & 30 & & & 318,1 & 68,9 & 21,6 \\
\hline \multicolumn{2}{|l|}{ TOTAL DE RECÉM NASCIDOS } & 105,0 & & 30 & & & 3,5 & 0,8 & 22,2 \\
\hline
\end{tabular}

Figura 33: Distribuição da freqüência e a média de pontuação de cada item e sub-item do NAS para RN internados na UTIN, período de 06 de novembro de 2006 a 06 de dezembro de 2006, HUUSP. São Paulo, 2006. 
A Figura 34 representa graficamente, o percentual de tempo despendido, pela equipe de enfermagem, nas atividades expressas no instrumento NAS, na Unidade Neonatal e UTIN.

Pode-se constatar, na figura 34, que as atividades relativas à monitorização e controles; procedimentos de higiene e mobilização e posicionamento correspondem a mais da metade do tempo dedicado ao cuidado, pela equipe de enfermagem, ou seja, 61,6\% na Unidade Neonatal e 53,4\% na UTIN.

No que se refere à proporção do tempo despendido na assistência ventilatória, verifica-se que na UTIN (8,3\%) é aproximadamente 3,3 vezes maior que na Unidade Neonatal (2,5\%).

Da mesma forma, à proporção de tempo despendido nas atividades que dão suporte renal representam, aproximadamente, o dobro do tempo na UTIN $(10,3 \%)$ em comparação à Unidade Neonatal $(5,5 \%)$. Com relação ao tempo dedicado nas atividades de suporte cardiovascular a proporção é três vezes maior na UTIN (1,5\%) do que na Unidade Neonatal (0,5\%).

As diferenças de tempo despendido nessas atividades diferenciam o perfil de necessidades requeridas pelos $\mathrm{RN}$, atendidos nessas Unidades. 


\section{ATIVIDADES BÁSICAS}

1. Monitorização e controles

2. Investigações laboratoriais

3. Medicação

4. Procedimentos de higiene

6.Mobilização/posicionamento

7.Suporte e cuidados ...

8. Tarefas administrativas ...

Suporte ventilatório

Suporte cardiovascular

Suporte renal

Intervenções específicas

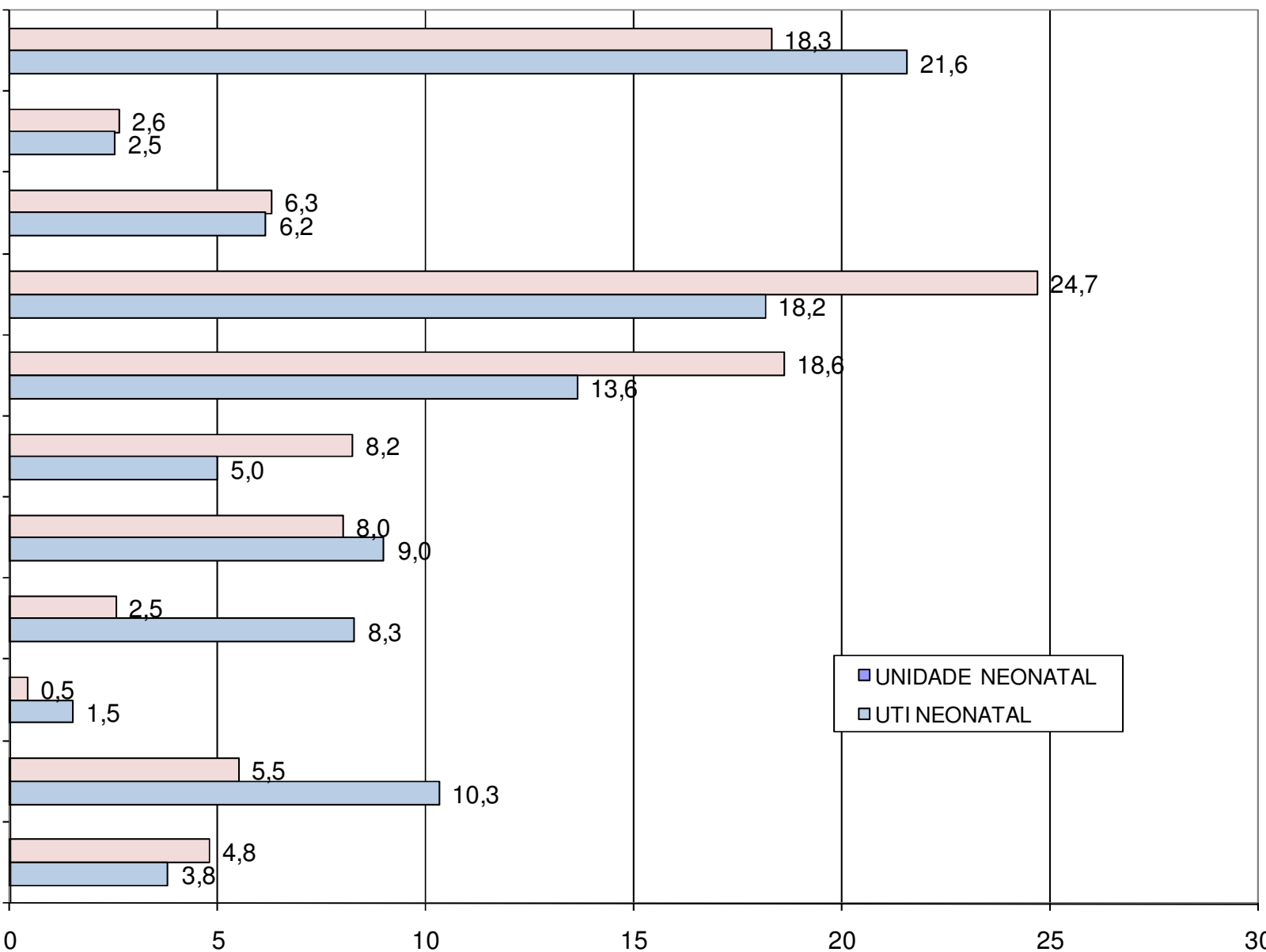

$30 \%$

Figura 34: Comparação entre cada item e subitem do NAS que demandam maior tempo da equipe de enfermagem no cuidado dos RN internados na Unidade Neonatal e UTIN, período de 06 de novembro de 2006 a 06 de dezembro de 2006, HU-USP. São Paulo, 2006. 


\section{CONCLUSÕES}

A falta de um instrumento padronizado capaz de identificar variações nas atividades do cuidado enfermagem, quantificar a carga de trabalho e adequar o quadro de profissionais às necessidades dos $\mathrm{RN}$, justifica o desenvolvimento desta pesquisa.

A pesquisa foi realizada na Unidade Neonatal e Unidade de Terapia Intensiva Neonatal do Hospital Universitário da Universidade de São Paulo (HUUSP), para avaliar o resultado da aplicação do instrumento NAS como medida da carga de trabalho de enfermagem em neonatologia.

O instrumento NAS foi aplicado no período de 06 de novembro a 06 de dezembro de 2006, 301 vezes na Unidade Neonatal e 106 vezes na UTIN. Participaram do estudo $59 \mathrm{RN}$, destes 48 admitidos na Unidade Neonatal e 11 na UTIN.

$\mathrm{Na}$ Unidade Neonatal $47,9 \%$ da amostra eram do sexo masculino e $52,1 \%$ do sexo feminino. Predominaram RN nascidos com mais de 38 semanas de gestação. Grande parte dos pacientes foi procedente do Alojamento Conjunto $(43,8 \%)$ e Centro Obstétrico (31,2\%). Em relação ao peso de nascimento, 58.4\% dos casos tinham peso entre $2500 \mathrm{~g}$ - 3499g. $83,3 \%$ dos RN internados permaneceram menos de 7 dias no hospital.

$\mathrm{Na}$ UTIN $63,6 \%$ da amostra eram do sexo masculino e $36,4 \%$ do sexo feminino. Com relação à idade gestacional houve um equilíbrio entre os valores: $36,4 \%$ para os RN nascidos com mais de 38 semanas de gestação e para os com menos de 32 semanas e $27,2 \%$ para aqueles com idade entre 33 e 37 semanas. Grande parte dos pacientes foi procedente do Centro Obstétrico (63,6\%). Em relação ao peso de nascimento, $45,5 \%$ dos casos tinham peso entre $1500 \mathrm{~g}-$ $2499 \mathrm{~g}$ e $27,2 \%$ entre $2500 \mathrm{~g}$ - $3499 \mathrm{~g}$. $54,5 \%$ dos RN permaneceram mais de 30 dias internados.

Para a Unidade Neonatal os indicadores (itens/subitens) mais freqüentemente pontuados foram: 1b - monitorização e controles; 3 - medicação; $4 b$ - procedimentos de higiene; $6 \mathrm{~b}$ - mobilização e posicionamento; $7 \mathrm{a}$ - suporte e 
cuidados aos familiares; 8a - tarefas administrativas e 22 - intervenções específicas na unidade.

A pontuação do NAS médio para a Unidade Neonatal foi de 66,9 pontos ( \pm 3,5 pontos). Nota-se que os RN internados geram carga de trabalho considerável enquanto permanecem na Unidade (em média, 67\% do tempo de 1 profissional de enfermagem). Ainda em relação ao tempo de assistência, considerando que cada ponto NAS equivale a 14,4 min (14 $\mathrm{min} 24 \mathrm{seg}$ ), corresponderiam à média de 963,4 min ou cerca de 16h 04 min de assistência por RN/dia. A Resolução COFEN no 293/04 (2004) preconiza 9h 24 min, o estudo de Rogenski (2006) identificou $11 \mathrm{~h} 24 \mathrm{~min}$.

O valor médio para a equipe de enfermagem calculada pela pontuação do NAS obtido da amostra do estudo foi de 26,7 profissionais. Em média, a equipe disponível em serviço foi de 20,7 profissionais. O número médio de profissionais requerido, segundo o NAS foi $29 \%$ mais elevado do que no quadro de profissionais de enfermagem disponível para a Unidade Neonatal. Isso pode indicar que nessa unidade deve haver sobrecarga de trabalho.

Para a UTIN os indicadores (itens/subitens) mais pontuados foram: 1c monitorização e controles; 3 - medicação; 4b - procedimentos de higiene; $6 b$ mobilização e posicionamento; 7a - suporte e cuidados aos familiares; 8a - tarefas administrativas; 9 - suporte ventilatório; 10 - cuidados com vias áreas superiores; 11 - tratamento para melhora da função pulmonar; 21 - alimentação enteral e 22 intervenções específicas.

A pontuação do NAS médio para a UTIN foi de 91,1 pontos ( \pm 4,0 pontos). Nota-se que os RN internados geram uma carga de trabalho muito elevada enquanto permanecem na Unidade (em média, 90\% do tempo de 1 profissional de enfermagem). Ainda em relação ao tempo de assistência, considerando que cada ponto NAS equivale a 14,4 min (14 min $24 \mathrm{seg}$ ), corresponderiam à média de 1311,9 min ou cerca de 21h 54 min de assistência por RN/dia. A Resolução COFEN no 293/04 (2004) preconiza 17h 54 min e a Portaria do Ministério da Saúde nº 3432/98 (1998) estabelece 19h 12 min. 
O valor médio para a equipe de enfermagem calculada pela pontuação do NAS obtido da amostra do estudo foi de 12,8 profissionais. Em média, a equipe disponível em serviço foi de 12,0 profissionais. A diferença entre o valor médio da equipe de enfermagem disponível e o valor médio da equipe de enfermagem requerida para o cuidado é menor que $1,7 \%$ sendo significativamente semelhantes e indicam que não havia sobrecarga de serviço na UTIN, baseados nestes valores.

A aplicação do instrumento NAS possibilitou identificar a proporção do tempo despendido pela equipe de enfermagem ao $\mathrm{RN}$, nas unidades estudadas. As intervenções/atividades de enfermagem que mais despendem o tempo da equipe de enfermagem, em ambas as unidades foram: monitorização e controles; procedimentos de higiene e mobilização e posicionamento, representando na Unidade Neonatal $61,1 \%$ do tempo de assistência e 53,4\% na UTIN.

O tempo dedicado pela equipe de enfermagem nas intervenções/atividades relativas ao suporte ventilatório (2,5\% na Unidade Neonatal e $8,3 \%$ na UTIN) e suporte renal (5,5\% na Unidade Neonatal e $10,3 \%$ na UTIN) diferenciam o perfil desses pacientes quanto ao tipo de assistência requerida em cada unidade. Essas atividades demandam uma carga de trabalho decorrente não só do tipo de cuidado, mas também do diagnóstico e da terapêutica do RN.

A aplicação do NAS permitiu a identificação e as variações da freqüência das intervenções/atividades de enfermagem requeridas nas unidades estudadas.

Os resultados encontrados sugerem que o instrumento NAS é capaz de fornecer informações que contemplam os diversos processos envolvidos no cuidado ao RN na assistência semi-intensiva e intensiva.

Portanto, o NAS foi identificado, neste estudo, como um instrumento adequado para medir a carga de trabalho da equipe de enfermagem na área neonatal uma vez que considera as necessidades de cuidado dos RN e pode ser utilizado como parâmetro para possibilitar o dimensionamento de pessoal de enfermagem nas Unidades estudadas. 


\section{REFERÊNCIAS}

1. Als $\mathrm{H}$. A synactive model of neonatal behavior organization: frameworks for the assessment of neurobehavioral development in the premature infant and for support of infants and parents in the neonatal intensive care environment. Phys Occup Ther Pediatr. 1986; 6: 3-54.

2. Bochembuzio L. Instrumento para classificação de recém-nascidos de acordo com o grau de dependência. [dissertação]. São Paulo (SP): Escola de Enfermagem da Universidade de São Paulo; 2002.

3. Bochembuzio L, Gaidzinski RR. Instrumento para classificação de recém-nascidos de acordo com o grau de dependência de cuidados de enfermagem. Acta Paul de Enferm. 2005; 18(4): 382-9.

4. Brasil. Ministério da Saúde. Portaria no 3432, de 12 de agosto de 1998. Estabelece critérios de classificação para as Unidades de Tratamento Intensivo - UTI. Diário Oficial da República Federativa do Brasil, Brasília, 13 de ago. 1998. Seção 1, p.108-10.

5. Brito ASJ de, Matsuo T, Gonzalez MRC, Carvalho ABR de, Ferrari LSL. Escore CRIB, peso ao nascer e idade gestacional na avaliação do risco de mortalidade neonatal. Rev Saúde Pública.2003; 37(5): 597-602.

6. Broughton SJ, Berry A, Jacobe S, Cheeseman P, Tarnow-Mordi WO, Greenough A and Neonatal Intensive Care Unit Study Group. The mortality index for neonatal transportation score: a new mortality prediction model for retrieved neonates. Pediatrics 2004; 114; 424-428.

7. Chamberlain JM, Pattel KM, Pollack MM. The pediatric risk of hospital admission score: a second-generation severity-of-illness score for pediatric emergency patients. Pediatrics 2005; 115; 2; 388-395.

8. Conishi RMY. Avaliação do NAS - Nursing activities Score - como instrumento de medida de carga de trabalho de enfermagem em UTI geral adulto [dissertação]. São Paulo (SP): Escola de Enfermagem, Universidade de São Paulo; 2005.

9. Conselho Federal de Enfermagem. Resolução ํo 293, de 21 de setembro de 2004. Fixa e estabelece parâmetros para dimensionamento do quadro de profissionais de enfermagem nas unidades assistenciais das instituições de saúde e assemelhados [on line]. Rio de Janeiro, 2004. Disponível em: http://corensp.org.br/072005/ (05 jul 2007). 
10. Costa MTZ da, Ventura GB, Melo AMAGP, Okay Y, Ramos JLA, Vaz FAC. CRIB escore: um instrumento para avaliar o risco de óbito em recém-nascidos prematuros. Pediatria (São Paulo). 1998; 20(3): 255260.

11. Cullen DJ, Civetta JM, Briggs BA, Ferrara LC. Therapeutic intervention scoring system: a method for quantitative comparision of patient care. Crit Care Med. 1974; 2(2): 57-60.

12. Dias MCCB. Aplicação do nursing activities score - NAS - como instrumento de medida de carga de trabalho de trabalho de enfermagem em UTI cirúrgica cardiológica. [dissertação]. São Paulo (SP): Escola de Enfermagem da Universidade de São Paulo; 2006.

13. Dini AP. Sistema de classificação de pacientes pediátricos: construção e validação de instrumento. [dissertação]. São Paulo (SP): Universidade Estadual de Campinas. Faculdade de Ciências Médicas; 2007.

14. Feldman LB, Gatto MAF, Cunha ICKO. História da evolução da qualidade hospitalar: dos padrões à acreditação. Acta Paul Enferm. 2005; 18(2): 213-19.

15. Fugulin FMT, Silva SHS, Shimizu HE, Campos FPF. Implantação do sistema de classificação de pacientes na unidade de clínica médica do hospital universitário da USP. Rev Med HU-USP 1994; 4(1/2): 63-8.

16. Fugulin FMT, Gaidzinski RR, Kurcgant P. Sistema de classificação de pacientes: identificação do perfil assistencial dos pacientes das unidades de internação do HU-USP. Rev Latino-Am. Enfermagem. 2005; 13(1): 110.

17. Gaidzinski RR Dimensionamento de pessoal de enfermagem em instituições hospitalares. [tese]. São Paulo (SP): Escola de Enfermagem da Universidade de São Paulo; 1998.

18. Georgieff MK, Mills MM, Bhatt P. Validation of two scoring systems which assess the degree of physiologic instability in critically ill newborn infants. Crit Care Med. 1989; 17: 17-21.

19. Gonçalves LA. Fatores associados à carga de trabalho de enfermagem em unidade de terapia intensiva de adultos no primeiro dia de internação. [dissertação]. São Paulo (SP): Escola de Enfermagem da Universidade de São Paulo; 2006. 
20. Gray JE, Richardson DK, McCormick MD, Workman-Daniels K, Goldmann DA. Neonatal therapeutic intervention scoring system: a therapy-based severity-of-illness index. Pediatrics. 1992; 90 (4): 561-67.

21. Gualda DMR. A organização do Departamento de Enfermagem do Hospital Universitário da Universidade de São Paulo: filosofias e pressupostos acadêmico-assistenciais. In: Cianciarullo TI, Gualda DMR, Melleiro MM, Anabuki MH. Sistema de assistência de enfermagem: evolução e tendências. São Paulo: Ícone; 2001; p.93-107.

22. Horta WA. Processo de enfermagem. São Paulo: EPU/EDUSP; 1979.

23. International Neonatal Network. The CRIB (clinical risk index for babies) score: a tool for assessing initial neonatal risk and comparing performance of neonatal intensive care units. Lancet. 1993; 342: 193-98.

24. Keene AR, Cullen DJ. Therapeutic intervention scoring system: update 1983. Crit Care Med. 1983; 11: 1-3.

25. Knaus WA, Zimermann JE, Wagner DP, et al. APACHE - acute physiology and chronic health evaluation: a physiologically based classification system. Crit Care Med. 1981; 9: 591-597.

26. Knaus WA, Zimermann JE, Wagner DP, et al. The APACHE III prognostic system: risk prediction of hospital mortality for critically III hospitalized adults. Chest. 1991; 100: 1619-1636.

27. Kruse JA, Thill-Baharozian MC, Carlson RW. Comparision of clinical assessment with APACHE $\|$ for predicting mortality risk in patients admitted to a medical intensive care unit. JAMA. 1988; 260(12): 17391742.

28. Livianu J, Anção MS, Akamine N, Andrei AM. Índices prognósticos em unidade de terapia intensiva. In: Knobel E. Condutas no paciente grave. São Paulo: Atheneu; 1994. p. 823-33.

29. Manthey M. A prática de primary nursing (enfermeira principal) Celebrando mais de 25 anos de melhoria do tratamento de pacientes. Boston: Blackwell Scientific Publications; 1980. 85p.

30. Martha VF, Garcia PC, Piva JP, Einlot PR, Bruno F, Rampon V. Comparação entre dois escores de prognóstico (PRISM e PIM) em unidade de terapia intensiva pediátrica. J Pediatr (Rio J). 2005; 81:25964. 
31. Matsuoka OT et al. Valor preditivo do "Clinical Risk Index for Babies" para o risco de mortalidade neonatal. Rev. Saúde Pública. 1998; 32 (6): $550-55$.

32. McCloskey JC, Bulechek GM. Classificação das intervenções de enfermagem. Trad. de Regina Machado Garcez. $3^{\mathrm{a}}$ Ed. Porto Alegre: Artmed; 2004.

33. Mendes RIP. Índice de utilização de tecnologias na avaliação dos processos assistenciais de recém-nascidos prematuros. [dissertação]. Rio de Janeiro (RJ): Instituto Fernandes Figueira da Fundação Oswaldo Cruz; 2005.

34. Mendes I, de Carvalho M, Almeida RT, Moreira ME. Use of technology as an evaluation tool of clinical care in preterm newborns. J Pediatr (Rio J). 2006; 82: 371-6.

35. Miranda DR, Rijk A, Schaufeli W. Simplified therapeutic intervention scoring system: the TISS-28 itens-results from a multicenter study. Crit Care Med. 1996; 24 (1): 64-73.

36. Miranda DR, Raoul N, Rijk A, Schaufeli W, lapichino G. Nursing activities score. Crit Care Med. 2003; 31(2): 374-82.

37. Motta PR. Transformação organizacional: a teoria e a prática de inovar. $3^{a}$ reimpressão. Rio de Janeiro: Ed Qualimark, 2000. 224p.

38. Nascimento LFC, Ramos R dos S. Aplicação do escore CRIB como preditor de óbito em unidade de terapia intensiva neonatal: uma abordagem ampliada. Rev. Bras. Saúde Mater. Infant. abril/jun. 2004; 4(2): 151-57.

39. North American Nursing Diagnosis Association. Diagnóstico de Enfermagem da NANDA: Definições e classificação: 2001-2002. Porto Alegre: Artmed; 2002.

40. Nunes B. Tradução para o português e validação de um instrumento de medida de gravidade na UTI: TISS-28 Therapeutic Intervention Scoring System. [dissertação]. São Paulo (SP): Escola de Enfermagem da Universidade de São Paulo; 2000.

41. Orem DE. Nursing concepts of pratice. 4ed. St Louis, Mosby-Year, 1991. 
42. Padilha KG, Sousa RMC de, Miyadahira AMK, Cruz DALM da, Vattimo MFF, Kimura M, Grossi SAA, Silva MCM da, Cruz VF, Ducci AJ. Therapeutic intervention scoring system - 28 (TISS-28): diretrizes para aplicação. Rev Esc Enferm USP. 2005; 39(2): 229-33.

43. Parry G, Tucker J, Tarnow-Mordi W, UK Neonatal Staffing Study Collaborative Group. CRIB II: an update of the clinical risk index for babies score. Lancet. 2003; 361(9371): 1789-91.

44. Pena FPM, Malik AM. Administração estratégica em hospitais. São Paulo (SP): Fundação Getúlio Vargas - EAESP; 2003.

45. Perroca MG. Instrumento de classificação de pacientes de Perroca: validação clínica. [tese]. São Paulo (SP): Escola de Enfermagem da Universidade de São Paulo; 2000.

46. Polit D, Hungler BP. Fundamentos de pesquisa em enfermagem. $3^{\text {a }}$ ed. Porto Alegre: Artes Médicas; 1995. Delineamento da Pesquisa; p. $107-$ 40.

47. Pollack MM, Yeh TS, Ruttiman UE, Holbrook PR, Fieds Al. Evaluation of pediatric intensive care. Crit Care Med. 1984; 12: 376-83.

48. Pollack MM, Ruttimann UE, Getson PR. Pediatric risk of mortality (PRISM) score. Crit Care Med. 1988; 16(11): 1110-1116.

49. Pollack MM, Pattel KM, Ruttimann UE. PRISM III: an update pediatric risk of mortality score. Crit Care Med. 1996; 24(5): 743-751.

50. Queijo AF, Padilha KG. Instrumento de medida de carga de trabalho de enfermagem em Unidade de Terapia Intensiva: Nursing Activities Score (NAS). Rev Paul Enf 2004; 23(2): 114-22.

51. Richardson DK, Gray JE, McCormick MC, Workman K, Goldmann DA. Score for neonatal acute psysiology: a psysiologic severity index for neonatal intensive care. Pediatrics 1993;91;617-623.

52. Richardson DK, Corcoran JD, Escobar GJ, Lee SK et al. SNAP II and SNAPPE II: simplified newborn illness severity and mortality risk scores. J Pediatr. 2001; 138: 92-100.

53. Rogenski KE. Tempo de assistência de enfermagem: identificação e análise em instituição hospitalar de ensino. [dissertação]. São Paulo (SP): Escola de Enfermagem da Universidade de São Paulo; 2006. 
54. Santos NC. Construção de instrumento para identificação da carga de trabalho da equipe de enfermagem em unidades pediátricas. [dissertação]. São Paulo (SP): Escola de Enfermagem da Universidade de São Paulo; 2006.

55. Schiesari LMC. Cenário da acreditação hospitalar no Brasil: evolução histórica e referências externas. [dissertação]. São Paulo (SP): Faculdade de Saúde Pública da Universidade de São Paulo; 1999.

56. Silveira RC, Schlabendorff M, Procianoy RS. Valor preditivo dos escores SNAP e SNAP-PE na mortalidade neonatal. Jornal de Pediatria. 2001; 77(6): 455-460.

57. Tranquitelli AM. Adaptação transcultural de um instrumento de medida de trabalho de enfermagem em Unidade de Terapia Intensiva: Type VI Methodology - Pacient Classification Tool. [tese]. São Paulo (SP): Escola de Enfermagem da Universidade de São Paulo; 2005.

58. Terzi R. Índices prognósticos em medida intensiva II: métodos. Rev Bras Terapia Intensiva 1997; 9 (1): 40-9.

59. Universidade de São Paulo. Hospital Universitário. Departamento de Enfermagem. Manual de gerenciamento da Unidade Neonatal. São Paulo, SP: 2006.

60. Universidade de São Paulo. Hospital Universitário. Departamento de Enfermagem. Manual de gerenciamento da Unidade de Terapia Intensiva Neonatal. São Paulo, SP: 2006.

61. Universidade de São Paulo. Hospital Universitário. Regimento 5 [on line] São Paulo; 2002. Disponível em: <http://www.hu.usp.br/arquivos/regimento hu. pdf> (01 jul 2007).

62.Zardo MS, Procianoy RS. Comparação entre diferentes scores de risco de mortalidade em unidade de tratamento intensivo neonatal. Rev Saúde Pública. 2003; 37(5): 591-6. 


\section{ANEXOS - Anexo 1 - Diagnóstico de enfermagem - UNIDADE NEONATAL - HU-USP}

ITEM

DIAGNÓSTICOS DE ENFERMAGEM / CARACTERÍSTICAS DEFINIDORAS / FATORES RELACIONADOS / FATORES DE RISCO

1 AUMENTO DO NIVEL DE BILIRRUBBINA: COndiç̧oes fisiologgicas/ patolöogicas

2

3

respiração; incapacidade de iniciar ou sustentar uma sucção eficaz; jejum oral prolo anormalidade anatômica

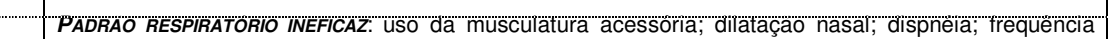
respiratória alterada

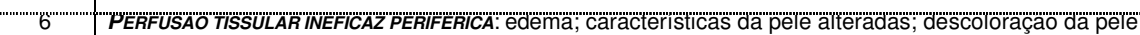

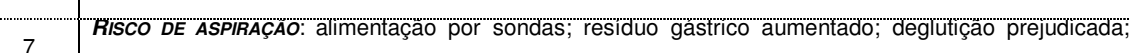

esfíncter esofágico inferior incompetente

8 RISCO DE INTEGRIDADE DA PELE PREJUDICADA: fatoroses mecänicos; excreçoes ou secreçoes, medicaçao

9

gestacional (GIG); mãe diabética; retardo na amamentação, hipotonia, tremores

RISCO DE PATERNIDADE OU MATERNIDADE PREJUDICADA: estresse; nascimeñto premätüro, separaçaco prolongada dos pais

11

(1)

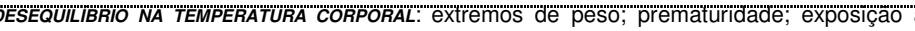

mbientes frios ou quentes; doença ou trauma afetando a regulação de temperatura

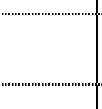

\section{AsSINATURA/COREN}

EVOLUCÇAO: P=PR̈ESENTE; ME=MELHORADO; PI=PIORADO; I=INALTERADO; R=RESOLVVIDO

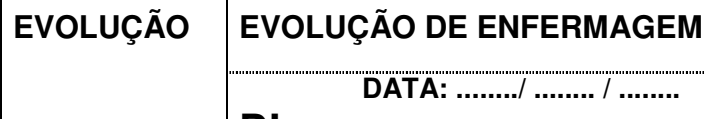

HORA:

DI:

DV:

\begin{tabular}{|l|l}
\hline & \\
\hline &
\end{tabular}

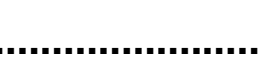


Luciana Bochembuzio

\section{Anexo 2- Prescrição de enfermagem - UNIDADE NEONATAL - HU-USP}

\begin{tabular}{|c|c|c|c|}
\hline $\mathrm{N}$ & ITEM & PRESCRIÇÃO DE ENFERMAGEM & FREQUÊNCIA \\
\hline 1 & 1 & Oferecer dieta por bomba de infusão em & \\
\hline 2 & (1) & Manter / colocar rampa anti-refluxo & \\
\hline 3 & 1.5 & Observar distensáo abdominal / nauseas e vômitos $/$ refluxo gástrico & \\
\hline 4 & 1.10 & Observar alteraçāo estado mental / eficácia da sedaçâo' & \\
\hline 5 & 1.10 .16 & Aspirar: VAS/ endotraqueal com sonda $\mathrm{n}^{-2}$ & \\
\hline 6 & 1.10 .16 & Manter decübito elevado a & \\
\hline 7 & 2. & Instilar soro nasal & \\
\hline 8 & 2 & Verificar com a mäe a realizaçâo da ordenha diáría & \\
\hline 9 & 2 & Encaminhar a mae ao Banco de leite & \\
\hline 10 & 2.10 .16 & Observar padrāo respiratorio / queda de saturaçâo & \\
\hline 111 & 3 & Estimular / observar interaçāo dos pais com o RN / criança & \\
\hline 12 & 3 & Colocar RN / criança no colo dos pais & \\
\hline 13 & 3 & Incentivar a participação dos pais nos cuidados & \\
\hline 14 & 4 & $\mid$ Realizar curativo com / & \\
\hline 115 & 4.5 & Realizar, auxiliar, acompanhar higiene oral com & \\
\hline 116 & 4.5 & Realizar, auxiliar, acompanhar higiene ocular com & \\
\hline 17 & 4.5 & Manter / aplicar curativo / & \\
\hline 18 & 5 & Manter /colocar colchāo caixa de ovo / casulo & \\
\hline 19 & 5 & Rodiziar / registrar o local do sensor de oximetro de pulso. & \\
\hline 20 & 5.9 & Estimular / auxiliar / supervisionar / realizar: mudança de decúbito. & \\
\hline 21 & 5.6 .14 & "'Observar: débito urinarín / distensāo vesical" & \\
\hline 22 & 6 & Realizar higiene întima com água e sabonete neutro. & \\
\hline 23 & 7 & Manter temperatura da incubadora em & \\
\hline 24 & 7 & 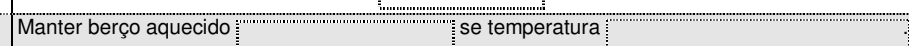 & \\
\hline 25 & 7.12 & Observar atividade / agitaçāo / prostraçăo & \\
\hline 266 & 7.16 & Observar perfusāo periferica & \\
\hline 27 & 8 & Manter extremidades aquecidas & \\
\hline 28 & 8.10 .16 & Observar coloraçáo / aspecto da pele & \\
\hline 29 & 8.14 .15 & Observar edema & \\
\hline 30 & 9 & Observar/estimular eliminaçoes intestinais & \\
\hline 31 & 9 & Verificar irradiância & \\
\hline 32 & 11 & Concentrar a realização de procedimentos & \\
\hline 33 & 11 & Respeitar horário de sono & \\
\hline 34 & 11 & Avaliar a necessidade de analgesicos antes da realização de procedimentos invasivos & \\
\hline 35 & 12 & Avaliar: local/intensidade qualidade / duraçao / prejüizos advindos da dor & \\
\hline 36 & 12.13 & Aplicar: frio / calor em & \\
\hline (37' & 14.15 & - Verificar glicoceto / densidade urinaria ${ }_{1}$ & \\
\hline 38 & 14.16 & Verificar PVC de & \\
\hline & & & \\
\hline & & & \\
\hline Assiin & $\prod_{\text {NATURAECC }}$ & & \\
\hline |Assin & NATURA E CC & & \\
\hline
\end{tabular}




\section{Anexo 3 - Diagnóstico de enfermagem - UTI NEONATAL - HU-USP}

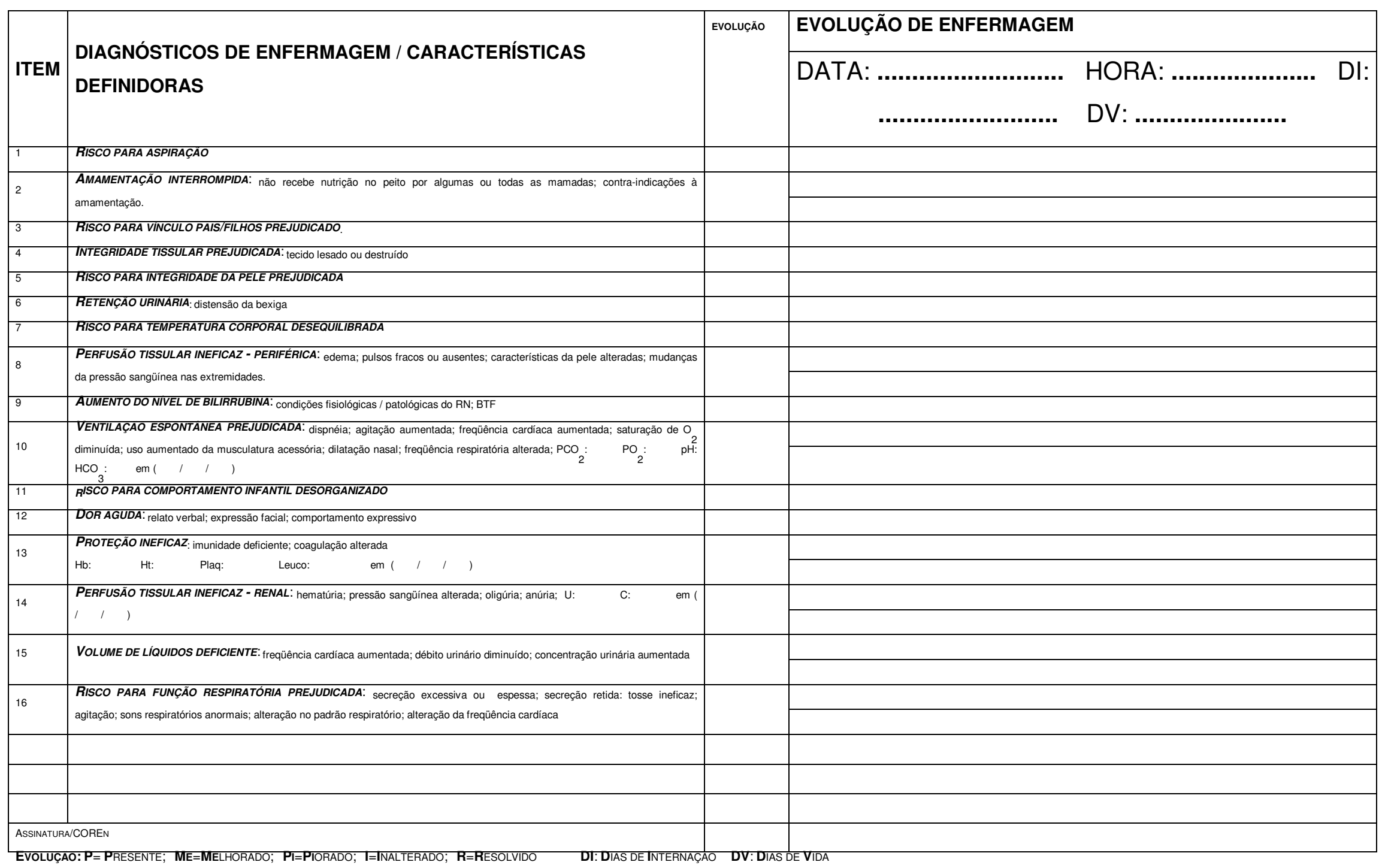




\section{Anexo 4 - Prescrição de enfermagem - UTI NEONATAL - HU-USP}

\begin{tabular}{|c|c|c|c|}
\hline $\mathrm{N}$ & ITEM & PRESCRIÇÃO DE ENFERMAGEM & FREQUÊNCIA \\
\hline 1 & 1 & Oferecer dieta por bomba de infusão em & \\
\hline "' & "1"i"' & Manter/ colocar rampa anti-refluxo & \\
\hline 3 & 7.5 & Observar distensaao abdominal'/nauseas e vomitos / refluxo gastrico & \\
\hline $4 "$ & 1.10 & Observar alteraçāo estado mental / eficácia da sedaçāo & \\
\hline $5 "$ & 1.10 .16 & Aspirar: VAS/endotraqueal com sonda n⿳-" & \\
\hline 6 & 1.10 .16 & Manter decúbito elevado a & \\
\hline 7 & |"2."' & Instilar soro nasal & \\
\hline 8 & 2 & Verificar com a măe a realizaçấo da ordenha diáría & \\
\hline 9 & 2 & Encaminhar a mäe ao Banco de leite & \\
\hline 10 & 2.10 .16 & Observar padrāo respiratorio / queda de saturaçāo & \\
\hline 111 & 3 & Estimular / observar interaçāo dos pais com o RN / criança & \\
\hline 12 & 3 & Colocar RN/ criançâ no colo dos pais & \\
\hline 13 & 3 & Incentivar a participaçāo dos pais nos cuidados & \\
\hline 14 & 4 & Realizar curativo com & \\
\hline 15 & 4.5 & Realizar, auxiliar, acompanhar higiene oral com & \\
\hline 16 & 4.5 & Realizar, auxiliar, acompanhar higiene ocular com & \\
\hline 17 & 4.5 & |em regiáo & \\
\hline 18 & 5 & Manter /colocar colchāo caixa de ovo / casulo & \\
\hline 19 & 5 & Rodiziar / registrar o local do sensor de oximetro de pulso. & \\
\hline 20 & 5.9 & Estimular / auxiliar / supervisionar/ realizar: mudança de decúbito. & \\
\hline 21 & 5.6 .14 & Observar: dèbito urinário / distensāo vesical' & \\
\hline 22 & 6 & "Reallizar higienene intima com agua e sabonete neutro." & \\
\hline 23 & 7 & Manter temperatura da incubadora em/lll & \\
\hline 24 & |7"' & Manter berço aquecido & \\
\hline 25 & 7.12 & Observar atividade/agitaçâo/ prostraçâa & \\
\hline 26 & 7.16 & Observar perfusāo periférica & \\
\hline 27 & 8 & Manter extremidades aquecidas & \\
\hline 28 & 8.10 .16 & Observar coloraçâao / aspecto da pele" & \\
\hline 29 & 8.14 .15 & Observar edema & \\
\hline 30 & & Observar/estimular eliminaçöes intestinais & \\
\hline 31 & 9 & "Verificar irradiância & \\
\hline 32 & 11 & Concentrar a realizaçāo de procedimentos & \\
\hline 33 & 111 & Respeitar horário de sono & \\
\hline 34 & 11 & Avaliar a necessidade de analgésicos antes da realizaçāo de procedimentos invasivos & \\
\hline 35 & 12 & Avaliar: local / intensidade / qualidade / duraçāo / prejuízos advindos da dor & \\
\hline 36 & 12.13 & Aplicar: frio / calor em & \\
\hline 37 & 14.15 & Verificar glicoceto / densidade urinária & \\
\hline 38 & 14.16 & Verificar PVC de $=\cdots$ & \\
\hline & & & \\
\hline & & & \\
\hline & & & \\
\hline & SINATURAE & COOREN & \\
\hline
\end{tabular}




\section{Anexo 5}

\section{FICHA DE IDENTIFICAÇÃO DEMOGRÁFICA E CLÍNICA DOS RECM-NASCIDOS}

Registro do RN:

Recém-nascido:

\section{Dados Demográficos}

Idade:

Sexo: $M() \quad F($ )

\section{Dados Clínicos}

Data da internação:

Hora/dias de internação:

Local de internação:

Motivo da internação:

Procedência:

Peso:

Altura:

Data de saída:

Condição de saída: 


\section{Anexo 6}

\section{ESCORE DE ATIVIDADES DE ENFERMAGEM - NAS}

\begin{tabular}{|c|c|}
\hline ATIVIDADES BÁSICAS & Pontos \\
\hline \multicolumn{2}{|l|}{ 1. MONITORIZAÇÃO E CONTROLES } \\
\hline 1a. Sinais vitais horários, cálculos e registro regular do balanço hídrico. & 4,5 \\
\hline $\begin{array}{l}\text { 1b. Presença à beira do leito e observação ou atividade contínua por } 2 \text { horas ou mais em algum } \\
\text { plantão, por razões de segurança, gravidade ou terapia, tais como: ventilação mecânica não } \\
\text { invasiva, desmame, agitação, confusão mental, posição prona, procedimentos de doação de } \\
\text { órgãos, preparo e administração de fluidos ou medicação, auxílio em procedimentos específicos. }\end{array}$ & 12,1 \\
\hline $\begin{array}{l}\text { 1c. Presença à beira do leito e observação ou atividade contínua por } 4 \text { horas ou mais em algum } \\
\text { plantão por razões de segurança, gravidade ou terapia, tais como os exemplos acima }\end{array}$ & 19,6 \\
\hline 2. INVESTIGAÇÕES LABORATORIAIS: bioquímica e microbiológicas & 4,3 \\
\hline 3. MEDICAÇÃO, exceto drogas vasoativas & 5,6 \\
\hline \multicolumn{2}{|l|}{ 4. PROCEDIMENTOS DE HIGIENE } \\
\hline $\begin{array}{l}\text { 4a. Realização de procedimentos de higiene tais como: curativos de feridas e cateteres } \\
\text { intravasculares, troca de roupa de cama, higiene corporal do paciente em situações especiais } \\
\text { (incontonência, vômito, queimaduras, feridas com secreção, curativos cirúrgicos complexos com } \\
\text { irrigação), procedimentos especiais (ex. isolamento). etc }\end{array}$ & 4,1 \\
\hline 4b. Realização de procedimento de higiene que durem mais do que 2 horas, em algum plantão & 16,5 \\
\hline 4c. Realização de procedimentos de higiene que durem mais do que 4 horas em algum plantão & 20,0 \\
\hline 5. CUIDADOS COM DRENOS - Todos (exceto sonda gástrica) & 1,8 \\
\hline
\end{tabular}

6. MOBILIZAÇÃO E POSICIONAMENTO incluindo procedimentos tais como: mudanças de decúbito, mobilização do paciente, transferência da cama para a cadeira; mobilização do paciente em equipe (ex. paciente imóvel, tração, posição prona)

\begin{tabular}{|l|c|}
\hline 6a. Realização do(s) procedimento(s) até 3 vezes em 24 horas & 5,5 \\
\hline $\begin{array}{l}\text { 6b. Realização do(s) procedimento(s) mais do que } 3 \text { vezes em } 24 \text { horas ou com } 2 \text { enfermeiros em } \\
\text { qualquer frequência }\end{array}$ & 12,4 \\
\hline 6c. Realização do(s) procedimento(s) com 3 ou mais enfermeiros em qualquer freqüência. & 17,0 \\
\hline
\end{tabular}

7. SUPORTE E CUIDADOS AOS FAMILIARES E PACIENTES incluindo procedimentos tais como telefonemas, entrevistas, aconselhamento. Frequetemente o suporte e cuidado, sejam aos familiares ou aos pacientes permitem à equipe continuar com outras atividades de enfermagem (ex. comunicação com o paciente durante procedimentos de higiene, comunicação com familiares enquanto presente à beira do leito observando o paciente)

7a. Suporte e cuidado aos familiares e pacientes que requerem dedicação exclusiva por cerca de uma hora em algum plantão tais como: explicar condições clínicas, lidar com a dor e angústia, lidar com circunstâncias familiares difíceis.

7b. Suporte e cuidado aos familiares e pacientes que requerem dedicacão exclusiva por 3 horas ou mais em algum plantão tais como: morte, circunstâncias trabalhosas (ex. grande número de familiares, problemas de linguagem, familiares hostis) 
Continuação - ESCORE DE ATIVIDADES DE ENFERMAGEM - NAS

\begin{tabular}{|c|c|}
\hline ATIVIDADES BÁSICAS (cont.) & Pontos \\
\hline \multicolumn{2}{|l|}{ 8. TAREFAS ADMINISTRATIVAS E GERENCIAIS } \\
\hline $\begin{array}{l}\text { 8a. Realização de tarefas de rotina tais como: processamento de dados clínicos, solicitação de } \\
\text { exames, troca de informações profissionais (ex. passagem de plantão, visitas clínicas) }\end{array}$ & 4,2 \\
\hline $\begin{array}{l}\text { 8b. Realização de tarefas administrativas e gerenciais que requerem dedicação integral por cerca } \\
\text { de } 2 \text { horas em algum plantão tais como: atividades de pesquisa, aplicação de protocolos } \\
\text { procedimentos de admissão e alta. }\end{array}$ & 23,2 \\
\hline $\begin{array}{l}\text { 8c. Realização de tarefas administrativas e gerenciais que requerem dedicação integral por cerca } \\
\text { de } 4 \text { horas ou mais de tempo em algum plantão tais como: morte e procedimentos de doação de } \\
\text { órgãos, coordenação com outras disciplinas }\end{array}$ & 30,0 \\
\hline \multicolumn{2}{|l|}{ SUPORTE VENTILATÓRIO } \\
\hline $\begin{array}{l}\text { 9. Suporte respiratório. Qualquer forma de ventilação mecânica/ventilação assistida } \\
\text { com ou sem pressão expiratória final positiva, com ou sem relaxantes musculares, } \\
\text { respiração espontânea com ou sem pressão expiratória final posistiva (ex CPAP ou } \\
\text { BiPAP), com ou sem tubo endotraqueal; oxigênio suplementar por qualquer método }\end{array}$ & 1,4 \\
\hline 10. Cuidado com vias aéreas artificiais. Tubo endotraqueal ou cânula de traqueostomia & 1,8 \\
\hline \begin{tabular}{|l|l|} 
11. Tratamento para melhora da função pulmonar. Fisioterpia torácica, espirometria \\
estimulada, terapia inalatória, aspiração endotraqueal.
\end{tabular} & 4,4 \\
\hline \multicolumn{2}{|l|}{ SUPORTE CARDIOVASCULAR } \\
\hline 12. Medicação vasoativa independente do tipo e dose & 1,2 \\
\hline $\begin{array}{l}\text { 13. Reposição intravenosa de grandes perdas de fluídos. Administração de fluídos > } \\
\text { 31/m2/dia independente do tipo de fluido administrado }\end{array}$ & 2,5 \\
\hline $\begin{array}{l}\text { 14. Monitorização do átrio esquerdo. cateter da artéria pulmonar com ou sem medida de } \\
\text { débito cardíaco. }\end{array}$ & 1,7 \\
\hline 15. Reanimação cardiorrespiratória nas últimas 24 horas (excluído soco precordial) & 7,1 \\
\hline \multicolumn{2}{|l|}{ SUPORTE RENAL } \\
\hline 16. Técnicas de hemofiltração. Técnicas dialíticas & 7,7 \\
\hline 17. Medida quantitativa do débito urinário (ex sonda vesical de demora) & 7,0 \\
\hline \multicolumn{2}{|l|}{ SUPORTE NEUROLÓGICO } \\
\hline 18. Medida de pressão intracraniana & 1,6 \\
\hline \multicolumn{2}{|l|}{ SUPORTE METABÓLICO } \\
\hline 19. Tratamento da acidose/alcalose metabólica complicada & 1,3 \\
\hline 20. Hiperalimentação intravenosa & 2,8 \\
\hline $\begin{array}{l}\begin{array}{l}\text { 21. Alimentação enteral. Através de tubo gástrico ou outra via gastrintestinal (ex: } \\
\text { jejunostomia) }\end{array} \\
\end{array}$ & 1,3 \\
\hline \multicolumn{2}{|l|}{ INTERVENÇÕES ESPECÍFICAS } \\
\hline $\begin{array}{l}\text { 22. Intervenções específicas na unidade de terapia intensiva. Intubação endotraqueal, } \\
\text { inserção de marca-passo, cardioversão, endoscopias. cirurgia de emergência no último } \\
\text { período de } 24 \text { horas, lavagem gástrica, Intervenções de rotinas sem conseqüências } \\
\text { diretas para as condições clínicas do paciente, tais como: Raio X, ecografia, } \\
\text { eletrocardiograma, curativos ou inserção de cateteres venosos ou arteriais, não estão } \\
\text { incluídos }\end{array}$ & 2,8 \\
\hline $\begin{array}{l}\text { 23. Intervenções específicas fora da unidade de terapia intensiva. Procedim } \\
\text { diagnósticos ou cirúrgicos. }\end{array}$ & 1,9 \\
\hline
\end{tabular}

Os sub-itens 1,4,6,7 e 8 são mutuamente excludentes 


\section{Anexo 7}

Avaliação diária das atividades NAS de cada um dos RN internados na Unidade Neonatal 
Luciana Bochembuzio

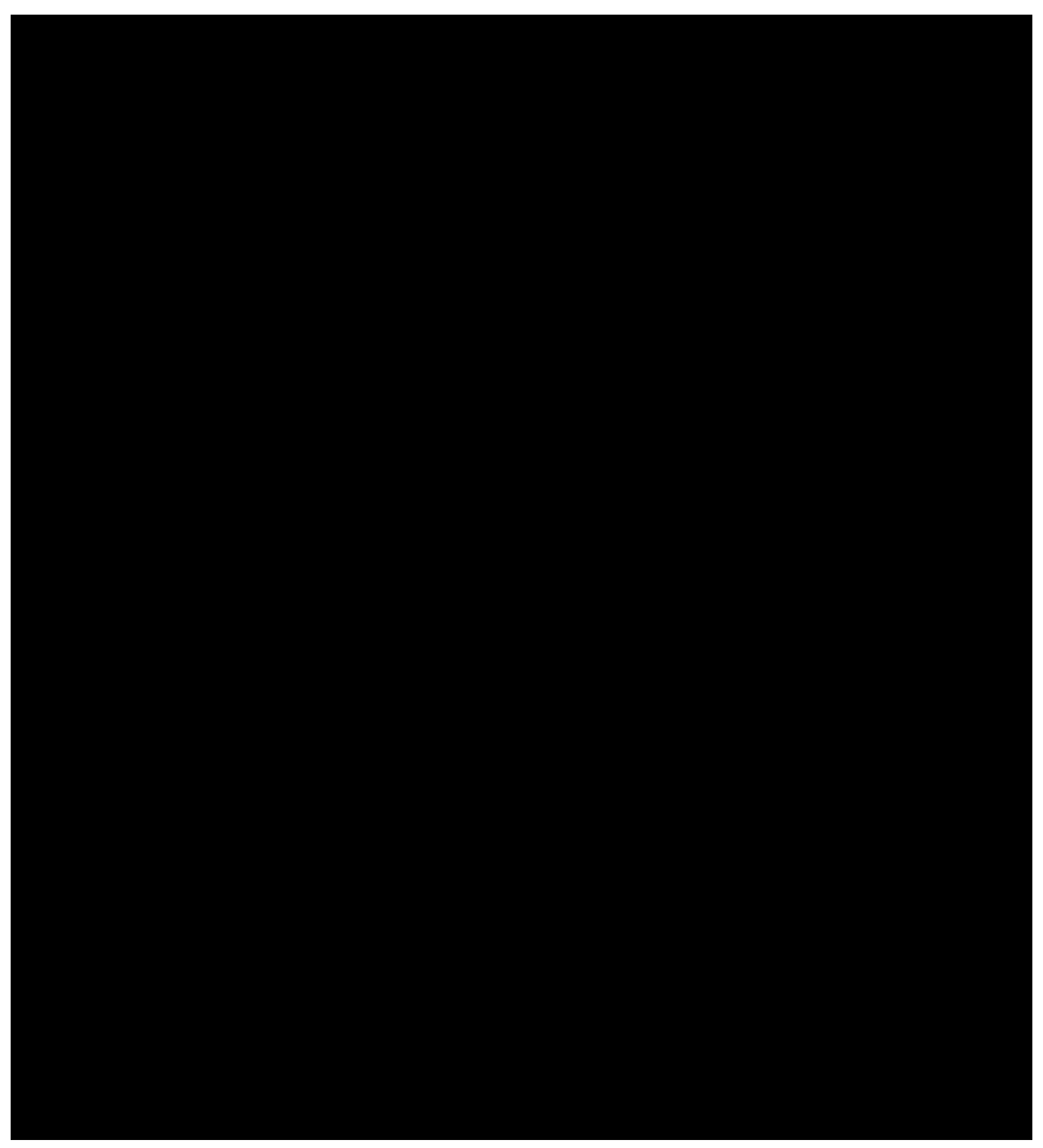


Luciana Bochembuzio

\begin{tabular}{|c|c|c|c|c|c|c|c|c|c|c|c|}
\hline \multirow{3}{*}{$\begin{array}{c}\text { NAS } \\
\text { ATIVIDADES BÁSICAS }\end{array}$} & \multirow[b]{3}{*}{ PONTOS } & \multicolumn{10}{|c|}{ sexta-feira, 10/11/2006 } \\
\hline & & \multicolumn{9}{|c|}{ RECÉM-NASCIDOS } & \multirow{2}{*}{$\begin{array}{r}\text { NO DIA } \\
99 \\
\end{array}$} \\
\hline & & $\mathrm{RN} 2$ & $\mathrm{RN} 3$ & RN5 & RN7 & RN9 & $\mathrm{RN} 13$ & $\mathrm{RN} 14$ & RN15 & RN23 & \\
\hline \multicolumn{12}{|l|}{ 1. Monitorização e controles } \\
\hline $1 \mathrm{a}$. & 4,5 & & & & & & & & & & \\
\hline $1 \mathrm{~b}$. & 12,1 & 12,1 & 12,1 & 12,1 & 12,1 & 12,1 & 12,1 & 12,1 & 12,1 & 12,1 & 108,9 \\
\hline 1c. & 19,6 & & & & & & & & & & \\
\hline 2. Investigações laboratoriais & 4,3 & & & & 4,3 & & & 4,3 & 4,3 & & 12,9 \\
\hline 3. Medicação & 5,6 & 5,6 & 5,6 & & 5,6 & 5,6 & 5,6 & & 5,6 & 5,6 & 39,2 \\
\hline \multicolumn{12}{|l|}{ 4. Procedimentos de higiene } \\
\hline $4 a$. & 4,1 & & & & & & & & & & \\
\hline $4 \mathrm{~b}$. & 16,5 & 16,5 & 16,5 & 16,5 & 16,5 & 16,5 & 16,5 & 16,5 & 16,5 & 16,5 & 148,5 \\
\hline 4c. & 20,0 & & & & & & & & & & \\
\hline 5. Cuidados com drenos & 1,8 & & & & & & & & & & \\
\hline \multicolumn{12}{|l|}{ 6.Mobilização/posicionamento } \\
\hline $6 a$. & 5,5 & & & & & & & & & & \\
\hline $6 \mathrm{~b}$. & 12,4 & 12,4 & 12,4 & 12,4 & 12,4 & 12,4 & 12,4 & 12,4 & 12,4 & 12,4 & 111,6 \\
\hline $6 c$. & 17,0 & & & & & & & & & & \\
\hline \multicolumn{12}{|l|}{ 7.Suporte e cuidados ... } \\
\hline $7 a$. & 4,0 & 4 & & 4 & 4 & 4 & 4 & 4 & 4 & 4 & 32 \\
\hline $7 \mathrm{~b}$. & 32,0 & & 32 & & & & & & & & 32 \\
\hline \multicolumn{12}{|l|}{ 8. Tarefas administrativas . } \\
\hline $8 \mathrm{a}$. & 4,2 & 4,2 & 4,2 & 4,2 & 4,2 & 4,2 & 4,2 & 4,2 & 4,2 & 4,2 & 37,8 \\
\hline $8 \mathrm{~b}$. & 23,2 & & & & & & & & & & \\
\hline 8c. & 30,0 & & & & & & & & & & \\
\hline \multicolumn{12}{|l|}{ Suporte ventilatório } \\
\hline 9. & 1,4 & & & 1,4 & & & & & 1,4 & & 2,8 \\
\hline 10. & 1,8 & & & & & & & & & & \\
\hline 11. & 4,4 & & & & & & & & & & \\
\hline \multicolumn{12}{|l|}{ Suporte cardiovascular } \\
\hline 12. & 1,2 & & & & & & & & & & \\
\hline 13. & 2,5 & & & & & & & & & & \\
\hline 14. & 1,7 & & & & & & & & & & \\
\hline 15. & 7,1 & & & & & & & & & & \\
\hline \multicolumn{12}{|l|}{ Suporte renal } \\
\hline 16. & 7,7 & & & & & & & & & & \\
\hline 17. & 7 & & & 7 & 7 & & & & 7 & 7 & 28 \\
\hline \multicolumn{12}{|l|}{ Suporte neurológico } \\
\hline 18. & 1,6 & & & & & & & & & & \\
\hline \multicolumn{12}{|l|}{ Suporte metabólico } \\
\hline 19. & 1,3 & & & & & & & & & & \\
\hline 20. & 2,8 & & & & & & & & & 2,8 & 2,8 \\
\hline 21. & 1,3 & & & & & & & & 1,3 & 1,3 & 2,6 \\
\hline \multicolumn{12}{|l|}{ Intervenções específicas } \\
\hline 22. & 2,8 & 2,8 & 2,8 & 2,8 & 2,8 & 2,8 & 2,8 & 2,8 & 2,8 & 2,8 & 25,2 \\
\hline 23. & 1,9 & & & & & 1,9 & & 1,9 & & 1,9 & 5,7 \\
\hline \multicolumn{2}{|l|}{ SOMA DOS PONTOS NAS } & 57,6 & 85,6 & 60,4 & 68,9 & 59,5 & 57,6 & 58,2 & 71,6 & 70,6 & 590 \\
\hline \multicolumn{2}{|l|}{ NAS MÉDIO NO DIA } & & & & & & & & & & 65,6 \\
\hline \multicolumn{2}{|l|}{ DESVIO PADRÃO } & & & & & & & & & & 9,5 \\
\hline
\end{tabular}




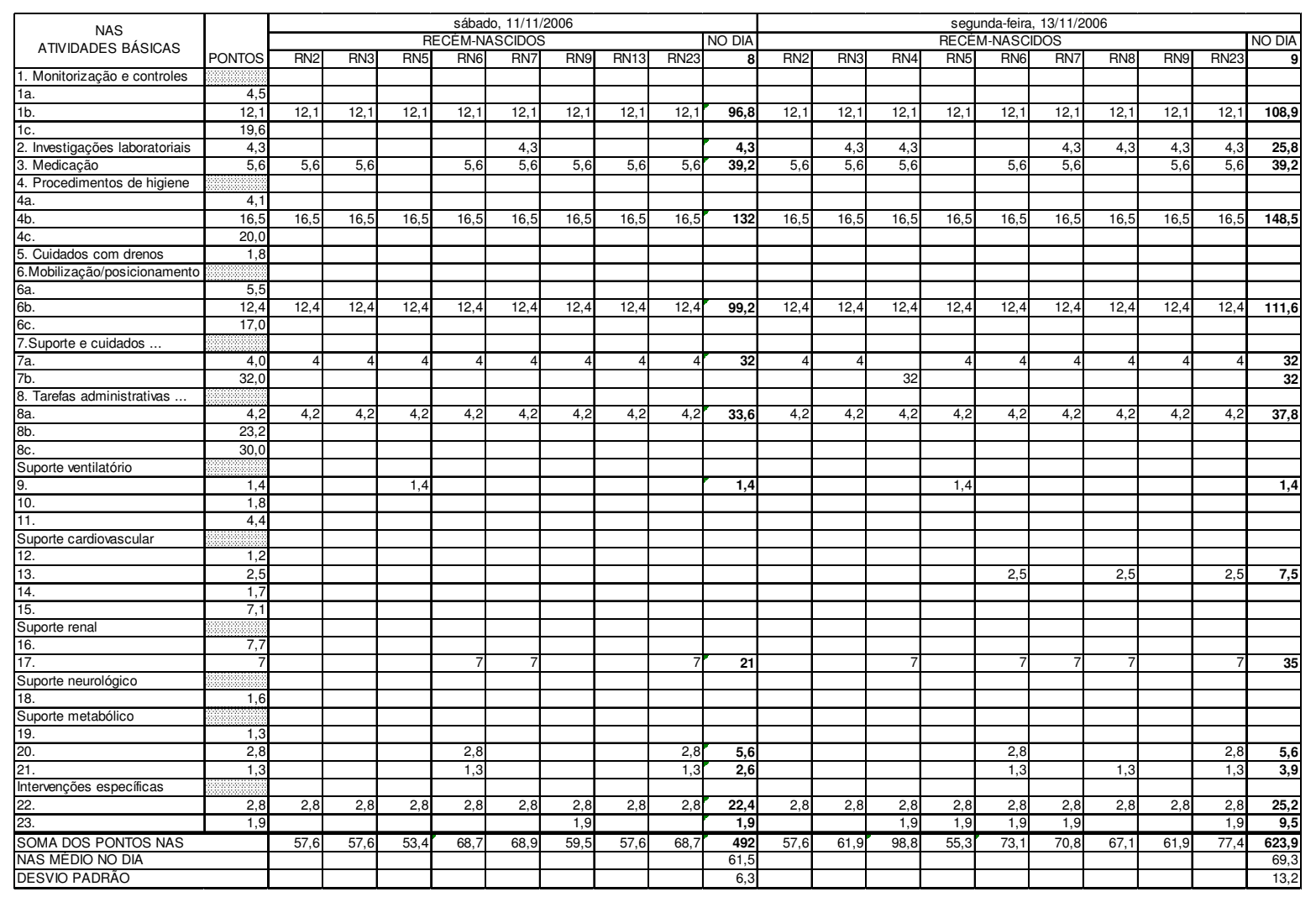




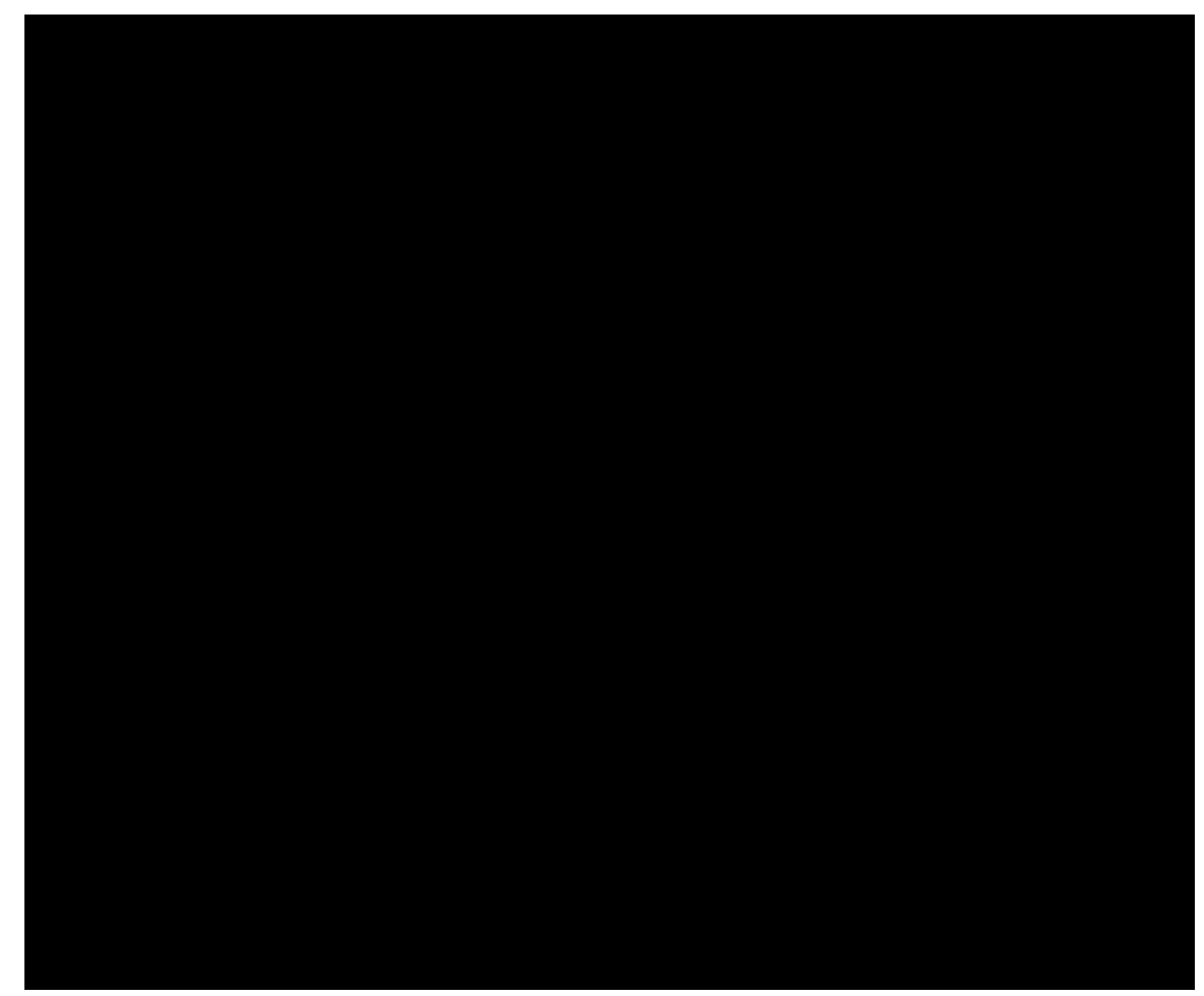


Luciana Bochembuzio

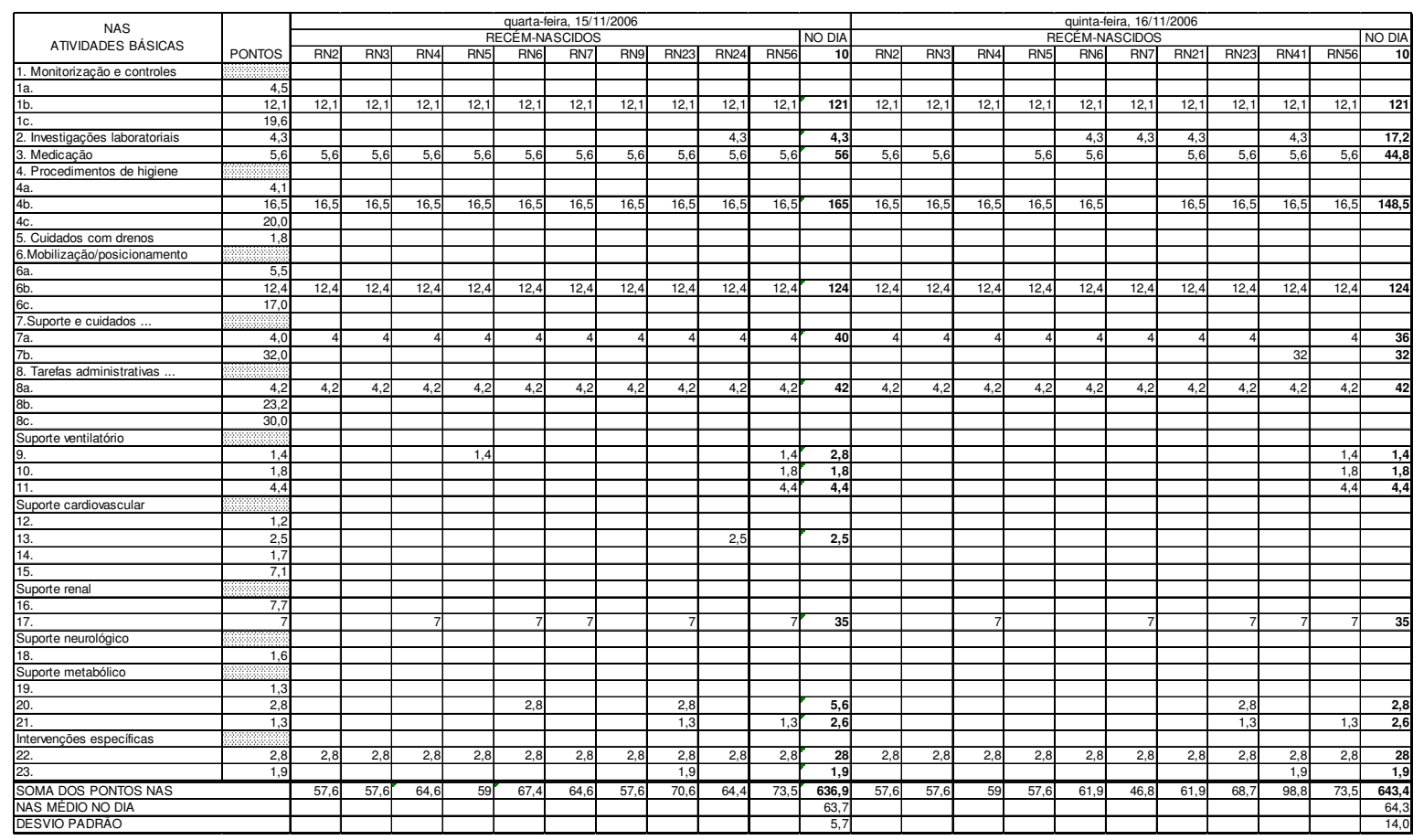




\begin{tabular}{|c|c|c|c|c|c|c|c|c|c|c|c|c|c|c|c|c|c|c|c|c|c|}
\hline \multirow{2}{*}{$\begin{array}{c}\text { NAS } \\
\text { ATIVIDADES BÁSICAS }\end{array}$} & \multirow[b]{2}{*}{ PONTOS } & \multicolumn{7}{|c|}{$\begin{array}{l}\text { sexta-feira, 17/11/2006 } \\
\text { ECEM-NASCIDOS }\end{array}$} & \multicolumn{7}{|c|}{$\begin{array}{c}\text { sábado, 18/11/2006 } \\
\text { RECEM-NASCIDOS }\end{array}$} & \multirow{2}{*}{\multicolumn{6}{|c|}{$\begin{array}{c}\text { domingo, 19/11/2006 } \\
\text { RECEM-NASCIDOS }\end{array}$}} \\
\hline & & $\mathrm{RN}_{1}$ & $\mathrm{RN}^{\mathrm{H}}$ & $\frac{E L N-1}{R N 3}$ & $\mathrm{RNA}^{2}$ & & $\mathrm{RN5}$ & $\frac{O D A}{6}$ & $\mathrm{RN1}$ & $11 \mathrm{RN}^{\mathrm{F}}$ & & RN41 & RN52 & RN56 & $\frac{10 \mathrm{DA}}{6}$ & RN21 & & & & & $\frac{N O D A}{5}$ \\
\hline 1. Monitorização e controles & & & & & & & & & & & & & & & & & & & & & \\
\hline & 4,5 & & & & & & & & & & & & & & & & & & & & \\
\hline ib. & 12,1 & 12,1 & 12,1 & 12,1 & 12,1 & 12,1 & 12, & 72,6 & 12,1 & 12,1 & 12,1 & 12,1 & 12,1 & 12,1 & 72,6 & 12,1 & 12,1 & 12,1 & 12,1 & 12,1 & 60,5 \\
\hline Ic. 2 2. Investigacōes laboratoriais & $\frac{19,6}{4.3}$ & & 4.3 & $4.3,3>0$ & 4.3 & & & 12,9 & 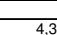 & 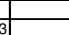 & 4,3 & - & $4.3 / 3,40$ & 工 & 12,9 & & $4.3,3>3$ & & 4,3, & & 8,6 \\
\hline 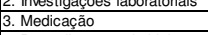 & 告, 5 & & $\frac{4,3}{5,6}$ & $\begin{array}{r}4.36 \\
5,6 \\
\end{array}$ & & 5,6 & 5, & $\frac{12,9}{22,4}$ & & 5,6 & $\frac{4,5}{5,6}$ & 5,6 & 5,6, & 5,6 & $\frac{12,9}{28}$ & 5,6 & $\begin{array}{ll}\frac{3,3}{5,6} \\
\end{array}$ & 5,6 & $\frac{4,3}{5,6}$ & 5,6 & $\frac{8,6}{28}$ \\
\hline 4. Procedimentos de higiene & & & & & & & & & & & & & & & & & & & & 3 & \\
\hline$\frac{4 \mathrm{a} .}{4 \mathrm{~b} .}$ & $\frac{4,1}{16,5}$ & 16.5 & 16.5 & 16.5 & 16.5 & 16.5 & 16. & $999>>2>$ & 76.5 & 16.5 & $\frac{7.5}{16.5}$ & $\frac{}{16.5}$ & $\frac{}{16.5}$ & 16.5 & 99 & $\frac{\mathrm{C}}{16.5}$ & 16.5 & 16.5 & $\frac{\mathrm{T}}{16.5}$ & $\frac{0}{16.5}$ & 82.5 \\
\hline 年. & $\frac{20,0}{20,0}$ & & & & & & & & & & & & & & & & & & & & \\
\hline 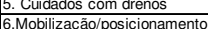 & 1,8 & & & & & & & & & & & & & & & & & & & & \\
\hline & 5,5 & & & & & & & & & & & & & & & & & & & & \\
\hline & 12,4 & 12,4 & 12,4 & 12,4 & 12,4 & $\mid 12,4$ & 12, & $\overline{74,4}$ & 12,4 & $\overline{12,4}$ & $\overline{12,4}$ & 12,4 & 12,4 & 12,4 & 74,4 & 12,4 & 12,4 & 12,4 & 12,4 & 12,4 & 62 \\
\hline $\begin{array}{l}\text { 6c. } \\
\text { 7. Suporte e cuidados. }\end{array}$ & 17,0 & & & & & & & & & & & & & - & & -1 & & & & & \\
\hline 7 a. & 4,0 & 4 & 4 & 4 & 4 & 4 & 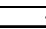 & 24 & 4 & & & 4 & & 4 & 16 & 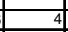 & 4 & 4 & & & 16 \\
\hline 8. Tarefas administrativas & 32,0 & & & & & & & & & & & & 32 & & & & & & & & 32 \\
\hline 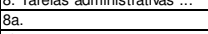 & 4,2 & 4,2 & 4,2 & 4,2 & 4,2 & 4,2 & 4,8 & 25,2 & 4,2 & 4,2 & 4,2 & 4,2 & 4,2 & 4,2 & 25,2 & 4,2 & 4,2 & 4,2 & 4,2 & 4,2 & 21 \\
\hline & $\frac{23,2}{300}$ & & & & & & & & & & & & & & & & & & & & \\
\hline $\begin{array}{l}\text { Sc. } \\
\text { Suporte ventilatárió }\end{array}$ & & & & & & & & & & & & & & & & & & & & & \\
\hline 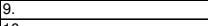 & 1,4 & & & & & & 1,8 & $\overline{1,4}$ & & & & & & 1,4 & 1,4 & & & & & $\frac{1,4}{4}$ & $\frac{1,4}{1,4}$ \\
\hline & 1,8 & & & & & & 1, & 1,8 & & & & & & 1,8 & 1,8 & & & & & & 1,8 \\
\hline 11. & 4.4 & & & & & & 4, & 4,4 & & & & & & 4,4 & 4,4 & & & & & & \\
\hline 12. & 1,2 & & & & & & & & & & & & & - & & & & & & & \\
\hline & $\frac{2,5}{1,7}$ & & & & & & & & & & & & & & & & & & & & \\
\hline & $\frac{1,1}{71}$ & & & & & & & & & & & & & & & & & & & & \\
\hline Suporte renal & ?in & & & & & & & & & & & & & & & & & & & & \\
\hline & $7,7]$ & & & & & & & & & & & & & & & & & & & & \\
\hline tiene & 7 & & & & & & & 14 & & & & & & & 14. & & & & & & 14 \\
\hline $\begin{array}{l}\text { pupone neurologico } \\
18 .\end{array}$ & 1,6 & & & & & & & & & & & & & & & & & & & & \\
\hline Suporte metabólico & & & & & & & & & & & & & & & & & & & & & \\
\hline & $\frac{1,3}{28}$ & & & & & & & & & & & & & & & & & & & & \\
\hline 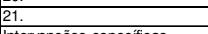 & $\frac{1,3}{1,3}$ & & & & & & 1, & 1,3 & & & & & & 1,3 & 1,3 & & & & & 1,3 & 1,3 \\
\hline Intervennạoeses especificicas & 2,8 & 2,8 & 2,8 & 2,8 & 2,8 & $2,8$. & 2, & $\overline{16,8}>2>3$ & 2,8 & 2,8 & 2,8 & 2,8 & 2,8 & 2,8 & $16,8]$ & 2,8 & 2,8 & 2,8 & 2,8 & $2,8]$ & \\
\hline & 1,9 & 1,9 & & 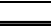 & - & & & 1,9 & 1,9 & 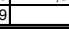 & 工 & & 1,9 & - & 3,8 & & & & 1,9 & & \\
\hline $\begin{array}{l}\text { OMA DOS PONTOS NAS } \\
\text { NAS MEDIONO NIA }\end{array}$ & & 53,9 & 61,9 & 61,9 & 63,3 & 57,6 & 73, & 372,1 & 58,2 & 57,6 & 96,9 & 57,6 & 91,8 & 73,5 & $\begin{array}{lll}435,6 \\
7,6]\end{array}$ & $\begin{array}{l}57,6 \\
\end{array}$ & 68,9 & 57,6 & \begin{tabular}{|c|}
1,8 \\
\end{tabular} & 73,5 & \begin{tabular}{|l|l|}
549,4 \\
699
\end{tabular} \\
\hline DESVIO PADRAO & & & & & & & & $\frac{0,4,6}{6,6}$ & & & & & & & $\begin{array}{ll}72,0,0 \\
18,0\end{array}$ & & & & & & 吕, 14,1 \\
\hline
\end{tabular}


Luciana Bochembuzio

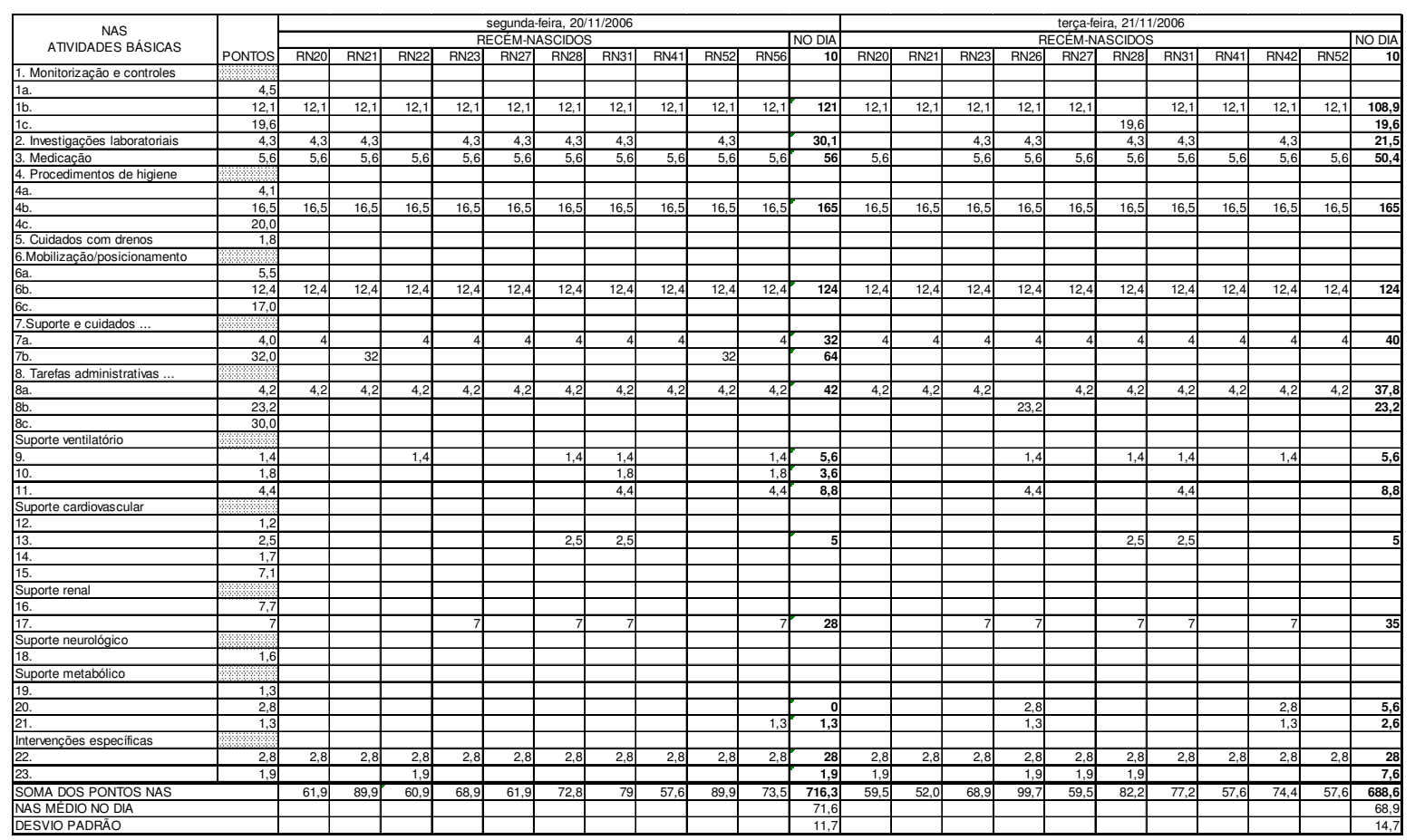


Luciana Bochembuzio

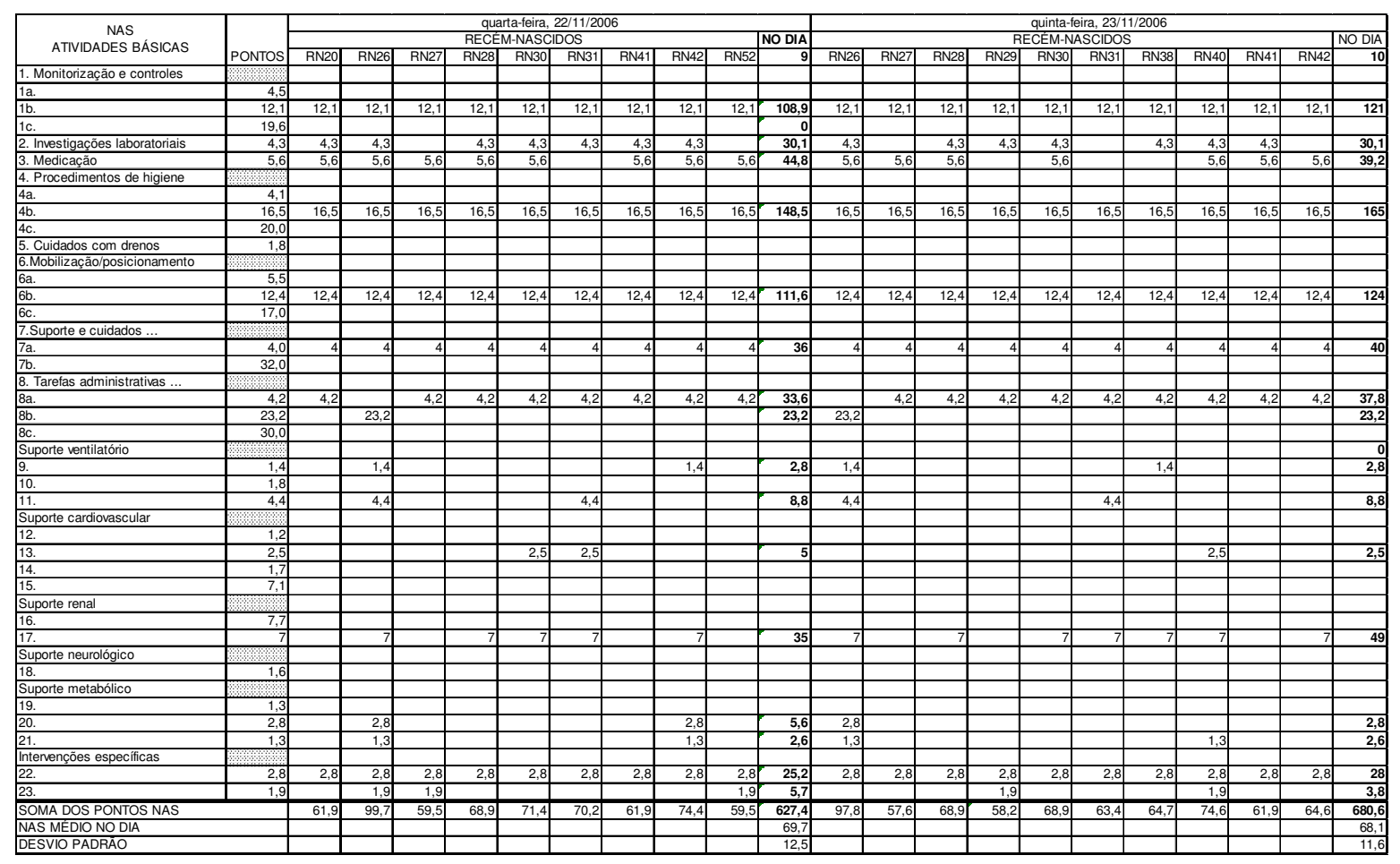




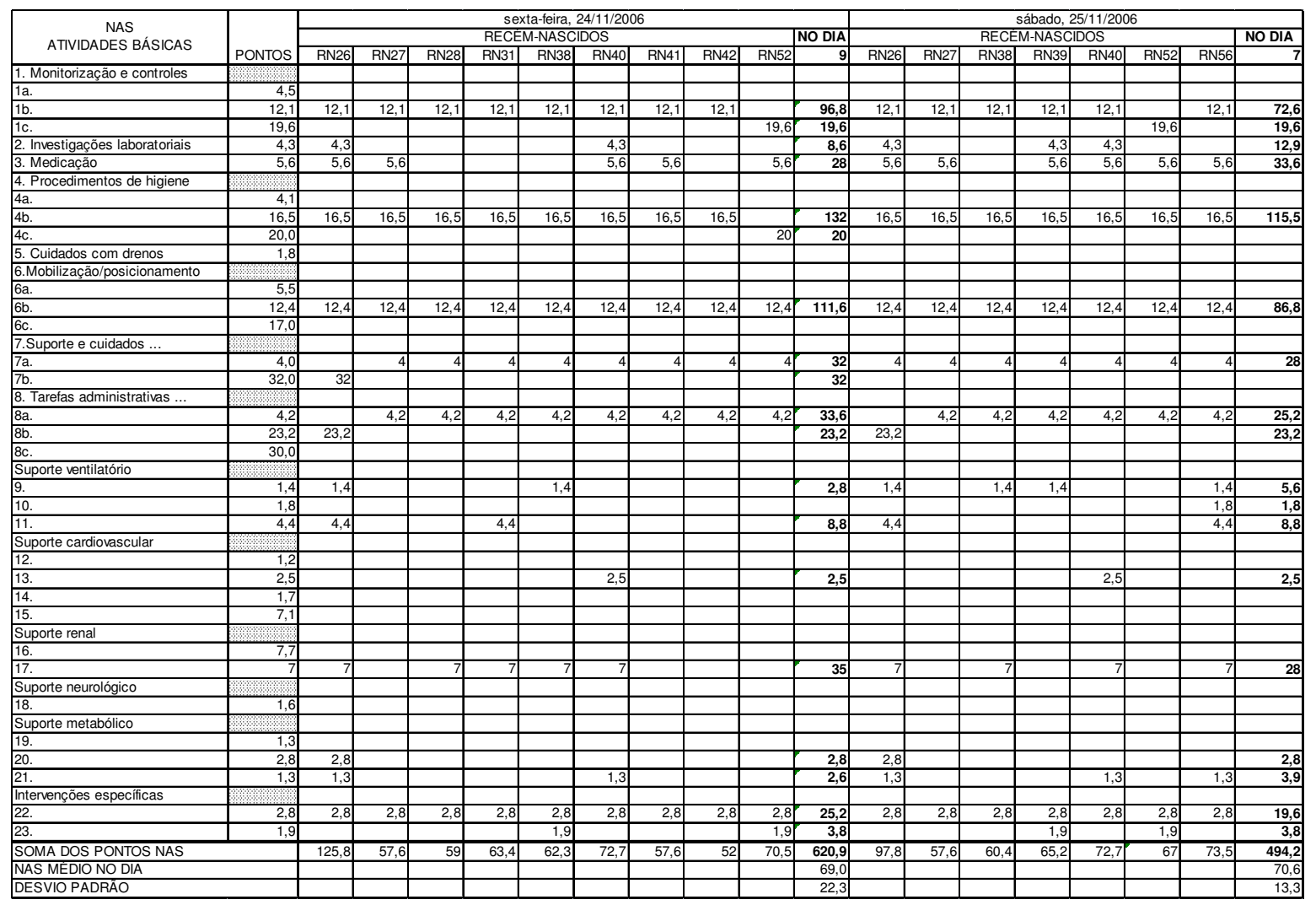


Luciana Bochembuzio

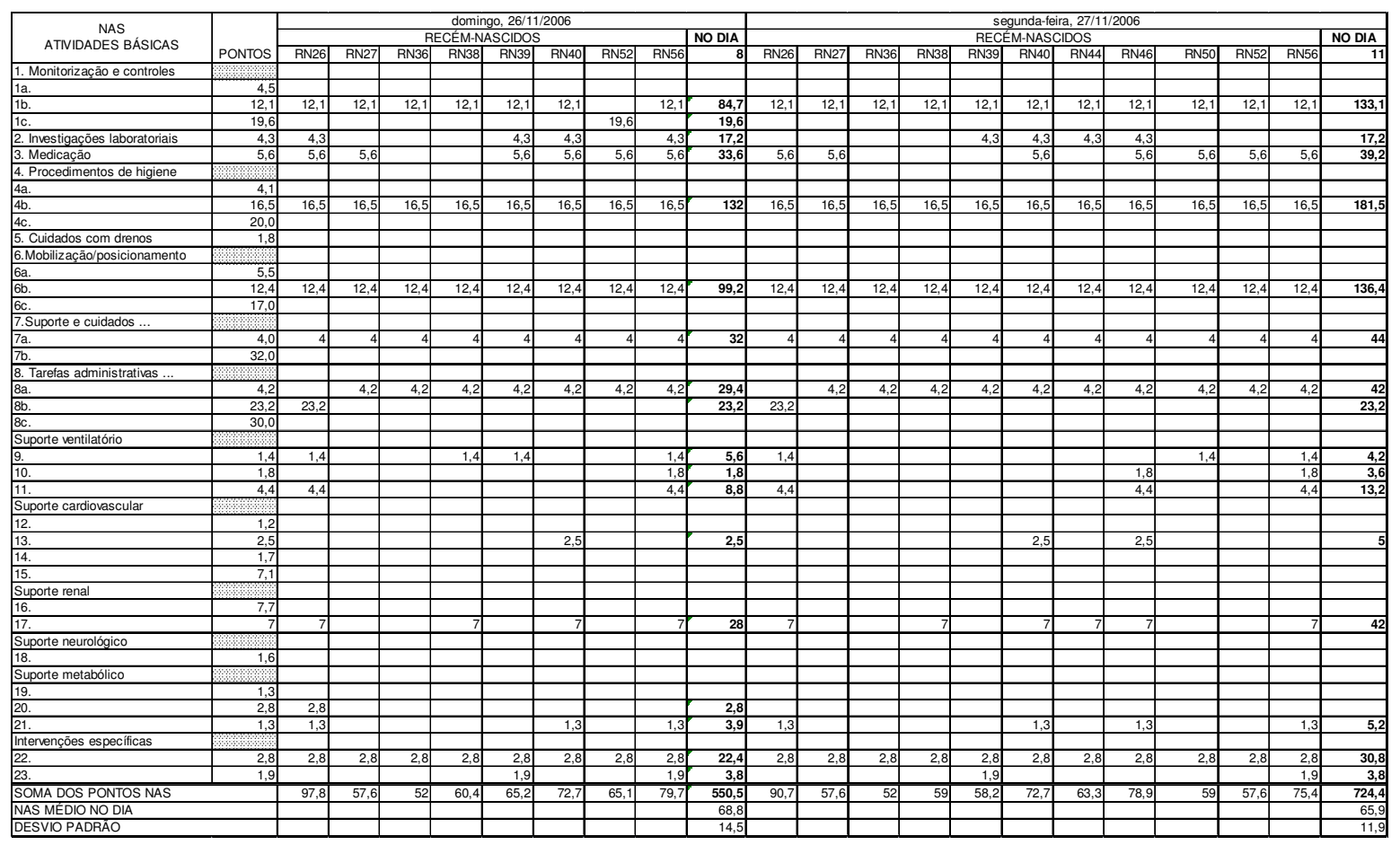




\begin{tabular}{|c|c|c|c|c|c|c|c|c|c|c|c|c|c|c|c|c|}
\hline \multirow{3}{*}{$\begin{array}{c}\text { NAS } \\
\text { ATNIDADES BÁSICAS }\end{array}$} & \multirow[b]{3}{*}{ PONTOS } & \multicolumn{15}{|c|}{ terça-feira, 28/11/2006 } \\
\hline & & \multicolumn{14}{|c|}{ RECEM-NASCIDOS } & \multirow{2}{*}{$\begin{array}{r}\text { NO DIA } \\
14 \\
\end{array}$} \\
\hline & & RN26 & RN27 & RN36 & RN37 & RN38 & RN39 & RN40 & RN43 & RN44 & \begin{tabular}{ll|} 
RN46 \\
\end{tabular} & RN50 & $\begin{array}{ll}\text { RN52 } \\
\end{array}$ & RN53 & RN56 & \\
\hline \multicolumn{17}{|l|}{ 1. Monitorização e controles } \\
\hline $1 \mathrm{a}$. & 4,5 & & & & & & & & & & & & & & & \\
\hline ib. & 12,1 & 12,1 & 12,1 & 12,1 & 12,1 & 12,1 & 12,1 & 12,1 & 12,1 & 12,1 & 12,1 & 12,1 & 12,1 & 12,1 & $\mid 12,1$ & 169,4 \\
\hline ic. & 19,6 & & & & & & & & & & & & & & & \\
\hline 2 Investigações laboratoriais & 4,3 & & & & 4,3 & & 4,3 & 4,3 & 4,3 & 4,3 & 4,3 & 4,3 & & 4,3 & & 34,4 \\
\hline 3. Medicação & 5,6 & 5,6 & 5,6 & & 5,6 & & & & 5,6 & & 5,6 & 5,6 & 5,6 & 5,6 & 5,6 & 50,4 \\
\hline \multicolumn{17}{|l|}{ 4. Procedimentos de higiene } \\
\hline $4 a$. & 4,1 & & & & & & & & & & & & & & & \\
\hline 4b. & 16,5 & 16,5 & 16,5 & 16,5 & 16,6 & 16,5 & 16,5 & 16,5 & 16,5 & 16,5 & \begin{tabular}{l|l}
16,5 \\
\end{tabular} & 16,5 & \begin{tabular}{c|}
16,5 \\
\end{tabular} & 16,5 & 16,5 & 231,1 \\
\hline 4c. & 20,0 & & & & & & & & & & & & & & & \\
\hline 5. Cuidados com drenos & 1,8 & & & & & & & & & & & & & & & \\
\hline \multicolumn{17}{|l|}{ 6. Mobilização/posicionamento } \\
\hline $6 a$. & 5,5 & & & & & & & & & & & & & & & \\
\hline 6b. & 12,4 & 12,4 & 12,4 & 12,4 & 12,4 & 12,4 & 12,4 & 12,4 & 12,4 & 12,4 & 12,4 & 12,4 & 12,4 & 12,4 & 12,4 & 173,6 \\
\hline $6 c$. & 17,0 & & & & & & & & & & & & & & & \\
\hline \multicolumn{17}{|l|}{ 7. Suporte e cuidados ... } \\
\hline $7 a$. & 4,0 & 4 & 4 & 4 & 4 & 4 & 4 & 4 & 4 & 4 & 4 & 4 & 4 & 4 & $\left.4\right|^{4}$ & 56 \\
\hline $7 \mathrm{~b}$. & 32,0 & & & & & & & & & & & & & & & \\
\hline \multicolumn{17}{|l|}{ 8. Tar efas administrativas ... } \\
\hline $8 \mathrm{a}$. & 4,2 & & 4,2 & 4,2 & 4,2 & 4,2 & 4,2 & 4,2 & 4,2 & 4,2 & 4,2 & 4,2 & 4,2 & 4,2 & 4,2 & 54,6 \\
\hline 86. & 23,2 & 23,2 & & & & & & & & & & & & & & 23,2 \\
\hline $8 \mathrm{cc}$. & 30,0 & & & & & & & & & & & & & & & \\
\hline \multicolumn{17}{|l|}{ Suporte ventilatório } \\
\hline 9. & 1,4 & 1,4 & & & 1,4 & & & & & & & & & 1,4 & 1,4 & 5,6 \\
\hline 10. & 1,8 & & & & 1,8 & & & & & & 1,8 & & & 1,8 & 1,8 & 7,2 \\
\hline 11. & 4,4 & 4,4 & & & 4,4 & & & & & & 4,4 & & & 4,4 & 4,4 & 22 \\
\hline \multicolumn{17}{|l|}{ Suporte cardiovascular } \\
\hline 12. & 1,2 & & & & & & & & 2,5 & & & & & & & 2,5 \\
\hline 13. & 2,5 & 2,5 & & & & & & & & & 2,5 & & & & & 5 \\
\hline 14. & 1,7 & & & & & & & & & & & & & & & \\
\hline 15. & 7,1 & & & & & & & & & & & & & & & \\
\hline \multicolumn{17}{|l|}{ Suporte renal } \\
\hline 16. & 7,7 & & & & & & & & & & & & & & & \\
\hline 17. & 7 & 7 & & & 7 & 7 & & 7 & 7 & 7 & 7 & & & 7 & 7 & 63 \\
\hline \multicolumn{17}{|l|}{ Suporte neurológico } \\
\hline 18. & 1,6 & & & & & & & & & & & & & & & \\
\hline \multicolumn{17}{|l|}{ Suporte metabólico } \\
\hline 19. & 1,3 & & & & & & & & & & & & & & & \\
\hline 20. & 2,8 & & & & & & & & & & & & & & & \\
\hline 21. & 1,3 & 1,3 & & & & & & & & & 1,3 & & & & 1,3 & 3,9 \\
\hline \multicolumn{17}{|l|}{ htervenções especfficas } \\
\hline 22. & 2,8 & 2,8 & 2,8 & 2,8 & 28 & 2,8 & 2,8 & 2,8 & 2,8 & 2,8 & 2,8 & 2,8 & 2,8 & 2,8 & 2,8 & 39,2 \\
\hline 23. & 1,9 & & & & & & & 1,9 & & & 1,9 & & & & & 3,8 \\
\hline SOMA DOS PONTOS NAS & & 93,2 & 57,6 & 52 & 76,6 & 59 & 56,3 & 65,2 & 71,4 & 63,3 & 80,8 & 61,9 & 57,6 & 76,5 & 73,5 & 944,9 \\
\hline NAS MÉDIO NO DIA & & & & & & & & & & & & & & & & 67,5 \\
\hline DESVIO PADRAOO & & & & & & & & & & & & & & & & 11,6 \\
\hline
\end{tabular}




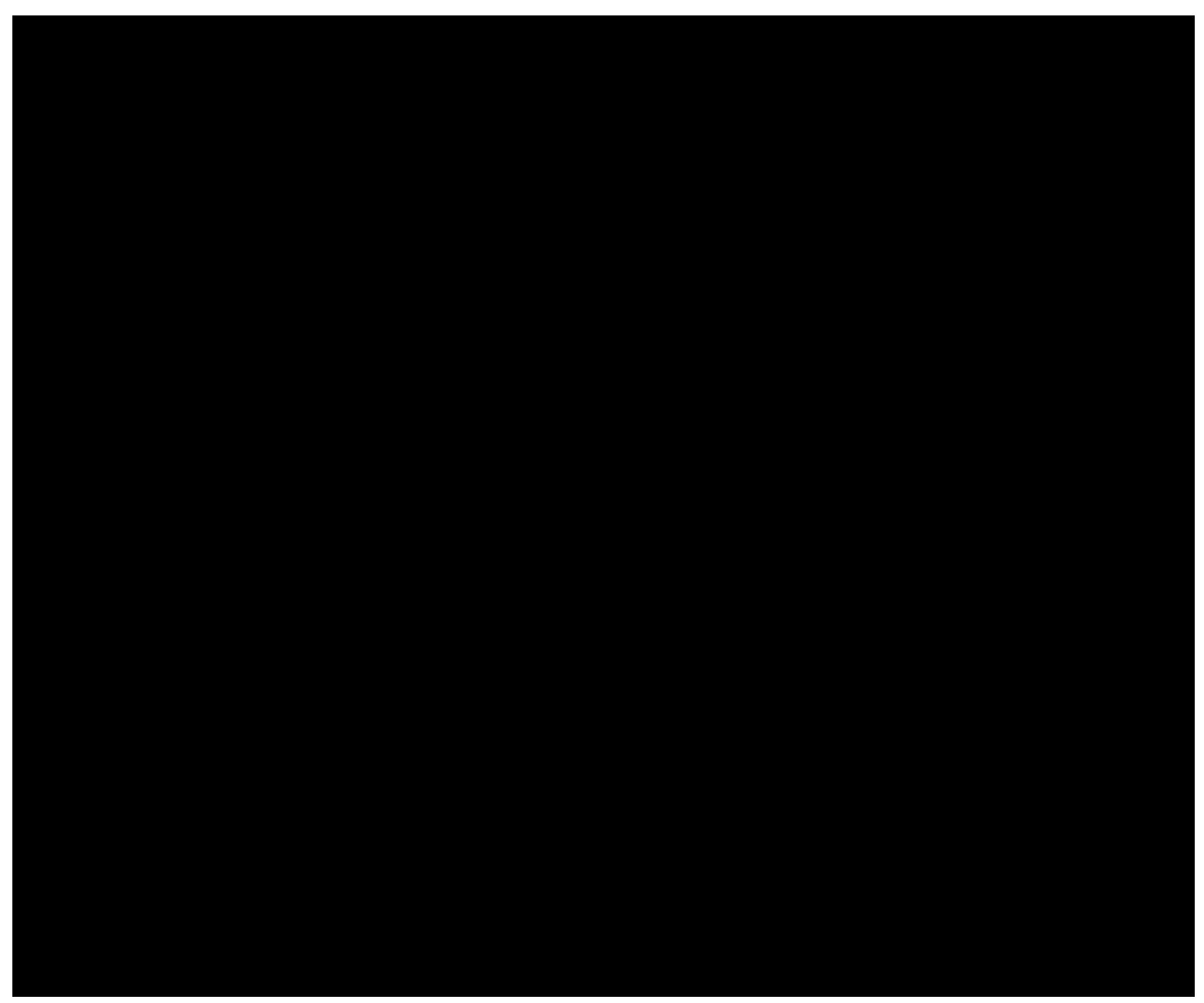




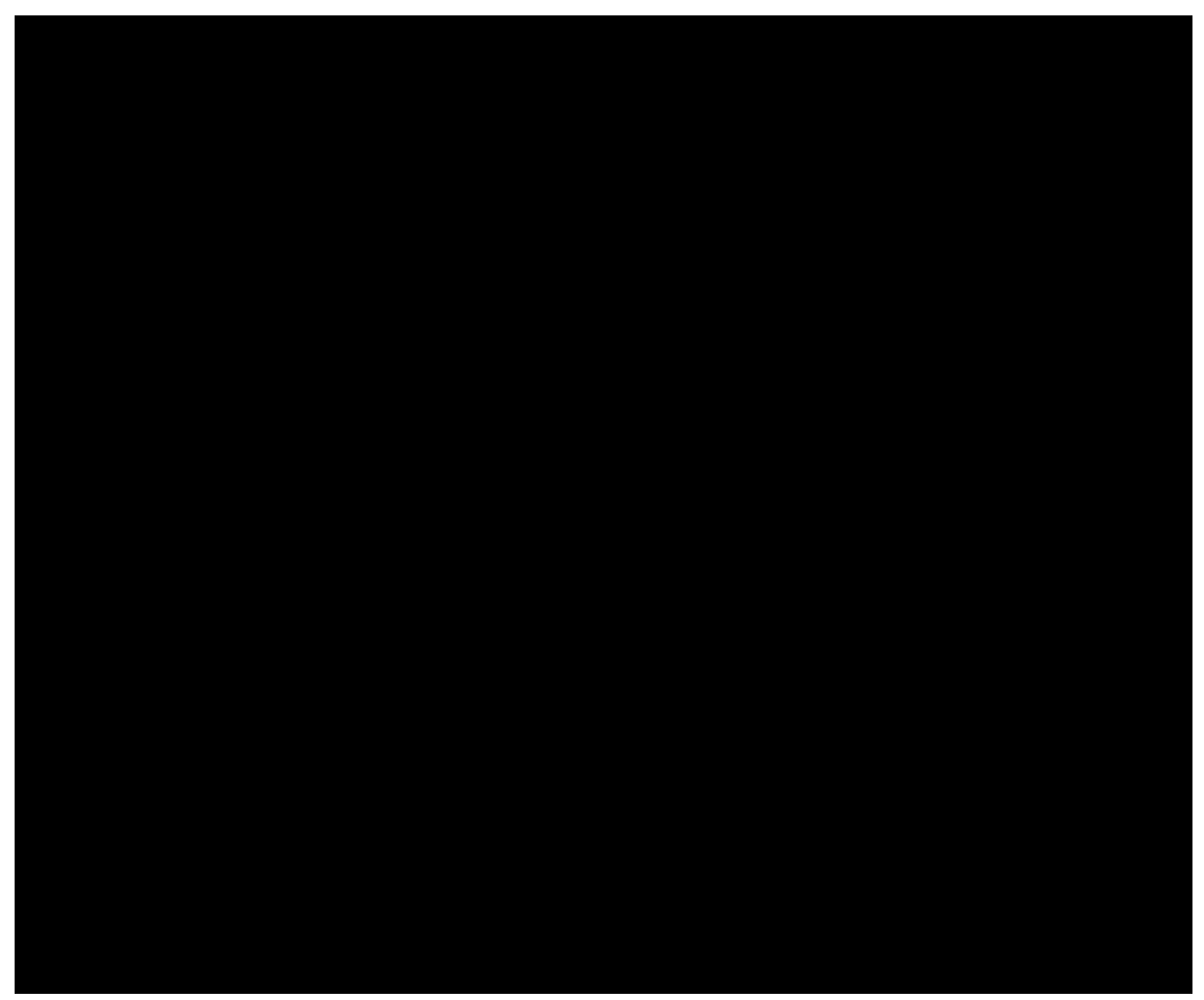


Luciana Bochembuzio

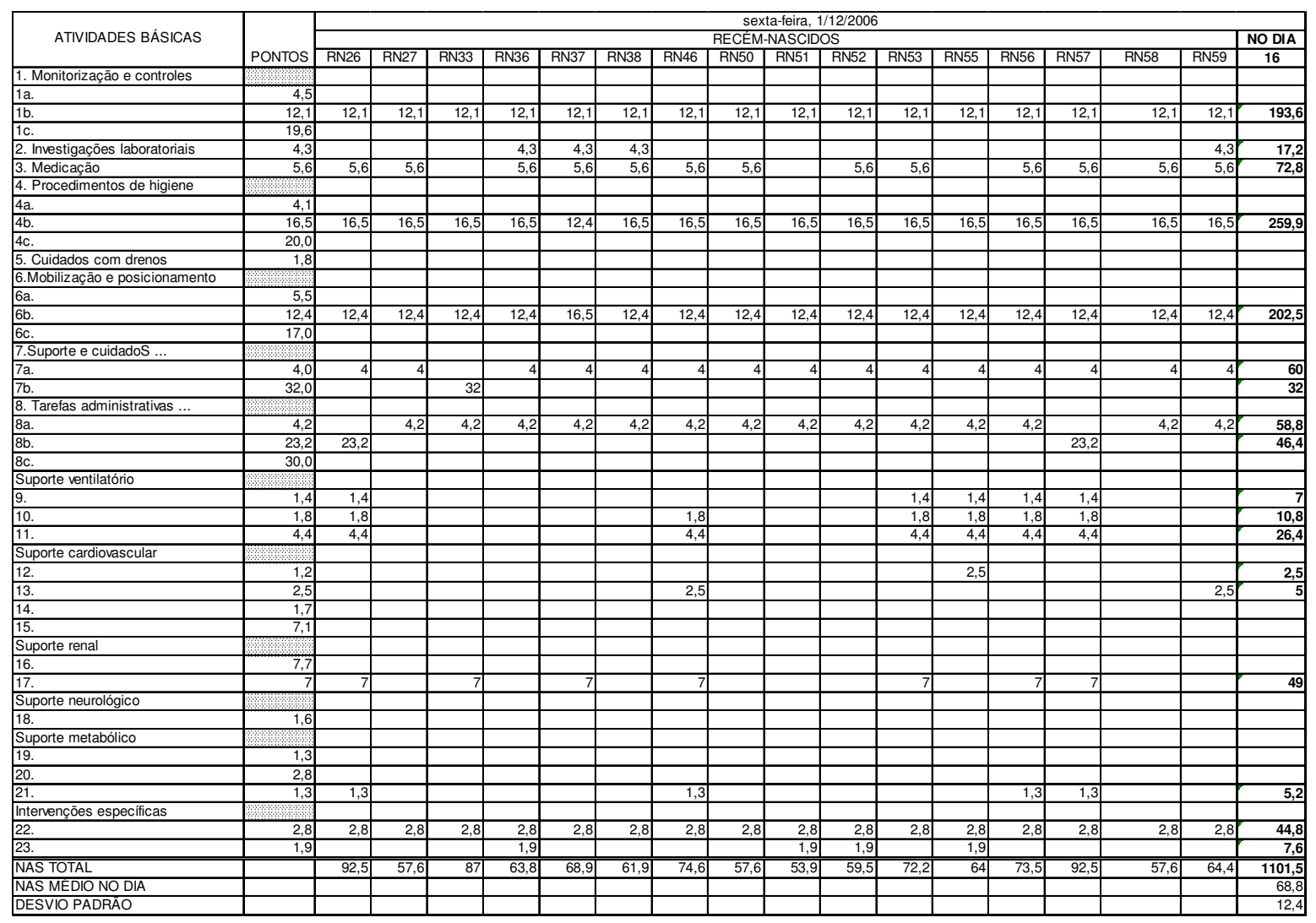


Luciana Bochembuzio

\begin{tabular}{|c|c|c|c|c|c|c|c|c|c|c|c|c|c|c|c|c|c|}
\hline \multirow{3}{*}{ ATIVIDADES BÁSICAS } & \multirow[b]{3}{*}{ PONTOS } & \multicolumn{16}{|c|}{ sábado, 2/12/2006 } \\
\hline & & \multicolumn{15}{|c|}{ RECEM-NASCIDOS } & \multirow{2}{*}{\begin{tabular}{|c|} 
NO DIA \\
15 \\
\end{tabular}} \\
\hline & & RN26 & RN27 & RN32 & RN33 & RN36 & RN37 & RN50 & \begin{tabular}{|l|l|} 
RN51 \\
\end{tabular} & \begin{tabular}{|l|l|} 
RN52 \\
\end{tabular} & RN53 & RN55 & RN56 & RN57 & RN58 & RN59 & \\
\hline \multicolumn{18}{|l|}{ 1. Monitorização e controles } \\
\hline $1 \mathrm{a}$. & 4,5 & & & & & & & & & & & & & & & & \\
\hline $1 \mathrm{~b}$. & 12,1 & 12,1 & 12,1 & 12,1 & 12,1 & 12,1 & 12,1 & 12,1 & 12,1 & 12,1 & 12,1 & 12,1 & 12,1 & 12,1 & 12,1 & 12,1 & 181,5 \\
\hline 1c. & 19,6 & & & & & & & & & & & & & & & & \\
\hline 2. Investigações laboratoriais & 4,3 & 4,3 & & 4,3 & 4,3 & & 4,3 & & & & & & & & & 4,3 & 21,5 \\
\hline 3. Medicação & 5,6 & 5,6 & 5,6 & & & 5,6 & 5,6 & 5,6 & & 5,6 & 5,6 & & 5,6 & 5,6 & 5,6 & 5,6 & 61,6 \\
\hline \multicolumn{18}{|l|}{ 4. Procedimentos de higiene } \\
\hline $4 a$. & 4,1 & & & & & & & & & & & & & & & & \\
\hline $4 \mathrm{~b}$. & 16,5 & 16,5 & 16,5 & 16,5 & 16,5 & 16,5 & 16,5 & 16,5 & 16,5 & 16,5 & 16,5 & 16,5 & 16,5 & 16,5 & 16,5 & 16,5 & 247,5 \\
\hline $4 \mathrm{cc}$. & 20,0 & & & & & & & & & & & & & & & & \\
\hline 5. Cuidados com drenos & 1,8 & & & & & & & & & & & & & & & & \\
\hline \multicolumn{18}{|l|}{ 6.Mobilização e posicionamento } \\
\hline $6 a$. & 5,5 & & & & & & & & & & & & & & & & \\
\hline $6 \mathrm{~b}$. & 12,4 & 12,4 & 12,4 & 12,4 & 12,4 & 12,4 & 12,4 & 12,4 & 12,4 & 12,4 & 12,4 & 12,4 & 12,4 & 12,4 & 12,4 & 12,4 & 186 \\
\hline $6 c$. & 17,0 & & & & & & & & & & & & & & & & \\
\hline \multicolumn{18}{|l|}{ 7. Suporte e cuidadoS ... } \\
\hline $7 \mathrm{a}$. & 4,0 & 4 & 4 & 4 & 4 & 4 & 4 & 4 & 4 & 4 & 4 & 4 & 4 & 4 & 4 & 4 & 60 \\
\hline $7 \mathrm{~b}$. & 32,0 & & & & & & & & & & & & & & & & \\
\hline \multicolumn{18}{|l|}{ 8. Tarefas administrativas. } \\
\hline $8 \mathrm{a}$. & 4,2 & & 4,2 & 4,2 & 4,2 & 4,2 & 4,2 & 4,2 & 4,2 & 4,2 & 4,2 & 4,2 & 4,2 & & 4,2 & 4,2 & 54,6 \\
\hline $8 \mathrm{~b}$. & 23,2 & 23,2 & & & & & & & & & & & & 23,2 & & & 46,4 \\
\hline 8c. & 30,0 & & & & & & & & & & & & & & & & \\
\hline \multicolumn{18}{|l|}{\begin{tabular}{|l} 
Suporte ventilatório \\
\end{tabular}} \\
\hline 9. & 1,4 & 1,4 & & & & & & & & & 1,4 & 1,4 & 1,4 & 1,4 & & & 7 \\
\hline 10. & 1,8 & 1,8 & & & & & & & & & 1,8 & 1,8 & 1,8 & 1,8 & & & 9 \\
\hline 11. & 4,4 & 4,4 & & & & & & & & & 4,4 & 4,4 & 4,4 & 4,4 & & & 22 \\
\hline \multicolumn{18}{|l|}{ Suporte cardiovascular } \\
\hline 12. & 1,2 & & & & & & & & & & & 2,5 & & & & & 2,5 \\
\hline 13. & 2,5 & & & & & & & & & & & & & & & & \\
\hline 14. & 1,7 & & & & & & & & & & & & & & & & \\
\hline 15. & 7,1 & & & & & & & & & & & & & & & & \\
\hline \multicolumn{18}{|l|}{\begin{tabular}{|l} 
Suporte renal \\
\end{tabular}} \\
\hline 16. & 7,7 & & & & & & & & & & & & & & & & \\
\hline 17. & 7 & 7 & & 7 & & & 7 & & & & 7 & & 7 & 7 & & & 49 \\
\hline \multicolumn{18}{|l|}{ Suporte neurológico } \\
\hline 18. & 1,6 & & & & & & & & & & & & & & & & \\
\hline \multicolumn{18}{|l|}{ Suporte metabólico } \\
\hline 19. & 1,3 & & & & & & & & & & & & & & & & \\
\hline 20. & 2,8 & & & & & & & & & & & & & & & & \\
\hline 21. & 1,3 & 1,3 & & & & & & & & & & & 1,3 & 1,3 & & & 3,9 \\
\hline \multicolumn{18}{|l|}{ Intervenções específicas } \\
\hline 22. & 2,8 & 2,8 & 2,8 & 2,8 & 2,8 & 2,8 & 2,8 & 2,8 & 2,8 & 2,8 & 2,8 & 2,8 & 2,8 & 2,8 & 2,8 & 2,8 & 42 \\
\hline 23. & 1,9 & & & & & & & & & & & & & & & & \\
\hline NAS TOTAL & & 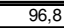 & $\begin{array}{l}57,6 \\
\end{array}$ & 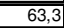 & \begin{tabular}{ll|}
63,3 \\
\end{tabular} & $\begin{array}{l}57,6 \\
\end{array}$ & $\begin{array}{l}68,9 \\
\end{array}$ & $\begin{array}{l}57,6 \\
\end{array}$ & 52 & \begin{tabular}{ll|}
57,6 \\
\end{tabular} & \begin{tabular}{|l|l|}
72,2 \\
\end{tabular} & \begin{tabular}{|c|}
62,1 \\
\end{tabular} & \begin{tabular}{ll|}
73,5 \\
\end{tabular} & \begin{tabular}{c|}
92,5 \\
\end{tabular} & $\begin{array}{l}57,6 \\
5\end{array}$ & (61,9 & \begin{tabular}{c|}
994,5 \\
\end{tabular} \\
\hline NAS MÉDIO NO DIA & & & & & & & & & & & & & & & & & 66,3 \\
\hline DESVIO PADRAOO & & & & & & & & & & & & & & & & & 13,0 \\
\hline
\end{tabular}




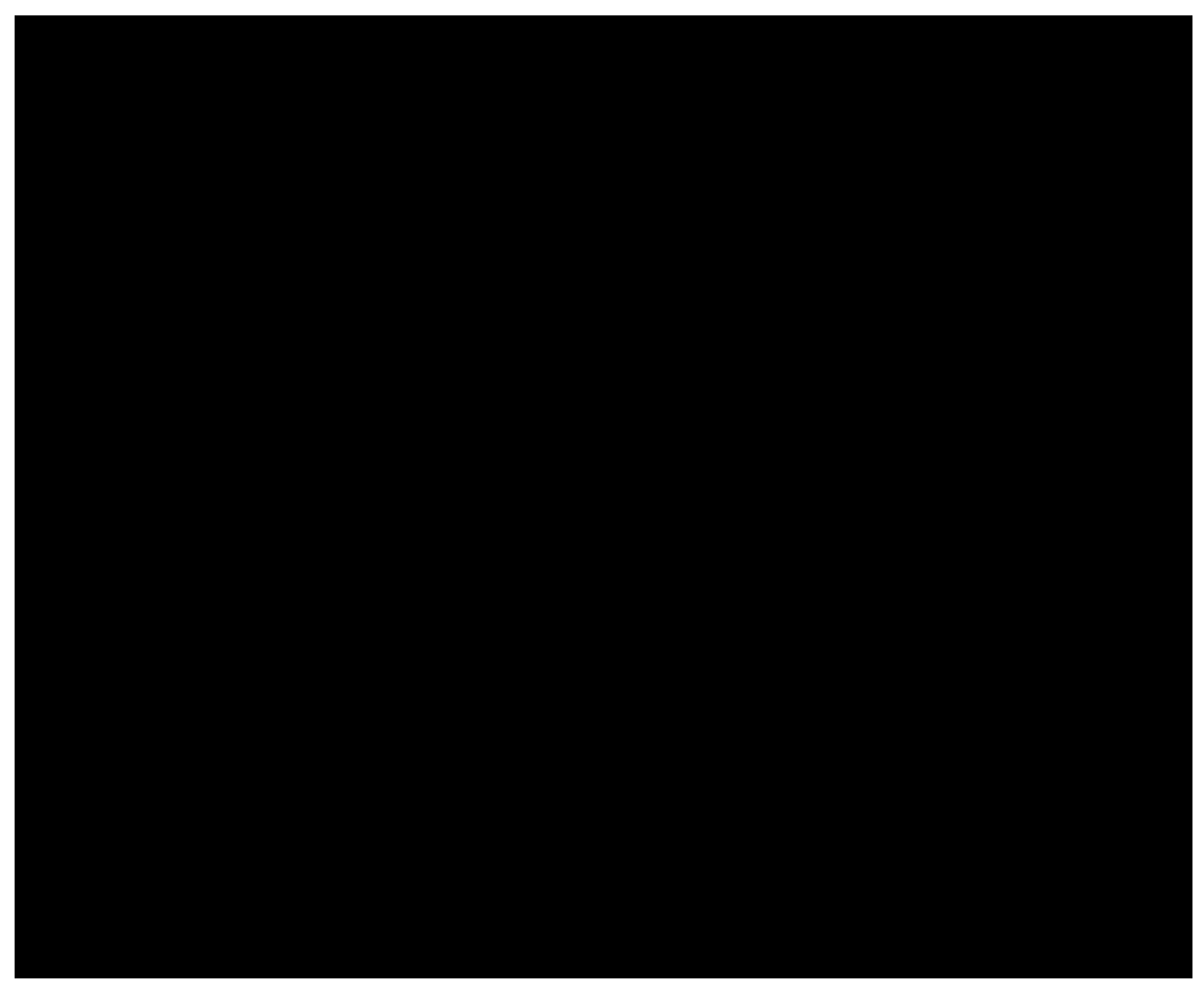




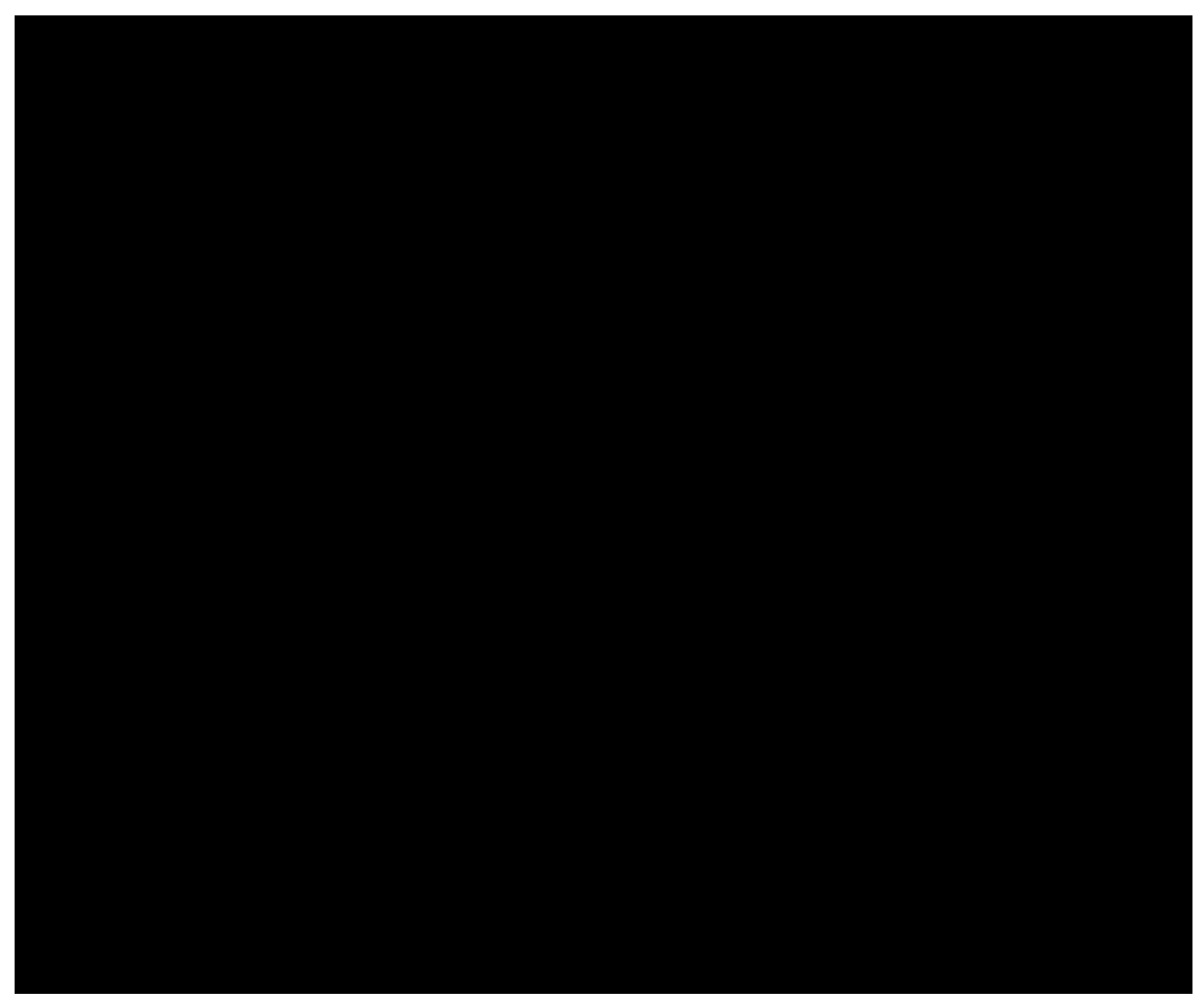


Luciana Bochembuzio

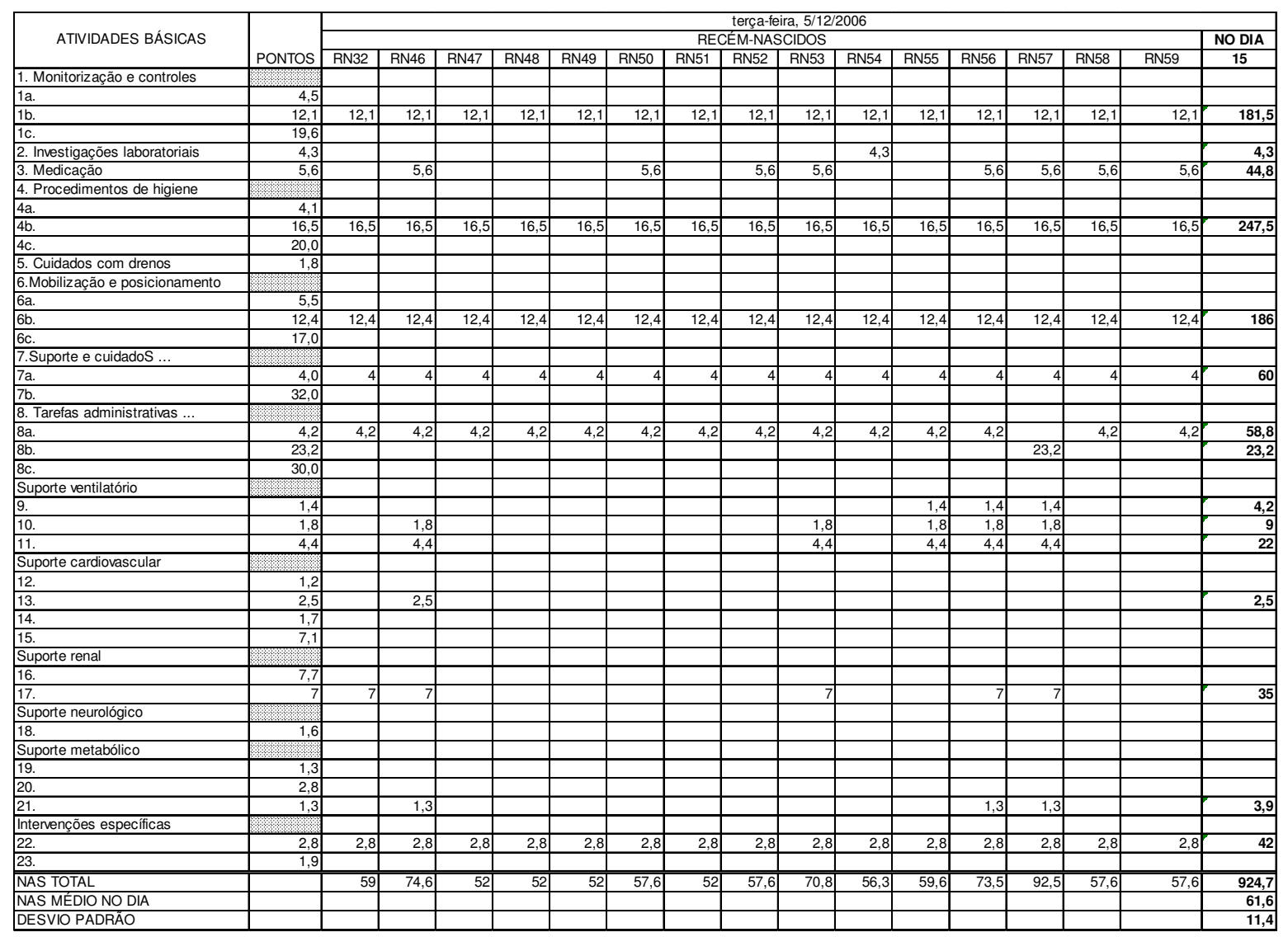




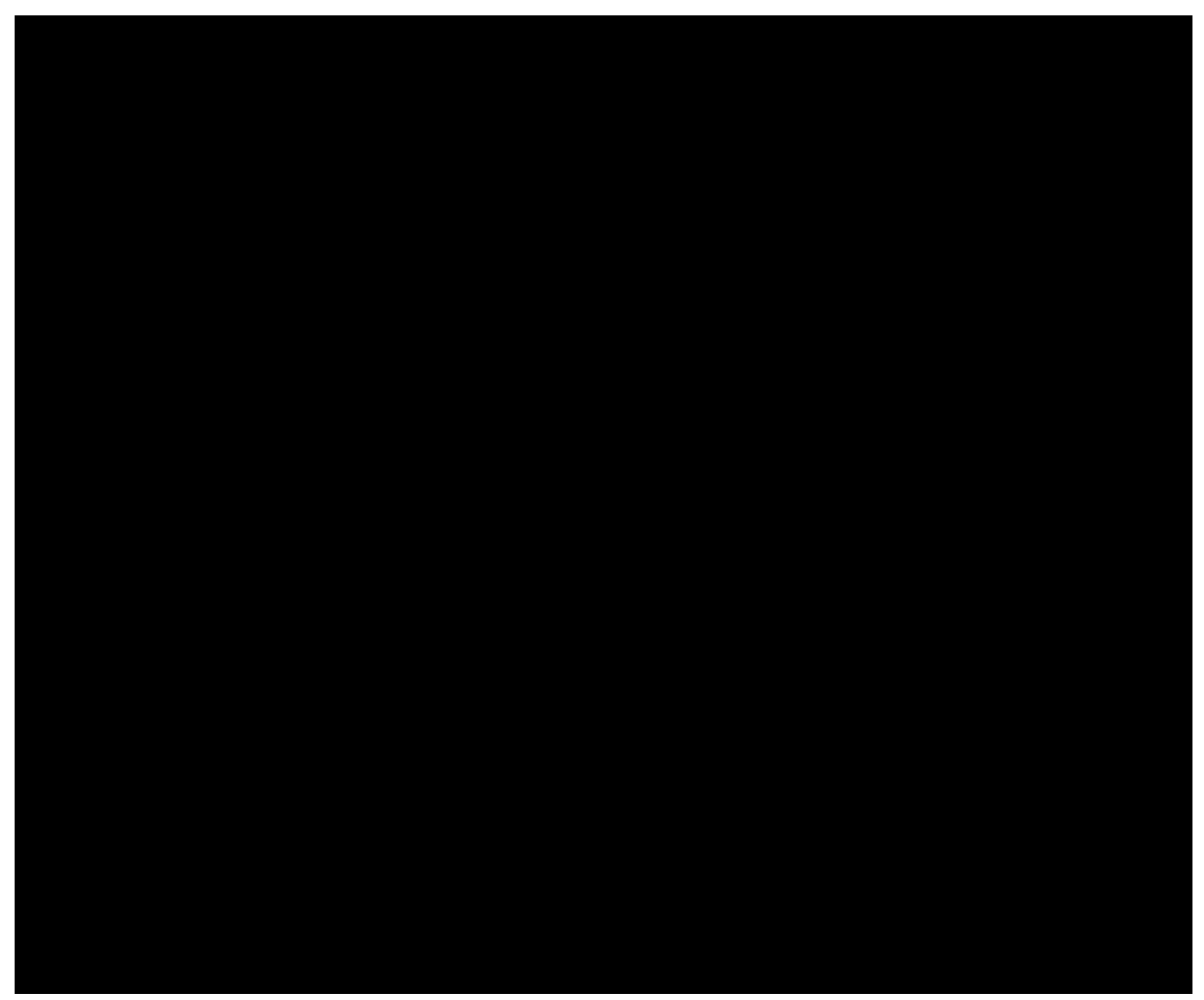




\section{Anexo 8}

\section{Avaliação diária das atividades NAS de cada um dos RN internados na UTI Neonatal}

\begin{tabular}{|c|c|c|c|c|c|c|c|c|c|c|c|c|c|c|c|c|c|}
\hline \multirow{3}{*}{$\begin{array}{l}\text { ATIVIDADES } \\
\text { BÁSICAS }\end{array}$} & \multirow[b]{3}{*}{ PONTOS } & \multicolumn{5}{|c|}{ segunda-feira, $6 / 11 / 2006$} & \multicolumn{5}{|c|}{ terça-feira, 7/11/2006 } & \multicolumn{6}{|c|}{ quarta-feira, 8/11/2006 } \\
\hline & & \multicolumn{4}{|c|}{ RECEM-NASCIDOS } & \multirow{2}{*}{\begin{tabular}{|c|} 
NO DIA \\
4
\end{tabular}} & \multicolumn{4}{|c|}{ RECEM-NASCIDOS } & \multirow{2}{*}{\begin{tabular}{|c|} 
NO DIA \\
4 \\
\end{tabular}} & \multicolumn{5}{|c|}{ RECEM-NASCIDOS } & \multirow{2}{*}{\begin{tabular}{|c|} 
NO DIA \\
5
\end{tabular}} \\
\hline & & RN23 & \begin{tabular}{|l|} 
RN46 \\
\end{tabular} & RN56 & RN57 & & RN23 & \begin{tabular}{|l|} 
RN46 \\
\end{tabular} & RN56 & RN57 & & RN6 & RN23 & \begin{tabular}{|l|} 
RN46 \\
\end{tabular} & RN56 & RN57 & \\
\hline \multicolumn{18}{|l|}{ 1. Monitorização e controles } \\
\hline $1 \mathrm{a}$. & 4,5 & & & & & & & & & & & & & & & & \\
\hline $1 \mathrm{~b}$. & 12,1 & & & & & & & & & & & & & & & & \\
\hline 1c. & 19,6 & 19,6 & 19,6 & 19,6 & 19,6 & 78,4 & 19,6 & 19,6 & 19,6 & 19,6 & 78,4 & 19,6 & 19,6 & 19,6 & 19,6 & 19,6 & 98 \\
\hline 2. Investigações laboratoriais & 4,3 & 4,3 & & & 4,3 & 8,6 & & 4,3 & 4,3 & 4,3 & 12,9 & 4,3 & & 4,3 & & & 8,6 \\
\hline 3. Medicação & 5,6 & 5,6 & 5,6 & 5,6 & 5,6 & 22,4 & 5,6 & 5,6 & 5,6 & 5,6 & 22,4 & 5,6 & 5,6 & 5,6 & 5,6 & 5,6 & 28 \\
\hline \multicolumn{18}{|l|}{ 4. Procedimentos de higiene } \\
\hline $4 a$. & 4,1 & & & & & & & & & & & & & & & & \\
\hline $4 \mathrm{~b}$. & 16,5 & 16,5 & 16,5 & 16,5 & 16,5 & 66 & 16,5 & 16,5 & 16,5 & 16,5 & 66 & 16,5 & 16,5 & 16,5 & 16,5 & 16,5 & 82,5 \\
\hline 4 4. & 20,0 & & & & & & & & & & & & & & & & \\
\hline 5. Cuidados com drenos & 1,8 & & & & & & & & & & & & & & & & \\
\hline \multicolumn{18}{|l|}{ 6.Mobilização e posicionamento } \\
\hline $6 a$. & 5,5 & & & & & & & & & & & & & & & & \\
\hline 6 b. & 12,4 & 12,4 & 12,4 & 12,4 & 12,4 & 49,6 & 12,4 & 12,4 & 12,4 & 12,4 & 49,6 & 12,4 & 12,4 & 12,4 & 12,4 & 12,4 & 62 \\
\hline $6 c$. & 17,0 & & & & & & & & & & & & & & & & \\
\hline \multicolumn{18}{|l|}{ 7. Suporte e cuidados } \\
\hline $7 a$. & 4,0 & 4 & 4 & 4 & 4 & 16 & 4 & 4 & 4 & 4 & 16 & & 4 & 4 & 4 & 4 & 16 \\
\hline $7 \mathrm{~b}$. & 32,0 & & & & & & & & & & & 32 & & & & & 32 \\
\hline \multicolumn{18}{|l|}{ 8. Tarefas administrativas ... } \\
\hline $8 \mathrm{a}$. & 4,2 & 4,2 & 4,2 & 4,2 & 4,2 & 16,8 & 4,2 & 4,2 & 4,2 & 4,2 & 16,8 & 4,2 & 4,2 & 4,2 & 4,2 & 4,2 & 21 \\
\hline $8 \mathrm{~b}$. & 23,2 & & & & & & & & & & & & & & & & \\
\hline 8c. & 30,0 & & & & & & & & & & & & & & & & \\
\hline Suporte ventilatório & & & & & & & & & & & & & & & & & \\
\hline 9. & 1,4 & 1,4 & 1,4 & 1,4 & 1,4 & 5,6 & 1,4 & 1,4 & 1,4 & 1,4 & 5,6 & 1,4 & 1,4 & 1,4 & 1,4 & 1,4 & 7 \\
\hline 10. & 1,8 & & 1,8 & 1,8 & 1,8 & 5,4 & & 1,8 & 1,8 & 1,8 & 5,4 & 1,8 & & 1,8 & 1,8 & 1,8 & 7,2 \\
\hline 11. & 4,4 & 4,4 & 4,4 & 4,4 & 4,4 & 17,6 & 4,4 & 4,4 & 4,4 & 4,4 & 17,6 & 4,4 & 4,4 & 4,4 & 4,4 & 4,4 & 22 \\
\hline Suporte cardiovascular & & & & & & & & & & & & & & & & & \\
\hline 12. & 1,2 & & & & & & & & & & & 1,2 & & & & & 1,2 \\
\hline 13. & $\frac{2,2}{2,5}$ & 2,5 & & & 2,5 & 5 & 2,5 & & & 2,5 & 5 & 2,5 & 2,5 & & & 2,5 & 7,5 \\
\hline 14. & 1,7 & & & & & & & & & & & & & & & & \\
\hline 15. & 7,1 & & & & & & & & & & & & & & & & \\
\hline Suporte renal & & & & & & & & & & & & & & & & & \\
\hline 16. & 7,7 & & & & & & & & & & & & & & & & \\
\hline 17. & 7 & 7 & 7 & 7 & & 28 & 7 & 7 & 7 & 7 & 28 & 7 & 7 & 7 & 7 & 7 & 35 \\
\hline Suporte neurológico & & & & & & & & & & & & & & & & & \\
\hline 18. & 1,6 & & & & & & & & & & & & & & & & \\
\hline Suporte metabólico & & & & & & & & & & & & & & & & & \\
\hline 19. & 1,3 & & & & & & & & & & & & & & & & \\
\hline 20. & 2,8 & 2,8 & 2,8 & & & 5,6 & 2,8 & 2,8 & & & 5,6 & & 2,8 & & & & 2,8 \\
\hline 21. & $\frac{2,0}{1,3}$ & \begin{tabular}{|c|c|}
1,3 \\
\end{tabular} & $\frac{2,0}{1,3}$ & 1,3 & 1,3 & $\frac{5,2}{5,2}$ & 1,3 & 1,3 & 1,3 & 1,3 & 5,2 & & 2,0 & 1,3 & 1,3 & 1,3 & 5,2 \\
\hline Intervenções específicas & & & & & & & & & & & & & & & & & \\
\hline 22. & 2,8 & 2,8 & 2,8 & 2,8 & 2,8 & 11,2 & 2,8 & 2,8 & 2,8 & 2,8 & 11,2 & 2,8 & 2,8 & 2,8 & 2,8 & 2,8 & 14 \\
\hline 23. & 1,9 & 1,9 & & & 1,9 & 3,8 & & & & & & & & & $\begin{array}{ll}, 0 \\
1,9\end{array}$ & & 1,9 \\
\hline SOMA DOS PONTOS NAS & & $\begin{array}{ll}90,7 \\
\end{array}$ & 83,8 & 81 & 89,7 & \begin{tabular}{ll|}
345,2 \\
\end{tabular} & 84,5 & 88,1 & 85,3 & 87,8 & \begin{tabular}{ll|}
345,7 \\
\end{tabular} & 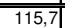 & 84,5 & 85,3 & 82,9 & 83,5 & 451,9 \\
\hline MEDIA DIARIA DOS PONTOS NAS & & & & & & 86,3 & & & & & 86,4 & & & & & & 90,4 \\
\hline DESVIO PADRAO & & & & & & 4,7 & & & & & 1,8 & & & & & & 14,2 \\
\hline
\end{tabular}




\begin{tabular}{|c|c|c|c|c|c|c|c|c|c|c|c|c|c|c|c|c|}
\hline \multirow{3}{*}{$\begin{array}{c}\text { NAS } \\
\text { ATIVIDADES BÁSICAS }\end{array}$} & \multirow[b]{3}{*}{ PONTOS } & \multicolumn{6}{|c|}{ quinta-feira, 9/11/2006 } & \multicolumn{5}{|c|}{ sexta-feira, 10/11/2006 } & \multicolumn{4}{|c|}{ sábado, 11/11/2006 } \\
\hline & & \multicolumn{5}{|c|}{ RECÉM-NASCIDOS } & \multirow{2}{*}{\begin{tabular}{|c|} 
NO DIA \\
5 \\
\end{tabular}} & \multicolumn{4}{|c|}{ RECÉM-NASCIDOS } & \multirow{2}{*}{\begin{tabular}{|c|} 
NO DIA \\
4 \\
\end{tabular}} & \multicolumn{3}{|c|}{ RECÉM-NASCIDOS } & \multirow{2}{*}{$\frac{\text { NO DIA }}{3}$} \\
\hline & & RN6 & RN23 & RN46 & RN56 & RN57 & & RN6 & RN46 & RN56 & RN57 & & RN46 & RN56 & RN57 & \\
\hline \multicolumn{17}{|l|}{ 1. Monitorização e controles } \\
\hline $1 \mathrm{a}$. & 4,5 & & & & & & & & & & & & & & & \\
\hline $1 \mathrm{~b}$. & 12,1 & & & & & & & & & & & & & & & \\
\hline 1c. & 19,6 & 19,6 & 19,6 & 19,6 & 19,6 & 19,6 & 98 & 19,6 & 19,6 & 19,6 & 19,6 & 78,4 & 19,6 & 19,6 & 19,6 & 58,8 \\
\hline 2. Investigações laboratoriais & 4,3 & 4,3 & & & & & 4,3 & 4,3 & & & & 4,3 & & & 4,3 & 4,3 \\
\hline 3. Medicação & 5,6 & 5,6 & 5,6 & 5,6 & 5,6 & 5,6 & 28 & 5,6 & 5,6 & 5,6 & 5,6 & 22,4 & 5,6 & 5,6 & 5,6 & 16,8 \\
\hline \multicolumn{17}{|l|}{ 4. Procedimentos de higiene } \\
\hline $4 a$. & 4,1 & & & & & & & & & & & & & & & \\
\hline $4 \mathrm{~b}$. & 16,5 & 16,5 & 16,5 & 16,5 & 16,5 & 16,5 & 82,5 & 16,5 & 16,5 & 16,5 & 16,5 & 66 & 16,5 & 16,5 & 16,5 & 49,5 \\
\hline 4c. & 20,0 & & & & & & & & & & & & & & & \\
\hline 5. Cuidados com drenos & 1,8 & & & & & & & & & & & & & & & \\
\hline \multicolumn{17}{|l|}{ 6.Mobilização e posicionamento } \\
\hline $6 a$. & 5,5 & & & & & & & & & & & & & & & \\
\hline $6 \mathrm{~b}$. & 12,4 & 12,4 & 12,4 & 12,4 & 12,4 & 12,4 & 62 & 12,4 & 12,4 & 12,4 & 12,4 & 49,6 & 12,4 & 12,4 & 12,4 & 37,2 \\
\hline $6 c$. & 17,0 & & & & & & & & & & & & & & & \\
\hline \multicolumn{17}{|l|}{ 7.Suporte e cuidados ... } \\
\hline $7 a$. & 4,0 & 4 & 4 & 4 & 4 & 4 & 20 & $4 \mid$ & 4 & 4 & 4 & 16 & 4 & 4 & 4 & 12 \\
\hline $7 \mathrm{~b}$. & 32,0 & & & & & & & & & & & & & & & \\
\hline \multicolumn{17}{|l|}{ 8. Tarefas administrativas ... } \\
\hline $8 \mathrm{a}$. & 4,2 & 4,2 & 4,2 & 4,2 & 4,2 & 4,2 & 21 & 4,2 & 4,2 & 4,2 & 4,2 & 16,8 & 4,2 & 4,2 & 4,2 & 12,6 \\
\hline $8 \mathrm{~b}$. & 23,2 & & & & & & & & & & & & & & & \\
\hline $8 \mathrm{c}$. & 30,0 & & & & & & & & & & & & & & & \\
\hline Suporte ventilatório & & & & & & & & & & & & & & & & \\
\hline 9. & 1,4 & 1,4 & 1,4 & 1,4 & 1,4 & 1,4 & 7 & 1,4 & 1,4 & 1,4 & 1,4 & 5,6 & 1,4 & 1,4 & 1,4 & 4,2 \\
\hline 10. & 1,8 & 1,8 & & 1,8 & 1,8 & 1,8 & 7,2 & 1,8 & 1,8 & 1,8 & 1,8 & 7,2 & 1,8 & 1,8 & 1,8 & 5,4 \\
\hline 11. & 4,4 & 4,4 & 4,4 & 4,4 & 4,4 & 4,4 & 22 & 4,4 & 4,4 & 4,4 & 4,4 & 17,6 & 4,4 & \begin{tabular}{l|l}
4,4 \\
\end{tabular} & 4,4 & 13,2 \\
\hline Suporte cardiovascular & & & & & & & & & & & & & & & & \\
\hline 12. & 1,2 & & & & & & & & & & & & & & & \\
\hline 13. & 2,5 & 2,5 & 2,5 & & & 2,5 & 7,5 & 2,5 & & & 2,5 & 5 & & & 2,5 & 2,5 \\
\hline 14. & 1,7 & & & & & & & & & & & & & & & \\
\hline 15. & 7,1 & & & & & & & & & & & & & & & \\
\hline Suporte renal & & & & & & & & & & & & & & & & \\
\hline 16. & 7,7 & & & & & & & & & & & & & & & \\
\hline 17. & 7 & 7 & 7 & 7 & 7 & 7 & 35 & 7 & 7 & 7 & 7 & 28 & 7 & 7 & 7 & 21 \\
\hline Suporte neurológico & & & & & & & & & & & & & & & & \\
\hline 18. & 1,6 & & & & & & & & & & & & & & & \\
\hline Suporte metabólico & & & & & & & & & & & & & & & & \\
\hline 19. & 1,3 & & & & & & & & & & & & & & & \\
\hline 20. & 2,8 & & 2,8 & & & & 2,8 & & & & & & & & & \\
\hline 21. & 1,3 & & 1,3 & 1,3 & 1,3 & 1,3 & 5,2 & 1,3 & 1,3 & 1,3 & 1,3 & 5,2 & 1,3 & \begin{tabular}{l|l}
1,3 \\
\end{tabular} & 1,3 & 3,9 \\
\hline Intervenções específicas & & & & & & & & & & & & & & & & \\
\hline 22. & 2,8 & 2,8 & 2,8 & 2,8 & 2,8 & 2,8 & 14 & 2,8 & 2,8 & 2,8 & 2,8 & 11,2 & 2,8 & 2,8 & 2,8 & 8,4 \\
\hline 23. & 1,9 & & & & 1,9 & & 1,9 & & & & & & & & 1,9 & \\
\hline SOMA DOS PONTOS NAS & & 86,5 & 84,5 & 81 & 82,9 & 83,5 & 418,4 & 87,8 & 81 & 81 & $83,5^{\circ \prime}$ & 333,3 & 81 & 81 & 89,7 & 251,7 \\
\hline MÉDIA DIÁRIA DOS PONTOS NA & & & & & & & 83,7 & & & & & 83,3 & & & & 83,9 \\
\hline DESVIO PADRÃO & & & & & & & 2,0 & & & & & 3,2 & & & & 5,0 \\
\hline
\end{tabular}




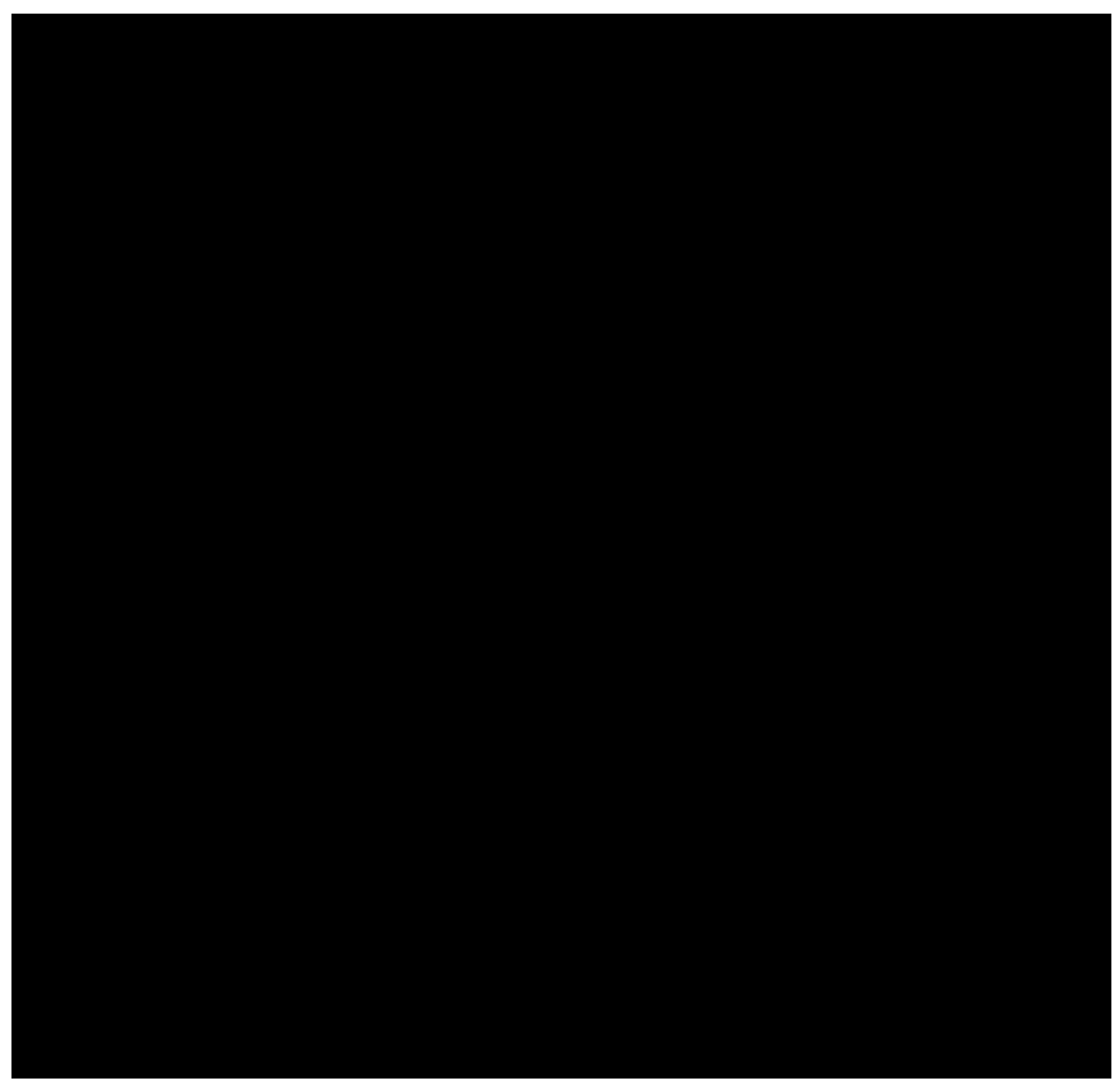




\begin{tabular}{|c|c|c|c|c|c|c|c|c|c|c|c|c|c|c|}
\hline \multirow{3}{*}{$\begin{array}{l}\text { NAS ATIVIDADES } \\
\text { BÁSICAS }\end{array}$} & \multirow[b]{3}{*}{ PONTOS } & \multicolumn{4}{|c|}{ quinta-feira, 16/11/2006 } & \multicolumn{4}{|c|}{ sexta-feira, $17 / 11 / 2006$} & \multicolumn{5}{|c|}{ sábado, 18/11/2006 } \\
\hline & & \multicolumn{3}{|c|}{ RECEM-NASCIDOS } & \multirow{2}{*}{\begin{tabular}{|c|} 
NO DIA \\
3 \\
\end{tabular}} & \multicolumn{3}{|c|}{ RECEM-NASCIDOS } & \multirow{2}{*}{\begin{tabular}{|c|} 
NO DIA \\
3
\end{tabular}} & \multicolumn{4}{|c|}{ RECÉM-NASCIDOS } & \multirow{2}{*}{\begin{tabular}{|c|} 
NO DIA \\
4 \\
\end{tabular}} \\
\hline & & RN42 & RN46 & RN57 & & RN42 & RN46 & RN57 & & RN28 & RN42 & RN46 & RN57 & \\
\hline \multicolumn{15}{|c|}{\begin{tabular}{|l|l|l} 
1. Monitorização e controles & 1.0 .8 \\
\end{tabular}} \\
\hline $1 \mathrm{a}$. & 4,5 & & & & & & & & & & & & & \\
\hline $1 \mathrm{~b}$. & 12,1 & & & & & & & & & & & & & \\
\hline 1c. & 19,6 & 19,6 & 19,6 & 19,6 & 58,8 & 19,6 & 19,6 & 19,6 & 58,8 & 19,6 & 19,6 & 19,6 & 19,6 & 78,4 \\
\hline 2. Investigações laboratoriais & 4,3 & 4,3 & 4,3 & 4,3 & 12,9 & 4,3 & 4,3 & 4,3 & 12,9 & 4,3 & 4,3 & 4,3 & 4,3 & 17,2 \\
\hline 3. Medicação & 5,6 & 5,6 & 5,6 & 5,6 & 16,8 & 5,6 & 5,6 & 5,6 & 16,8 & 5,6 & 5,6 & 5,6 & 5,6 & 22,4 \\
\hline \multicolumn{15}{|l|}{ 4. Procedimentos de higiene } \\
\hline $4 a$. & 4,1 & & & & & & & & & & & & & \\
\hline $4 \mathrm{~b}$. & 16,5 & 16,5 & 16,5 & 16,5 & 49,5 & 16,5 & 16,5 & 16,5 & 49,5 & 16,5 & 16,5 & 16,5 & 16,5 & 66 \\
\hline 4c. & 20,0 & & & & & & & & & & & & & \\
\hline 5. Cuidados com drenos & 1,8 & & & & & & & & & & & & & \\
\hline \multicolumn{15}{|l|}{ 6.Mobilização e posicionamento } \\
\hline $6 a$. & 5,5 & & & & & & & & & & & & & \\
\hline $6 b$. & 12,4 & 12,4 & 12,4 & 12,4 & 37,2 & 12,4 & 12,4 & 12,4 & 37,2 & 12,4 & 12,4 & 12,4 & 12,4 & 49,6 \\
\hline 6c. & 17,0 & & & & & & & & & & & & & \\
\hline \multicolumn{15}{|l|}{ 7.Suporte e cuidados ... } \\
\hline 7a. & 4,0 & 4 & 4 & 4 & 12 & 4 & 4 & 4 & 12 & 4 & 4 & 4 & 4 & 16 \\
\hline $7 \mathrm{~b}$. & 32,0 & & & & & & & & & & & & & \\
\hline \multicolumn{15}{|l|}{ 8. Tarefas administrativas } \\
\hline $8 \mathrm{a}$. & 4,2 & 4,2 & 4,2 & & 8,4 & 4,2 & 4,2 & & 8,4 & 4,2 & 4,2 & 4,2 & & 12,6 \\
\hline $8 b$. & 23,2 & & & 23,2 & 23,2 & & & 23,2 & 23,2 & & & & 23,2 & 23,2 \\
\hline $8 \mathrm{c}$. & 30,0 & & & & & & & & & & & & & \\
\hline \multicolumn{15}{|l|}{ Suporte ventilatório } \\
\hline 9. & 1,4 & 1,4 & 1,4 & 1,4 & 4,2 & 1,4 & 1,4 & 1,4 & 4,2 & 1,4 & 1,4 & 1,4 & 1,4 & 5,6 \\
\hline 10. & 1,8 & 1,8 & 1,8 & 1,8 & 5,4 & 1,8 & 1,8 & 1,8 & 5,4 & 1,8 & 1,8 & 1,8 & 1,8 & 7,2 \\
\hline 11. & 4,4 & 4,4 & 4,4 & 4,4 & 13,2 & 4,4 & 4,4 & 4,4 & 13,2 & 4,4 & 4,4 & 4,4 & 4,4 & 17,6 \\
\hline Suporte cardiovascular & & & & & & & & & & & & & & \\
\hline 12. & 1,2 & & & & & & & & & & & & & \\
\hline 13. & 2,5 & 2,5 & 2,5 & 2,5 & 7,5 & & 2,5 & 2,5 & 5 & 2,5 & & 2,5 & & 5 \\
\hline 14. & 1,7 & & & & & & & & & & & & & \\
\hline 15. & 7,1 & & & & & & & & & & & & & \\
\hline Suporte renal & & & & & & & & & & & & & & \\
\hline 16. & 7,7 & & & & & & & & & & & & & \\
\hline 17. & 7 & 7 & 7 & 7 & 21 & 7 & 7 & 7 & 21 & 7 & 7 & 7 & 7 & 28 \\
\hline Suporte neurológico & & & & & & & & & & & & & & \\
\hline 18. & 1,6 & & & & & & & & & & & & & \\
\hline Suporte metabólico & & & & & & & & & & & & & & \\
\hline 19. & 1,3 & & & & & & & & & & & & & \\
\hline 20. & 2,8 & & 2,8 & 2,8 & 5,6 & 2,8 & 2,8 & & 5,6 & & 2,8 & 2,8 & & 5,6 \\
\hline 21. & 1,3 & 1,3 & 1,3 & 1,3 & 3,9 & 1,3 & 1,3 & 1,3 & 3,9 & & 1,3 & 1,3 & 1,3 & 3,9 \\
\hline Intervenções específicas & & & & & & & & & & & & & & \\
\hline 22. & 2,8 & 2,8 & 2,8 & 2,8 & 8,4 & 2,8 & 2,8 & 2,8 & 8,4 & 2,8 & 2,8 & 2,8 & 2,8 & 11,2 \\
\hline 23. & 1,9 & 1,9 & & & 1,9 & & & & & 1,9 & & 1,9 & & 3,8 \\
\hline SOMA DOS PONTOS NAS & & 89,7 & 90,6 & 109,6 & 289,9 & 88,1 & 90,6 & 106,8 & 285,5 & 88,4 & 88,1 & 92,5 & 104,3 & 373,3 \\
\hline MÉDIA DIÁRIA DOS PONTOS NA & & & & & 96,6 & & & & 95,2 & & & & & 93,3 \\
\hline DESVIO PADRÃO & & & & & 11,2 & & & & 10,2 & & & & & 7,6 \\
\hline
\end{tabular}


Luciana Bochembuzio

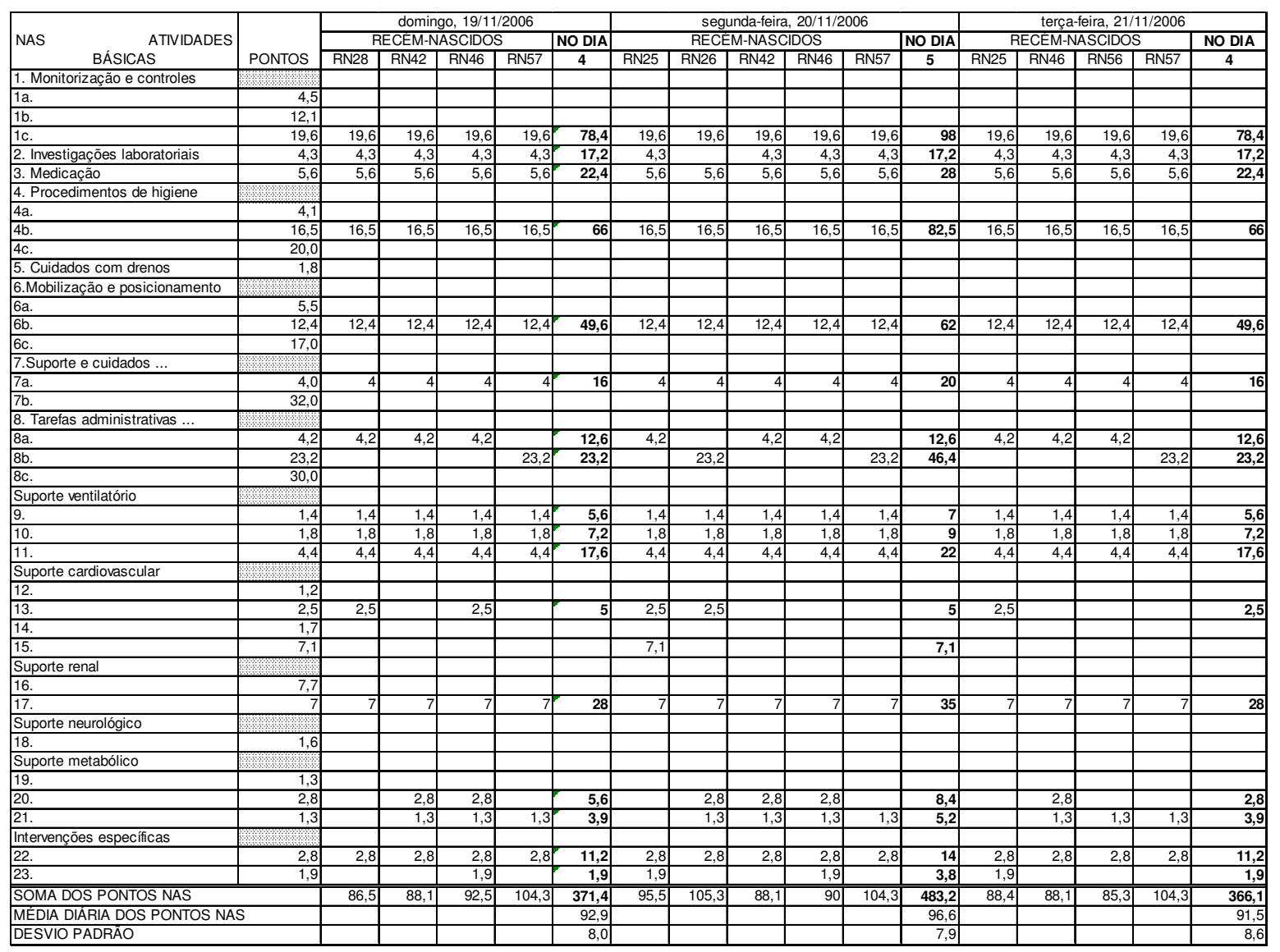




\begin{tabular}{|c|c|c|c|c|c|c|c|c|c|c|c|c|c|c|c|c|}
\hline \multirow{3}{*}{$\begin{array}{l}\text { NAS } \\
\text { BÁSICAS }\end{array}$} & \multirow[b]{3}{*}{ PONTOS } & \multicolumn{5}{|c|}{ quarta-feira, 22/11/2006 } & \multicolumn{5}{|c|}{ quinta-feira, 23/11/2006 } & \multicolumn{5}{|c|}{ sexta-feira, 24/11/2006 } \\
\hline & & \multicolumn{4}{|c|}{ RECEEM-NASCIDOS } & \multirow{2}{*}{\begin{tabular}{|c|} 
NO DIA \\
4 \\
\end{tabular}} & \multicolumn{4}{|c|}{ RECÉM-NASCIDOS } & \multirow{2}{*}{\begin{tabular}{|c|} 
NO DIA \\
4
\end{tabular}} & \multicolumn{4}{|c|}{ RECEM-NASCIDOS } & \multirow{2}{*}{$\frac{\text { NO DIA }}{4}$} \\
\hline & & RN25 & RN46 & RN56 & RN57 & & RN25 & \begin{tabular}{l|l} 
RN46 \\
\end{tabular} & RN56 & RN57 & & RN25 & RN46 & \begin{tabular}{l|l} 
RN56 \\
\end{tabular} & RN57 & \\
\hline \multicolumn{17}{|l|}{ 1. Monitorização e controles } \\
\hline 1 1a. & 4,5 & & & & & & & & & & & & & & & \\
\hline 1b. & 12,1 & & & & & & & & & & & & & & & \\
\hline 1c. & 19,6 & 19,6 & 19,6 & 19,6 & 19,6 & 78,4 & 19,6 & 19,6 & 19,6 & 19,6 & 78,4 & 19,6 & 19,6 & 19,6 & 19,6 & 78,4 \\
\hline 2. Investigações laboratoriais & 4,3 & 4,3 & 4,3 & 4,3 & & 12,9 & 4,3 & 4,3 & 4,3 & & 12,9 & & & & & \\
\hline 3. Medicação & 5,6 & 5,6 & 5,6 & 5,6 & 5,6 & 22,4 & 5,6 & 5,6 & 5,6 & 5,6 & 22,4 & 5,6 & 5,6 & 5,6 & 5,6 & 22,4 \\
\hline \multicolumn{17}{|l|}{ 4. Procedimentos de higiene } \\
\hline $4 a$. & 4,1 & & & & & & & & & & & & & & & \\
\hline $4 \mathrm{~b}$. & 16,5 & 16,5 & 16,5 & 16,5 & 16,5 & 66 & 16,5 & 16,5 & 16,5 & 16,5 & 66 & 16,5 & 16,5 & 16,5 & 16,5 & 66 \\
\hline $4 \mathrm{c}$. & 20,0 & & & & & & & & & & & & & & & \\
\hline 5. Cuidados com drenos & 1,8 & & & & & & & & & & & & & & & \\
\hline \multicolumn{17}{|l|}{ 6.Mobilização e posicionamento } \\
\hline $6 a$. & 5,5 & & & & & & & & & & & & & & & \\
\hline $6 \mathrm{~b}$. & 12,4 & 12,4 & 12,4 & 12,4 & 12,4 & 49,6 & 12,4 & 12,4 & 12,4 & 12,4 & 49,6 & 12,4 & 12,4 & 12,4 & 12,4 & 49,6 \\
\hline $6 c$. & 17,0 & & & & & & & & & & & & & & & \\
\hline \multicolumn{17}{|l|}{ 7. Suporte e cuidados $\ldots$} \\
\hline $7 \mathrm{a}$. & 4,0 & 4 & 4 & 4 & 4 & 16 & 4 & 4 & 4 & 4 & 16 & 4 & 4 & 4 & 4 & 16 \\
\hline $7 \mathrm{~b}$. & 32,0 & & & & & & & & & & & & & & & \\
\hline \multicolumn{17}{|l|}{ 8. Tarefas administrativas } \\
\hline $8 \mathrm{a}$. & 4,2 & 4,2 & 4,2 & 4,2 & & 12,6 & 4,2 & 4,2 & 4,2 & & 12,6 & 4,2 & 4,2 & 4,2 & & 12,6 \\
\hline $8 \mathrm{~b}$. & 23,2 & & & & 23,2 & 23,2 & & & & 23,2 & 23,2 & & & & 23,2 & 23,2 \\
\hline 8c. & 30,0 & & & & & & & & & & & & & & & \\
\hline Suporte ventilatório & & & & & & & & & & & & & & & & \\
\hline 9. & $\overline{1,4}$ & 1,4 & 1,4 & 1,4 & 1,4 & 5,6 & 1,4 & 1,4 & 1,4 & 1,4 & 5,6 & 1,4 & 1,4 & 1,4 & 1,4 & 5,6 \\
\hline 10. & 1,8 & 1,8 & 1,8 & 1,8 & 1,8 & 7,2 & 1,8 & 1,8 & 1,8 & 1,8 & 7,2 & 1,8 & 1,8 & 1,8 & 1,8 & 7,2 \\
\hline 11. & 4,4 & 4,4 & 4,4 & 4,4 & 4,4 & 17,6 & 4,4 & 4,4 & 4,4 & 4,4 & 17,6 & 4,4 & 4,4 & 4,4 & 4,4 & 17,6 \\
\hline Suporte cardiovascular & & & & & & & & & & & & & & & & \\
\hline 12. & 1,2 & & & & & & & & & & & & & & & \\
\hline 13. & 2,5 & 2,5 & & & & 2,5 & 2,5 & & & & 2,5 & 2,5 & 2,5 & & & 5 \\
\hline 14. & 1,7 & & & & & & & & & & & & & & & \\
\hline 15. & 7,1 & & & & & & & & & & & & & & & \\
\hline Suporte renal & & & & & & & & & & & & & & & & \\
\hline 16. & 7,7 & & & & & & & & & & & & & & & \\
\hline 17. & 7 & 7 & 7 & 7 & 7 & 28 & 7 & 7 & 7 & 7 & 28 & 7 & 7 & 7 & 7 & 28 \\
\hline Suporte neurológico & & & & & & & & & & & & & & & & \\
\hline 18. & 1,6 & & & & & & & & & & & & & & & \\
\hline Suporte metabólico & & & & & & & & & & & & & & & & \\
\hline 19. & 1,3 & & & & & & & & & & & & & & & \\
\hline 20. & 2,8 & 2,8 & 2,8 & & & 5,6 & 2,8 & 2,8 & & & 5,6 & 2,8 & 2,8 & & & 5,6 \\
\hline 21. & 1,3 & & 1,3 & 1,3 & 1,3 & 3,9 & 1,3 & 1,3 & 1,3 & 1,3 & 5,2 & 1,3 & 1,3 & 1,3 & 1,3 & 5,2 \\
\hline Intervenções específicas & & & & & & & & & & & & & & & & \\
\hline 22. & 2,8 & 2,8 & 2,8 & 2,8 & 2,8 & 11,2 & 2,8 & 2,8 & 2,8 & 2,8 & 11,2 & 2,8 & 2,8 & 2,8 & 2,8 & 11,2 \\
\hline 23. & 1,9 & 1,9 & & 1,9 & & 3,8 & 1,9 & & 1,9 & & 3,8 & 1,9 & & & & 1,9 \\
\hline SOMA DOS PONTOS NAS & & \begin{tabular}{c|}
91,2 \\
\end{tabular} & 88,1 & 87,2 & 100 & 366,5 & 92,5 & 88,1 & 87,2 & 100 & 367,8 & 88,2 & 86,3 & 81 & 100 & $\begin{array}{ll}355,5 \\
\end{array}$ \\
\hline MEDIA DIÁRIA DOS PONTOS NA & & & & & & 91,6 & & & & & 92,0 & & & & & 89,1 \\
\hline DESVIO PADRĀO & & & & & & 5,8 & & & & & 5,8 & & & & & 8,0 \\
\hline
\end{tabular}


Luciana Bochembuzio

\begin{tabular}{|c|c|c|c|c|c|c|c|c|c|c|c|c|c|c|c|c|c|}
\hline \multirow{3}{*}{ NAS AÁSICAS ATIVIDADES } & \multirow[b]{3}{*}{ PONTOS } & \multirow{2}{*}{\multicolumn{4}{|c|}{ sábado, 25/111/2006 }} & \multirow{2}{*}{\multicolumn{4}{|c|}{ domingo, 26/11/2006 }} & \multirow{2}{*}{\multicolumn{4}{|c|}{\begin{tabular}{|c|} 
segunda-feira, 27/11/2006 \\
\end{tabular}}} & \multicolumn{4}{|c|}{ terça-feira, 28/11/2006 } \\
\hline & & & & & NO DIA & & & & & & & & & & & & NO DIA \\
\hline & & RN25 & RN46 & RN57 & 3 & RN25 & \begin{tabular}{|l|l} 
RN46 \\
\end{tabular} & RN57 & 3 & RN25 & \begin{tabular}{|l|l|} 
RN43 \\
\end{tabular} & RN57 & & RN25 & RN45 & \begin{tabular}{|l|l|} 
& RN57 \\
\end{tabular} & \\
\hline \multicolumn{18}{|l|}{ 1. Monitorizaçäo e controles } \\
\hline 1 a. & 4,5 & & & & & & & & & & & & & & & & \\
\hline $1 \mathrm{ib.}$. & 12,1 & & & & & & & & & & & & & & & & \\
\hline 1c. & 19,6 & 19,6 & 19,6 & 19,6 & 58,8 & 19,6 & 19,6 & 19,6 & $\begin{array}{ll}58,8 \\
\end{array}$ & 19,6 & 19,6 & 19,6 & 58,8 & 19,6 & 19,6 & 19,6 & 58,8 \\
\hline 2. Investigaçōes laboratoriais & 4,3 & & & & & & 4,3 & & 4,3 & & 4,3 & 4,3 & 8,6 & 4,3 & 4,3 & & 8,6 \\
\hline 3. Medicação & 5,6 & 5,6 & 5,6 & 5,6 & 16,8 & 5,6 & 5,6 & 5,6 & 16,8 & 5,6 & 5,6 & 5,6 & 16,8 & 5,6 & 5,6 & 5,6 & 16,8 \\
\hline \multirow{2}{*}{\multicolumn{18}{|c|}{\begin{tabular}{|l|} 
4. Procedimentos de higiene \\
4a.
\end{tabular}}} \\
\hline & & & & & & & & & & & & & & & & & \\
\hline $4 \mathrm{~b}$. & 16,5 & 16,5 & 16,5 & 16,5 & 49,5 & 16,5 & 16,5 & 16,5 & 49,5 & 16,5 & 16,5 & 16,5 & 49,5 & 16,5 & 16,5 & 16,5 & 49,5 \\
\hline $4 \mathrm{c}$. & 20,0 & & & & & & & & & & & & & & & & \\
\hline 5. Cuidados com drenos & 1,8 & & & & & & & & & & & & & & & & \\
\hline \multicolumn{18}{|l|}{ 6.Mobilizaçăo e posicionamento } \\
\hline $6 a$. & 5,5 & & & & & & & & & & & & & & & & \\
\hline 66. & 12,4 & $\overline{12,4}$ & $\overline{12,4}$ & 12,4 & 37,2 & 12,4 & 12,4 & 12,4 & 37,2 & $\overline{12,4}$ & 12,4 & 12,4 & 37,2 & 12,4 & $\overline{12,4}$ & 12,4 & 37,2 \\
\hline 6c. & 17,0 & & & & & & & & & & & & & & & & \\
\hline \multicolumn{14}{|l|}{ 7. Suporte e cuidados. } & & & & \\
\hline$\frac{7 \mathrm{a} .}{7 \mathrm{~b} .}$ & 4,0 & 4 & 4 & & 12 & & 4 & 4 & 12 & 4 & 4 & 4 & 12 & 4 & & & 12 \\
\hline \multirow{2}{*}{\multicolumn{18}{|c|}{ 8. Tarefas administrativas }} \\
\hline & & & & & & & & & & & & & & & & & \\
\hline & 4,2 & 4,2 & 4,2 & & 8,4 & 4,2 & 4,2 & & 8,4 & 4,2 & 4,2 & & 8,4 & 4,2 & 4,2 & & 8,4 \\
\hline $8 \mathrm{bb}$. & 23,2 & & & 23,2 & 23,2 & & & 23,2 & 23,2 & & & 23,2 & 23,2 & & & 23,2 & 23,2 \\
\hline & 30,0 & & & & & & & & & & & & & & & & \\
\hline \multicolumn{18}{|l|}{ Suporte ventilatório } \\
\hline & 1,4 & $\overline{1,4}$ & 1,4 & 1,4 & \begin{tabular}{ll|}
4,2 \\
\end{tabular} & $\overline{1,4}$ & 1,4 & $\overline{1,4}$ & 4,2 & $\overline{1,4}$ & 1,4 & 1,4 & 4,2 & 1,4 & 1,4 & 1,4 & 4,2 \\
\hline 10. & 1,8 & 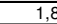 & $\begin{array}{ll}1,8 \\
\end{array}$ & $1, \varepsilon$ & 5,4 & $\overline{1, \varepsilon}, 20$ & 1,8 & $1, \varepsilon$ & 5,4 & 1,8 & 1,8 & 1,8 & 5,4 & 1,8 & $\overline{1,8}$ & 1,8 & \\
\hline 11. & 4,4 & $4,4,4,4,4$ & 4,4 & $4,4,4,4,4$ & 13,2 & $4,2,3,2,4$ & 4,4 & $4,4,4,4,4$ & 13,2 & 4,4 & 4,4 & 4,4 & 13,2 & 4,4 & 4,4 & 4,4 & $\overline{13,2}$ \\
\hline \multicolumn{18}{|l|}{\begin{tabular}{|l} 
Suporte cardiovascular \\
12
\end{tabular}} \\
\hline 12. & 1,2 & & & & & & & & & & & & 0 & & & & \\
\hline 13. & 2,5 & 2,5 & 2,5 & & 5 & 2,5 & 2,5 & & 5 & 2,5 & 2,5 & & 5 & 2,5 & 2,5 & & 5 \\
\hline 14. & 1,7 & & & & & & & & & & & & & & & & \\
\hline \multirow{2}{*}{\multicolumn{18}{|c|}{\begin{tabular}{|l|}
15. \\
Suporte renal
\end{tabular}}} \\
\hline & & & & & & & & & & & & & & & & & \\
\hline \multicolumn{18}{|c|}{7,7} \\
\hline & 7 & 7 & 7 & & 21 & & 7 & 7 & $21 \mid$ & 7 & & & 21 & 7 & 7 & & 21 \\
\hline \multirow{2}{*}{\multicolumn{18}{|c|}{\begin{tabular}{|l|} 
Suporte neurológico \\
18.
\end{tabular}}} \\
\hline & 1,6 & & & & & & & & & & & & & & & & \\
\hline Suporte metabólico & & & & & & & & & & & & & & & & & \\
\hline 19. & 1,3 & & & & & & & & & & & & & & & & \\
\hline 20. & $2,8]$ & $2,8>-2>$ & 2,8 & & 5,6 & 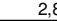 & & & 2,8 & 2,8 & & & 2,8 & 2,8 & 2,8 & & 5,6 \\
\hline 21. & 1,3 & 1,3 & 1,3 & 1,3 & 3,9 & & 1,3 & 1,3 & 2,6 & 1,3 & & 1,3 & 2,6 & 1,3 & 1,3 & 1,3 & 3,9 \\
\hline Intervençōes espećfificas & & & & & & & & & & & & & & & & & \\
\hline 22. & 2,8 & 2,8 & 2,8 & 2,8 & 8,4 & $2, \varepsilon$ & 2,8 & 2,8 & 8,4 & 2,8 & 2,8 & 2,8 & 8,4 & 2,8 & 2,8 & 2,8 & 8,4 \\
\hline 23. & 1,9 & 1,9 & & & 1,9 & & 1,9 & & 1,9 & & 1,9 & & 1,9 & & 1,9 & & 1,9 \\
\hline SOMA DOS PONTOS NAS & & 88,2 & 86,3 & 100 & 274,5 & 85 & 89,7 & 100 & 274,7 & 86,3 & 88,4 & 104,3 & 279 & 90,6 & 92,5 & 100 & 283,1 \\
\hline $\begin{array}{l}\text { MEDIA DIARIA DOS PONTOS NAS } \\
\text { DESVIO PADRÃO }\end{array}$ & & & & & $\frac{91,5}{74}$ & & & & 91,6 & & & & 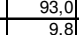 & & & & 94,4 \\
\hline DESVIOPADRAO & & & & & & & & & & & & & & & & & \\
\hline
\end{tabular}




\begin{tabular}{|c|c|c|c|c|c|c|c|c|c|c|c|c|c|c|c|c|}
\hline \multirow{3}{*}{$\begin{array}{l}\text { NAS } \\
\text { BÁSICAS }\end{array}$} & \multirow[b]{3}{*}{ PONTOS } & \multicolumn{4}{|c|}{ quarta-feira, 29/11/2006 } & \multicolumn{4}{|c|}{ quinta-feira, 30/11/2006 } & \multicolumn{3}{|c|}{ sexta-feira, $1 / 12 / 2006$} & \multicolumn{4}{|c|}{ sábado, 2/12/2006 } \\
\hline & & \multicolumn{3}{|c|}{ RECEM-NASCIDOS } & \multirow{2}{*}{\begin{tabular}{|c|c|c|} 
NO DIA \\
3
\end{tabular}} & \multicolumn{3}{|c|}{ RECEM-NASCIDOS } & \multirow{2}{*}{\begin{tabular}{|c|} 
NO DIA \\
3
\end{tabular}} & \multicolumn{2}{|c|}{ ECEM-NASCIDO } & \multirow{2}{*}{\begin{tabular}{|c|} 
NO DIA \\
2
\end{tabular}} & \multicolumn{3}{|c|}{ RECEMM-NASCIDOS } & \multirow{2}{*}{$\frac{\text { NO DIA }}{3}$} \\
\hline & & RN25 & RN26 & RN45 & & RN25 & \begin{tabular}{l|l} 
RN26 \\
\end{tabular} & RN45 & & RN25 & RN45 & & RN25 & \begin{tabular}{|l|} 
RN45 \\
\end{tabular} & RN46 & \\
\hline \multicolumn{17}{|l|}{ 1. Monitorização e controles } \\
\hline $1 \mathrm{a.}$. & 4,5 & & & & & & & & & & & & & & & \\
\hline $1 \mathrm{~b}$. & 12,1 & & & & & & & & & & & & & & & \\
\hline 1c. & 19,6 & 19,6 & 19,6 & 19,6 & 58,8 & 19,6 & 19,6 & 19,6 & 58,8 & 19,6 & 19,6 & 39,2 & 19,6 & 19,6 & 19,6 & 58,8 \\
\hline 2. Investigações laboratoriais & 4,3 & & & 4,3 & 4,3 & & & & & 4,3 & & 4,3 & & 4,3 & & 4,3 \\
\hline 3. Medicação & 5,6 & 5,6 & 5,6 & 5,6 & 16,8 & 5,6 & 5,6 & 5,6 & 16,8 & 5,6 & 5,6 & 11,2 & 5,6 & 5,6 & 5,6 & 16,8 \\
\hline \multicolumn{17}{|l|}{ 4. Procedimentos de higiene } \\
\hline $4 a$. & 4,1 & & & & & & & & & & & & & & & \\
\hline 4b. & 16,5 & 16,5 & 16,5 & 16,5 & 49,5 & 16,5 & 16,5 & 16,5 & 49,5 & 16,5 & 16,5 & 33 & 16,5 & 16,5 & 16,5 & 49,5 \\
\hline 4c. & 20,0 & & & & & & & & & & & & & & & \\
\hline 5. Cuidados com drenos & 1,8 & & & & & & & & & & & & & & & \\
\hline 6.Mobilização e posicionamento & & & & & & & & & & & & & & & & \\
\hline $6 a$. & 5,5 & & & & & & & & & & & & & & & \\
\hline $6 \mathrm{~b}$. & 12,4 & 12,4 & 12,4 & 12,4 & 37,2 & 12,4 & 12,4 & 12,4 & 37,2 & 12,4 & 12,4 & 24,8 & 12,4 & 12,4 & 12,4 & 37,2 \\
\hline 6c. & 17,0 & & & & & & & & & & & & & & & \\
\hline 7. Suporte e cuidados ... & & & & & & & & & & & & & & & & \\
\hline $7 \mathrm{a}$. & 4,0 & 4 & 4 & 4 & 12 & 4 & 4 & 4 & 12 & 4 & 4 & 8 & 4 & 4 & 4 & 12 \\
\hline $7 \mathrm{~b}$. & 32,0 & & & & & & & & & & & & & & & \\
\hline 8. Tarefas administrativas $\ldots$ & & & & & & & & & & & & & & & & \\
\hline $8 \mathrm{a}$. & 4,2 & 4,2 & & 4,2 & 8,4 & 4,2 & & 4,2 & 8,4 & 4,2 & 4,2 & 8,4 & 4,2 & 4,2 & 4,2 & 12,6 \\
\hline 8 b. & 23,2 & & 23,2 & & 23,2 & & 23,2 & & 23,2 & & & & & & & \\
\hline $8 \mathrm{c}$. & 30,0 & & & & & & & & & & & & & & & \\
\hline Suporte ventilatório & & & & & & & & & & & & & & & & \\
\hline 9. & 1,4 & 1,4 & 1,4 & 1,4 & 4,2 & 1,4 & 1,4 & 1,4 & 4,2 & 1,4 & 1,4 & 2,8 & 1,4 & 1,4 & 1,4 & $\overline{4,2}$ \\
\hline 10. & 1,8 & 1,8 & 1,8 & 1,8 & 5,4 & 1,8 & 1,8 & 1,8 & 5,4 & 1,8 & 1,8 & 3,6 & 1,8 & 1,8 & 1,8 & 5,4 \\
\hline 11. & 4,4 & 4,4 & 4,4 & 4,4 & 13,2 & 4,4 & 4,4 & 4,4 & 13,2 & 4,4 & 4,4 & 8,8 & 4,4 & 4,4 & 4,4 & 13,2 \\
\hline Suporte cardiovascular & & & & & & & & & & & & & & & & \\
\hline 12. & 1,2 & & & & & & & & & & & & & & & \\
\hline 13. & 2,5 & 2,5 & & 2,5 & 5 & 2,5 & & 2,5 & 5 & 2,5 & 2,5 & 5 & 2,5 & 2,5 & & 5 \\
\hline 14. & 1,7 & & & & & & & & & & & & & & & \\
\hline 15. & 7,1 & & & & & & & & & & & & & & & \\
\hline Suporte renal & & & & & & & & & & & & & & & & \\
\hline 16. & 7,7 & & & & & & & & & & & & & & & \\
\hline 17. & 7 & 7 & 7 & 7 & 21 & 7 & 7 & 7 & 21 & 7 & 7 & 14 & 7 & 7 & 7 & 21 \\
\hline Suporte neurológico & & & & & & & & & & & & & & & & \\
\hline 18. & 1,6 & & & & & & & & & & & & & & & \\
\hline Suporte metabólico & & & & & & & & & & & & & & & & \\
\hline 19. & 1,3 & & & & & & & & & & & & & & & \\
\hline 20. & 2,8 & 2,8 & & 2,8 & 5,6 & 2,8 & & 2,8 & 5,6 & 2,8 & 2,8 & 5,6 & 2,8 & 2,8 & & 5,6 \\
\hline 21. & 1,3 & 1,3 & 1,3 & 1,3 & 3,9 & 1,3 & 1,3 & 1,3 & 3,9 & 1,3 & 1,3 & 2,6 & 1,3 & 1,3 & 1,3 & 3,9 \\
\hline Intervenções específicas & & & & & & & & & & & & & & & & \\
\hline 22. & 2,8 & 2,8 & 2,8 & 2,8 & 8,4 & 2,8 & 2,8 & 2,8 & 8,4 & 2,8 & 2,8 & 5,6 & 2,8 & 2,8 & 2,8 & 8,4 \\
\hline 23. & 1,9 & & 1,9 & 1,9 & 3,8 & & & & & 1,9 & & 1,9 & & & 1,9 & 1,9 \\
\hline SOMA DOS PONTOS NAS & & 86,3 & 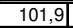 & $\overline{92,5}$ & 280,7 & 86,3 & 100 & 86,3 & 272,6 & 92,5 & 86,3 & \begin{tabular}{|c|}
178,8 \\
\end{tabular} & 86,3 & 90,6 & 82,9 & 259,8 \\
\hline MEDIA DIARIA DOS PONTOS NAS & & & & & 93,6 & & & & 90,9 & & & 89,4 & & & & 86,6 \\
\hline DESVIO PADRĀO & & & & & 7,9 & & & & 7,9 & & & 4,4 & & & & 3,9 \\
\hline
\end{tabular}




\begin{tabular}{|c|c|c|c|c|c|c|c|c|c|c|c|}
\hline \multirow{3}{*}{$\begin{array}{l}\text { ATIVIDADES } \\
\text { BÁSICAS }\end{array}$} & \multirow[b]{3}{*}{ PONTOS } & \multicolumn{5}{|c|}{ domingo, 3/12/2006 } & \multicolumn{5}{|c|}{ segunda-feira, 4/12/2006 } \\
\hline & & \multicolumn{4}{|c|}{ RECÉM-NASCIDOS } & \multirow{2}{*}{$\begin{array}{c}\text { NO DIA } \\
4\end{array}$} & \multicolumn{4}{|c|}{ RECÉM-NASCIDOS } & \multirow{2}{*}{$\frac{\text { NO DIA }}{4}$} \\
\hline & & RN25 & RN26 & RN45 & RN46 & & RN25 & RN26 & RN45 & RN46 & \\
\hline \multicolumn{12}{|l|}{ 1. Monitorização e controles } \\
\hline $1 a$. & 4,5 & & & & & & & & & & \\
\hline $1 \mathrm{~b}$. & 12,1 & & & & & & & & & & \\
\hline 1c. & 19,6 & 19,6 & 19,6 & 19,6 & 19,6 & 78,4 & 19,6 & 19,6 & 19,6 & 19,6 & 78,4 \\
\hline 2. Investigações laboratoriais & 4,3 & & & 4,3 & & 4,3 & & 4,3 & & 4,3 & 8,6 \\
\hline 3. Medicação & 5,6 & 5,6 & 5,6 & 5,6 & 5,6 & 22,4 & 5,6 & 5,6 & 5,6 & 5,6 & 22,4 \\
\hline \multicolumn{12}{|l|}{ 4. Procedimentos de higiene } \\
\hline $4 a$. & 4,1 & & & & & & & & & & \\
\hline $4 \mathrm{~b}$. & 16,5 & 16,5 & 16,5 & 16,5 & $\mid 16,5$ & 66 & 16,5 & 16,5 & 16,5 & 16,5 & 66 \\
\hline $4 c$. & 20,0 & & & & & & & & & & \\
\hline 5. Cuidados com drenos & 1,8 & & & & & & & & & & \\
\hline \multicolumn{12}{|l|}{ 6.Mobilização e posicionamento } \\
\hline s & 5,5 & & & & & & & & & & \\
\hline $6 \mathrm{~b}$. & 12,4 & 12,4 & 12,4 & 12,4 & $\overline{12,4}$ & 49,6 & 12,4 & 12,4 & 12,4 & 12,4 & 49,6 \\
\hline 6c. & 17,0 & & & & & & & & & & \\
\hline \multicolumn{12}{|l|}{ 7.Suporte e cuidados ... } \\
\hline $7 a$. & 4,0 & 4 & 4 & 4 & 4 & 16 & 4 & 4 & 4 & 4 & 16 \\
\hline $7 \mathrm{~b}$. & 32,0 & & & & & & & & & & \\
\hline \multicolumn{12}{|l|}{ 8. Tarefas administrativas $\ldots$} \\
\hline $8 a$. & 4,2 & 4,2 & & 4,2 & 4,2 & 12,6 & 4,2 & & 4,2 & 4,2 & 12,6 \\
\hline $8 b$. & 23,2 & & 23,2 & & & 23,2 & & 23,2 & & & 23,2 \\
\hline 8c. & 30,0 & & & & & & & & & & \\
\hline \multicolumn{12}{|l|}{ Suporte ventilatório } \\
\hline 9. & 1,4 & 1,4 & 1,4 & 1,4 & $\overline{1,4}$ & 5,6 & 1,4 & 1,4 & 1,4 & 1,4 & 5,6 \\
\hline 10. & 1,8 & 1,8 & 1,8 & 1,8 & 1,8 & 7,2 & 1,8 & 1,8 & 1,8 & 1,8 & 7,2 \\
\hline 11. & 4,4 & 4,4 & 4,4 & 4,4 & 4,4 & 17,6 & 4,4 & 4,4 & 4,4 & 4,4 & 17,6 \\
\hline \multicolumn{12}{|l|}{ Suporte cardiovascular } \\
\hline 12. & 1,2 & & & & & & & & & & \\
\hline 13. & 2,5 & 2,5 & & 2,5 & & 5 & 2,5 & & 2,5 & & 5 \\
\hline 14. & 1,7 & & & & & & & & & & \\
\hline 15. & 7,1 & & & & & & & & & & \\
\hline \multicolumn{12}{|l|}{ Suporte renal } \\
\hline 16. & 7,7 & & & & & & & & & & \\
\hline 17. & 7 & 7 & 7 & 7 & 7 & 28 & 7 & 7 & 7 & 7 & 28 \\
\hline \multicolumn{12}{|l|}{ Suporte neurológico } \\
\hline 18. & 1,6 & & & & & & & & & & \\
\hline \multicolumn{12}{|l|}{ Suporte metabólico } \\
\hline 19. & 1,3 & & & & & & & & & & \\
\hline 20. & 2,8 & 2,8 & & 2,8 & & 5,6 & 2,8 & & 2,8 & & 5,6 \\
\hline 21. & 1,3 & 1,3 & 1,3 & 1,3 & 1,3 & 5,2 & 1,3 & 1,3 & & 1,3 & 3,9 \\
\hline \multicolumn{12}{|l|}{ Intervenções específicas } \\
\hline 22. & 2,8 & 2,8 & 2,8 & 2,8 & 2,8 & 11,2 & 2,8 & 2,8 & 2,8 & 2,8 & 11,2 \\
\hline 23. & 1,9 & & & & & & 1,9 & 1,9 & 1,9 & 1,9 & 7,6 \\
\hline SOMA DOS PONTOS NAS & & 86,3 & 100 & 90,6 & 81 & 357,9 & 88,2 & \begin{tabular}{l|l|}
106,2 \\
\end{tabular} & 86,9 & 87,2 & 368,5 \\
\hline MÉDIA DIÁRIA DOS PONTOS NAS & & & & & & 89,5 & & & & & 92,1 \\
\hline DESVIO PADRÃO & & & & & & 8,0 & & & & & 9,4 \\
\hline
\end{tabular}




\begin{tabular}{|c|c|c|c|c|c|c|c|c|c|}
\hline \multirow{3}{*}{$\begin{array}{l}\text { NAS } \\
\text { BÁSICAS }\end{array}$} & \multirow[b]{3}{*}{ PONTOS } & \multicolumn{4}{|c|}{ terça-feira, 5/12/2006 } & \multicolumn{4}{|c|}{ quarta-feira, 6/12/2006 } \\
\hline & & \multicolumn{3}{|c|}{ RECÉM-NASCIDOS } & \multirow{2}{*}{$\frac{\text { NO DIA }}{3}$} & \multicolumn{3}{|c|}{ RECÉM-NASCIDOS } & \multirow{2}{*}{$\frac{\text { NO DIA }}{3}$} \\
\hline & & RN25 & \begin{tabular}{l|l} 
RN26 & \\
\end{tabular} & RN45 & & \begin{tabular}{l|l} 
RN25 \\
\end{tabular} & RN26 & RN45 & \\
\hline \multicolumn{10}{|l|}{ 1. Monitorização e controles } \\
\hline $1 \mathrm{a}$. & 4,5 & & & & & & & & \\
\hline $1 \mathrm{~b}$. & 12,1 & & & & & & & & \\
\hline $1 \mathrm{c.}$ & 19,6 & 19,6 & 19,6 & 19,6 & 58,8 & 19,6 & 19,6 & 19,6 & 58,8 \\
\hline 2. Investigações laboratoriais & 4,3 & 4,3 & & 4,3 & 8,6 & & & 4,3 & 4,3 \\
\hline 3. Medicação & 5,6 & 5,6 & 5,6 & 5,6 & 16,8 & 5,6 & 5,6 & 5,6 & 16,8 \\
\hline \multicolumn{10}{|l|}{ 4. Procedimentos de higiene } \\
\hline $4 a$. & 4,1 & & & & & & & & \\
\hline 4b. & 16,5 & 16,5 & 16,5 & 16,5 & 49,5 & 16,5 & 16,5 & 16,5 & 49,5 \\
\hline 4c. & 20,0 & & & & & & & & \\
\hline 5. Cuidados com drenos & 1,8 & & & & & & & & \\
\hline \multicolumn{10}{|l|}{ 6.Mobilização e posicionamento } \\
\hline $6 a$. & 5,5 & & & & & & & & \\
\hline $6 b$. & 12,4 & 12,4 & 12,4 & 12,4 & 37,2 & 12,4 & 12,4 & 12,4 & 37,2 \\
\hline 6c. & 17,0 & & & & & & & & \\
\hline \multicolumn{10}{|l|}{ 7.Suporte e cuidados ... } \\
\hline $7 a$. & 4,0 & 4 & 4 & 4 & 12 & 4 & 4 & 4 & 12 \\
\hline $7 b$. & 32,0 & & & & & & & & \\
\hline \multicolumn{10}{|l|}{ 8. Tarefas administrativas } \\
\hline $8 a$. & 4,2 & 4,2 & & 4,2 & 8,4 & 4,2 & & 4,2 & 8,4 \\
\hline $8 \mathrm{~b}$. & 23,2 & & 23,2 & & 23,2 & & 23,2 & & 23,2 \\
\hline 8c. & 30,0 & & & & & & & & \\
\hline \multicolumn{10}{|l|}{ Suporte ventilatório } \\
\hline 9. & 1,4 & 1,4 & 1,4 & 1,4 & 4,2 & 1,4 & 1,4 & 1,4 & 4,2 \\
\hline 10. & 1,8 & 1,8 & 1,8 & 1,8 & 5,4 & 1,8 & 1,8 & 1,8 & 5,4 \\
\hline 11. & 4,4 & 4,4 & 4,4 & 4,4 & 13,2 & 4,4 & 4,4 & 4,4 & 13,2 \\
\hline \multicolumn{10}{|l|}{ Suporte cardiovascular } \\
\hline 12. & 1,2 & & & & & & & & \\
\hline 13. & 2,5 & 2,5 & & 2,5 & 5 & 2,5 & & 2,5 & 5 \\
\hline 14. & 1,7 & & & & & & & & \\
\hline 15. & 7,1 & & & & & & & & \\
\hline \multicolumn{10}{|l|}{ Suporte renal } \\
\hline 16. & 7,7 & & & & & & & & \\
\hline 17. & 7 & 7 & 7 & 7 & 21 & 7 & 7 & 7 & 21 \\
\hline \multicolumn{10}{|l|}{ Suporte neurológico } \\
\hline 18. & 1,6 & & & & & & & & \\
\hline \multicolumn{10}{|l|}{ Suporte metabólico } \\
\hline 19. & 1,3 & & & & & & & & \\
\hline 20. & 2,8 & 2,8 & & 2,8 & 5,6 & 2,8 & & 2,8 & 5,6 \\
\hline 21. & 1,3 & 1,3 & 1,3 & & 2,6 & 1,3 & 1,3 & & 2,6 \\
\hline \multicolumn{10}{|l|}{ Intervenções específicas } \\
\hline 22. & 2,8 & 2,8 & 2,8 & 2,8 & 8,4 & 2,8 & 2,8 & 2,8 & 8,4 \\
\hline 23. & 1,9 & & & 1,9 & 1,9 & 1,9 & & 1,9 & 3,8 \\
\hline \multicolumn{2}{|l|}{ SOMA DOS PONTOS NAS } & 90,6 & 100 & 91,2 & 281,8 & 88,2 & 100 & 91,2 & 279,4 \\
\hline MÉDIA DIÁRIA DOS PONTOS NAS & & & & & 93,9 & & & & 93,1 \\
\hline DESVIO PADRÃO & & & & & 5,3 & & & & 6,1 \\
\hline
\end{tabular}




\section{Anexo 9}

\section{(2)}

São Paulo, 15 de setembro de 2006.

If pora) $S^{\text {ras) }}$

Profa. Dra. Raquel Rapone Galdzinski

Departamento de Enfermagem

Hospital Universitário

UNIVERSIDADE DE SÃO PAULO

RFFERENTE: Projeto de Pesquisa "Avaliaçî́o do modelo Nursing Activities Scare (NAS) em Neonatologia" - Co-autor(es): Luciana Bochembuzio - Registro CEPHU/USP: $681 / 06$ - SISNEP CAAE: 0041.0.198.000-06

Prezado(a) Senhor(a)

O Comitê de Ética em Pesquisa do Hospital Universitário da Universidade de Săo Paulo, em reunilio ondinária realizada no dia 18 de agosto de 2006, analisou o projeto de pesquisa acima citado, considerando-o como APROVADO, bem como, seu Termo de Consentimento Livre e Esclarecido.

Lembramos que cabe ao pesquisador elaborar e apresentar a este Comitê, relatórios anuais (parciais ou final, em funçẵo da duração da pesquisa), de acordo com a Resoluçẫo 196/96 do Conselho Nacional de Saúde, item IX.2 letra c.

O primeiro relatório está previsto para 18 de agosto de 2007.

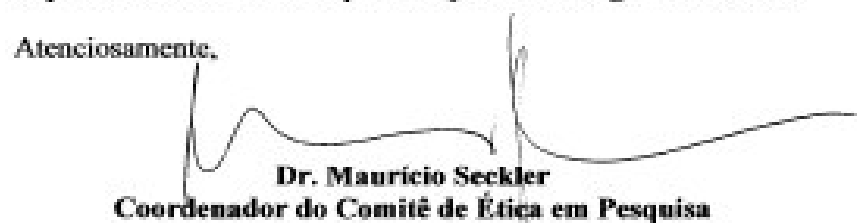
Hospital Universitário da USP 


\section{AUTORIZAÇÃo}

Autorizo a reprodução e/ou divulgação total ou parcial da presente obra, por meio convencional ou eletrônico, desde que seja citada a fonte.

Nome da autora: Luciana Bochembuzio

Assinatura:

Instituição: Hospital Universitário

Local: Universidade de São Paulo

Endereço: Av. Prof. Lineu Prestes, 2565

E-mail: luboch@hu.usp.br 
